


\title{
ÁMBITOS DEL DERECHO: REFLEXIONES SOBRE TENDENCIAS Y PROBLEMAS JURÍDICOS EN COLOMBIA
}

\author{
Compiladores \\ Edimer Leonardo Latorre Iglesias \\ Jackeline Cecilia Saravia Caballero \\ UNIVERSIDAD SERGIO ARBOLEDA \\ Escuela de Derecho "Rodrigo de Bastidas" \\ Santa Marta, Colombia
}

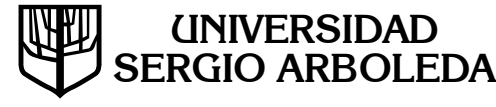


Ámbitos del derecho: reflexiones sobre tendencias y problemas jurídicos en Colombia; compiladores Edimer Leonardo Latorre Iglesias, Jackeline Cecilia Saravia Caballero Santa Marta: Universidad Sergio Arboleda. Escuela de Derecho "Rodrigo de Bastidas", 2014.

$278 \mathrm{p}$.

ISBN: 978-958-8866-12-3

1. DERECHO - INVESTIGACIONES

2. EDUCACIÓN SUPERIOR -INVESTIGACIONES - COLOMBIA -

I. LATORRE IGLESIAS, EDIMER LEONARDO, comp. II. SARAVIA

CABALLERO, JACKELINE CECILIA, comp.

340.072 ed. 21

\section{ÁMBITOS DEL DERECHO:}

REFLEXIONES SOBRE TENDENCIAS Y PROBLEMAS JURÍDICOS EN COLOMBIA

(C) Universidad Sergio Arboleda

Sede Santa Marta

Escuela de Derecho "Rodrigo de Bastidas"

Edimer Leonardo Latorre Iglesias (Compilador)

Jackeline Cecilia Saravia Caballero (Compiladora)

Calle 18 \# 14A-18.

Tel.: (575) 4346444 ext. 106 y 107

www.usergioarboleda.edu.co/santamarta/

Santa Marta, Colombia

Edición: agosto de 2014

Queda prohibida toda reproducción por cualquier medio sin previa autorización escrita del editor.

Edición realizada por el Fondo de Publicaciones

Universidad Sergio Arboleda.

Carrera 15 No. 74-40

Teléfono: (571) 3257500 ext. 2131

www.usergioarboleda.edu.co

Bogotá, D.C.

Director editorial: Jaime Barahona Caicedo

Diseño de carátula y

diagramación: Jimmy F. Salcedo Sánchez

Impresión: Digiprint Editores E.U.

Bogotá, D.C. Colombia

ISBN: $\quad$ 978-958-8866-12-3 


\section{Contenido}

PRESENTACIÓN. .5

Juan Alberto Polo Figueroa

REFLEXIONES SOBRE GATOS NEGROS, BULIMIA EDUCATIVA Y LA NECESIDAD DE PREGUNTAR .9

LA LEY PARA EL HOMBRE Y NO EL HOMBRE PARA LA LEY: UNA MIRADA AL DERECHO DESDE EL HUMANISMO CRISTIANO

HUELLA EMOCIONALES: ANÁLISIS EN TEXTOS DE PERSONAS EN CONDICIÓN DE DESPLAZAMIENTO FORZOSO.... 43

María Alejandra Olarte Molina, Marisol Ramírez Rivera, Candy Beatriz Díaz Granados Hernández

AUTONOMÍA DE LA JURISDICCIÓN ESPECIAL INDÍGENA EN EL ESTADO COLOMBIANO

Dayana Saltaren B., Margarita Tamaris B., Xiomara Vera W.

¿QUÉ RECONOCIMIENTO LE OTORGA

LA CONSTITUCIÓN POLÍTICA COLOMBIANA DE 1991

AL DERECHO INTERNACIONAL HUMANITARIO?

Kamila Andrea Pimienta Peñaloza, Daniel José Montenegro Cervantes

EL ABANDONO DEL IMAGINARIO SOCIAL REFERENTE:

LA VÍCTIMA NO SIEMPRE ES IDEAL

Ángela Patricia Villadiego Gómez

CARACTERIZACIÓN DE LOS DERECHOS INDIVIDUALES

DE LAS PERSONAS SEXUALMENTE DIVERSAS, VIGENTES EN

EL ORDENAMIENTO JURÍDICO COLOMBIANO AL AÑO 2013...105

Yamid Enrique Cotrina Gulfo

MARCO NORMATIVO. ASOCIACIONES PÚBLICO-PRIVADAS:

ANÁLISIS DE LA LEY 1508 DE 2012

Eddi Leonardo Molina Franky 
EL MODELO ECONÓMICO CONSTITUCIONAL:

UN ANÁLISIS JURSIPRUDENCIAL

Beliña Herrera Tapias, María Claudia Boneu Cantillo

MIRADA JURISPRUDENCIAL DE LA PARTICIPACIÓN

CIUDADANA EN LA POLÍTICA AMBIENTAL DE LA

CONSTITUCIÓN POLÍTICA DE COLOMBIA DE 1991

Roberto Jiménez González

LA INEJECUCIÓN DE LAS OBLIGACIONES POR LA CULPA

DEL DEUDOR EN EL DERECHO ROMANO Y EN EL DERECHO

CIVIL COLOMBIANO.

Mavelin Cantillo Gómez, Jassir Alvarez Estrada

FORTALECIMIENTO LOCAL DE LOS DERECHOS DE

LOS CONSUMIDORES: PROMOCIÓN Y PROTECCIÓN DE LOS

DERECHOS DEL CONSUMIDOR, EN LA CIUDAD DE SANTA

MARTA (COLOMBIA), EN EL MARCO DEL NUEVO ESTATUTO

DEL CONSUMIDOR

Edimer Leonardo Latorre Iglesias, Cindy Caterine Díaz Areiza

TEJEDORAS DE RECONCILIACIÓN PARA CONSTRUIR

LA PAZ. MUJERES VÍCTIMAS: UN EJEMPLO PARA LA REGIÓN

Y EL PAÍS.

Katherine Paola Castro Molina, Carlos Alberto Peña Orozco

EL PRÍNCIPE DE MAQUIAVELO:

UNA OBRA DE POLÍTICA SISTEMATIZADA

Carlos Alberto Peña Orozco, Katherine Paola Castro Molina

ESFERAS DE LA PROPIEDAD INTELECTUAL:

MEDIDAS EN FRONTERAS ADPIC, IMPLEMENTACIÓN

LEGAL EN LATINOAMÉRICA

Berónica Narváez Mercado, Rodrigo Parraguez Ruiz

HOLOGRAMÁTICA Y GESTIÓN PEDAGÓGICA

EN LA FORMACIÓN JURÍDICA EN COLOMBIA

Félix Mendoza de la Espriella

EL CAMINO A LA IMPUNIDAD: LA SITUACIÓN DE

LOS DERECHOS HUMANOS DE LOS NIÑOS, NIÑAS Y

ADOLESCENTES EN EL PROCESO DE JUSTICIA Y PAZ 259

Margarita Jaimes Velásquez 


\section{PRESENTACIÓN}

Conforme a los lineamientos legales vigentes, las instituciones de educación superior deben velar por la adecuada formación en investigación que permita desarrollar una actitud crítica y una capacidad creativa para encontrar alternativas para el avance de la ciencia y del país. Es por esto que, hoy por hoy, la investigación científica se constituye en uno de los principales ejes del progreso social y que la generación de nuevo conocimiento transite de la mano del desarrollo de los países, de ahí que su importancia crezca cada día más.

La Universidad Sergio Arboleda, comprometida con la generación, gestión y uso del conocimiento, estructurado a partir de los principios de la filosofía cristiana y humanística, reconoce en la investigación y la innovación una misión sustantiva inherente a la formación integral de profesionales idóneos con espíritu ético y cívico, creativo y crítico, valores propios de una Sociedad del Conocimiento.

El quehacer de la investigación en la Universidad debe contribuir en:

- El desarrollo integral de competencias propias del perfil profesional en los campos artísticos, científicos, tecnológicos o humanísticos, fundamentando la formación en el aprender a aprender y aprender haciendo.

- Asistir en el desarrollo, creación e innovación de programas, métodos y técnicas pedagógicas que fortalecen los programas curriculares, y demás 
quehaceres relacionados con la formación y la capacitación que ejecuta la Universidad.

- La generación de conocimiento pertinente y relevante para la sociedad Colombiana.

En este sentido, la Universidad ha priorizado la realización de la investigación científica, desarrollo tecnológico e innovación, de carácter interdisciplinario y aplicado, que responda a las prioridades sociales en el ámbito nacional y regional. El alcance de estos esfuerzos incluye otras actividades de ciencia, tecnología e innovación necesarias para la gestión, explotación y apropiación social del conocimiento.

De ahí que la Escuela de Derecho ha puesto especial énfasis en el fortalecimiento de la investigación, como claro desarrollo de sus políticas de extensión y proyección social, y bajo el entendido de que las funciones de una universidad no solo se deben quedar en la docencia directa y en la extensión; teniendo en cuenta que el propósito de la investigación está orientado a la producción de nuevo conocimiento, a la generación de la ciencia, la tecnología y la innovación. Este carácter deontológico de la investigación científica propende por contribuir a la solución de problemas nacionales e internacionales y a la promoción del desarrollo científico, social, económico y sostenible.

Los semilleros de investigación, como escenarios de aprendizaje de la investigación, están concebidos en la Escuela de Derecho, como espacios académicos creados para estimular los proyectos desarrollados por nuestros estudiantes, a través del aprendizaje de competencias de investigación y de la difusión de los resultados de los mismos. Se busca con ello incentivar a los jóvenes investigadores, abrir espacios para la sana crítica, generar criterios de mejoramiento y fortalecer el trabajo interdisciplinar.

Esperamos que los trabajos de investigación consignados en este libro de memorias, que recogen las ponencias mejor evaluadas presentadas en el IV encuentro de Semilleros de Investigación, que se desarrolló el día 5 de noviembre del año 2013, tengan una buena acogida y que su difusión estimule a muchos jóvenes a superar el miedo y pasar de la potencia al acto, 
dejando a un lado el tabú con que se ha cubierto la actividad investigativa. Agradecemos la asistencia y la colaboración de los ponentes que han participado en este evento y para nosotros es un honor saludar a las universidades por su compromiso evidenciado durante el desarrollo del mismo:

- Universidad Pontifica Bolivariana. Sede Montería.

- Universidad del Atlántico.

- Universidad de Manizales.

- Universidad Sergio Arboleda. Bogotá

- Corporación Universitaria de la Costa

- Universidad Cooperativa de Colombia.

- Universidad Simón Bolívar de Barranquilla.

- Universidad Autónoma de Bucaramanga (UNAB).

- Corporación Universitaria Rafael Núñez. Cartagena.

De antemano la Escuela de Derecho de la Universidad Sergio Arboleda y su grupo de investigación "Joaquín Aarón Manjarrés" les extienden una invitación a no claudicar en esta tarea de formar investigadores con pertinencia y sentido humanístico.

Juan Alberto Polo Figueroa

Decano

Escuela de Derecho

Universidad Sergio Arboleda

Seccional Santa Marta 



\section{REFLEXIONES SOBRE GATOS NEGROS, BULIMIA EDUCATIVA Y LA NECESIDAD DE PREGUNTAR'}

\section{Resumen}

La ponencia esboza de forma reflexiva las falencias del modelo educativo en Colombia, en cuanto a su conexión holística, con la formación para la investigación. Precisa la importancia de refundar los procesos de investigación formativa desde la experiencia de los semilleros de investigación. En particular, se propone la redefinición de las ideas de ciencia, así como lo propositivo del rescate de la importancia de la pregunta como un elemento diferenciador en las didácticas contemporáneas.

Palabras clave: investigación formativa, semilleros de investigación, pregunta de investigación, ideas de ciencia, ignorancia.

\section{Abstract}

The paper outlines reflexively, the shortcomings of the educational model in Colombia, in their holistic connection with research training. It points out the importance of formative research processes from

1 El autor, Edimer Leonardo Latorre Iglesias, es sociólogo de la Universidad de Antioquia, actualmente candidato a doctor en Sociología Jurídica e Instituciones políticas de la Facultad de Derecho de la Universidad Externado de Colombia. Se desempeña como profesor de tiempo completo y director del grupo de investigación "Joaquín Aarón Manjarrez”, de la Escuela de Derecho de la Universidad Sergio Arboleda, Seccional Santa Marta. edimer.latorre@usa.edu.co 
the experience of the incubator research, in particular the redefinition of the ideas of science as well as purposeful proposed rescue of the importance of the question, as a differentiator in contemporary teaching.

Keywords: formative research, incubator research, research question, science notions, ignorance.

\section{A manera de introducción}

Es muy difícil encontrar un gato negro en una habitación oscura. Especialmente cuando no hay ningún gato.

Antiguo proverbio

En una ocasión pude apreciar un aviso a la entrada de un colegio que me impactó: "Para los niños el mundo es nuevo, para nosotros también". Es increíble la capacidad de preguntarse sobre el mundo, los objetos y la realidad que tienen los niños. Cuando se está cerca de niños, se puede apreciar su infinita capacidad de cuestionar su entorno y lo que ocurre en el mismo. Pero en un momento determinado y particularmente cuando ya han pasado por procesos educativos en serie, los niños que van a la escuela se asemejan a la metáfora que propone Pink Floyd, al comparar la educación con una gran maquinaria que convierte a los niños en carne molida.

Es dura la comparación, pero muy cercana a la realidad. Veo constantemente en mis clases que los estudiantes que antes preguntaban han perdido su motivación al debate, los que antes problematizaban su entorno pasan a formar parte de la masa anónima de miradas vacías en el tedio rutinario de las aulas de clase.

Esto es producto de lo que podríamos llamar el modelo bulímico de educación. Definirlo es muy sencillo: atragantar los cerebros con montañas de datos y hechos, para luego vomitarlos en exámenes tipo Ecaes y cumplir con los requisitos para acceder a un nivel superior. Lo triste de esta historia es que el método bulímico sigue en crecimiento hasta llegar a las más altas cotas de los programas educativos (Firestein, 2013). No existe un modelo 
pedagógico que realmente esté centrado en la pregunta, en el cuestionamiento. Esta declaración de principios, encerrada en ese aviso del colegio, plantea propositivamente uno de los grandes problemas de la educación en Colombia: un modelo obsoleto de educación y de construcción del conocimiento.

Lo anterior se evidencia en los procesos formativos de metodología de la investigación que dirigimos a nivel universitario, donde es palpable la ausencia de una mirada creativa proyectada hacia la realidad, hacia el contexto. La anterior afirmación se puede constatar en las precisiones que bosqueja el destacado científico Rodolfo Llinás (2014):

La escuela nos enseña la ubicación geográfica de los ríos, pero jamás nos explica la importancia del agua. Sabemos dónde queda Caquetá, aprendemos de memoria los nombres de las ciudades capitales y sabemos ubicar a Mesopotamia en el mapamundi. Somos un baúl repleto de contenidos, pero vacío de contexto. De ahí nuestra dificultad para aplicar el conocimiento en la realidad".

Una educación sin contexto, sin proyección al entorno, sin elaboración conceptual que le dé un significado a la vida y al entorno del estudiante, es una educación desconectada, impertinente y condenada al fracaso o como lo afirma Ken Robinson, la educación puede terminar siendo el Valle de la muerte. En esta perspectiva, nos encontramos con niños que poco a poco, al ser educados, van cerrando sus ojos a lo nuevo.

Esta ponencia aboga por ahondar en nuevas instancias reflexivas sobre la forma como se enseña investigación científica en las universidades. Pretende de igual forma, hacer una reflexión crítica, basada en la experiencia de más de cinco años en los procesos de acompañamiento y coordinación de semilleros de investigación en la Escuela de Derecho de la Universidad Sergio Arboleda, Seccional Santa Marta. Procesos que, a través de didácticas de investigación formativa, tratan de romper el modelo bulímico de educación y construir un escenario significativo que dinamice y potencie la pregunta como eje central de la formación. 
Por ello en primera instancia se propende por analizar las diversas ideas clásicas de ciencia, las cuales viven en el imaginario colectivo y se convierten en trabas a un pensamiento crítico, para en un segundo momento, plantear la necesidad de construir entornos significativos para el cuestionamiento, el desarrollo de la creatividad y del pensamiento sistémico. Concluye la ponencia, precisando la importancia de la ignorancia científica, que en últimas es la que nos permite trascender los campos predeterminados del saber científico.

\section{Las ideas clásicas de la ciencia: cebollas, rompecabezas y un iceberg que se derrite}

Stuart Firenstein (2013), nos da una visión general de las ideas afincadas en los imaginarios colectivos sobre la ciencia, las cuales se nutren de un modelo basado en la lógica lineal del pensar, propio de la modernidad y de sus pautas racionalizantes. Son lugares comunes y altamente estereotipados de lo que es hacer ciencia. Firenstein (2013), los clasifica en tres: 1) la idea de la ciencia como una cebolla; 2) la ciencia como un rompecabezas, y 3) la ciencia como un iceberg. Acerquémonos detenidamente a cada una de estas visiones afincadas en el inconsciente colectivo de las sociedades contemporáneas, como grandes trancones vehiculares que cierran la vía del pensamiento científico.

La ciencia como cebolla. Esta metáfora la entendemos cuando nos transportamos a la imagen que surge al quitar las capas de la cebolla y nos acercarnos al centro (si las lágrimas lo permiten). Representa esta concepción, la idea de que las cosas están ocultas a la mirada y de que si metódicamente quitamos cada capa de cebolla, encontraremos la verdad objetiva y las leyes que de ella se derivan. Lastimosamente la ciencia no se mueve así, no se trata de desgajar la cebolla; en ocasiones lo que los científicos hacen es picarla en múltiples trozos o simplemente se trata de destruir la cebolla. Yo los invito a que mejor hagan un buen uso de esa cebolla, se la coman en una buena receta gastronómica (hibridación, combinación o fusión).

La segunda mirada, es la de pensar que la ciencia es una labor rutinaria y metódica de colocar las piezas que faltan para poder armar 
el gran rompecabezas. Tristemente la realidad es otra. En el caso del rompecabezas (compra uno y verifica), ya viene incluido en la caja la forma que este debe tener y las indicaciones en caso de que no podamos armarlo (algunos tienen página web).

La realidad del científico al abordar el mundo de lo real, el mundo de los hechos fácticos, es que no hay diseño, no hay indicaciones y mucho menos existe la posibilidad de la figura, las figuras surgen de lo que logramos inferir. No hay nada mejor que cuando estamos armando nuestro rompecabezas, tengamos que meter algunas fichas a empujones, ya que, no cuadra con la figura, o en el peor de los casos, nos sobren fichas. Recuerda cuando arreglaste ese electrodoméstico en la casa de tu primer amor; funcionaba ¿cierto? Te hacías la pregunta: ¿dónde puedo esconder estos tornillos que me sobraron?

La tercera mirada, acorde con la visión crítica de Firestein (2013), la encuentro en casi todos los sitios donde se discute sobre ciencia. La idea atrincherada en las mentes del colectivo, de que la ciencia es un iceberg y de que es necesario mirar lo que está oculto debajo del agua. Ojala así de sencilla y simple fuera la labor del científico. Sería muy fácil, simplemente derretiríamos el iceberg o nos sumergiríamos en torno a él. Pero la realidad es mucho más esquiva y compleja. En ocasiones vemos las cosas, pero en verdad no sabemos ver lo que estamos viendo: ya que la mayoría de las veces, vemos lo que somos.

Me imagino que en este momento te debes estar preguntando: ¿bueno y a todas estas, cuál es su propuesta? Para explicar una idea diferente de ciencia propongo que ustedes vean la película Thor. Está basada en los cómics del dios Thor, creados por Stan Lee (a lo mejor, por la magia del azar, ya viste esa película). Hay algo que me encanta de este filme: su fusión entre magia y ciencia. Dice el dios Thor en uno de los pasajes: “... en nuestro mundo, la magia y la ciencia son una sola”. La idea de la ciencia que verifico en mis procesos investigativos está más cercana a estos postulados. Sé que los positivistas que estén leyendo esto deben estar a punto de despedazarme cual cebolla por esta afirmación herética. 
Pero ciertamente esta idea ya fue matizada en ocasiones anteriores por un gran divulgador de la ciencia: Carl Sagan (2005). En su obra póstuma, El mundo y sus demonios, planteaba una gran preocupación: le aterraba la forma como los colectivos sociales se obnubilaban con las visiones pseudocientíficas que explicaban el mundo. Le abrumaba cómo la magia, la magia mediática de la televisión y del cine, la magia de los políticos o la magia y la fuerte creencia en lo no científico, en lo sobrenatural, servía de referente para comprender y dar sentido a la existencia. Su preocupación estaba en el rechazo de las masas, con la fuerza de la negación fanática, a la magia inherente a los procesos científicos. En este momento invito al fantasma de Sagan (2005, p. 32) a que venga en nuestra ayuda: "Podría afirmarse que se abraza la pseudociencia en la misma proporción que se comprende mal la ciencia real... En algunos países, casi todo el mundo cree en la astrología y la adivinación, incluyendo los líderes gubernamentales".

Cuando digo que la ciencia es mágica, me refiero a otro tipo de magia, a la que surge de nuestra inteligencia intuitiva (Gladwell, 2005), a la que aparece cuando queremos explicar el funcionamiento de algo o entender cómo sucede algo. Esta magia es poderosa, ya que tiene la capacidad de solucionar un problema, pero tiene al mismo tiempo el poder de plantear nuevos problemas.

En otras palabras, la magia de la ciencia estriba en que es capaz de irradiar preguntas frente a las respuestas que ofrece. Ya Savater (2003) afirmaba que la labor de la filosofía no es la de responder, no es la de dar respuestas y mucho menos la de saberlo todo; es todo lo contrario, la labor del filósofo es la de preguntar, simple y llanamente, su labor es cuestionar una y otra vez. Viene a mi mente Sócrates bebiendo la cicuta y el guardián, regañándolo para que se estuviera quieto. Sócrates le dice que su oficio es darle la cicuta cuantas veces sea necesario, el trabajo de un filósofo (su oficio) es discernir de forma sistemática y constante.

Por ende, queda de relieve que el uso de la pregunta como mediación para el aprendizaje científico es vital, ahí radica la magia de la ciencia y eso debemos contagiarlo a nuestros estudiantes. Me apasiona la idea de una ciencia que es capaz de proyectar en su entorno la capacidad de asombrarnos 
frente a lo que vemos y lo que sentimos en el mundo actual. Pero todo esto es un gran pre-texto, que nos lleva a la necesidad de reconfigurar los espacios para la creación de preguntas y el redescubrimiento del asombro creativo.

\section{Universidades, cafeterías y la importancia de no saberlo todo}

En una de mis clases una señorita, muy bella, estaba siempre pendiente de sus redes sociales en el trascurso de las sesiones. Obviamente su desempeño no era el más meritorio, cuando la recriminé y la exhorté a que mejorara, me quedó mirando con una cierta molestia en su semblante y me gritó en tono enérgico:

¡Es que usted no me ha motivado lo suficiente! Aún resuenan sus palabras en mis oídos. Ella diseñaba la estrategia clásica, la que todo buen Colombiano hace, o mejor la que todo buen latinoamericano está acostumbrado a hacer. Ella buscaba culpables y ya lo había encontrado: Yo. Pero noten ustedes que antes de eso, yo estaba buscando un culpable; para mí el problema era ella.

Si analizamos la crisis de la educación en Colombia, nos daremos cuenta de que nos la pasamos buscando culpables. Los ministros del despacho dicen que son los docentes, los docentes que son los estudiantes, los estudiantes que son sus padres y los padres al final dicen que es un problema del vientre materno. En verdad el problema no estaba dentro de los dos (ella y yo), estaba entre los dos. Siempre he creído que la educación es un acto puro de erotismo, esto implica la presencia y la coimplicación de los sujetos en la práctica como tal. Que uno solo esté motivado no es suficiente. Pero necesitamos detenernos más en este hecho en particular.

Es famoso el experimento de Skinner (Pearsall, 2006), realizado en ratas de laboratorio, el cual marcó una fuerte tendencia en la comprensión de la conducta de los drogadictos. Skinner colocó cables direccionados al cerebro de ratas, especialmente a la parte donde se produce la felicidad. Las ratas descargaban energía mediante un botón, después de aprender a usarlo, las ratas lo oprimían cada vez que deseaban sentir felicidad. El problema descubierto por Skinner, es que después de las primeras 
descargas, las ratas eran propensas a mantener el botón apretado, incluso hasta el hecho de consumirse lentamente. Las ratas morían de inanición, solo consumían la droga que les producía felicidad.

Este experimento marcó los estudios y análisis sobre la drogadicción. Nos señalaba que no podíamos escapar a la búsqueda desenfrenada de placer que estaba escondida en nuestro cerebro. Afortunadamente, otro psicólogo puso en jaque esta teoría. Me refiero a Bruce Alexander.

Después de revisar una y otra vez el experimento de Skinner, consideraba que algo había de malo en el experimento. Lo estudió de arriba abajo y viceversa y encontró una variable clave: las ratas de Skinner, vivían en unas condiciones totalmente deplorables. Unas encima de otras, llenas de excremento, en condiciones totalmente indignas. Igual ocurría con los monos de laboratorio, estaban todo el tiempo amarrados a un árbol, con una sola mano libre, con la cual obviamente, se inyectaban heroína (Pearsall, 2006).

Es por esto que decidió hacer un experimento que modificara esta variable. Construyó un parque de diversiones para ratas. El parque poseía todas las comodidades de un hotel cinco estrellas, hecho para ratas. Las celdas eran amplias, llenas de latas y rollos, con espacios que producían gratificación. El resultado fue asombroso, las ratas no consu mieron la heroína, mientras las ratas que vivían en jaulas en condiciones denigrantes, consumían hasta el cansancio. Lo increíble de la historia es que Alexander tomó ratas del grupo de jaulas convencionales y las pasó al grupo del parque de ratas, estas abandonaron sus hábitos de consumo.

En este experimento de laboratorio vivenciamos un aspecto vital en la urdimbre propositiva de esta ponencia: el poder del contexto (Pearsall, 2006).

No es el docente o el profesor. Lo que se logra demostrar con los semilleros de investigación y con el proceso de acompañamiento de los mismos es que el solo hecho de sacarlos del formalismo de las clases, de los horarios rígidos y celosamente guardados por docentes vigilantes, rompe todo el proceso contextual tradicional. Recuerdo con gratitud mis 
años de estudiante universitario, y recuerdo con el poder de la nostalgia que ocurría cuando finalizaba una clase, todos rodeábamos al profesor y nos dirigíamos a la cafetería, nos peleábamos para invitarlo a un café, cuando el accedía a esto (en su gran mayoría todos lo hacían), la verdadera clase surgía ante nosotros.

El profesor nos daba mucho más de lo que brindaba en su tradicional esquema de clase. Recuerdo estas sesiones como grandes procesos de preparación para el mundo académico. El profesor señalaba gustos, pasiones, textos que lo habían impactado, historias de vida que en la confianza creada en esa cafetería, alrededor de un café, no podía ofrecer en el salón de clases, nos brindaba experiencias de su pasado profesional y nos regalaba sus claves para la vida, era simplemente magia en acción.

En el fondo lo que me preocupa es que los salones de clase y las dinámicas en su interior se basan en la competencia, en la búsqueda implacable del logro individual: los estudiantes son caballos desbocados en búsqueda de la beca o del mejor puntaje, pareciese que su única meta en el Derby universitario es el promedio. En esta competencia no queda tiempo para nada, obviamente no hay tiempo para un café con el profesor y el profesor ocupado en sus múltiples tareas de profesor de tiempo completo (léase repleto) lo que menos piensa es irse a la cafetería a perder su tiempo. Las cafeterías de las universidades hoy distan mucho de lo que eran en el pasado, ahora son templos del comercio, de los juegos (lúdica creativa) y de la televisión (casi todas tienen televisores).

Los espacios para la interacción creativa se vuelven escurridizos en el mundo universitario, paradójicamente no es posible hallar un lugar que permita leer, escribir y pensar. Es bastante absurdo que el lugar que te enseña a pensar no tiene escenarios para pensar (no entra la biblioteca en mi lista, ya que es prácticamente imposible estudiar y pensar en una biblioteca o en un sala de estudio de una universidad; inténtenlo y me cuentan, por lo general es constante la voz de la bibliotecaria, hagan silencio...).

Uno de los logros que hemos alcanzado en la experiencia de los semilleros de investigación es la creación de contextos diferenciales y significativos para que los estudiantes interaccionen y los docentes cumplan 
realmente con la función de ser auxiliares cognitivos. Pero ello obedece a que nuestro proceso gira en torno a los siguientes aspectos:

1. Es absolutamente opcional la participación del estudiante. No conduce a puntos extras, puntaje preferencial, no da notas y no es una opción de grado, es simplemente participar para aprender. Garantizamos que la temática o el área genere adicción apasionada en los interesados.

2. El otro factor es la ruptura de los formalismos tradicionales de las sesiones de clase, les pedimos que escojan al docente. Es importante que ellos lo escojan, no que el docente los escoja. No evaluamos al semillero en función del docente, evaluamos al docente en función del semillero.

3. Les pedimos que sean autónomos, ellos mismos deben crear sus pautas, su sistema de organización, su direccionamiento estratégico. Cuando encontramos a un estudiante demasiado ocupado para perder tiempo con nosotros, lo invitamos a reflexionar sobre si es verdad que quiere pertenecer o no al proceso. Me encargo de que el tiempo desaparezca; solo cuando dejamos de pensar en el tiempo, es cuando empezamos a pensar.

4. Finalmente reconstruimos algunos espacios en función de nuestras necesidades. Son espacios donde los invito a desconectarse de las redes sociales y de sus smartphones, son lugares donde recupero el poder de la palabra y el poder la pregunta, donde se valora por encima de todo la capacidad de equivocarnos. Nuestro eslogan es: "La única pregunta mal hecha es la pregunta que no se hace".

Para ir finalizando este aparte, quiero señalar que la tarea más difícil es lograr romper el paradigma de creer que la educación consiste en poder demostrar que uno se las sabe todas. Creo que el gran reto que hay que asumir con los estudiantes y en gran parte de la comunidad científica es el ego, ya que este no nos deja percibir los errores de nuestras aproximaciones al mundo de lo real, de ahí que lo ineludible en los procesos de creación de contextos significativos sea enseñar la fuerza arrolladora del error y la importancia de no saberlo todo. 


\section{A manera de conclusiones}

Participaba en un encuentro nacional de semilleros de investigación, cuando el sonido que proyectaba el micrófono anuncio la intervención de un joven, denominado por el evento representante estudiantil a nivel nacional de los semilleros de investigación. Supuestamente él haría una disertación sobre el papel de los semilleros en el aprendizaje de la investigación. Para sorpresa mía (en verdad para tristeza), el joven inició haciendo un recuento del proceso emancipatorio que debían vivenciar los jóvenes dentro de los semilleros de investigación. Para esta "promesa de la investigación”, y lo que trascribo a continuación es textual, "había llegado el momento de que los integrantes de los semilleros de investigación dejaran de ser los carga ladrillos de los investigadores".

Sus palabras aún retumban en ese auditorio y en mi cabeza. Además de la convicción del proceso revolucionario que según él se estaba vivenciando, me dejó altamente confundido esa afirmación: cargar ladrillos. Desde una mirada crítica, sus palabras encierran dos grandes supuestos subyacentes a la forma convencional y aceptada de hacer investigación y de educar en la ciencia de la investigación en Colombia.

La primera es la mirada elitista de hacer investigación. Esta mirada desprecia el trabajo de campo, desprecia la tarea de hacer inmersión en las realidades que nos circundan, desprecia salirse de las aulas. Creen firmemente los elitistas de la investigación que ser científico social es estar en la comodidad de una oficina y no tener que mirar por la ventana para no chocarnos con la realidad, la cual es negada constantemente. Es el efecto burbuja de la investigación. Una investigación que desconoce la realidad no puede cambiarla.

El segundo supuesto tácito es más grave aún. Es el que niega la parte más increíble de la investigación: el trabajo de campo. Esa tarea ardua de recoger información, cotejarla una y otra vez, interpretar y reinterpretar, diseñar el armazón con el cual confirmaremos o negaremos nuestras hipótesis, construir y reconstruir, una y otra vez, nuestra visión teórica para tratar de apresar esa esquiva realidad. En el fondo, pareciese que los investigadores quieren investigar sin investigar. Es decir, nos limitamos a 
construir investigaciones superficiales que poco se proyectan al entorno y que tienen muy pocas probabilidades de transformarlo. Negarle a un joven la posibilidad de iniciar su vida académica y científica en el área de la investigación desde lo básico, es negarle la aventura de entender que el mundo es diferente, si lo miramos con los ojos de la diferencia.

Por ende debemos rescatar la importancia de cargar ladrillos. La importancia de empezar desde lo básico, con el sudor, el cansancio y siendo la pregunta y la disquisición los orientadores de nuestro camino. De ahí que inste a los grupos y organizaciones que están reunidos en este evento, a cargar ladrillos, a cargar los ladrillos del conocimiento que se puede construir, en un contexto basado en interacciones significativas, donde por fin entendamos que investigar es la magia de la vida.

Me despido con una historia muy personal. En una ocasión mi hijo menor me preguntó sobre cómo debía hacer una tarea.

Él me afirmó que no sabía cómo hacer un cuento sobre sus vacaciones. Le dije que simplemente tenía que contar una historia que a él le había pasado, enfaticé en la necesidad de que la dijera con sus propias palabras. Se sentó a mi lado, mientras yo escribía esta ponencia y lo vi hacer su cuento, que además incluía dibujos. El resultado me dejó sorprendido y quiero compartirlo con ustedes, el cuento se llama "Un día en la playa" (hechos que este autor por más que lo ha intentado no logra recordar):

Un día estaba en la playa con mi papá, mi mamá y mi hermano. Ese día estaba jugando con las olas en competencia con mi hermano y vino una ola fuerte y me caí en el mar, yo di dos volteretas, y me arrastró con la tierra y me asustó tanto que me puse a llorar y mi papi me dijo, esos son los primeros golpes del mar, así que sigue adelante, de lo que se trata es de ser un gran pez.

Los invito a navegar en el mar del conocimiento sin importar cuántos golpes nos den sus olas, ya sabemos que solo tenemos que ser un gran pez. 


\section{Referencias}

Firenstein, Stuart (2013). La búsqueda de la ignorancia. En: https:// www.youtube.com/watch?v=nq0_zGzSc8g.

Gladwell, Malcolm (2005). Inteligencia intuitiva: ¿Por qué sabemos la verdad en dos segundos? Barcelona: Taurus.

LLinás, Rodolfo (2014). Los maestros siguen pensando que son dueños del conocimiento. En: http://www.elespectador. com/noticias/educacion/ los-maestros-siguen-pensando-son-duenos-del-conocimientarticulo-489552.

Pearsall, Paul (2006). El último libro de autoayuda que necesitara. Bogotá: Grupo Editorial Norma.

SAgan, Carl (2005). El mundo y sus demonios: la ciencia como una luz en la obscuridad. Bogotá: Planeta.

Savater, Fernando (2003). Las preguntas de la vida. Barcelona: Ariel. 



\section{LA LEY PARA EL HOMBRE Y NO EL HOMBRE PARA LA LEY: UNA MIRADA AL DERECHO DESDE EL HUMANISMO CRISTIANO'}

\section{Resumen}

Cuando se habla de la ley y se quiere hacer un análisis a esta realidad omnipresente en el hombre, es necesario contextualizarla históricamente, de tal manera que su significado sea despojado de un nivel de ambigüedad que ponga en peligro su esencia; la ponencia propone un análisis que tiende a resignificar el aporte de la filosofía cristiana a una visión del derecho con un alto componente humanista.

Palabras clave: Filosofía del derecho, humanismo cristiano, iusnaturalismo, derecho cristiano, derecho Agustiniano.

1 Esta ponencia es un resumen del Estado del Arte de la investigación: Humanismo Cristiano en Rodrigo Noguera Laborde, desarrollada por el Grupo de Investigación Joaquín Aarón Manjarrez de la Escuela de Derecho de la Universidad Sergio Arboleda, Seccional Santa Marta. Los autores, José Ariel Parra director del proyecto, es filósofo de la universidad Santo Tomás, mágister en Docencia e Investigación Universitaria, director de Investigación para la formación de la Escuela de Derecho de la Universidad Sergio Arboleda, seccional Santa Marta (Jose.parra@usa.edu.co); Carlos Julio Agudelo Gómez coinvestigador, es Licenciado en Filosofía y Ciencias Religiosas, de la Universidad Santo Tomás, mágister en Docencia e Investigación Universitaria, es investigador y director del semillero de investigación Humanismo Cristiano de la Escuela de Derecho de la Universidad Sergio Arboleda, Seccional Santa Marta (carlos.agudelo@usa.edu.co). 


\section{Abstract}

When one speaks about the law and analysis wants to be done to this omnipresent reality in the man, it is a necessary set in a context historically, in such a way that his meaning is taken off of a level of ambiguity that puts in danger his essence; the presentation proposes an analysis that tends to re-mean the contribution of the Christian philosophy to a vision of the right with a high humanist component.

Keywords: Philosophy of the right, christian humanism, natural law, right christian, right agustiniano.

\section{Introducción}

Si se mira en la historia qué se ha dicho de la ley, se encuentra una huella relativamente cercana en la obra de Homero titulada La Ilíada. Aquí encontramos que "Zeus desencadena su ira cuando los hombres decretan leyes injustas o no observan la justicia” (Fasso, 1982. p. 20). Los griegos, adalides de la ley, dejan entrever que es en La Ilíada donde ellos comienzan a insinuar cuál va a ser la concepción de ley que adoptarán; la ley tiene un origen sagrado, puesto que son los dioses quienes revelan a los reyes una serie de leyes y les dan la autoridad de ponerlas en práctica en el pueblo.

Las revelaciones recibidas por los reyes se convierten en mandato que los padres les transmiten a los hijos y de esta manera el gobierno y la ley se convierten en patrimonio de la clase dominante, esta clase superior se encarga de proteger y custodiar la ley que siendo sobrenatural se vuelve natural cuando se le aplica al pueblo. El pueblo respetuoso de la tradición y de la ley consuetudinaria obedece, algunos por convicción y otros por temor a los dioses y a los gobernantes, sin embargo en esta forma de gobierno se comienzan a presentar excesos de autoridad puesto que algunos gobiernos de turno interpretan los mandatos divinos a su manera y esto se convierte en un problema de legitimidad de la autoridad.

Frente a la anterior afirmación encontramos un pasaje explícito en Sófocles cuando en Antígona, Creonte ordena a Antígona, a Ismene y al pueblo en general dejar insepulto a Polinices por haber deshonrado al 
Estado, cuando Creonte interroga a Antígona por haber desobedecido sus órdenes, Antígona le contesta:

Esas leyes no las promulgó Júpiter, tampoco Justicia, la compañera de los dioses infernales; no, ellos no han impuestos esas leyes, ni creí que tus decretos tuvieran fuerza para borrar e invalidar las leyes divinas, de manera que un mortal pudiese quebrantarlas. Pues no son de hoy ni de ayer, sino que siempre han estado en vigor y nadie sabe cuándo aparecieron. Por esto no debía yo, por temor al castigo, de ningún hombre violarlas para exponerme a sufrir el castigo de los dioses (Sófocles 2011, p. 173).

La contundencia de las palabras en el argumento de defensa de Antígona deja ver que existen unas leyes las cuales son eternas y el hombre no conoce el momento en que comenzaron a regir, pero una cosa si comprende con claridad, esto es, que las leyes divinas no se deben violar aún en contra de las leyes emitidas por un mortal, puesto que el castigo por desobedecer a un mortal es la muerte pero el castigo por desobedecer las leyes divinas es el enfado de los dioses.

La ley natural se encuentra en los cimientos de cualquier otra ley, es la ley natural un mandato eterno, concreto, preciso y justo en este caso la ley se denomina divina, porque nace de los dioses y ellos no se equivocan, los que se equivocan son los hombres que la interpretan desde su patrón jurídico social o religioso, por consiguiente el gobernador debe pedir luces a los dioses para poder interpretar la ley natural lo más cercano al querer y a la intención de los legisladores, es decir a las divinidades.

Las huellas o estela de la ley natural después de Homero y Sófocles las encontramos en los presocráticos; cada uno de ellos buscando dar respuesta a la pregunta sobre el universo se remite de forma insistente a los elementos de la naturaleza. Es curiosa esta referencia puesto que aunque siempre un elemento de la naturaleza, un elemento físico está en cada una de las teorías, los mismos presocráticos hacen ascender dicho elemento hasta convertirlo en una realidad que va más allá de las apariencias. En efecto, además de darle a dichos elementos características físicas y naturales les dan otras que son sobrenaturales y hasta espirituales. A este respecto encontramos 
que Anaxímenes dice que todo proviene del aire infinito y después de cumplir con su cometido todo regresa a él; Anaximandro califica al apeiron como una materia primordial, ilimitada, homogénea, indeterminada, incualificada, eterna imperecedera, inmutable incorruptible, inagotable, generadora de todos los seres y a la cual regresan todos los seres.

Heráclito de manera enfática afirma que existe un elemento que está en la base de toda la existencia; ese es el fuego, pero antes del fuego ubica la razón, el logos que es el responsable del orden y de la armonía cósmica, el logos es una ley natural necesaria, además mientras todo lo demás se mueve, muda, la razón o el logos es inalterable y no cambia. Parménides frente al principio de la existencia dice que lo que existe es el ser y le da las siguientes características: es uno, eterno, imperecedero, inmóvil, continuo, homogéneo, lleno, compacto, finito y esférico.

Para Anaxágoras la responsable de la aparición y desaparición de todas las cosas es una mente universal que la denomina Nous, es una mente infinita, libre, potentísima, purísima, no mezclada, inteligentísima, conocedora de todas las cosas, es la encargada de impulsar las homeomerías o los torbellinos para que se pueda formar el cosmos.

Se puede ver claramente que en el fondo de todas las teorías presocráticas encontramos una constante, el cosmos es producto de la intervención de una fuerza o ley natural y de unos elementos físicos con características casi divinas; la ley natural inexorable y presente en todas las teorías anteriormente descritas, se enfrenta de forma no agresiva a la existencia humana, el hombre hace parte de la creación y por lo tanto está llamado a respetar y a asumir esas leyes, el hombre consciente de su existencia natural que se compromete con él mismo, a respetar, conservar y defender lo que la naturaleza le ha ofrecido para alcanzar la felicidad como lo ha hecho la naturaleza con todos los demás seres; desde la perspectiva de la naturaleza no existe ley que se le impongan a los seres para causarles daño, sino que se le impone para favorecer su existencia.

Se podría afirmar que ningún ser intenta violar alguna de estas leyes puesto que por instinto o por otro mecanismo, descubre que no debe hacerlo puesto que si así procede las consecuencias serán fatales para el individuo 
no así para la especie, cada uno de los seres y por su puesto cada uno de los hombre está convocado por la naturaleza a conservar su vida y solo podrá lograr este propósito si lee en la naturaleza lo que debe hacer y lo que debe evitar.

Las leyes naturales o primarias son lecciones cotidianas que ayudan al hombre para que este analice las leyes secundarias o positivas. Dentro de la vida del hombre existen las leyes naturales, las cuales le han permitido vivir en sociedad pero estas, como se verá, han sido copiadas de lo que la naturaleza física o divina nos presenta:

Heráclito hablando de manera explícita sobre la ley natural dice que todas las leyes humanas se nutren de una única ley divina... queda claro que la idea de un fundamento absoluto de las leyes positivas está presente en el pensamiento presocrático, continúa Heráclito, esta ley divina que es la primera y verdadera ley no puede ser otra que el Logos, la razón universal, sustancia y principio de toda realidad a la que el hombre accede gracias a la filosofía (Fasso, 1982, p. 23).

Los fragmentos de los presocráticos que han llegado hasta nuestra época dejan ver claramente que la concepción de un orden jurídico, de un orden social fue tomado de la armonía cósmica y del orden natural que ellos por la contemplación descubrieron, de tal manera que la ley natural que está presente en el cosmos les sirvió de modelo y de paradigma para construir las diferentes formas de gobierno y para proponer las leyes que fueron posteriormente codificadas.

La construcción de la sociedad se puede entender hasta este momento como el producto de un análisis detenido y muy cuidadoso en donde el instinto es superado y sustituido por la reflexión y por la búsqueda de mecanismos que hicieran agradable y placentera la convivencia entre los hombres, este fin no puede estar viciado en su origen por intenciones mezquinas ni intereses sospechosos; es comprensible que algunas de las leyes y normas consensuadas sufrieron cambios importantes cuando descubrieron en ellas algunos elementos que podrían perjudicar al hombre individual o a la colectividad. 
En el camino de la ley natural encontramos unos momentos en los cuales el hombre ha perdido la dirección y al tomar otro sendero interpreta la ley natural desde una perspectiva nueva y discutible. Para entrar en el tema es pertinente recordar que los presocráticos tenían claro que existen leyes que provienen de los dioses y son consideradas divinas, y además existen otras leyes que provienen de la naturaleza y son perfectas; estas leyes no escritas ni codificadas son anteriores a las elaboradas por el hombre y superiores a toda otra ley, si esto es así, si son perfectas, anteriores y superiores al hombre, nunca atentarán contra el hombre, porque al atentar contra el hombre no serían perfectas puesto que el hombre hace parte de la naturaleza.

Los sofistas en algunas de sus intervenciones dejan ver que para ellos existen dos tipos de leyes, una llamada nomos, que es artificial, puesto que por costumbre o por consenso se pone en práctica en la comunidad; otra llamada physis, natural, esta es para algunos sofistas la ley verdadera, es la más justa; Calícles en el diálogo Gorgias dice:

Respecto a las leyes, como son obra de los más débiles y del mayor número, a lo que yo pienso no han tenido al tomarlas en cuenta más que a sí mismos y a sus intereses, y no aprueban ni condenan nada sino con esta única mira. Para atemorizar a los fuertes, que podrían hacerse más e impedir a los otros que llegaran a hacerlo, dicen que es cosa fea e injusta tener alguna ventaja sobre los demás y que trabajar por llegar a ser más poderoso es hacerse culpable de injusticia. Porque siendo los más, más débiles creo que se tiene por muy dichosos si todos están por un mismo rasero. Por esta razón es injusto y feo, en el orden de la ley, tratar de hacerse superior a los demás, y se ha dado a esto el nombre de injusticia. Pero la naturaleza demuestra, a mi juicio, que el que vale más tenga más que otro que vale menos, y el más fuerte más que el más débil... En esta clase de empresas se obra, yo creo, conforme a la naturaleza, y se sigue la ley de la naturaleza, aunque quizá no se consulte la ley, la ley que los hombres han establecido (Platón, 2007, p. 238).

La interpretación que Gorgias le da a la ley physis o ley natural conduce a ver en dicha ley un proceder instintivo y propio de la naturaleza animal, como él mismo lo argumenta en su discurso, la ley del más fuerte no es 
una ley divina ni una ley animal en cuanto que hasta el animal utiliza la fuerza solo en momentos vitales o de supervivencia, en cambio cuando se afirma que el que vale más debe tener más que el que vale menos, así no sucede entre los demás seres puesto que en la naturaleza todos valen igual, solo que cuando se trata de defender la vida cada uno acude a su capacidad natural para defenderse; es necesario tomar con discreción el concepto de valer más para no caer en error.

La tabla de valoración teniendo en cuenta lo dicho por Gorgias sería que se impone la supremacía del más fuerte sobre el más débil. El hombre que hace parte de la naturaleza, desde su origen se ha diferenciado de los demás animales y no se pueden comparar de manera literal las costumbres ni las leyes que utilizan los demás animales, con las leyes y las costumbres del hombre como animal racional; el hombre animal racional no está movido ni manejado por el instinto como sí lo están los demás seres, la razón es lo que diferencia al hombre y desde la razón la ley natural no puede ser la fuerza ni el instinto, si hablamos de la naturaleza humana y de la ley natural del hombre esta no puede ser otra que la recta razón.

En los sofistas se encuentran múltiples interpretaciones de la ley natural, a tal punto que no sería preciso quedarnos con lo dicho por Calícles en cuanto que se encuentra, por ejemplo en Antifón, que el hombre al violar la ley humana podría evadir el castigo utilizando su fuerza y su destreza, pero el que viole la ley natural no podrá evadir el castigo de los dioses, aquí la ley natural tiene otra connotación, es una ley emanada de los dioses y no se confunde con la ley del más fuerte sino que es una ley que está inscrita en la conciencia del hombre de manera natural.

En este contexto se continua viendo que la ley natural es central para la actividad del ser humano, la lectura sesgada que se haga de algunos sofistas hace pensar que el afán por entender la ley natural ha llevado al hombre a proponer en algunos momentos teorías que podrían ir en contra del mismo hombre pero estas tendencias han sido modificadas por una concepción de la universalidad del actuar humano que difiere frente al actuar instintivo de los animales; la ley natural sigue siendo el cimiento para la creación de otro tipo de leyes. 
Superada la participación histórica de los sofistas en la construcción del orden jurídico y social en la antigua Atenas, se encuentra la novedosa participación de un personaje que marcó de forma trascendente una ruta sobre el hombre y su comportamiento: Jesús. De ahí que abordemos la impronta del humanismo cristiano y su posterior evolución en los tratadistas fuertemente influenciados por una visión humana de la ley y su aplicación.

\section{La concepción de la ley en el cristianismo}

En el proceso la historia encuentra una propuesta de ley que muestra de qué manera el hombre se aferra a unas normas las cuales son consideradas perfectas y su cumplimiento se hace por convicción personal y social. El legislador en el momento que está elaborando la ley la hace para el hombre y esto se confirma porque tiene en cuenta toda la actividad cotidiana de la humanidad, esta ley es universal y se encuentra un pacto, un contrato donde se encuentra premios y castigos; con esto se confirma que el hombre puede fallar, aunque está llamado a cumplir.

La ley en el cristianismo se debe dividir en dos momentos; el primero se puede llamar la ley mosaica:

Sin embargo, todos estos textos delatan un espíritu común, a saber, el espíritu de Ezequiel, que codificaba las prescripciones que permiten a Israel hablar de la presencia de su Dios en el Templo. (Ez 48,35) y ofrecen la Tora del Templo ahí que se llame hoy el conjunto de esos textos Código Sacerdotal. Él muestra cómo Dios, por sus grandes instituciones marca las etapas de la historia: la ley de la fecundidad Adán, la ley del temor a la sangre con Noé, la ley de la circuncisión con Abraham, la ley del Santuario con Moisés y Aaron. Este conjunto precisamente ha dado su marco al Pentateuco entero y ofrece aun en Josué una legislación complementaria. Pero Josué no hizo en eso sino aplicar y adaptar la ley de Moisés, tal como se la dio también a conocer al pueblo en Siquem. Así pues la Tora comprende los cinco libros de Moisés: El Pentateuco (Bauer, 1967, p. 570).

En la Ley mosaica se encuentra la realidad económica, social, política, histórica de un pueblo que ha puesto su confianza en un dios y que recibe 
una serie de mandatos, confiados, que al cumplirlos encontrarán además de la salvación también una serie de beneficios a nivel individual como social. Con fundamento en un análisis jurídico se encuentra que estas leyes emanadas por parte de una autoridad extramundana, se admiten por parte del hombre como leyes perfectas y su cumplimiento debe ser obligatoria; en el pueblo de Israel que se caracterizará por ser cumplidores de la ley, algunas veces este cumplimiento los llevó a ser injustos, por el apego literal de la letra de dicha ley.

Esta ley, a pesar que proviene de un ser superior no es extraña ni lejana al hombre, está cerca de su mente y de su corazón para que pueda ser interpretada y cumplida con la finalidad de que el hombre pueda recibir los beneficios que por cumplir la ley se merece, o recibir el castigo por no cumplirla en su totalidad: "La ley es considerada como una magnitud absoluta, es la expresión eterna del querer Divino, revelada a Israel por un privilegio de su gracia, por eso se ama la ley, como se ama una realidad Divina” (Bauver, 1967, p. 571).

El pueblo judío como receptor de la ley mosaica se ha convertido en celoso cumplidor de dicha ley, puesto que consideran que Dios ha confiado en ellos no solo una ley sino que en ella les dio la sabiduría para estar en su presencia eterna en la medida que defiendan respeten y cumplan la ley y además están llamados también a darla a conocer para que todo el mundo conociéndola se salve por su eficacia y por la gracia de Dios.

Así como en la cultura Griega, encontramos en la cultura Hebrea que existe una ley no creada por el hombre sino por un ser superior, la cual tiene un carácter divino y natural y el hombre mediante un intermediario la conoce y sabe que esta nunca atentará contra la tranquilidad del hombre, puesto que su finalidad es darle la posibilidad de buscar la perfección y la felicidad, la cual podrá encontrar en la medida que la cumpla y la ponga en práctica en todos los acontecimientos de la vida.

El mandamiento que sale del ser superior, aunque es un misterio, el hombre logra comprenderlo y comienza a vivir bajo estos parámetros, en estas reglas acogidas en el Antiguo Testamento por el pueblo de Dios encuentra el ser humano una seguridad la cual lo conduce a evitar hacerle 
daño al ser superior y de manera específica a su semejante. Se podría afirmar que para que el pueblo cumpla estas leyes recibe antes una instrucción que es considerada una educación para actuar correctamente.

La otra dimensión de la ley cristiana se puede llamar la ley del Amor. De esta los agiógrafos hablan de que tiene que ver de forma directa con la obra realizada por Jesús, San Pablo en sus diversas Epístolas propone un análisis entre la ley como letra y ley como espíritu; afirma que la ley como letra (aquí letra se entiende como ley mosaica) puede llegar a dominar y a esclavizar al hombre que se queda en lo literal del mandato y no supera el aspecto gramatical.

La ley como Espíritu es la que libera al hombre del cumplimiento y le permite superar la letra y comprender lo que la ley quiere mandar, el mandato del Cristo supera la ley mosaica y le da la libertad al hombre para que conociendo la ley la cumpla o no, si la cumple estará con Cristo si no la cumple se aleja de Él pero puede regresar puesto que la alianza definitiva no es iniciativa del hombre sino de Cristo:

Pablo formula la frase como juicio a cerca de la ley en cuanto imperativo de la voluntad de Dios. Esa ley es caracterizada por él como letra; es decir, como un imperativo puramente externo de Dios, como mera prescripción, que no tiene en sí misma la fuerza para dar al hombre el cumplimiento de lo que se le manda. Y por eso se puede decir que la letra, es decir, la ley Mosaica mata, pues lleva al hombre, que está sometido a ella y no la puede cumplir, a la maldición de Dios, y, con ello, a la muerte Eterna. Así esta frase se cubre o superpone con otras afirmaciones del Apóstol en que se atribuye a la ley de Moisés efecto funesto o corruptor para el hombre (Bauer, J. B. 1967, p. 574).

Como se ha dicho en el Antiguo Testamento la ley está considerada como un todo y plasmada en la Torá, es decir en el Pentateuco. El pueblo la recibe de Dios y está obligado a cumplirla so pena de sufrir males en lo personal y en lo social ("ustedes serán mi pueblo y yo seré vuestro Dios"). La ley se escribió y se codificó para que el hombre no la olvide y la recuerde cada vez que se proponga hacer un acto que vaya en contra de dicha ley. 
Es de anotar que la ley mosaica es perfecta por provenir de Dios, pero el error se puede encontrar en la interpretación de ella por parte del hombre y posteriormente la puesta en práctica, ya que la tradición la convierte en una obligación rigurosa que puede llevar al hombre a la muerte si deja de cumplir algo de esta ley.

En el Nuevo Testamento Jesús entra en polémica con algunos grupos de judíos como los fariseos cuando les hace ver que la ley está escrita para ser libres y actuar convencidos de que la ley busca fundamentalmente la salvación y la convivencia fraterna entre los hombres, no un instrumento de discusión y de señalamiento para con sus hermanos.

La doctrina y el testimonio que Jesús propone al pueblo judío y al pueblo greco-romano es vivir la libertad de los hijos de Dios ajustándose a la ley y especialmente a la norma superior que es el Amor, de manera repetitiva se encuentra en el Nuevo Testamento, en Mateo 22, 34 ss, Jesús dice a los fariseos que el mandamiento más importante de la ley es "Ama al Señor tu Dios con todo tu corazón, con toda tu alma y con toda tu mente". Este es el más importante y el primero de los mandamientos. Y el segundo es parecido a este; dice: "Ama a tu prójimo como a ti mismo". Estos dos mandamientos son la base de toda la ley y de las enseñanzas de los profetas.

Es evidente que la nueva concepción de ley propuesta por Jesús no busca abolir la ley mosaica, sino que le imprime una nueva lectura en la que aparece con fuerza e importancia el espíritu de la ley y no solo la letra de la ley. El comportamiento del hombre se somete a una toma de conciencia personal y social, de tal manera que el cumplimiento de la ley no se fundamenta en una imposición sino en una opción; según la propuesta cristiana, el hombre no debe actuar por temor al castigo sino por amor al prójimo, un amor que es fruto o consecuencia del amor al gran legislador que es Dios.

Esta nueva ley, llamada la ley del amor, impulsa al hombre a proceder regido por una conciencia clara, por un mandato intrínseco que se debe hacer realidad en un contexto extrínseco, es decir, tanto en la vida personal como en la vida social; teniendo en cuenta lo anterior se puede comprender de manera amplia, evidente y clara que esta nueva ley propuesta por Cristo es la que asegura que quien la cumpla será libre. 
La doctrina cristiana comienza a ser cuestionada por las autoridades que rigen el imperio romano puesto que Jesús rompe el paradigma viejo donde la sumisión, el temor y la imposición le obligaban a cumplir unas leyes para poder vivir una aparente paz. Unos siglos posteriores se encuentra el análisis que hace sobre este tema algunos filósofos y teólogos destacados como lo es San Agustín de Hipona, quien nos habla que la fuente de la ley, del comportamiento y de la conducta humana no es propiamente la razón del hombre, sino que el cimiento de la ley, de la nueva ley, es la fe que opera a través del amor; por lo tanto, para que el hombre pueda cumplir la nueva ley del amor requiere pedir la gracia y la misericordia que solo Dios le puede conceder.

En una de sus obras llamada De civitates Dei, expone su teoría sobre la legitimidad de la ley y del Estado, nos habla de dos ciudades, una ciudad terrena y una ciudad celeste; con respecto a la ciudad terrena nos dice que para que un Estado pueda tener valor se requiere que sea producto de la justicia, es decir, que todo lo que suceda allí tenga como fundamento a Dios porque si no es así los Estados serían solo unas empresas criminales donde la banda de malhechores que tienen un jefe este sería la autoridad, el jefe que actúa de manera arbitraria reparte el botín según lo acordado; allí, en este pequeño grupo o en estos pequeños grupos, también existiría una ley pero no una ley legítima, sino una ley que permite el crimen y la injusticia.

En este contexto de ideas, San Agustín contempla la existencia del Estado y de la ley, no niega su existencia pero enfatiza que ese Estado y esa ley debe provenir del legislador supremo Dios. El hombre en la ciudad terrena anhela profundamente la justicia pero esta solo se podrá vivir de manera imperfecta porque la ley y la justicia verdadera solo se encuentra en el Estado que fundó Cristo y el cual es regido por Dios. La justicia para San Agustín es dar a Dios lo suyo, servirlo y cumplir su voluntad. Solo cuando en el Estado reine la voluntad de Dios se podrá llamar verdadero Estado. Al hacer referencia al estado romano, San Agustín afirma que este no ha existido como tal porque le ha faltado estar sometido a la voluntad divina y por lo tanto no ha habido verdadera justicia en él, tal y como lo precisa cuando señala que: 
También la ciudad terrena que no vive de la fe dese la paz terrena, y la concordia entre el mandar y el obedecer entre los ciudadanos, la encamina a que observe cierta unión y conformidad de voluntades en las cosas que conciernen a la vida mortal. Pero como la ciudad terrena tuvo ciertos sabios, hijos suyos, a quienes reprueba la doctrina del cielo los cuales, o porque lo pensaron así o porque los engañaron los demonios creyeron que era menester conciliar muchos dioses a las cosas humanas, a cuyos diferentes oficios, por decirlo así, estuviese sujetas diferentes cosas; a uno el cuerpo y a otro el alma; y el mismo cuerpo, a uno la cabeza y a otro el cuello, y todos los demás a cada uno el suyo, así mismo en el alma a uno el ingenio y a otro la sabiduría, a otro la ira, a otro la concupiscencia y en la misma cosa necesaria a la vida, a uno el ganado, a otro el trigo, a otro el vino, a otro el aceite. Así que la ciudad celestial, entre tanto que es peregrina en la tierra, y convocando de entre todas las naciones ciudadanos, va siendo sociedad peregrina sin atender a diversidad de costumbres, leyes e institutos, que es lo que conserva la paz terrena y sin reformar o quitar cosa alguna, antes observando y siguiendo exactamente cuya diversidad, así que también la ciudad celestial en esta su peregrinación usa la paz terrena y en cuanto puede, salva la piedad y religión, guarda y desea la uniformidad de las voluntades humanas en las cosas que pertenecen a la naturaleza mortal de los hombre, direccionando todo hacia la paz celestial (San Agustín, 1985, p. 334-335; 485-486).

Dentro del mismo contexto del teocentrismo pero ubicándonos unos siglos más adelante, encontramos a otro eximio filósofo y teólogo Isidoro de Sevilla quien frente al tema de la ley interviene de manera importante mostrando una tendencia clara sobre el iusnaturalismo. Para este escritor derecho y ley están relacionados, afirma que el derecho es el género y la ley es la especie. Esto significa que la ley es una especie de derecho, la ley está relacionada con la razón pero para que sea verdadera ley debe acatar la religión y la doctrina la ley debe ser buena, justa y honesta, además debe estar de acuerdo con la naturaleza, la ley no puede ser interpretada de manera arbitraria sino que debe apuntar siempre a la utilidad de la mayoría de los ciudadanos. 
La soberanía de la ley se encuentra por encima de cualquier legislador humano, por lo tanto el gobernante es el primero que debe obedecer y cumplir las leyes para que puedan exigirle a sus súbditos el cumplimiento de estas. La participación de Isidoro de Sevilla aunque no fue una construcción de la ley y del derecho muy original, si logró marcar un camino para las discusiones posteriores frente a la importancia de la ley y a su naturaleza, se sigue afirmando que la naturaleza de la ley debe proceder de la voluntad de Dios. Aunque la razón humana es la que sistematiza las normas estas no serán válidas ni lícitas si carecen de la fuerza que le da el saber que en el cimiento de las leyes se encuentra el germen divino, la justicia y la búsqueda del bien común, hasta el siglo IX se sostiene que la ley apunta al bienestar del hombre y que las leyes no pueden ir en contra de ese fin porque dejarían de ser leyes para convertirse en normas arbitrarias, Fasso caracteriza este planteamiento:

La postura de Isidoro inclinada a colocar a los súbditos en una posición de no absoluta subordinación al poder regio, influyó probablemente también la nueva realidad jurídica de los siglos posteriores al VI, la concepción del derecho inspiradora de las instituciones y la legislación de los pueblos germánicos invasores establecidos ahora permanentemente en los territorios del viejo imperio romano de occidente. (Fasso, 1982, p. 149).

El derecho natural comienza a tomar fuerza y el pueblo logra una participación en las decisiones jurídico sociales, de tal manera que ya no son solo cumplidores de la ley sino que son vigilantes para que esta sea cumplida y se pueda lograr una cierta equidad dentro de los límites que le permite el momento histórico. La ley sigue apuntando a favorecer al hombre y a lograr el objetivo de la armonía, la justicia y la tranquilidad individual y social.

\section{La ley en la visión jurídica de San Agustín}

En el siglo XI y después de una larga discusión teológica sobre el derecho, sobre la ley y la justicia, se encuentra una figura intelectual el cual representa el primer intento de síntesis sobre los problemas filosóficos y teológicos, este personaje se fundamenta en San Agustín quien le da cierta importancia 
al alma en cuanto que es la que ejerce las decisiones sobre las acciones humanas.

Es el alma que viendo al supremo creador ordena los actos humanos siguiendo la ley que el ser superior le ha iluminado. El alma conociendo a ley superior no puede más que seguirla porque al seguirla está siendo justo y esa justicia personal la debe irradiar en la sociedad. Cuando el alma se aparta de lo que debe ser y comienza a actuar como no debe, pierde la rectitud original, pierde su naturaleza y al perder esto dicha alma queda privada de su esencia y todos los actos que ella ejerza lo hará de manera injusta.

Se puede deducir que para San Anselmo la ley que dirige los actos humanos es la que procede de Dios pero como el hombre no puede ver ni entender plenamente lo que Dios desea, el alma, que es lo más cercano a Dios, le infunde su tarea que es la de actuar de manera justa en todos los casos. Cuando el alma queda privada de la presencia de Dios es cuando el hombre comienza a actuar a partir de una ley que no procede de Dios, sino de su propio instinto y las acciones originadas de esta circunstancia son malas.

El camino que ha sido señalado por los filósofos y teólogos hasta este momento tiene como fundamento la presencia de un ser superior el cual es el legislador que busca la felicidad del hombre. La exigencia hecha al hombre para que pueda alcanzar la felicidad anhelada es conocerlo, amarlo y respetar su voluntad. Quien lo hace logrará vivir sin dificultades poniendo la justicia y la ley como garantes para mantener la relación con el legislador. Quien no lo busca, quien no se esfuerza por conocerlo no alcanzará la felicidad y sus actos estarán por fuera de la ley, su injusticia lo hará infeliz y solo dejará de serlo cuando su alma busque ansiosamente al ser superior.

En el Proslogium, San Anselmo acude al salmista cuando dice lo siguiente:

Señor, he buscado tu rostro, Señor, buscaré tu rostro, no aparte de mi tu faz, arráncame del abismo en que estoy y levántame hasta ti purifica, ilumina el ojo de mi alma para que pueda por fin contemplarte, que el 
alma reúna todas sus fuerzas y que con todo el esfuerzo de su inteligencia vaya hacia ti oh Señor (Proslogium. XVIII, p. 391).

El aporte anselmiano permite concluir que es la obediencia y la búsqueda permanente del legislador superior lo que le posibilita al hombre vivir a la sombra de la ley y lograr que sus actos sean buenos. La bondad y la justicia en san Anselmo están unidas de forma sustancial, puesto que Dios le otorgó a la naturaleza natural, racional la facultad de ser justo es decir bueno, pero el hombre dentro de su libertad puede optar por no serlo y así cae en injusticia. Cuando voluntariamente el hombre opta por ser injusto sus actos serán malos y reprochables.

Siguiendo las huellas en el camino de las leyes desde algunos filósofos, se encuentra en el siglo XVIII con uno de los representantes de la Escolástica, Santo Tomás de Aquino, quien dejó un legado en muchos temas los cuales siguen teniendo vigencia en las discusiones filosóficas y teológicas en la actualidad.

En primer momento se debe hablar del hombre desde la perspectiva tomista, ya que es el hombre el sujeto idóneo y activo de la ley, es de aclarar que Santo Tomás además de ser filósofo es teólogo y algunos de sus argumentos están fundamentados desde la perspectiva cristiana:

Se dice que el hombre fue hecho a imagen de Dios, no por razón del cuerpo, sino por razón de aquello en que supera a los otros animales y por esto en el génesis después de decir hagamos al hombre a nuestra imagen y semejanza se añade: para que domine sobre los peces del mar, etc., ahora bien, el hombre supero a todos los animales porque tiene razón y entendimiento y así es imagen de Dios por la razón y el entendimientos que son incorpóreas (Santo Tomás, 1947, p. 175).

Los animales se parecen al hombre en lo biológico y en lo corporal, además tienen en común que están sujetos a unas leyes que son generales para todos. Para Santo Tomás, el hombre se va a diferenciar de manera sustancial de los demás animales especialmente porque tiene razón y entendimiento, el legislador superior sabiendo que el hombre posee estas facultades dicta unas leyes específicamente para el hombre. Este está 
obligado a conocerlas pero acudiendo a su libertad y a su voluntad puede acogerlas, cumplirlas o apartarse de ellas y no cumplirlas si opta por una de estas dos posibilidades agradara a Dios cumpliéndolas y desagradara a Dios incumpliéndolas, la razón del entendimiento le indican lo que debe hacer de tal manera que si no hace esto no lo hace por ignorancia sino por libertad.

Santo Tomás desarrolla el tema político de manera amplia, comienza afirmando que el hecho de que el hombre necesita vivir en sociedad es porque su naturaleza no está dirigida a vivir y a recorrer el camino de la vida en soledad; no es el instinto como ocurre en los demás animales sino la razón la que le permite ver con claridad al hombre que sus semejantes son los que le permiten desarrollar todas sus habilidades como ser humano, es la comunidad y la vida en sociedad la que le permite al hombre descubrir que su vida y su relación con el mundo tiene unas características exclusivas. Como un solo hombre no puede caminar solo en la vida se necesita un orden social donde el gobernante tenga en cuenta especialmente la integralidad de sus gobernados:

Todo gobernante debe tener como finalidad el procurar el bien de aquel cuyo gobierno ha asumido así, el fin del gobernante de una nave es conducir ilesa hasta el cuerpo de resguardo dicha nave en medio de los peligros del mar, el bien de toda multitud asociada es el de conservar la unidad de donde resulta la paz (Santo Tomás, 1985, p. 251).

La autoridad del gobernante según Santo Tomás debe estar necesariamente apoyada en la autoridad de legislador superior, la ley divina es anterior a la ley humana, si un gobernante legisla ordenando al hombre a actuar en contra de la ley divina el hombre no está obligado a cumplir dichas normas porque estas irán en contra o del cuerpo o del alma y la norma se encontraría viciada desde su origen porque quien la elaboró no tuvo en cuenta el querer del legislador superior, lo deja claro en el siguiente pasaje:

Uno y altísimo es el creador omnipotente de todo, rey poderoso, el Dios gobernante que se sienta sobre su trono a que todos deben tener. Por estas palabras es claro de quien procede en las criaturas todo ser, 
poder y obrar y por consiguiente todo gobierno y mucho más de quien depende el del rey como antes se mostró (Santo Tomás, 1985, p. 309).

Es reiterativo Santo Tomás frente a la ley procedente de un legislador superior; no existe otra ley que esté por encima de ésta puesto que toda ley si busca ser justa requiere del cimiento que es la ley emanada de Dios. La ley eterna conduce a toda creatura a su fin, esta ley no la conoce de forma directa la razón humana, solo la podrá conocer de forma refleja, es decir en las creaturas y en la perfección del universo. La creatura humana se encuentra inmersa en la ley eterna pero en la práctica concreta la ley eterna en el hombre se denomina ley natural. Fasso clarifica este aspecto:

Santo Tomás ve a la ley natural principalmente como la forma dentro de la cual el hombre debe encauzar su querer, para que su voluntad y la consiguiente acción estén en conformidad con la ley natural, y por ende, moral. Y esta forma es la de la racionalidad. La ley Natural hace referencia a aquello por lo que el hombre está inclinado a obrar por naturaleza y es propio estar inclinado a obrar conforme la razón (Fasso, 1982, p. 182).

La interpretación que se ha hecho de la ley eterna como la presenta Santo Tomás ha suscitado alguna controversia. La ley eterna se encuentra en un nivel superior a la razón humana; sin embargo, esta misma ley que en el hombre se denomina ley natural es la que mediante la razón dirige al hombre a comportarse atendiendo lo que ésta ley le ordena. La ley eterna es la ley natural. Si el hombre reconoce claramente la ley natural por qué no reconoce la ley eterna, además si cumple la ley natural por ende ya está cumpliendo la ley eterna. Esta discusión enriquece el tema puesto que permite la participación de todo aquel que esté interesado en continuar la discusión.

\section{Conclusiones}

En el siglo XIII el Derecho Natural era interpretado desde la perspectiva teocéntrica. Esta tendencia se prolongó hasta la llamada Escuela Franciscana, uno de sus representantes es Juan Duns Escoto y otro es Guillermo de Occam quienes continúan afirmando que la ley natural es la 
que le permite al hombre alcanzar la felicidad. La ley natural procede de la voluntad divina, la cual es la que le presenta al hombre la posibilidad de atender sus normas o de aportar por no hacerlo.

Desde Juan Duns Escoto, se puede inferir que Dios le ha permitido al hombre utilizar la razón para llegar tanto a la verdad como al conocimiento del Bien, es mediante la recta razón que el hombre logra comprender y alcanzar el fin que debe perseguir la creatura humana para llegar a ser hombre en su plenitud. Todos los seres por su origen llegan a la existencia dotados de un bien, son buenos o apetecibles en sí mismos pero no todos poseen el mismo bien. El hombre posee la libertad y la voluntad que le permite seguir o rechazar la ley natural que le muestra el bien y el mal.

Escoto afirma que el origen del bien es el querer divino, y por el solo hecho de que Él lo quiera ya es bueno. Es claro, como ya se dijo, que el hombre tiene una voluntad y una libertad las cuales puede utilizar acudiendo al libre albedrío. Existe una ley natural divina y una voluntad divina las cuales difieren de manera sustancial de la naturaleza humana y de la voluntad humana en tanto que estas no actúan a partir de un capricho, sino que su actuar se encuentra intrínsecamente en su esencia divina y en su entendimiento divino: "Por tanto, lo que deriva de la voluntad divina es la obligatoriedad de la ley moral y su fuerza vinculante, no el contenido de la ley" (Meriño, 1993, p. 254).

La norma suprema a la cual se debe someter el hombre es la voluntad y el entendimiento divino. Este sometimiento no es arbitrario sino que responde al origen de donde procede todo ser y especialmente el hombre, porque el hombre comprende, conoce y acepta por su naturaleza racional la existencia tanto de la voluntad divina como la del conocimiento divino.

\section{Referencias}

FAssó, Guido (1982). Historia de la filosofía del Derecho, Tomo 1. Madrid: Ediciones Pirámide.

Sófocles (2005). Antígona. México: Editorial Época. 
De Aquino, Santo Tomás (2002). Suma teológica. Madrid: Editorial BAC.

San Agustín (2002). Ciudad de Dios. México: Editorial Porrúa.

Merino, José Antonio (1993). Historia de la filosofía Franciscana. Madrid: Editorial BAC.

Fraile, Guillermo (1965). Historia de la Filosofía, Tomo 1. Madrid: Editorial BAC.

San Anselmo. Obras completas, Tomo 1. Madrid: Editorial BAC.

De Aquino, Santo Tomás (1985). Opúsculo sobre el gobierno. México: Editorial Porrúa.

Bauer Herder, Johannes (1985). Diccionario de teología Bíblica. Barcelona: Editorial Herder. 


\title{
HUELLA EMOCIONALES: ANÁLISIS EN TEXTOS DE PERSONAS EN CONDICIÓN DE DESPLAZAMIENTO FORZOSO
}

\author{
María Alejandra Olarte Molina', Marisol Ramírez Rivera², \\ Candy Beatriz Díaz Granados Hernández ${ }^{3}$
}

\section{Resumen}

El presente avance de investigación, corresponde al análisis de discurso realizado a entrevistas de desplazados, con el fin de identificar y explicar las emociones y valoraciones en los textos de estas personas. Así se podrá contribuir y hacer unos aportes, por una parte en lo científico/académico se pretende demostrar que la metodología de análisis del discurso propuesta produce o genera nuevo conocimiento en cuanto a la producción textual. En cuanto a lo social, las evidencias encontradas pueden contribuir a las metodologías que se están utilizando para que los sujetos (desplazados) trabajen sus emociones y lleguen al acto de resiliencia, se perfeccionen y produzcan mejores resultados.

1 Investigadora de la Universidad Sergio Arboleda, comunicadora social y periodista, integrante del grupo INVENI.

2 Estudiante de Comunicación Social y Periodismo con énfasis en Medios Audiovisuales, integrante del semillero de investigación INVENI Minor.

3 Estudiante de Comunicación Social y Periodismo con énfasis en Medios Audiovisuales, integrante del semillero de investigación INVENI Minor. 
Palabras clave: Expresiones lingüísticas, narraciones, emociones, entrevistas, desplazados.

\section{Abstract}

This research applicable to the analysis of discourse interviews conducted displaced, in order to identify and explain the emotions and values in texts of these people. So you can contribute and make a contribution, first in the scientific/academic is to demonstrate that the methodology of discourse analysis approach, produce or generate new knowledge to textual production. As far as social evidence found may contribute to the methodologies that are being used for subjects (IDPs) work their emotions and come to act resilience are improved and produce better results.

Keywords: Linguistic expressions, narratives, emotions, enterviews, displaced persons.

\section{Introducción}

"Huellas emocionales en textos de desplazados en Santa Marta", es una investigación en curso en la Ciudad, que estamos desarrollando los integrantes del Grupo Inveni del Departamento de Humanidades de la Universidad Sergio Arboleda, Santa Marta.

Este proyecto fue presentado en el mes de mayo en el Encuentro Regional de Semilleros de Investigación enla ciudad de Santa Marta. Creemos que por sus objetivos, justificación, trascendencia, significatividad y sustentación del proyecto fue seleccionado para representar al departamento del Magdalena en los encuentros nacionales realizados en Bucaramanga en el año 2012 y en Montería en el 2013.

¿Qué nos propusimos y qué hemos logrado?

Como en todo semillero, hemos logrado conformar un grupo de universitarios dispuesto a estudiar y trasegar por los caminos de la investigación. Creemos que es un objetivo que debe cumplir cualquier semillero de investigación sea con estudiantes de educación media o universitarios; 
igualmente, logramos apropiarnos de un conjunto de elementos teóricos que nos permitirán alcanzar los objetivos de percibir y explicar las emociones y valoraciones en los textos de los desplazados. Por otra parte, hemos iniciado la recolección de las narraciones y comentarios de los desplazados en la ciudad de Santa Marta.

\section{Desarrollo de la investigación}

Al interrogante, ¿cómo hemos desarrollado las acciones propuestas en el proyecto?, tenemos que resaltar como dijimos en la introducción tres aspectos fundamentales: la integración del grupo de trabajo, la socialización de los elementos teóricos de la investigación y la recolección y transcripción de las narraciones y comentarios de los desplazados.

Para conocimiento de los asistentes nos proponemos recordar algunas observaciones sobre la metodología centrado en los participantes en la investigación, el corpus o muestra objeto de análisis, el enfoque investigativo y las herramientas de análisis.

En cuanto a los participantes distinguimos entre investigadores y entrevistados.

Los investigadores están conformados por el Grupo INVENI, constituido por Nicolás Ignacio Polo Figueroa (director), Alba Lucía Bustamante Hernández, (coordinadora del semillero) Alfredo Avendaño Pantoja (docente investigador) y los integrantes del semillero INVENI Minor Marisol Ramírez, Paola Álvarez, Candy Díaz Granados, Fabiana Ramírez y María Alejandra Olarte (joven investigadora).

Los entrevistados están conformados por un número de desplazados. Entre ellos tenemos: Jaime Meléndez, Fanny Pantoja, Betsabe Ortiz, Onis Nieto, Elsy Movilla, Ligia Pacheco, Carmelina Orozco y Maritza Quiroz. En literatura lingüística se les denomina informantes, término que ha adquirido connotaciones despectivas, por su empleo en actividades de policía y espionaje, no bien vistas por la academia.

Este grupo de entrevistados parecería poco adecuado numéricamente, si la producción textual de ellos fuera solo producto de una entrevista; pero 
no es así, por cuanto la metodología está pensada más en función de la profundidad en el estudio de las evidencias que en las variadas entrevistas puedan suministrarnos los desplazados seleccionados.

En relación con la socialización de los elementos teóricos de la investigación hay que anotar dos tipos acciones: la relativa a los instrumentos y la de las bases teóricas acerca del análisis del discurso. Se socializó el esquema propuesto por Hymes (1962) descrito en el acrónimo SPEAKING, que aparece explicado en el siguiente cuadro:

\begin{tabular}{|c|l|}
\hline S & Es la situación (espacio-temporal-circunstancial) \\
\hline P & $\begin{array}{l}\text { Corresponde a participantes (hablante-emisor } \\
\text { escritornarrador/oyente-lector) }\end{array}$ \\
\hline E & Son los fines, intensiones o propósitos de la comunicación \\
\hline A & $\begin{array}{l}\text { Secuencia de actos lingüísticos (enunciativos, } \\
\text { compromisivos y declarativos) }\end{array}$ \\
\hline K & Es la clave (entendida como tono o modo) \\
\hline I & Son los instrumentos (lengua oral/escrita/imágenes) \\
\hline N & Corresponde a las normas (socio-culturales) \\
\hline G & En el género o las diferente \\
\hline
\end{tabular}

Igualmente se discutieron un conjunto de términos que muestran o evidencian la posición del desplazado con respecto a lo que está diciendo; son los llamados evidenciales.

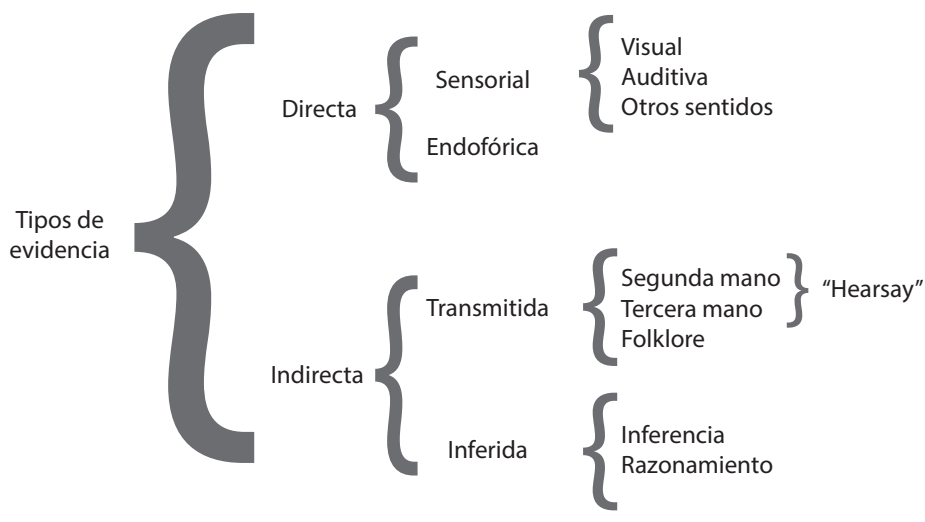


En cuanto a los instrumentos hemos sido instruidos para utilizar las entrevistas semiestructuradas propuestas por Serrano (2009) quien la define como "la combinación de estímulos con una lista de preguntas previamente elaboradas, donde prevalece más lo segundo que lo primero, como cuando lo que se quiere es recabar información referencial, esto es, socialmente cristalizada, en la que la persona entrevistada es considerado un cualificado trasmisor de la misma”.

Sin embargo, el principal elemento teórico adoptado fue el enfoque cualitativo, dado que esta investigación tiene un enfoque cualitativo en que, mediante el análisis del discurso, pretendemos hacer una descripción, interpretación y explicación de las emociones que podemos encontrar en las narraciones, comentarios y observaciones de los desplazados en relación con el evento del desplazamiento y los eventos posteriores al mismo los cuales conforman la situación de desplazado en la ciudad de Santa Marta, a partir del corpus recolectado mediante las entrevistas, antes definidas.

\section{El Corpus (muestra)}

Estamos recogiendo una muestra de narraciones y comentarios de los desplazados mediante varias entrevistas a cada uno de los miembros seleccionados. El material recogido mediante grabaciones de audio y video será debidamente transcrito con el alfabeto de fonética Internacional (AFI); pretendemos que queden recogidas todas las expresiones lingüísticas que sean índices y señales de las emociones de los desplazados.

\section{El análisis textual del discurso}

Este análisis del discurso de los desplazados se basa en la metodología de Morales y Galiazzi (2007). Este propone una lectura atenta del texto; a continuación se realizan unos procesos de deconstrucción; es decir, de desmembración del mismo para encontrar unidades singulares. Con estas, mediante un método deductivo identificaremos las categorías emocionales y de resilencia propuestas por la psicología de las emociones. Por otra parte, la lectura a profundidad de los textos y subsecuentes entrevistas podremos obtener algunas categorías emergentes; es decir, algunas categorías no previstas en la concepción teórica adoptada. 
Categorías de emociones: Existen seis categorías básicas de emociones:

- Miedo: Anticipación de una amenaza o peligro que produce ansiedad, incertidumbre, inseguridad.

- Sorpresa: Sobresalto, asombro, desconcierto. Es muy transitoria. Puede dar una aproximación cognitiva para saber qué pasa.

- Aversión: Disgusto, asco. Solemos alejarnos del objeto que nos produce aversión.

- Ira: Rabia, enojo, resentimiento, furia, irritabilidad.

- Alegría: Diversión, euforia, gratificación, contentos. Da una sensación de bienestar, de seguridad.

- Tristeza: Pena, soledad, pesimismo.

Categorías de resiliencia: se entiende por resiliencia la capacidad para recuperarse y sobreponerse con éxito a la adversidad. Se puede proponer una definición pragmática de la misma que hunda sus raíces en las realidades educativas, terapéuticas y sociales:

La resiliencia es la capacidad de una persona o de un grupo para desarrollarse bien, para seguir proyectándose en el futuro a pesar de acontecimientos desestabilizadores, de condiciones de vida difíciles y de traumas a veces graves. Pero la resiliencia no es una cuestión individual, es el signo visible de un tejido de relaciones y experiencias que enseñan a la gente dominio, arte de vencer obstáculos, amor, coraje, moral y esperanza (Cyrulnik, 2001).

Este trabajo de interpretar las emociones de los textos carecería de carácter explicativo de lo que está pasando al interior del desplazado si no nos diéramos a la tarea de identificar cuáles son las evidencias que muestran el estado emocional del desplazado. Entre las evidencias distinguimos con Bermúdez (2005) las directas e indirectas. Las primeras están relacionadas con los cinco sentidos (oír, ver, sentir, palpar y gusto) o con referencias a oídas o segunda o tercera mano (me contaron, decían, le contaron a mi esposo, se escuchaba). Las indirectas corresponden a razonamientos o inferencias aducidas por el desplazado. 


\section{La recolección de la muestra}

Antes de entrar a la recolección y transcripción de los textos, cada uno de los investigadores hizo una primera entrevista a los desplazados previamente seleccionado. El objetivo fue establecer un clima o ambiente de empatía que permitiera un conocimiento mutuo entre desplazados e investigadores; una especie de ruptura de hielo; dinámica que nos ha dado frutos, porque nos ha facilitado la labor posterior con los entrevistados.

Realizada esta primera entrevista, se procedió a una segunda entrevista en la cual se han obtenido los siguientes resultados.

Los desplazados han manifestado emociones, como son: temor, decepción, rencor, rabia, entre otros.

\section{A manera de conclusión}

Estas primeras aproximaciones a la problemática de los desplazados nos han permitido descubrir un mundo de injusticias que no solo están en el evento mismo del desplazamiento, sino en los eventos posteriores productos del desplazamiento. Por eso las huellas aparecen más evidentes en aquellos apartes de los avatares de la vida de cómo desplazados.

En segundo lugar, tenemos bien claro cuál es la metodología más adecuada para el análisis de la muestra; sabemos cómo emplearla y estamos prestos a mostrar cómo se puede pasar de la simple recolección de testimonios de los desplazados a explicar cómo se encuentran psicológica y socialmente, mediante un metatexto extraído de sus testimonios. 


\section{Referencias}

Acevedo, Victoria, Mondragón, Hugo (2005). Resiliencia y Escuela [Versión electrónica]. En: Pensamiento psicológico. Recuperado el 22 de mayo de 2012 en http://redalyc.uae- mex.mx/redalyc/pdf/801/80100503. pdf.

Benveniste, Emile (1971). Problemas de lingüística general. México: Siglo XXI.

BRuner, Jerome (2003), La fábrica de historias. México: Fondo de Cultura Económica.

Castello, Monserrat; Corcelles, Mariona; Iñesta, Anna; Vega Norma; Bañales, Gerardo (2011). En Revista Signos No. 44 (76). Chile: U. Pontificia de Valparaíso.

Ducrot, Oswald (1986). El decir y lo dicho Polifonía de la enunciación. Barcelona: Paidós.

Cyrulnik, B. (2001). Los patitos feos. Barcelona: Gedisa S.A.

Ferrari, Laura (2009). Marcadores de modalidad epistémica y evidencial de la subjetividad, recuperado de Internet.

Franco, Natalia; Nieto, Patricia; Rincón (s.f.). Tácticas y estrategias para contar Bogotá: Centro de competencia en Comunicación para América Latina.

Halliday, M.A.K (1994). El lenguaje como semiótica social. México Fondo de Cultura Económica.

Hood, Susan \& Martin, J. R. (2005), "Invocación de actitudes: El juego de la gradación de la valoración en el discurso". En Revista Signos N. 38 (58), Valparaíso.

Hymes, Dell (1962). "Competencia comunicativa”. En Forma y Función: Bogotá: Universidad Nacional. 
Larraín, Antonia y Medina, Lorena (s.f) Análisis de la enunciación. Distinciones operativas para un análisis dialógico del discurso (bajado de Internet).

Melillo, Aldo; SuÁrez, Néstor (2001). Resiliencia: descubriendo las propias fortalezas. Buenos Aires: Paidós.

Morales, Oscar y Cassany, Daniel (2008), "Interpretaciones de la atenuación en artículos de revisión de Odontología”. En: Revista Signos No. 41.

Polo, Nicolás (2000), Saberes lingüísticos. Bogotá: Universidad Nacional.

Polo, Bustamante y Avendaño (2010). Fundamentos teóricos y pedagógicos para la escritura. Santa Marta. Editorial Diké. 



\title{
AUTONOMÍA DE LA JURISDICCIÓN ESPECIAL INDÍGENA EN EL ESTADO COLOMBIANO
}

\author{
Dayana Saltaren B., Margarita Tamaris B., Xiomara Vera W.
}

\section{Resumen}

Desde la legislación de indias de 1542, se precavía que en los conflictos entre indígenas se aplicaran sus propios usos y costumbre, siempre que no fueran claramente injustos, pero no se les era reconocido como un grupo étnico y cultural e independiente. Fue hasta la Constitución Política de 1991 cuando Colombia se convirtió en un Estado social de derecho, donde se les debía garantizar todos los derechos a las personas por pertenecer a un conglomerado social, política y jurídicamente organizado. La jurisdicción especial indígena está claramente consagrada en el artículo 246 superior: "Las autoridades de los pueblos indígenas podrán ejercer funciones jurisdiccionales dentro de su ámbito territorial, de conformidad con sus propias normas y procedimientos, siempre que no sean contrarios a la Constitución y leyes de la república. La ley establecerá las formas de coordinación de esta jurisdicción especial con el sistema judicial nacional". Sin embargo, no es posible entender ésta sobre los derechos humanos de las demás personas que conforman la sociedad colombiana por la pluralidad del Estado, y se hace necesario identificar en qué momento la jurisdicción ordinaria es competente. Es por ello que nuestra investigación se enfoca hacia el análisis del alcance jurídico de la autonomía concedida a las comunidades indígenas dentro del ordenamiento jurídico del país. 
Palabras clave: Autonomía, diversidad étnica y cultural, ordenamiento jurídico, jurisdicción especial, comunidad indígena, competencia, derechos fundamentales y jurisdicción ordinaria.

\section{Abstract}

From the legislation of indies of 1542 , one was anticipating that in the conflicts between aborigens, his own uses and custom were applied, providing that they were not clearly unjust, but they were not been recognized as an ethnic and cultural and independent group. It was up to the Political Constitution of 1991 when Colombia turned into a Social State of Law, where it had to them to guarantee all the rights to the persons for belonging to a social conglomerate, politics and juridically organized. The special indigenous jurisdiction is clearly dedicated in the top article 246: "The authorities of the indigenous peoples will be able to exercise jurisdictional functions inside his territorial area, conformity with his own procedure and procedures, providing that they are not opposite to the Constitution and laws of the republic. The law will establish the forms of coordination of this special jurisdiction with the judicial national system". Nevertheless, it is not possible to understand this one on the human rights of other persons that they shape the Colombian company for the plurality of the State and it becomes necessary to identify in that moment the ordinary jurisdiction is competent. It is for it that our investigation focuses towards the analysis of the juridical scope of the autonomy granted to the indigenous communities inside the juridical classification of the country.

Keywords: Autonomy, ethnic and cultural diversity, juridical classification, special jurisdiction, indigenous community, competition, fundamental rights and ordinary jurisdiction.

\section{Introducción}

Antes de la Constitución de 1991 el país era una sociedad monocultural que tenía como fin la igualdad de creencias, acompañado de un mismo idioma organizado en una familia monogámica. También perseguía que todos 
conformáramos una misma cultura, sometidos a un único sistema jurídico en un territorio determinado. Después, Colombia con la Constitución de 1991 pasó a ser un Estado social de derecho donde se reconoce la diversidad de etnias y culturas, con la obligación de protegerlas y preservarlas como patrimonio nacional. Dentro de esta diversidad se halla la población Indígena a la cual no solo se le ha reconocido su cultura sino que también se le ha dado autonomía y poder jurisdiccional para la organización de su comunidad y su proyecto de vida. Ahora bien, teniendo en cuenta estos derechos registrados en la Carta Política se denota una independencia jurisdiccional total reflejado en el artículo 246 que señala:

Las autoridades de los pueblos indígenas podrán ejercer funciones jurisdiccionales dentro de su ámbito territorial, de conformidad con sus propias normas y procedimientos, siempre que no sean contrarios a la Constitución y leyes de la república. La ley establecerá las formas de coordinación de esta jurisdicción especial con el sistema judicial nacional.

A partir de este artículo se han generado ciertas divergencias en cuanto a su interpretación y aplicación, lo que conlleva que las comunidades indígenas abusen de estas atribuciones concedidas por el Estado hasta tal punto de violar los derechos fundamentales del ser humano. Esto texto ayuda a esclarecer la divergencia entre la Constitución y las leyes del Estado colombiano y las normas de los indígenas.

El problema central de nuestra investigación se centra en la falta de limitación jurisdiccional del Estado hacia los pueblos indígenas, lo que buscamos no es negarle los derechos concedidos a estos ni intervenir en sus costumbres y tradiciones ancestrales como legado histórico de nuestra patria. Nuestro interés se ciñe a que haya responsabilidad legal por parte de las comunidades indígenas hacia nuestra jurisdicción ordinaria, respetando nuestras leyes sin dejar de lado sus potestades referentes a su organización social interna. Es comprensible que por la deuda histórica el Estado les retribuya a estas comunidades todos los derechos que le fueron violados en el pasado, incluso mucho después de la independencia colombiana. Lo que no es admisible es que hagan mal uso de estas potestades, es decir, cometiendo 
actos que van en contra de la Constitución y la ley, que han se han evidenciado a lo largo de estos últimos años.

La discusión sobre la autonomía de la jurisdicción indígena siempre ha permanecido, pero se ha intensificado recientemente debido a los constantes conflictos que han protagonizado las comunidades indígenas defendiendo su autonomía y los derechos otorgados por la norma de normas, pero extralimitándose en ello y violando los derechos fundamentales de los demás. Esto despertó nuestro interés por indagar acerca de los pueblos indígenas en Colombia, su organización social interna, el papel que desempeñan en nuestra nación y sobre todo los poderes jurisdiccionales que poseen, siendo este último el principal objeto de la presente investigación. Para tal efecto es necesario profundizar en el tema desde el punto de vista constitucional, jurisprudencial además de la antropología jurídica. Por tal motivo es menester realizar una amplio estudio sobre los parámetros que el Estado ha fijado a estas comunidades y su respectivo cumplimiento o, en su defecto, la libertad absoluta sobre su territorio, población y poder jurisdiccional. Tiene la obligación de proteger a todos sus habitantes y de preservar la diversidad étnica y cultural como patrimonio nacional.

\section{Antecedentes constitucionales y legales}

Desde la legislación de Indias de 1542, se precavía que en los conflictos entre indígenas, se aplicaran sus propios usos y costumbres, siempre que no fueran claramente injustos. En el periodo Republicano, la Ley 89 de 1890 permitía, en su artículo 5, que los cabildos sancionaran con penas correccionales los comportamientos de los comuneros indígenas que constituyeran faltas menores, siempre y cuando estos no tipifican los delitos establecidos en la ley penal. El artículo 2 de la Ley 72 de 1892 entregaba la autoridad judicial, civil, penal, para los indígenas que vivieran en misiones, a los respectivos misioneros.

En los sucesivos códigos penales, la Corte Suprema de Justicia, basada en el principio de que los indígenas estaban excluidos de la aplicación de las normas penales, en virtud de lo establecido en el artículo 1 de la Ley 89 de 1890, expedía conceptos encontrados: en septiembre de 1950, atribuía 
a los misioneros la competencia para juzgarlos, basado este concepto en la Ley 72 de 1892. En mayo de 1970, establecía que no existía autoridad para juzgarlos.

Finalmente, el 20 de septiembre de 1984, la Corte se pronunció para fijar los alcances del Código Penal de 1980 conceptuando que el indígena no civilizado que incurra en un delito será considerado como inimputable y se le aplicará la medida del art. 96 del Código Penal, que consiste en el reintegro a su medio ambiente natural "siempre y cuando su condición de indígena le impida conocer el sentido antijurídico de su comportamiento o comportarse adecuadamente a su comprensión"1.

La Corte justificó así su sentencia:

El hecho de que el indígena tenga un desarrollo cultural diverso al correspondiente hombre civilizado, en manera alguna permite aseverar que aquel sea inmaduro en el sentido estricto del vocablo. Se trata simplemente de dos visiones diferentes del mundo y, en últimas, de la presencia de dos escalas distintas de valores sin que sea dable dar preeminencia a alguna de ellas, a no ser como resultado de la imposición de quienes detentan los factores reales de dominación.

\section{Características del Estado monocultural}

En 1991, Colombia pasó a ser una nación monocultural a una multicultural. ¿Qué implicaciones concretas, para el marco de la política pública que implementa el Instituto Colombiano de Bienestar Familiar, tiene el reconocimiento constitucional de que la nación es diversa culturalmente?

E1 Estado monocultural negó reconocimiento jurídico y político a toda diferencia étnica o cultural a pueblos como el wayú, una de las 93 culturas indígenas existentes en el territorio nacional, al definirlas como una limitación, como un signo de atraso para alcanzar la sociedad deseable.

La sociedad monocultural buscó la homogeneidad de todos los colombianos, definiendo políticas públicas específicas para que todos

${ }^{1}$ Carlos Perafán Simonds 1995. Sistemas Jurídicos Paez Kogi Wayúu y Tule. Edit. Guadalupe Ltda. 
alcanzáramos a ser hijos de un solo Dios, con el fin de que tuviéramos iguales creencias con respecto al bien y el más, habláramos una sola lengua y organizáramos la familia a la manera monogámica. Todos debíamos regirnos por un solo ordenamiento jurídico y territorial que tenía el monopolio para dirimir los conflictos y disyuntivas que afectaban a los individuos. Este Estado, que basaba y sustentaba sus actuaciones en el reconocimiento de una cultura occidental cuyo centro eran los sujetos individuales, los cuales debían ser protegidos como seres libres e independientes, otorgaba derechos y ejercía obligaciones que se establecían excluyendo a todo aquel que se diferenciara del modelo mayoritario.

En dicho Estado las instituciones planificaron y determinaron políticas públicas orientadas a todos los colombianos sin distingo alguno, como en el caso del registro civil que desconocían y desvalorizaban la existencia real de otros sistemas políticos, de gobierno, religiosos, de creencias y de derecho; horizontes de bienestar diferentes; organizaciones familiares no monogámicas con sus propias reglas de sucesión de bienes; distintos derechos para hombres y mujeres; formas de crianza y socialización alternativos y, ante todo grupos humanos que, al contrario del sistema liberal, que asume el sujeto individual como el centro de los derechos y deberes, consideran un sujeto colectivo y como tal resistieron la pretensión de Occidente de ser como este sistema demandaba, logrando mantenerse como pueblos distintos.

Hoy existen en Colombia 93 pueblos indígenas. Muchos de ellos son étnica y culturalmente distintos, algunos comparten la cultura mayoritaria que les fue impuesta, todos se sienten indígenas y demandan de las instituciones del Estado protección a sus derechos. En 1991 eran 87 pueblos; hasta el 2002 fueron reconocidos formalmente seis pueblos que, a fin de sobrevivir al cruel sistema monocultural y tener posibilidades de existencia sin discriminación, escondieron estratégicamente su identidad. Representan el 2\% de la población total. Poseen características específicas de apropiación del medio, que se manifiestan actividades como la caza, la pesca, la recolección, la agricultura, el comercio y la minería. Muchos de ellos viven hoy en las ciudades o municipios de Colombia pero la mayoría habitan en las regiones de selva, sabana y desierto. Están distribuidos en 
200 municipios del territorio nacional y aunque poseen 25.000 hectáreas habitadas bajo la figura de resguardos, solo ocupan una quinta parte del territorio colombiano.

\section{Consagración de la jurisdicción especial indígena en la Constitución Política de 1991}

La propuesta para que las comunidades indígenas contaran con su propia jurisdicción fue presentada a la Asamblea Nacional Constituyente por el representante indígena Lorenzo Muelas Hurtado. La jurisdicción especial indígena enfatiza el carácter del Derecho de los pueblos indígenas, a la luz de la teoría de los derechos diferenciados de grupo. Tanto el texto de la misma Constitución, como el derecho internacional y las afirmaciones de la Corte Constitucional en la jurisprudencia así lo afirman.

El artículo 246 de la Constitución dispone que "las autoridades de los pueblos indígenas podrán ejercer funciones jurisdiccionales". Esto se deriva del hecho de que la jurisdicción, como función soberana del Estado, no necesita ser reconocida, sino regulada constitucionalmente. Para los pueblos indígenas, que no son Estados independientes, la posibilidad de administrar justicia sí necesita de un reconocimiento expreso. El hecho de que en el caso de la Constitución colombiana este reconocimiento no se haga por la vía de un imperativo, sino del verbo "poder", indica que la Constitución no pretende atribuir una función, sino un derecho a los pueblos indígenas.

El segundo tipo de argumento a favor de esta interpretación, como ya se dijo, proviene de los desarrollos que se han hecho con respecto a los derechos de los pueblos indígenas en el contexto internacional. Ya se mostraron los diversos instrumentos según los cuales la posibilidad de regirse por instituciones propias aparece como un derecho.

La Corte Constitucional colombiana reiteró que se trata de una potestad, de una atribución que la Constitución adscribe a las autoridades de los pueblos indígenas. Así, sobre el artículo 246 de la Constitución, en la sentencia 139 de 1996, se afirma lo siguiente: "El análisis de esta norma muestra los elementos centrales de la jurisdicción indígena en nues- 
tro ordenamiento constitucional: la posibilidad de que existan autoridades judiciales propias de los pueblos indígenas" ${ }^{2}$.

En la sentencia T-254 de 1994, se afirma que "la Constitución autoriza a las autoridades de los pueblos indígenas el ejercicio de funciones jurisdiccionales ${ }^{3}$.

La jurisprudencia de la Corte es aún más clara al respecto en la sentencia T-349 de 1996. En esta, la Corte Constitucional reconoce la autonomía de las comunidades en cuanto a su decisión de asumir el conocimiento de un caso o no; dispone el siguiente:

Consultar a la comunidad Embera-Chamí, reunida en pleno, sobre su disponibilidad para juzgar nuevamente al sindicado, conforme a sus prácticas tradicionales, de las que hace parte la pena imponible (que debe pugnarse dentro de la comunidad), o si se considera que han de ser los jueces ordinarios quienes lleven a término el juzgamiento ${ }^{4}$.

La Corte aquí en lugar de obligar la comunidad a realizar nuevamente el procedimiento, ordenar que se consulte la comunidad para que sea ella la que decida si asume el conocimiento del caso nuevamente o no. Y es precisamente esto lo que se desprende de considerar que la administración de justicia es un derecho y no una función de las autoridades indígenas.

\section{Población indígena en Colombia}

En un país como Colombia, reconocido por su rica diversidad cultural expresada en la multiplicidad de identidades y expresiones culturales de los pueblos y comunidades que la conforman como Nación, los grupos étnicos representan, de acuerdo con el censo realizado por el DANE

${ }^{2}$ Corte Constitucional. (1996). Sentencia No. C-139/96. Recuperado el 6 de Septiembre del 2012, del sitio web: http://www.corteconstitucional.gov.co/ relatoria/1996/C-139-96.htm

${ }^{3}$ Corte Constitucional. (19949. Sentencia No. T-254/94. Recuperado el 12 de Septiembre del 2012, del sitio web: http://www.corteconstitucional.gov.co/ relatoria/1994/T-254-94.htm

${ }^{4}$ Corte Constitucional. (1996. Sentencia No. T-349/96. Recuperado el 12 de Septiembre del 2012, del sitio web: http://www.corteconstitucional.gov.co/ relatoria/1996/T-349-96.htm 
(Departamento Administrativo Nacional de Estadísticas) del año 2005, el $13.77 \%$ del total de la población colombiana, en donde la población afrodescendiente representa la mayoría con el 10,40\%, seguida por los pueblos indígenas con 3,36\% y el pueblo ROM o gitano con el 0,01\%5.

Según los datos registrados por el DANE en el censo 2005, el total de la población indígena de Colombia es de 1.392 .623 personas distribuidas en 93 pueblos indígenas, cifra discutida por la ONIC (Organización Nacional Indígena de Colombia) quien afirma que:

Son 102 pueblos indígenas y por los datos del Ministerio del Interior y de Justicia que reporta que en el país hay 87 pueblos indígenas reconocidos. Una de las principales razones para la disparidad en estos datos surge de la pregunta de pertenencia a un grupo étnico la cual se fundamentó en el auto-reconocimiento de las personas ${ }^{6}$.

No obstante la situación frente a los datos de los pueblos indígenas, es innegable el valor que el territorio nacional adquiere como espacio de congregación de una amalgama de visiones, pensamientos, lenguas y prácticas de usos y costumbres diversos, que florecieron desde el arribo de los primeros pobladores a la región como una forma de entender, representar, interactuar y adaptarse al mundo y las realidades particulares de cada territorio.

A partir de 1980 se inicia una política clara sobre las tierras ocupadas tradicionalmente por los pueblos indígenas, con la figura legal del resguardo. Esta forma de organización territorial se reafirmó en los artículos 63 y 329 de la Constitución Política de 1991, en donde se consagra que las tierras de los resguardos indígenas son propiedad colectiva, inalienable, imprescriptible e inembargable. La definición de resguardo indígena se encuentra establecida en el artículo 21 del Decreto 2164 de 1995 como una institución legal y sociopolítica de carácter especial, conformada por una o más comunidades indígenas, que con un título de propiedad colectiva

5 Ministerio de Cultura.(2010). Grupos Étnicos. Recuperado el 20 de Agosto del 2012, del sitio web: http://mincultura.gov.co/?idcategoría=21356

6 Ministerio de la Cultura. (2010). Censos y Demografía. Recuperado el 20 de Agosto de 2012, del sitio web: http://www.mincultura.gov. co/?idcategoria=38605 
goza de las garantías de la propiedad privada, poseen su territorio y se rigen para el manejo de éste y su vida interna por una organización autónoma amparada por el fuero indígena y su sistema normativo propio.

\section{Entidad responsable de determinar la población indígena en Colombia}

E1 DANE es la entidad responsable de la planeación, levantamiento, procesamiento, análisis y difusión de las estadísticas oficiales de Colombia. El proyecto de estadísticas para los grupos étnicos se enmarca dentro de las políticas del DANE de producir, analizar y difundir la información estratégica que permita visibilizar y caracterizar estadísticamente estas poblaciones.

La primera parte de la investigación se llevó a cabo mediante la revisión documental de la población objeto de estudio. Al indagar sobre la disposición y ubicación de estos grupos culturales se encontró que los pueblos indígenas en Colombia se hallan agrupados en 81 familias lingüísticas distribuidas en una gran parte del territorio nacional (Arango R, 2004); de igual forma, ocupan más de 30 millones de hectáreas (INCODER, 2004), con una población agrupada de, aproximadamente, 658.000 personas residentes en 754 resguardos (DANE, Proyecciones de Población, 2004).

\section{Ente titulador de territorios de los pueblos indígenas}

E1 Instituto Colombiano de Desarrollo Rural (INCODER) es una entidad adscrita al Ministerio de Agricultura y Desarrollo Rural, realiza anualmente convocatoria pública con el fin de otorgar Subsidios Integrales para la compra de Tierras (SIT), en cuyos lotes se puedan desarrollar proyectos productivos sostenibles. El subsidio es estímulo económico para las familias desplazadas, campesinas y vulnerables, entre ellas población de negritudes y comunidades indígenas.

\section{Funciones}

- Planificar y ejecutar los procedimientos para la constitución, ampliación, saneamiento y reestructuración de los resguardos indígenas en beneficio de sus comunidades. 
- Adquirir y expropiar tierras y mejoras para dotar a las comunidades negras e indígenas, deslindar y clarificar las tierras de estas comunidades.

\section{Población indígena por departamento}

La mayoría de la población indígena colombiana se ubica en el área rural del país, en los resguardos indígenas legalmente constituidos, en las parcialidades indígenas o en territorios no delimitados legalmente. Se encuentran ubicados en las regiones naturales como la selva, las sabanas naturales de la Orinoquía, los Andes colombianos, en los valles interandinos y en la planicie del Caribe.

De acuerdo con el Censo Nacional del DANE de 2005, de los 42'090.502 colombianos, 1'378.884 pertenecen a diversas comunidades indígenas $(3.28 \%$ del total de la población) que tienen presencia en 27 departamentos y 228 municipios del país, en 710 resguardos titulados, que ocupan una extensión de aproximadamente 34 millones de hectáreas, el 29,8\% del territorio nacional. Estas cifras evidencian un incremento significativo del $127 \%$ en el número de resguardos y del $7 \%$ en el territorio por ellos ocupados. Los departamentos con mayor porcentaje de indígenas son Guainía, Vaupés, La Guajira, Amazonas, Vichada, Cauca y Nariño. Los departamentos de La Guajira, Cauca, y Nariño concentran aproximadamente la mitad de los indígenas del país?.

En las cabeceras municipales de los pequeños municipios y en las grandes ciudades del país reside una minoría de indígenas que ha ido creciendo como consecuencia del proceso migratorio hacia las zonas urbanas del país por los cambios culturales, el agotamiento de las tierras de los resguardos, especialmente de la zona andina, y por el desplazamiento forzado de las comunidades a raíz de la lucha por la tierra que tienen los actores armados ilegales en los territorios correspondientes a los resguardos, especialmente en las regiones de la sierra nevada de Santa Marta, y del Urabá y en los departamentos de Cauca, Córdoba, Guaviare, Nariño y Putumayo.

Elsa Rodríguez Palau, Astrid Hernández Romero, Lina Marcela Salamanca Rodríguez, Fabio Alberto Ruíz García. (2007). Colombia una Nación Multicultural. Su Diversidad Étnica. Recuperado el día 27 de agosto del 2012, del sitio web: http:// www.dane.gov.co/files/censo2005/etnia/sys/colombia_nacion.pdf 
Tabla I. Distribución de la población indígena según etnias por territorio DANE y departamentos

\begin{tabular}{|c|c|}
\hline $\begin{array}{c}\text { Territoriales DANE y } \\
\text { departamentos }\end{array}$ & Pueblos indígenas o etnias \\
\hline \multicolumn{2}{|l|}{ Norte } \\
\hline Atlántico & Mokana \\
\hline Cesar & Arhuaco, Kogui, Wiwa, Yuko, kankuamo \\
\hline La Guajira & Arhuaco, Kogui, Wayuu, Wiwa \\
\hline Magdalena & Arhuaco, Chimila, Kogui, Wiwa \\
\hline Sucre & Senú \\
\hline \multicolumn{2}{|l|}{ Nor occidental } \\
\hline Antioquia & Embera, Embera Chamí, EmberaKatio, Senú, Tule \\
\hline Córdoba & Embera Katio, Senú \\
\hline Chocó & $\begin{array}{l}\text { Embera, EmberaChamí, EmberaKatio, Tule, } \\
\text { Waunan }\end{array}$ \\
\hline \multicolumn{2}{|l|}{ Nor oriental } \\
\hline Arauca & $\begin{array}{l}\text { Betoye, Chiricoa, Hitnu, Kuiba, Piapoco, Sikuani, } \\
\text { U'wa }\end{array}$ \\
\hline Norte de Santander & Barí, U’wa \\
\hline Santander & (U'wa), Guanes \\
\hline \multicolumn{2}{|l|}{ Central } \\
\hline Boyacá & U’wa, Muisca \\
\hline Caquetá & $\begin{array}{l}\text { Andoke, Coreguaje, Coyaima, Embera, } \\
\text { Emberakatio, Inga, Makaguaje, Nasa, Uitoto }\end{array}$ \\
\hline Casanare & $\begin{array}{l}\text { Amorúa, Kuiba, Masiguare, Sáliba, Sikuani, Tsiripu, } \\
\text { Yaruros, U'wa }\end{array}$ \\
\hline Cundinamarca & Muisca \\
\hline Huila & Coyaima, Dujos, Nasa, Yanacona \\
\hline Meta & Achagua, Guayabero, Nasa, Piapoco, Sikuani \\
\hline
\end{tabular}




\begin{tabular}{|c|c|}
\hline $\begin{array}{c}\text { Territoriales DANE y } \\
\text { departamentos }\end{array}$ & Pueblos indígenas o etnias \\
\hline Amazonas & $\begin{array}{l}\text { Andoke, barasana, Bora, Cocama, Inga, Karijona, } \\
\text { Kawiyarí, Kubeo, Letuama, Makuna, Matapí, } \\
\text { Miraña, Nonuya, Ocaina, Tanimuka, Tariano, } \\
\text { Tikuna, Uitoto, Yagua, Yauna, Yukuna, Yuri }\end{array}$ \\
\hline Guainía & Kurripako, Piapoco, Puinave, Sicuani, Yeral \\
\hline Guaviare & $\begin{array}{l}\text { Desano, Guayabero, Karijona, Kubeo, Kurripako, } \\
\text { Nukak, Piaroa, Piratapuyo, Puinave, Sikuani, } \\
\text { Tucano, Wanano }\end{array}$ \\
\hline Vaupés & $\begin{array}{l}\text { Bara, Barasana, Carapana, Desano, Kawiyarí, } \\
\text { Kubeo, Kurripako, Makuna, Nukak, Piratapuyo, } \\
\text { Pisamira, Siriano, Taiwano, Tariano, Tatuyo, Tucano, } \\
\text { Tuyuka, Wanano, Yurutí }\end{array}$ \\
\hline Vichada & Kurripako, Piapoco, Piaroa, Puinave, Sáliba, Sikuane \\
\hline \multicolumn{2}{|l|}{ Centro occidental } \\
\hline Caldas & Cañamomo, Embera, Embera Chamí, Embera Katio \\
\hline Risaralda & Embera, Embera Chamí \\
\hline Tolima & Coyaima, Nasa \\
\hline \multicolumn{2}{|l|}{ Sur occidental } \\
\hline Cauca & $\begin{array}{l}\text { Coconuco, Embera, Eperara Siapidara, Guambiano, } \\
\text { Guanaca, Inga, Nasa, Totoró, Yanacona }\end{array}$ \\
\hline Nariño & Awa, Embera, Eperara Siapidara, Inga, Kofán, Pasto \\
\hline Putumayo & $\begin{array}{l}\text { Awa, Coreguaje, Embera, Embera Katio, Inga, } \\
\text { Kamëntsa, Kofán, Nasa, Siona, Uitoto }\end{array}$ \\
\hline Valle del Cauca & Embera, Embera Chamí, Nasa, Waunan \\
\hline
\end{tabular}

Fuente: DANE, Censo general $2005^{\circ}$.

8 Elsa Rodríguez Palau, Astrid Hernández Romero, Lina Marcela Salamanca Rodríguez, Fabio Alberto Ruíz García. (2007). Colombia una Nación Multicultural. Su Diversidad Étnica. Recuperado el día 27 de agosto del 2012, del sitio web: http://www.dane.gov.co/files/censo2005/etnia/sys/colombia_nacion.pdf 
Tabla 2. Resguardos indígenas por territorial DANE y departamento

\begin{tabular}{|c|c|c|c|}
\hline DEPARTAMENTOS & $\begin{array}{l}N^{\circ} \text { DE RESGUARDOS } \\
\text { EN MUNICIPIOS }\end{array}$ & $\begin{array}{l}\text { MUNICIPIOS CON } \\
\text { RESGUARDOS }\end{array}$ & $\begin{array}{l}\text { POBLACIÓN INDÍGENA } \\
\text { PROYECTADA 20II }\end{array}$ \\
\hline Amazonas & 29 & 10 & 27.379 \\
\hline Antioquia & 45 & 21 & 19.238 \\
\hline Arauca & 26 & 6 & 4.410 \\
\hline Boyacá & 2 & 2 & 4.700 \\
\hline Caldas & 8 & 5 & 49.031 \\
\hline Caquetá & 45 & 10 & 7.742 \\
\hline Casanare & II & 4 & 6.691 \\
\hline Cauca & 93 & 26 & 233.135 \\
\hline Cesar & II & 5 & 42.801 \\
\hline Chocó & 119 & 26 & 54.009 \\
\hline Córdoba & 4 & 4 & 51.859 \\
\hline Guainía & 25 & 4 & 16.800 \\
\hline Guaviare & 25 & 3 & 10.267 \\
\hline Huila & 16 & 10 & 6.699 \\
\hline La Guajira & 26 & II & 241.516 \\
\hline Magdalena & 5 & 5 & 8.421 \\
\hline Meta & 20 & 6 & 11.034 \\
\hline Nariño & 65 & 20 & $|24.84|$ \\
\hline Norte de Santander & 9 & 6 & 4.865 \\
\hline Putumayo & 66 & 13 & 26.409 \\
\hline Risaralda & 6 & 3 & 10.506 \\
\hline Santander & 2 & 2 & 919 \\
\hline Sucre & 3 & 3 & 17.823 \\
\hline Tolima & 72 & 7 & 23.635 \\
\hline Valle del Cauca & 26 & 14 & 9.903 \\
\hline Vaupés & 5 & 4 & 19.533 \\
\hline Vichada & 32 & 4 & 30.063 \\
\hline Total & 796 & 234 & 1.064 .229 \\
\hline
\end{tabular}

Fuente: INCODER, Resguardos indígenas legalmente constituidos, 2010 y DANE, proyecciones de población indígena en resguardos a 30 de junio de $2010^{\circ}$.

9 Los Pueblos Indígenas de Colombia en el Lumbral del Nuevo Milenio. Departamento NacionaldePlaneación2006. Recuperadoeldía27 deAgosto de 2012, de: http://www. dnp.gov.co/Programas/DesarrolloTerritorial/ OrdenamientoyDesarrolloTerritoria 1/Grupos\%C3\%89tnicos/tabid/273/ default.aspx 


\section{Derechos y jurisdicción indígena}

Se consideran grupos étnicos en Colombia los 84 pueblos indígenas que hablan 64 lenguas diferentes; 10.5 millones de afrocolombianos; 8.000 gitanos, miembros del pueblo ROM, organizados en 30 kapunias y 24.000 raizales que viven en San Andrés, Providencia y Santa Catalina ${ }^{10}$.

Como se expresa en la Constitución Política, el propósito del reconocimiento y protección de esta diversidad étnica y cultural de la Nación es aceptar y respetar las distintas culturas y las necesidades particulares de todas y cada una de ellas para garantizar su supervivencia.

Los grupos étnicos, además de ser titulares de los derechos establecidos para la población mayoritaria: vida, libertad, igualdad, nacionalidad, educación, salud, vivienda y empleo, entre otros, son titulares de derechos especiales, colectivos e integrales en relación con el territorio, la autonomía, la identidad cultural y la jurisdicción especial.

A diferencia de los derechos colectivos expresados en la Constitución Política como aquellos pertenecientes a todos los miembros de la comunidad, los derechos colectivos de los grupos étnicos contienen lo histórico y lo espiritual de las propias tradiciones y costumbres. Estos derechos son además integrales porque, dependiendo de cada etnia, un solo derecho abarca otros.

En el siguiente cuadro se observaran los derechos especiales de los grupos étnicos:

${ }^{10}$ Defensoría del Pueblo. (2005). Derechos de los Grupos Étnicos. Colombia, Bogotá D.C. 


\section{Cuadro I.}

\begin{tabular}{|c|c|c|c|}
\hline Indígenas & Afrocolombianos & Raizales & Rom \\
\hline $\begin{array}{l}\text { Territorio, que pueden } \\
\text { ser en: parcialidades, } \\
\text { resguardos ancestrales } \\
\text { o predios baldíos. } \\
\text { El derecho a la } \\
\text { propiedad colectiva } \\
\text { sobre los territorios } \\
\text { connota los derechos } \\
\text { a: transferencia de } \\
\text { recursos, la consulta y } \\
\text { la concentración. }\end{array}$ & $\begin{array}{l}\text { Territorio: derecho a la } \\
\text { propiedad colectiva sobre } \\
\text { los territorios títulos } \\
\text { colectivamente connota } \\
\text { los derechos a la consulta } \\
\text { y a la concentración. }\end{array}$ & $\begin{array}{l}\text { Territorio: derecho } \\
\text { al y territorio } \\
\text { ancestral de } \\
\text { San Andrés y } \\
\text { Providencia. }\end{array}$ & $\begin{array}{l}\text { Concepto amplio } \\
\text { de territorio. }\end{array}$ \\
\hline $\begin{array}{l}\text { Identidad cultural: } \\
\text { el derecho a la } \\
\text { identidad cultural } \\
\text { significa el respeto a } \\
\text { sus usos, costumbres } \\
\text { y tradiciones de } \\
\text { recursos, la consulta y } \\
\text { la concentración. }\end{array}$ & $\begin{array}{l}\text { Identidad cultural: } \\
\text { derecho a ser } \\
\text { reconocidos y } \\
\text { fortalecidos, a partir de } \\
\text { sus usos costumbre y } \\
\text { tradiciones. }\end{array}$ & $\begin{array}{l}\text { Identidad cultural: } \\
\text { derecho a ser } \\
\text { reconocidos y } \\
\text { fortalecidos, a } \\
\text { partir de sus usos } \\
\text { y costumbres e } \\
\text { identidad propia. }\end{array}$ & $\begin{array}{l}\text { Identidad cultural: } \\
\text { derecho a ser } \\
\text { reconocidos y } \\
\text { fortalecidos, a } \\
\text { partir de sus usos } \\
\text { y costumbre e } \\
\text { identidad propia. }\end{array}$ \\
\hline $\begin{array}{l}\text { Autonomía: este } \\
\text { derecho está asociado } \\
\text { al reconocimiento de } \\
\text { sus propias formas de } \\
\text { organización y control } \\
\text { social, a la existencia } \\
\text { de autoridades propias, } \\
\text { al ejercicio de sus } \\
\text { formas de justicia } \\
\text { dentro del ámbito } \\
\text { de sus territorios y, } \\
\text { fundamentalmente, a } \\
\text { la toma de decisión es } \\
\text { sobre la vida interna } \\
\text { de las comunidades. } \\
\text { Este incluye los } \\
\text { derechos a la consulta y } \\
\text { concentración. }\end{array}$ & $\begin{array}{l}\text { Autonomía: este derecho } \\
\text { les permite tomar } \\
\text { decisiones propias para } \\
\text { su vida, su organización } \\
\text { o en temas de cómo va } \\
\text { a su la salud, educación } \\
\text { y el desarrollo propio. } \\
\text { Esto incluye los derechos } \\
\text { a la consulta y la } \\
\text { concertación. }\end{array}$ & $\begin{array}{l}\text { Autonomía: este } \\
\text { derecho les permite } \\
\text { tomar decisiones } \\
\text { propias para su vida, } \\
\text { su organización } \\
\text { o temas de salud } \\
\text { y el desarrollo } \\
\text { propio. Esto incluye } \\
\text { los derechos a } \\
\text { la consulta y la } \\
\text { concertación. }\end{array}$ & $\begin{array}{l}\text { Autonomía: } \\
\text { este derecho } \\
\text { permite tomar } \\
\text { decisiones propias } \\
\text { para su vida, su } \\
\text { organización o en } \\
\text { temas de cómo } \\
\text { va a ser la salud, } \\
\text { la educación y el } \\
\text { desarrollo propio. } \\
\text { Esto incluye } \\
\text { los derechos a } \\
\text { la consulta y la } \\
\text { concertación. }\end{array}$ \\
\hline $\begin{array}{l}\text { Jurisdicción especial: } \\
\text { derecho a tener normas } \\
\text { y procedimientos } \\
\text { dentro de sus } \\
\text { comunidades. }\end{array}$ & & & \\
\hline
\end{tabular}

Fuente: Defensoría del Pueblo. Derechos de los grupos étnicos, 2005. 


\section{Ley de origen derecho ancestral de los pueblos indígenas}

Nuestros derechos como pueblos indígenas nacen desde el origen con nuestra existencia y la garantizan; son integrales y colectivos, hacen parte de un mundo propio, reflejan nuestra identidad étnica y cultural, y determinan las formas y el respeto para relacionarnos entre nosotros, con la naturaleza, los espíritus y con los demás seres vivos que nos acompañan. Por eso, cuando hablamos de derechos de los pueblos indígenas, tenemos que comenzar por lo primero y propio: nuestra Ley de Origen, nuestro mayor derecho o derecho propio, que nos asiste y otorga identidad. Son nuestras leyes, formas de gobierno y justicia propias $^{11}$.

La Ley de Origen es la ciencia tradicional de la sabiduría y el conocimiento ancestral indígena, para el manejo de todo lo material y espiritual, cuyo cumplimiento garantiza el equilibrio y la armonía de la naturaleza, el orden y la permanecia de la vida, del universo y de nosotros como pueblos indígenas, como guardianes de la naturaleza; regula las acciones entre los seres vivientes desde las piedras hasta el ser humano, en la perspectiva de la unidad y la convivencia en los territorios ancestrales legados desde la materialización del mundo.

Nuestra concepción del universo es integral. La integralidad territorial y política es la máxima connotación ancestral de nuestros pueblos, que se sustenta en la misión de protección y conservación, acciones que nuestras autoridades deben ejercer y cumplir. Todos los elementos del territorio son portadores de vida y se constituyen en principio de vida entre todo lo existente, visto desde el orden social y político, como también desde la visualización profunda del pensamiento y del espíritu ${ }^{12}$.

\section{Los principios de la diversidad étnica y cultural, y de autonomía de las comunidades indígenas}

La consagración del principio de diversidad étnica y cultura que modifica y destituye el modelo de Estado monocultural expresados en los artículos

${ }^{11}$ Universidad Nacional de Colombia. (2011). Gabriel Nemogá (Editor). Naciones Indígenas en los Estados Contemporáneo. Bogotá D.C, Colombia.

${ }^{12}$ Apartes de documento de la Organización Nacional Indígena de Colombia. 
1 y 7 de la Carta Política, resulta ser el fundamento de los dispuesto por los artículos 8 , tocante a la protección de la riqueza cultural de la nación; 9, que señala el derecho a la autodeterminación de los pueblos; 10, sobre la oficialidad de las lenguas de los grupos étnicos; 68, sobre el respeto en materia educativa, de modo que se valoren otros principios, contenidos y métodos para inducir conocimientos; 70, que define a la cultura como fundamento de la nacionalidad colombiana y ofrece reconocimiento a la igualdad y dignidad de todas las culturas; y 72, que define la protección del patrimonio arqueológico de la nación.

Siguiendo el espíritu de la Constitución, la Corte considera que las diferencias étnicas y culturales son igualmente valiosas, de modo que ninguna sociedad es superior a otra, ya sea por sus creencias, su sistema jurídico, su organización familiar o las maneras de obtener económicamente el sustento. Todas son formas de obtener económicamente el sustento. Todas son formas de pensar y vivir bien la vida según cada pueblo. Define que la sociedad colombiana está constituida por una congregación de pueblos y sociedades socioculturales diferenciadas, que determinan la imposibilidad de referirse a una sola noción y concepción hegemónica y unitaria de la naturaleza humana. Las manifestaciones distintas que portan los colombianos, empíricamente demostrables, subrayan el carácter multicultural de la nación colombiana. Bajo estas condiciones, la Constitución admite, y, por lo mismo, valora que el individuo, como sujeto individual de derecho, y los pueblos, como sujeto colectivo de derecho, puedan definir su identidad con base en sus diferencias específicas y en los valores étnicos y culturales concretos, y no conforme a un concepto abstracto y general de ciudadanía, como por ejemplo el definido por los Estados liberales unitarios y monoculturales (ST-496/ 96).

\section{La jurisdicción especial indígena como un derecho}

La corte es aún más clara al respecto, reconociendo la autonomía de las comunidades en cuanto a su decisión de asumir el conocimiento de un caso o no, ya que se presentan casos en los cuales las autoridades, con base en la ponderación de los efectos que un fallo tendría sobre la comunidad, y en uso de su potestad, solicitan la actuación de la jurisdicción nacional ordinaria. 
La Corte, en lugar de obligar a la comunidad a realizar nuevamente el procedimiento, ordena una consulta al interior de la comunidad para que sea ella misma la que decida si aboca el conocimiento del caso nuevamente o no. $\mathrm{Y}$ es precisamente esto, lo que se desprende de considerar un derecho y no una función de las autoridades indígenas al administrar justicia.

En efecto, cuando se atribuye un derecho, se le abre al titular la posibilidad de hacer aquello a que se le autoriza, o de negarse a realizarlo. Entonces, la importancia de entender el ejercicio de funciones jurisdiccionales por parte de las autoridades indígenas como un derecho y no como una obligación radica en que los pueblos indígenas, dentro de la autonomía que se les confiere, pueden decidir si asumen o no el ejercicio de estas funciones. En este sentido, si la autoridad indígena se niega a conocer de un caso, no está incurriendo en una denegación de justicia, simplemente está ejerciendo su derecho, pero también, si la autoridad indígena decide asumir el conocimiento del caso, y las reglas vigentes determinan que es competente, debe conferirse igual valor a sus decisiones (St-349/96).

\section{Límites jurídicos y éticos a los principios de diversidad étnica y cultural, y autonomía de los pueblos indígenas}

La autonomía política y jurídica reconocida a las comunidades indígenas por el constituyente, por su parte, debe ejercerse dentro de los estrictos parámetros señalados por el mismo texto constitucional: de conformidad con sus usos y costumbres, siempre y cuando no sean contrarios a la Constitución y a la ley, de forma que se asegure la unidad naciona $1^{13}$.

La Constitución ha utilizado herramientas de interpretación que hacen aportes muy valiosos. La definición de mínimos jurídicos, los llamados "test de igualdad" para definir que una persona se encuentra en una igual situación que otra, o si el trato que se le da a una persona es igualitario o discriminatoriamente negativo, es una valiosísima. Igualmente, abre la posibilidad de proporcionar el impacto de una decisión.

${ }^{13}$ Corte Constitucional. (1994). Sentencia No. T-254/94. Recuperado el 5 de Septiembre del 2012, del sitio web: http://www.corteconstitucional.gov.co/ relatoria/1994/T-254-94.htm 
La corte determina, entonces, con respecto a los mínimos jurídicos que no cualquier norma constitucional o legal prevalece sobre los derechos de los pueblos. Esta mirada es fundamental porque, en general, se considera que un derecho es obligatorio por estar en la Constitución o en un determinado código. La Corte manifiesta que "solo las disposiciones que se funden en un principio de valor superior al de la diversidad étnica y cultural pueden imponerse a este principio de diversidad":

1. El derecho a la vida.

2. El derecho a la integridad del cuerpo.

3. El derecho a no ser esclavizado.

4. El derecho a un debido proceso.

Estos son los cuatro mínimos jurídicos obligatorios para todos los colombianos, sin distinción de etnia, raza o cultura.

Considerando que solo con un alto grado de autonomía es posible la supervivencia cultural, puede concluirse como regla para el intérprete la de la maximización de la autonomía de las comunidades indígenas y, por lo tanto, la de la minimización de las restricciones a las indispensables para salvaguardar intereses de superior jerarquía. Esta regla supone que al ponderar los intereses que puedan enfrentarse en un caso concreto al interés de la preservación de la diversidad étnica de la Nación, solo serán admisibles las restricciones a la autonomía de las comunidades, cuando se cumplan las siguientes condiciones: que se trate de una medida necesaria para salvaguardar un interés de superior jerarquía; que se trate de la medida menos gravosa para la autonomía que se les reconoce a las comunidades étnicas ${ }^{14}$.

Dado que los pueblos se resistieron al Estado monocultural, conservando y manteniendo muchas manifestaciones de sus culturas para homogenizarse como colombianos iguales, la Corte ha manifestado que muchos de estos usos y costumbres, bajo la consagración del principio de diversidad

${ }^{14}$ Corte Constitucional. (1994). Sentencia No. T-349/96. Recuperado el 6 de Septiembre del 2012, del sitio web: http://www.corteconstitucional.gov.co/ relatoria/1996/T-349-96.htm 
étnica y cultura, se encuentran en tensión con el sistema de derechos fundamentales consagrados en la Constitución.

Este conflicto se presenta toda vez que mientras el principio de diversidad persigue la protección y aceptación de cosmovisiones y parámetros valorativos diversos e incluso contrarios a los postulados de la ética universal de mínimos, el segundo se funda en normas transculturales y universales que permitirán la convivencia pacífica entre las naciones.

Sin embargo, este conflicto entre principios, derechos y valores no exime al Estado de su deber, con base en el artículo $2^{\circ}$ de la Constitución, de responder para proteger los derechos de todas las personas en su calidad de ciudadanos individuales y de reconocer en los pueblos, como sujeto colectivo de derechos, las diferencias y necesidades particulares que surgen de la configuración de un pueblo indígena y/o de la pertenencia de personas a pueblos culturales específicos.

La autonomía de los pueblos indígenas implica que un pueblo pueda tomar las decisiones que son vitales para su permanencia como grupo, es decir, que deben darse las condiciones para que estas decisiones puedan ser tomadas. En los pueblos indígenas existen diferentes formas de gobernarse, de manejar la autoridad y de dar solución a asuntos diversos. Estas formas hacen parte de la jurisdicción especial indígena, la cual enfatiza el carácter de derechos diferenciados de grupo y la posibilidad de regirse por sus propias instituciones. Todo esto con el fin de buscar la vida de un pueblo y tomar decisiones para poder seguir siendo un pueblo distinto con una cultura alterna. La Corte Constitucional reiteró que se trata de una potestad, de una atribución que la constitución hace a las autoridades de los pueblos indígenas en el artículo constitucional 330, que confiere a los pueblos indígenas la posibilidad de gobernarse con autoridades propias, según sus usos y costumbres.

\section{Conclusiones}

Como resultado de nuestra investigación acerca de la autonomía indígena y su interpretación por parte de estas comunidades, hemos llegado a la conclusión de que la jurisdicción indígena por cierta permisividad del 
Estado se ha convertido en una violación a la Constitución y a las leyes colombianas. Es cierto que los indígenas tienen derecho a practicar sus tradiciones y sus costumbres y que tiene cierta autonomía para configurar su organización social para conservarnos como un Estado multicultural, el problema radica en la mala interpretación del Derecho de Autonomía que se les ha otorgado. No es plausible que ellos traspasen la jurisdicción ordinaria amparándose en dicha autonomía que le concede el artículo 246 de la Carta Política de 1991.

Si bien es cierto que las minorías indígenas tienen la facultad de organizarse en sus asuntos civiles, económicos y sociales, la disyuntiva se genera al momento de tocar los asuntos penales y constitucionales, que en cierta medida son contradictorios a las normas del país y en otras suelen ser muy flexibles a la hora de castigar los delitos o faltas. Ante esta situación, el Estado se halla en una encrucijada, puesto que por un lado debe proteger los derechos de las comunidades indígenas como parte de la identidad nacional. Y por otro se debe velar por la conservación de los derechos fundamentales de todas las personas que habitan en el territorio nacional, de igual forma por su seguridad en pro de la unión nacional.

La pregunta que surge alrededor de esta problemática es la siguiente: ¿Cómo delimitar la autonomía de la jurisdicción de los pueblos indígenas cuando estos violen la constitución y la ley? Una posible solución apunta a una intervención más óptima del Estado referente a las decisiones judiciales que toman los indígenas por resolución de su Derecho de Autonomía. Para nuestro concepto, el Estado tiene la obligación de inspeccionar todo lo concerniente a la jurisdicción indígena y balancear.

\section{Referencias}

Corte Constitucional (1994). Sentencia No. T-254/94. Recuperado el 5 de Septiembre del 2012, del sitio web: http://www. corteconstitucional. gov.co/relatoria/1994/T-254-94.htm

Corte Constitucional (1994). Sentencia No. T-349/96. Recuperado el 6 de Septiembre del 2012, del sitio web: http://www. corteconstitucional. gov.co/relatoria/1996/T-349-96.htm 
Corte Constitucional (1996). Sentencia No. T-349/96. Recuperado el 12 de Septiembre del 2012, del sitio web: http://www. corteconstitucional. gov.co/relatoria/1996/T-349-96.htm

Corte Constitucional (1996). Sentencia No. C-139/96. Recuperado el 6 de Septiembre del 2012, del sitio web: http://www. corteconstitucional. GOV.CO/RELATORIA/I996/C-I39-96.HTM

Corte Constitucional (1999). Sentencia No. T-254/94. Recuperado el 12 de Septiembre del 2012, del sitio web: http://www. corteconstitucional. gov.co/relatoria/1994/T-254-94.htm

Defensoría del Pueblo (2005). Derechos de los grupos étnicos. Colombia, Bogotá, D.C.

DNP (2012). Los pueblos indígenas de Colombia en el umbral del nuevo milenio. Departamento Nacional de Planeación 2006. Recuperado el día 27 de agosto de 2012, de: http://www.dnp.gov.co/ Programas/DesarrolloTerritorial/OrdenamientoyDesarrolloTerritorial/ Grupos\%C3\%89tnicos/tabid/273/default.aspx

Ministerio de Cultura (2010). Grupos étnicos. Recuperado el 20 de agosto del 2012, del sitio web: http://mincultura.gov. co/?idcategoría $=21356$

Ministerio de la Cultura (2010). Censos y demografía. Recuperado el 20 de agosto de 2012, del sitio web: http://www. mincultura.gov. co/?idcategoria $=38605$

Perafán Simonds, Carlos (1995). Sistemas jurídicos Paez Kogi Wayúu y Tule. Edit. Guadalupe Ltda.

Rodríguez Palau, Elsa; Hernández Romero, Astrid; Salamanca, Lina Marcela; Rodríguez, Fabio; Ruíz García, Alberto (2007). Colombia una Nación multicultural. Su diversidad étnica. Recuperado el día 27 de agosto del 2012, del sitio web: http://www.dane.gov.co/ files/censo2005/etnia/ sys/colombia_nacion.pdf

Universidad Nacional de Colombia (2011). Gabriel Nemogá (Editor). Naciones Indígenas en los Estados Contemporáneos. Bogotá D.C., Colombia. 



\title{
¿QUÉ RECONOCIMIENTO LE OTORGA LA CONSTITUCIÓN POLÍTICA COLOMBIANA DE 199| AL DERECHO INTERNACIONAL HUMANITARIO?'
}

\author{
Kamila Andrea Pimienta Peñaloza ${ }^{2}$, \\ Daniel José Montenegro Cervantes ${ }^{3}$
}

1 Este proyecto investigativo terminado, respaldado y subscrito a la REDCOLCI (Red Colombiana de Semilleros de Investigación), presentado a manera de ponencia mediante conferencias y poster, en la ciudad de Santa Marta, Valledupar y Montería, se enfoca en esencia a divulgar lo que se refiere puntualmente a la evolución normativa del Derecho Internacional Humanitario en nuestra legislación interna, así como lo que salvaguarda o abarca este derecho, que tiende a ser confundido, según la experiencia ya expuesta, con los Derechos Humanos.

2 Estudiante de sexto semestre de la escuela de Derecho Rodrigo de Bastidas de la Universidad Sergio Arboleda, Santa Marta. Adscrita al semillero de Derecho Público y Derecho Penal, los cuales pertenecen al Grupo de Investigación Joaquín Aarón Manjarres (II-2013). Semillerista desde tercer semestre, participante del Concurso Universitario de Técnicas de Juicio Oral y el XXXIII Congreso Colombiano de Derecho Procesal de la Universidad Libre de Colombia en la Ciudad de Cartagena. Destacada participación en el Encuentro Regional de Estudiantes de Derecho de Valledupar. Actualmente me encuentro cursando una Capacitación de gestión pública por parte de la Escuela Superior de Administración Pública (ESAP). Correo electrónico: ppkamila1994@gmail.com

3 Estudiante de sexto semestre de la Escuela de Derecho Rodrigo de Bastidas de la Universidad Sergio Arboleda, Santa Marta. Adscrito al semillero de Derecho Público, el cual pertenece al Grupo de Investigación Joaquín Aarón Manjarres (II-2013). Participó en el Concurso Universitario de Juicio oral obteniendo como resultado el grato honor de haber pertenecido al equipo ganador del premio. Correo electrónico: danielblackmount@gmail.com 


\section{Resumen}

E1 Derecho Internacional Humanitario como la humanización de la guerra, es de obligatorio cumplimiento para los países, más allá de que estos ratifiquen convenios internacionales. En Colombia, siendo un país internacionalmente conocido por los visos de sangre y violencia fratricida, es un instrumento sumamente importante, hasta el punto que se incluye en nuestra Constitución a través de la figura denominada Bloque de Constitucionalidad. Sin embargo, a pesar de esta obligación legal y moral, cada día en nuestro país florecen atentados contra los bienes tutelados y nuestro ordenamiento parece olvidarse de este deber jurídico. Colombia debe procurar la aplicación del DIH a cabalidad, pues los motivos por los cuales se acogieron estas normas sobreviven aún en la actualidad de la sociedad.

Conceptos clave: Bloque de constitucionalidad, Derecho Internacional Humanitario, humanización de la guerra, evolución jurisprudencial del DIH, Convenios de Ginebra y sus protocolos.

\section{Abstract}

International humanitarian law as the humanization of war, is mandatory for countries beyond ratify these international conventions. In Colombia, being a country internationally known for the appearances of blood and fratricidal violence, is an extremely important, to the point that is included in our Constitution through the figure called Constitutional Bloc. However, despite this legal and moral obligation, every day in our country flourish attacks on the protected and our system seems to forget this legal duty. Colombia must ensure the implementation of IHL fully, because the reasons for which these standards are welcomed survive even today in society.

Key concepts: Constitutionality block, International Humanitarian Law, humanization of war, jurisprudential evolution of IHL, Geneva Conventions and its protocols. 


\section{Introducción}

La actividad racional inherente al ser humano ha despertado a través de los años que los hombres, en la búsqueda de respuestas a todas las dudas generadas a partir de ambigüedades, desconocimientos e interrogantes, utilicen herramientas y procesos a través de los cuales se logren sanear dichos vacíos conceptuales, para así propender por ser cada vez más conscientes de la realidad en la que se desenvuelven.

Precisamente de allí, de la búsqueda de un mayor conocimiento, nace la idea de llevar procesos investigativos con el fin de aprehender lo que se desconoce.

Este proyecto investigativo terminado, respaldado y subscrito a la REDCOLCI (Red Colombiana de Semilleros de Investigación), presentado a manera de ponencia mediante conferencias y poster, en la ciudad de Santa Marta, Valledupar y Montería, en los meses de mayo del $1^{\circ}$ al 3 de 2013 y de octubre del 10 al 14 del presente año respectivamente, se enfoca en esencia en divulgar lo que se refiere puntualmente a la evolución normativa del Derecho Internacional Humanitario en nuestra legislación interna, así como lo que salvaguarda o abarca este derecho, que tiende a ser confundido, según la experiencia ya vivenciada, con los Derechos Humanos, y en un país como este, que se encuentra sumido desde hace siglos en una violencia indudable y despiadada, la guerra y el conflicto, debería ser de común conocimiento entre nosotros los colombianos.

\section{Justificación}

¿Es superior el Derecho Internacional Humanitario a la Constitución Política Colombiana de 1991? La prevalencia del DIH sobre los ordenamientos jurídicos de los países ha sido un tema muy controvertido, pues establecer como superior al DIH desvirtúa la posición del Estado como soberano en su territorio. En Colombia, hasta la Constitución de 1991 no se estableció la posición del DIH dentro de nuestro ordenamiento jurídico. Desde la creación del DIH han existido diferentes posturas doctrinales sobre quién prevalece en un país: ¿El DIH o el ordenamiento jurídico interno? Con este proyecto se pretende clarificar la ubicación del DIH en 
nuestro ordenamiento jurídico interno, pues a raíz de la defensa a ultranza de los DDHH en la Constitución de 1991, el DIH se ha convertido una herramienta esencial para proteger y salvaguardar a determinados sujetos.

\section{Objetivos}

\section{Objetivos generales:}

Determinar la posición del DIH en el ordenamiento jurídico colombiano.

\section{Objetivos específicos:}

- Analizar la jurisprudencia emanada de la Corte Constitucional sobre el DIH en Colombia.

- Examinar las posiciones doctrinales que se han establecido a través de la historia respecto a la prevalencia del DIH sobre el ordenamiento jurídico interno de los países.

- Determinar la inclusión del DIH en el ordenamiento jurídico colombiano a través del bloque de constitucionalidad.

\section{Metodología}

La metodología que se implementó en este proyecto se enfoca en el método cualitativo basándose específicamente en conceptos, información actualizada, doctrina y sentencias que abordan de manera amplia el tema en cuestión, enfocado a la interacción social empleando métodos de recolección de datos, describiendo la realidad y la relación del tema con la sociedad.

La globalización del derecho ha implicado el establecimiento de normas comunes en todas las áreas tanto civil, penal, laboral, familia y no menos importante el derecho constitucional. Indudablemente con la culminación de sucesos abyectos y difíciles de superar tales como guerras, tragedias naturales, pandemias, que han necesitado la unión de todos los pueblos en la búsqueda de un mundo mejor, se ha llegado a la creación de un cuerpo normativo capaz de permear todos y cada uno de los ordenamientos jurídicos 
y que se ha radicado en cada una de las personas en el momento de nacer. Estas normas en principio se ubican como derecho natural, pero estas van más allá, puesto que son la base fundamental para el establecimiento del Derecho Internacional Humanitario. La manera en que se integra el Derecho Internacional Humanitario a los distintos ordenamientos jurídicos mundiales y la obligatoriedad del mismo se vio de manera de clara cuando el 17 de Noviembre de 1993, en la Haya (Holanda) se crea un tribunal internacional para juzgar los crímenes cometidos en la guerra civil que se dieron en la antigua Yugoslavia, territorio que hoy en día comprende los países de Serbia, Montenegro, Croacia y Eslovaquia.

Ya como concepto preciso, se puede decir que el Derecho Internacional Humanitario es el conjunto de normas de origen consuetudinario o convencional, cuya finalidad, en tiempo de conflicto armado es, por una parte, proteger a las personas que no participan en ella, o han dejado de participar en las hostilidades y, por otra, limitar los métodos y medios de hacer la guerra ${ }^{4}$.

La integración del Derecho Internacional Humanitario al ordenamiento jurídico colombiano ha sido un proceso arduo. Los órganos legislativos del país han establecido mediante distintas sentencias cómo se integran las normas de carácter internacional para así lograr establecer un ordenamiento jurídico armónico en que se respeten las normas de carácter internacional. La obligatoriedad del Derecho Internacional se impone a todas las partes que participen de un conflicto armado, no solo a las Fuerzas Armadas de aquellos Estados que hayan ratificado los convenios internacionales. El Derecho Internacional Humanitario es universal, efectivo para todos los pueblos civilizados que se amparen en los valores de la humanidad, no puede ser derogado ni ante el peor conflicto.

Asimismo, el desarrollo del Derecho Internacional Humanitario en Colombia se viene dando más que todo desde la Constitución de 1991. En la Constitución de 1886 creada por Rafael Núñez no se planteó de

${ }^{4}$ Robledo, C y Serrano, C. (1999). El DIH y su aplicación en Colombia. Santa Fé de Bogotá. Comité Internacional de la Cruz Roja. (2005). Derecho Internacional Humanitario, respuesta a sus preguntas 
manera clara y explícita la aplicación del Derecho Internacional, ni mucho menos se reconoció validez y superioridad como se haría posteriormente. Esta constitución se refería al Derecho de Gentes como el Derecho de los conflictos armados, es decir, el conjunto de normas que limitan las acciones bélicas en caso de guerra exterior o conmoción interior con el fin de proteger el respeto y la dignidad humana. Tampoco se enunciaron los principios general que formaban parte del Derecho Internacional como parte del ordenamiento estatal, dejando para el Estado colombiano una potestad casi arbitraria a la hora de manejar los conflictos que pudieran surgir tanto exterior como interiormente.

Por el contrario, la Constitución de 1991 impulsada por el expresidente César Gaviria, le dio un lugar al Derecho Internacional Humanitario y se manifiesta la obligatoriedad de este como la de los Derechos Humanos. El artículo 93 enuncia lo relativo a los Derechos Humanos y al Derecho Internacional, estableciendo lo siguiente:

Los tratados y convenios internacionales ratificados por el Congreso, que reconocen los Derechos Humanos y que prohíben su limitación en los estados de excepción. Prevalecen en el orden interno.

Los derechos y deberes consagrados en se interpretarán de conformidad con los tratados internacionales sobre derechos humanos ratificados por Colombia 5 .

Así pues, este artículo establece la primacía del Derecho Internacional convencional referente a los Derechos Humanos. A su vez, impone una prevalencia de los tratados y convenios ratificados por Colombia, al igual que la obligación de interpretar la Constitución conforme a estos convenios integrados en virtud del Bloque de Constitucionalidad, para de esta manera garantizar la aplicación del Protocolo II.

En este orden de ideas, el artículo 94 enuncia que "los derechos y garantías contenidos en la Constitución y en los convenios internacionales vigentes, no debe entenderse como negación de otros que, siendo inherentes

${ }^{5}$ Constitución Política de Colombia, 1991. Artículo 93. 
a la persona humana, no figuren expresamente en ellos”. Dicho artículo, en el fondo, establece la posibilidad de aplicar derechos no consagrados en el texto constitucional o incluso en los convenios y tratados no ratificados por Colombia, cuando se trate de derechos inherentes a la persona humana. De acuerdo a este artículo, que sea inherente o fundamental no depende de la enunciación expresa en el ordenamiento positivo sino de su consagración en el derecho natural.

Por otra parte, el artículo 214, inciso 2, se afirma que no podrán suspenderse los Derechos Humanos ni las libertades fundamentales. En todo caso se respetarán las reglas del Derecho Internacional Humanitario. Una ley estatutaria regulará las facultades del gobierno durante los estados de excepción y establecerá los controles judiciales y las garantías para proteger los derechos, de conformidad con los tratados internacionales. Las medidas que se adopten deberán ser proporcionales a la gravedad de los hechos?

Se configura en esta norma un valor supraconstitucional del Derecho Internacional Humanitario en cuanto a la regulación de los parámetros a los que se sujetan las facultades presidenciales durante los estados de excepción, por lo que dispone que "en toda situación, se respetarán las reglas del Derecho Internacional Humanitario”. Al reconocer la superioridad del Derecho Internacional Humanitario se protegen los valores humanitarios reconocidos a nivel internacional. Por esto se acoge de forma automática al Derecho Internacional Humanitario en el ordenamiento jurídico nacional. Este acogimiento automático implica una supranacionalidad de las normas provenientes del Derecho Internacional Humanitario, lo cual las hace obligatorias pero estas no constituyen una violación a la soberanía de la nación ya que este concepto, el día de hoy, es más flexible ya que siempre se ha buscado proteger la libertad en la autodeterminación estatal; por tanto, no implica un desconocimiento de las reglas y principios de aceptación general.

De acuerdo con la sentencia C-067 de 2003, la normatividad constitucional no es asunto exclusivo de los artículos que formalmente hacen parte

6 Constitución Política de Colombia 1991. Artículo 94.

7 Constitución Política de Colombia, 1991. Artículo 214, inciso 2. 
del texto de la Carta Política. El Estatuto Superior está constituido por un grupo más extenso de principios, reglas y normas de derecho positivo que constituyen el denominado Bloque de Constitucionalidad y que comparten con los artículos del texto de la Carta la mayor jerarquía normativa en el orden interno. De esta forma, la noción bloque de constitucionalidad busca transmitir la idea de que la constitución de un Estado es mucho más extensa que su texto constitucional, dado que existen otras disposiciones, situadas en otros instrumentos o recopilaciones, que de la misma manera son normas constitucionales.

El primer elemento en contribuir a este cambio fue la introducción en el texto constitucional de seis importantes artículos que definirían los parámetros de adopción de las normas internacionales en el orden interno. Estos fueron:

a) El artículo 9o, el cual reconoció que las relaciones exteriores del Estado se fundamentan en la soberanía nacional, en el respeto por la autodeterminación de los pueblos y en el reconocimiento de los principios del derecho internacional aceptados por Colombia;

b) El artículo 93, según el cual "Los tratados y convenios internacionales ratificados por el Congreso, que reconocen los derechos humanos y que prohíben su limitación en los estados de excepción, prevalecen en el orden interno. Los derechos y deberes consagrados en esta Carta, se interpretarán de conformidad con los tratados internacionales sobre derechos humanos ratificados por Colombia".

c) El artículo 94, que establece que "la enunciación de los derechos y garantías contenidos en la Constitución y en los convenios internacionales vigentes, no debe entenderse como negación de otros que, siendo inherentes a la persona humana, no figuren expresamente en ellos." E1 artículo 214, al regular los estados de excepción, dice en su numeral 2: "No podrán suspenderse los derechos humanos ni las libertades fundamentales. En todo caso se respetarán las reglas del derecho internacional humanitario." 
d) El artículo 53 que preceptúa: "Los convenios internacionales del trabajo debidamente ratificados hacen parte de la legislación interna", y el artículo 102 que dice en su inciso 2 que: "Los límites señalados en la forma prevista por esta Constitución, solo podrán modificarse en virtud de tratados aprobados por el Congreso, debidamente ratificados por el Presidente de la República"

Además, los convenios sobre Derecho Internacional Humanitario prevalecen en el orden interno en la medida en que éstos forman con el texto constitucional un bloque de constitucionalidad, que para este caso podría entenderse como una unión de normas para ejercer una acción conjunta en contra de los infractores de las normas humanitarias. De esta manera, se armoniza el principio de supremacía de la Constitución como norma de normas con la prevalencia de los tratados ratificados por Colombia.

Ciertamente, el Convenio de Ginebra es un tratado internacional que contiene las principales normas destinadas a limitar las acciones en guerra. Este convenio protege a las personas que no participan en las hostilidades y a los que ya no pueden seguir participando en los combates. Este convenio es la versión actualizada del Convenio de Ginebra sobre los combatientes heridos y enfermos, posterior a los textos adoptados en 1864, 1906 y 1929. Consta de 64 artículos, que establecen que se debe prestar protección a los heridos y los enfermos, pero también al personal médico y religioso, a las unidades médicas y al transporte médico. Tiene dos anexos que contienen un proyecto de acuerdo sobre las zonas y las localidades sanitarias, y un modelo de tarjeta de identidad para el personal médico y religioso.

Los Convenios de Ginebra y sus Protocolos adicionales son la piedra angular del derecho internacional humanitario, es decir, el conjunto de normas jurídicas que regulan las formas en que se pueden librar los conflictos armados y que intentan limitar los efectos de éstos?.

Estos convenios y sus protocolos constituyen uno de los principales instrumentos que tiene el Derecho Internacional Humanitario para

${ }_{8}$ Corte Constitucional, sentencia C-067/03, M.P Marco Gerardo Morroy Cabra.

9 Comité Internacional de la Cruz Roja. Los convenios de Ginebra de 1949 y sus protocolos adicionales. Publicado el 29 de octubre de 2010. 
la protección de las víctimas del conflicto armado. Estos tratados son aceptados por la comunidad mundial en general, los cuales están basados en la protección a los heridos, prisioneros de guerra, enfermos, náufragos y personas civiles que integran las consecuencias de una guerra. Los convenios de Ginebra constituyen abiertamente un elemento impor tante en lo referente al manejo de la hostilidades y la protección a la población civil, pero el hecho de que posteriormente se hayan aprobado dos protocolos adicionales no generan que estos reemplacen los convenios establecidos el año de 1949 sino que simplemente entran es a complementar ese proceso de regularización de los conflictos.

E1 Protocolo I fue aprobado el 8 de junio de 1977 y su entrada en vigencia fue el 7 de diciembre de 1978. Este protocolo va dirigido a la protección de las víctimas de los conflictos armados y principalmente encaminado a adicionar aclaraciones y nuevas disposiciones. En su preámbulo el Protocolo I hace una proclamación de su deseo de que la paz reine entre los pueblos, se permite a la vez recordar que, de conformidad con la Carta de las Naciones Unidas, todos los Estados tienen el deber de abstenerse a utilizar las amenazas o el uso de la fuerza en contra de la soberanía, la integridad territorial o la independencia política de cualquier Estado y a su vez reitera que es necesario reafirmar y desarrollar disposiciones que protejan a las víctimas de los conflictos armados y de igual manera completar las medidas de refuerzo para la aplicación de tales disposiciones, señala a su vez que las disposiciones que este integra deben interpretarse en el sentido de que legitime o autorice cualquier acto de agresión u otro uso de la fuerza incompatible con la Carta de la Naciones Unidad, por último reafirma que las disposiciones establecidas en los Convenios de Ginebra y las de este mismo protocolo deben aplicarse en toda circunstancia a todas las personas protegidas por estos tratados, sin distinción alguna.

E1 Protocolo II igualmente fue aprobado y entró en vigencia en las mismas fechas del Protocolo I. E1 Protocolo II va enfocado en la protección de las víctimas en conflictos armados no internacionales. En su preámbulo, este Protocolo hace alusión a los principios humanitarios que constituyen el fundamento del respeto a la persona humana en las circunstancias de conflictos armados que no tienen un carácter internacional, recuerda, 
asimismo, que los instrumentos internacionales relativos a los derechos humanos deben ofrecer una protección fundamental, y relaciona a su vez la necesidad de garantizar la protección a las víctimas de los conflictos armados y se permite enunciar también que en los casos no previstos por el derecho vigente, la persona humana quedará bajo la salvaguardia de los principios de humanidad y de las exigencias de la conciencia pública.

En este se establecen algunas leyes internacionales que se esmeran por ofrecer una mejor protección a las víctimas de los conflictos internos. El alcance de estas leyes es más limitado que la de los otros Convenios de Ginebra, por respeto a los derechos soberanos de cada país y deberes de los gobiernos nacionales.

Así, los principios del Derecho Internacional Humanitario consagrados en los Convenios de Ginebra y en sus dos protocolos constituyen un inventario ético mínimo que se puede aplicar en situaciones de conflictos, sean estos nacionales o internacionales, que a su vez son aceptados en su totalidad por la comunidad internacional por lo que se determina que este hace parte del Ius Cogens o Derecho Consuetudinario de los pueblos. El profesor Eduardo Suárez define el Ius Cogens como "aquellos principios que la conciencia jurídica de la humanidad, revelada por sus manifestaciones objetivas, considera como absolutamente indispensable para la coexistencia y la solidaridad de la comunidad internacional en un momento determinado de su desarrollo orgánico”. En el artículo 53 de la Convención de Viena de 1969 se establece que las normas Ius Cogens deben ser entendidas como "una norma aceptada y reconocida por la comunidad internacional de estados en su conjunto como norma que no admite acuerdo en contrario y que sólo puede ser modificada por una norma ulterior de Derecho Internacional General que tenga el mismo carácter".

Entrando en materia jurisprudencial, son muchas las sentencias de la Corte Constitucional que hacen referencia al Derecho Internacional Humanitario. La mayoría están relacionadas con casos de desplazamiento forzoso y el conflicto armado que tan sangrientamente azota nuestro país desde hace decenas de años. Estas sentencias son abordadas casi siempre desde un punto de origen penal, declamando la integración de normas 
internacionales de justicia en el Derecho Penal. Sin embargo, todas estas sentencias tienen en común que se aborda el tema de cómo se integra el Derecho Internacional Humanitario en el ordenamiento jurídico interno colombiano. Ejemplos de esta situación son las sentencias A-038/13, T-009/13, C-110/13, T-097/12, C-781/12, T-699a/11, C-193/11, T-578/10, C-666/08, T-821/07, SU-256/99, etc.

Nuestro grupo seleccionó para este análisis tres sentencias que a nuestro juicio consideramos las más importantes en materia de Derecho Internacional Humanitario y su integración en nuestro ordenamiento jurídico. Estas sentencias son la C-225 de 1995, la C-177 de 2001 y la C-291 de 2007.

En la sentencia C-225 de 1995, la Corte Constitucional se pronuncia con total amplitud sobre el Derecho Internacional Humanitario, abordando elementos y factores importantes que permitieron una inclusión armónica al ordenamiento jurídico colombiano. En esta sentencia se expone claramente que el Derecho Internacional Humanitario en Colombia es válido en todo tiempo y además de ello, se hace una inclusión automática de este mismo al ordenamiento jurídico interno. Con el fin de dar más claridad al tema, la Corte detalla y define claramente el Bloque de constitucionalidad, el derecho a la paz, orden público, convivencia pacífica. En esta se desarrolla de manera amplia y clara la humanización de la guerra y la cláusula Martens.

Como resultado, la Corte en esta sentencia con su revisión clarifica y pone fin a todas aquellas críticas que se le hacía a la inclusión del derecho internacional humanitario a nuestra carta política. Con énfasis la Corte reafirma que los Protocolos I y II, y en general el tratado completo fue incluido de manera correcta y no restringe de ninguna manera derechos fundamentales al poner en ejecución el tratado, puesto que existe una perfecta coincidencia entre los valores protegidos por la constitución colombiana y este Convenio debido a que todos los elementos incluidos en el anterior reposan en el respeto de la dignidad de la persona humana. Teniendo claro ya que los convenios de derecho internacional humanitario prevalecen en el orden interno. 
¿Cómo armonizar el mandato del artículo 93, que confiere prevalencia y por ende supremacía en el orden interno a ciertos contenidos de los convenios de derechos humanos con el artículo $4^{\circ}$ que establece la supremacía de la Constitución? La corte considera que el bloque de constitucionalidad permite armonizar los principios y mandatos que aparentemente se encuentran en contradicción como lo son el artículo $4^{\circ}$ y 93 de la constitución. El único sentido que se le puede dar a la prevalencia de los tratados de derecho internacional humanitario es que estos forman con el resto del texto constitucional un "bloque de constitucionalidad" y este respeto lo impone la misma ley en el momento en que se consagran claramente en la constitución (art. 214). Es así como se armoniza totalmente el principio de supremacía de la constitución con la prevalencia de los tratados ratificados por Colombia ${ }^{10}$.

En mérito de todo lo expuesto anteriormente la Corte Constitucional de la República de Colombia en nombre del pueblo y por mandato de la constitución, resuelve declarar EXEQUIBLE el "Protocolo adicional a los Convenios de Ginebra del 12 de agosto de 1949, relativo a la protección de las víctimas de los conflictos armados sin carácter internacional (Protocolo II)" hecho en Ginebra el 8 de junio de 1977. Segundo: Declarar EXEQUIBLE la Ley 171 del 16 de diciembre de 1994, por medio de la cual se aprueba el "Protocolo adicional a los Convenios de Ginebra del 12 de agosto de 1949, relativo a la protección de las víctimas de los conflictos armados sin carácter internacional (Protocolo II)"11.

De igual manera, en la sentencia C-177 de 2001, la Corte Constitucional enfrenta el fenómeno del bloque de constitucionalidad, su obligatoriedad y su integración en la normatividad de Colombia. Más concretamente, esta obra de la jurisprudencia colombiana trata el genocidio como un delito de lesa humanidad, reprochado y sancionado por la comunidad internacional y las normas de Derecho Internacional aplicables a este tipo penal internacional. Así pues, dicha sentencia trata sobre una demanda de inconstitucionalidad que se le hizo al artículo 322A (parcial) del Código Penal Colombiano, el cual describe el tipo penal del genocidio.

${ }^{10}$ Corte Constitucional, sentencia C-225 de 1995, M.P Alejandro Martínez Caballero.

${ }^{11}$ Corte Constitucional, sentencia C-225 de 1995, M.P Alejandro Martínez Caballero. 


\section{Ley 589 de 2000:}

Por medio de la cual se tipifica el genocidio, la desaparición forzada, el desplazamiento forzado y la tortura; y se dictan otras disposiciones.

Artículo 322A. Genocidio. El que con el propósito de destruir total o parcialmente a un grupo nacional, étnico, racial, religioso o político que actúe dentro del margen de la Ley, por razón de su pertenencia al mismo, ocasionare la muerte de sus miembros, incurrirá en prisión de cuarenta y cinco (45) a sesenta (60) años, en multa de quinientos (500) a dos mil (2000) salarios mínimos mensuales vigentes y en interdicción de derechos y funciones públicas de cinco (5) a diez (10) años ${ }^{12}$.

Consiguientemente, este mismo artículo forma parte de la Ley 589 de 2000, la cual trata el genocidio, la desaparición forzada, el desplazamiento forzoso y la tortura, todos castigados en su calidad de crímenes de lesa humanidad. La norma en cuestión fue demandada, pues se plantea un sujeto pasivo determinado que va contra el derecho a la vida, el derecho a la igualdad en los derechos fundamentales, el derecho a la integridad personal y el derecho a la libertad. Dicho sujeto pasivo determinado atenta contra estos derechos en la medida en que sólo son protegidos aquellos grupos de personas de las acciones funestas que puedan provocar grupos dentro de la ley, desconociendo las acciones de aquellas bandas que se mueven por fuera de la misma y, por tanto, yendo contra los principios de la Constitución y contra las normas establecidas por el Derecho Internacional Humanitario.

Llegados a este punto, la Corte Constitucional dio la razón a la demandante y estuvo de acuerdo en que el legislador actuó contra la Constitución y el mismísimo Bloque de Constitucionalidad al ir contra los principios internacionales del Derecho, declarando inexequible el aparte señalado de la norma demandada. En esta sentencia, la Corte Constitucional se expresa de la siguiente manera:

El genocidio es considerado por la comunidad universal como un delito de Derecho Internacional, contrario al espíritu y a los fines que persigue las Naciones Unidas y que el mundo civilizado condena en su conjunto.

${ }^{12}$ Ley 589 de 2000. 
... es del caso tener en cuenta que el Derecho Internacional de los Derechos Humanos hacen parte, entre otros, el Pacto Internacional de Derechos Civiles y Políticos, suscrito el 21 de diciembre de 1966, aprobado por Ley 74 de 1968 y ratificado el 29 de octubre de 1969

... debe igualmente señalarse que, como en reiterada jurisprudencia esta Corte Constitucional, lo ha puesto de presente, el derecho internacional público está también integrado por preceptos y principios materiales aceptados por la comunidad internacional, denominados ius cogens ${ }^{13}$.

De igual manera, en esta misma sentencia se cita una jurisprudencia anterior, la C-225 de 1995, explicando cómo el Protocolo II de la Convención de Ginebra, la Convención de la Haya y todo el Derecho Internacional Humanitario en general debe entenderse como parte del sistema jurídico colombiano y, por tanto, se les debe un obligatorio cumplimiento.

Ya en el año 2007, en sentencia C-291, la Corte Constitucional siguió manteniendo la ratificación de los tratados internacionales, conservando así la postura de que estos deben seguirse obligatoriamente. Sin embargo, en esta sentencia se añadió un parámetro adicional no contemplado anteriormente en lo que se refiere a la acogida del Derecho Internacional Humanitario en el ordenamiento jurídico colombiano: el hecho de que una de las partes no respete el Derecho Internacional Humanitario no implica que la otra parte deba faltarle al mismo. La Corte Constitucional lo explicó de la siguiente manera:

La obligación de respetar y de hacer respetar el derecho internacional humanitario no es de carácter sinalagmático o recíproco, es decir, su satisfacción por los Estados no depende del cumplimiento que le otorguen, a su vez, las otras partes enfrentadas en el conflicto. El carácter no recíproco de estas obligaciones se deriva directamente de la naturaleza fundamental de las normas y principios que mediante ellas se busca preservar, así como del hecho de que dichas obligaciones son erga omnes y por ende se adquieren frente a la comunidad internacional en su conjunto ${ }^{14}$.

\footnotetext{
${ }^{13}$ Corte Constitucional, sentencia C-177 de 2001, M.P Fabián Morón Díaz.

${ }^{14}$ Corte Constitucional, sentencia C-291 de 2007, M.P Manuel José Cepeda Espinosa.
} 
Por otro 1ado, el Decreto 4100 de 2011 fue expedido y entró en vigencia el día 2 de noviembre del año 2011. A través de este acto administrativo, no sólo se crea, sino que se organiza lo pertinente al Sistema Nacional de Derechos Humanos y Derecho Internacional Humanitario. De igual manera se modifica la Comisión Intersectorial de Derechos Humanos y Derecho Internacional Humanitario, además de ser dictadas otras disposiciones anexas.

Siguiendo este orden de ideas, el Presidente de la República de Colombia, en ejercicio de las facultades que le confiere nuestra Carta Política y las que le otorga igualmente la ley, especialmente las consignadas en los artículos 189 numeral 11 de la Constitución Política, 45 de la Ley 489 de 1998 y $2^{\circ}$ de la Ley 1450 de 2011, decreta que debe ser incluida la reglamentación pertinente en términos de derechos humanos internacionales al mundo jurídico de nuestro país, es decir, que se añaden aquellas normatividades que se basan en fundamentos prioritarios para el Gobierno Nacional y de esta manera continuar con la evolución y los distintos avances en materia de respeto y garantía de los derechos que le atañen a todos los seres humanos.

Es pertinente mencionar que esta decisión se basó en principios tales como igualdad, complementariedad, subsidiariedad y corresponsabilidad, los cuales se requieren para la aplicación armónica de políticas, planes, programas y estrategias por parte de las instituciones públicas.

Por otro lado, en el marco de diseño e implementación de la Política Integral de Derechos Humanos y Derecho Internacional Humanitario, el Gobierno Nacional estima preponderante destacar a nivel internacional el compromiso con la defensa y promoción de los Derechos Humanos y el Derecho Internacional Humanitario y propiciar de esta manera una relación de colaboración constructiva con la comunidad internacional. Por lo cual procura la articulación de los lineamientos sobre medidas de prevención, atención, asistencia y reparación integral a las víctimas del conflicto armado interno, de acuerdo con lo establecido en la Ley 1448 de 2011.

Por lo anterior y por medio de 20 artículos, se pretende articular y coordinar las políticas, entidades, instancias y normas del orden nacional 
y territorial para promover la protección de los Derechos Humanos y el Derecho Internacional Humanitario. De igual manera, se reestructura y fortalece la Comisión Intersectorial de Derechos Humanos y Derecho Internacional Humanitario liderada por el vicepresidente de la República en aspectos como la integración y sus funciones.

Como resultado, el decreto percibe entonces VI capítulos, que tratan: Iel Sistema Nacional de Derechos Humanos y Derecho Internacional $\mathrm{Hu}-$ manitario, fundamentado en los principios ya esbozados; IIla pertinencia de la Comisión Intersectorial de Derechos Humanos y Derecho Internacional Humanitario; IIIla Secretaría Técnica y sus funciones; IVlos Grupos Técnicos; Vla Estructura Territorial y VIentrada en Vigencia.

A modo de conclusión, es claro que el Derecho Internacional Humanitario es una de las herramientas más grandes que tiene el Derecho Internacional para hacer cumplir sus principios y normas en los Estados que acojan principios éticos, morales y humanos. El Derecho Internacional Humanitario, en toda su extensión, es de obligatorio acogimiento y cumplimiento para los países, más allá de que estos firmen y ratifiquen convenios y tratados internacionales.

En Colombia el Derecho Internacional Humanitario es un instrumento sumamente importante, hasta tal punto que se incluye en nuestra Constitución a través de la figura conocida como Bloque de Constitucionalidad, lo cual implica que este sea interpretado junto con la Carta Magna de nuestro país y, a su vez, que tenga un carácter ulterior a esta. Sin embargo, a pesar de esta obligación legal y moral, cada día en nuestro país florecen atentados contra los bienes tutelados por este derecho y nuestro ordenamiento parece olvidarse de este deber jurídico. Colombia debe procurar la aplicación del Derecho Internacional Humanitario en su cabalidad, pues los motivos por los cuales se acogieron estas normas sobreviven aún en la actualidad de la sociedad colombiana.

\section{Resultados y avances}

Los distintos elementos analizados (Constitución Política de Colombia de 1991 y sentencias emanadas de la Corte) aportaron datos esclarecedores 
sobre la integración del DIH en el ordenamiento jurídico interno de Colombia, lo que permitió hacer un recorrido a través del tiempo e historia de nuestro país. Teniendo como base lo antes mencionado, se trató igualmente su obligatoriedad y su ejecución dentro de la Constitución actual. Es así como a través de esta investigación se ha pretendido la divulgación de este tema, que es pertinente y atinente a todos los que residimos y domiciliamos en Colombia, y que tiende a ser confundido con el derecho humanitario.

Se han realizado charlas en la ciudad de Valledupar, Santa Marta y Montería acerca de este tema que es de interés común por la situación en la que se encuentra sumido nuestro país. De igual manera, fue inscrito y aprobado por la Redcolsi a nivel nacional y hace parte del banco de elegibles, entre los 134 mejores proyectos, para participar en ferias y encuentros de talla internacional, que son realizados en países como Argentina, Brasil, Chile, entre otros.

\section{REFERENCIAS}

Constitución Política de Colombia, 1991. Artículo 93.

Constitución Política de Colombia, 1991. Artículo 94.

Constitución Política de Colombia, 1991. Artículo 214, inciso 2.

Corte Constitucional, Sentencia C-067/03, M.P. Marco Gerardo Monroy Cabra.

Comité Internacional de la Cruz Roja.

Los convenios de Ginebra de 1949 y sus protocolos adicionales. Publicado el 29 de octubre de 2010.

LEY 589 DE 2000.

Corte Constitucional, Sentencia C-177 de 2001, M.P. Fabián Morón Díaz.

Corte Constitucional, Sentencia C-291 de 2007, M.P. Manuel José Cepeda Espinosa. 


\title{
EL ABANDONO DEL IMAGINARIO SOCIAL REFERENTE: LA VÍCTIMA NO SIEMPRE ES IDEAL'
}

\author{
Ángela Patricia Villadiego Gómez²
}

\section{Resumen}

El médico italiano Benigno Di Tullio afirmaba que, la actuación que puede desarrollar la víctima tiene una particular importancia tanto que puede participar notoriamente en las relaciones de la "criminogénesis", y en virtud de ello, podrían originarse estímulos que podrían desencadenar y vigorizar impulsos delictuales.

Por tradición, la creencia social ha menospreciado la consideración de un agresor y un culpable alterno al que comete el hecho criminoso. A esto se debe que el comportamiento de la víctima quede relegado, es decir, la actuación que desempeña o la que pudiere darse lugar por parte de la víctima no tiene una significancia relevante, asegurándole una posible "amnistía social" respecto a los

1 Este avance de investigación es resultado de la propuesta de investigación "La participación de las victimas infungibles enla comisión del delito", desarrollada en el marco de la línea de investigación Orden, Sociedad y Conflicto, del grupo de investigación INVIUS de la universidad del Atlántico de Colombia, BarranquillaAtlántico, realizada en conjunto de la catedrática investigadora Leticia Hundek Pichón, Coordinadora del grupo de investigación y semillero "KALO".

2 Ángela Patricia Villadiego Gómez, Estudiante de Derecho de la Universidad del Atlántico. Correo electrónico: angelavilladiego@ gmail.com 
hechos delictivos. Esto ha llevado a que solo se reconozca a la víctima como 'ideal' o complemente inocente.

Palabras clave: Víctimas, delito, responsabilidad, victimización, sociedad.

\section{Abstract}

The Italian doctor Benigno Di Tullio, claimed that the performance that can develop the victims is particularly important because they can participate in relationships of genesis of crime and under it, it may lead stimuli that might trigger and invigorate pulse criminology.

By tradition, the social belief belittled consideration of an alternate guilty aggressor and who commits the act criminalizes. This is due to he behavior of the victim is left relegated, that is, the action that plays or place that may be part of the victim has no relevant significance, assuring a possible "social amnesty" about the crimes. This has led to only recognize the victim as "ideal" or supplement innocent.

Keywords: Victims, crime, responsibility, victimization, society.

\section{Introducción}

E1 médico italiano Benigno Di Tullio ${ }^{3}$, afirmaba que, la actuación de la víctima podría tener una particular importancia en las relaciones de la "criminogénesis", en virtud de la cual podrían originarse estímulos que podrían desencadenar y vigorizar impulsos delictuales y las fuerzas crimino-impelentes.

Por tradición, la creencia social ha menospreciado la consideración de un agresor y un culpable alterno al que comete el hecho criminoso. A esto se debe que el comportamiento de la víctima quede relegado, es decir, la actuación que desempeña o la que pudiere darse lugar por parte de la víctima no tiene una significancia relevante, asegurándole una posible

${ }^{3}$ DI TULLIO, Benigno (1937). Uno de los principales fundadores de la Sociedad Internacional de Criminología, en Roma. 
"amnistía social" respecto a los hechos delictivos. Esto ha llevado a que solo se reconozca a la víctima como "ideal" o complemente inocente.

Sin embargo, se ha logrado distinguir su actuación frente a su agresor. Resulta menester dicha separación para establecer la relación entre el agresor y el agredido respecto a un grado de responsabilidad en la que puede incluso operar una víctima para suscitar la génesis de su propia victimización.

\section{Planteamiento del problema}

Por tradición, el imaginario social ha menospreciado considerar la existencia de un culpable alterno a quien comete el hecho o actuaciones delictivas, es decir diferente del agresor; ignorando con ello, la posible participación de la víctima al facilitar supuestos evidentes, que pueden resultar voluntarios o involuntarios. A esto se debe que el comportamiento de la víctima en la dinámica de la crimino-génesis quede relegado, es decir, la actuación que desempeña o la que pudiere darse a lugar por parte de la víctima no acredita una mayor relevancia, asegurándole una posible "amnistía social" respecto a los hechos delictivos. Todo ello ha llevado a que solo se reconozca socialmente a la víctima como "ideal" o idóneamente inocente.

Sin embargo, la doctrina ha podido distinguir comportamientos que contribuyen efectivamente en la victimización; sea facilitándola o provocándola, que a su vez permiten separar su actuación frente a su agresor. Esta separación resulta ser sumamente importante al momento de establecer la relación entre el agresor y el agredido respecto a un grado de responsabilidad en la que puede incluso operar una víctima para suscitar el origen de su propia victimización. Con todo, no se ha profundizado sobre aspectos y tópicos relacionados al tema que permitan acrecentar el grado de familiarización con el mismo.

De acuerdo con lo anterior, se ha formulado la siguiente pregunta problema: ¿Por qué se afirma que actualmente se ha abandonado el imaginario social referente? ¿Cuál es la importancia que tiene la víctima en la comisión del delito? 


\section{La idealidad de la víctima}

La víctima ideal o enteramente inocente es aquella que no desarrolla actuación alguna dentro del delito, simplemente se ve afectada por él. Así, se puede decir que es totalmente ajena a la actividad criminal que se desencadene. No tiene participación activa, por tanto, su escala de culpabilidad sería nula. Su idealidad supone una inocencia absoluta y entera exclusión de responsabilidad frente a los hechos delictuales. Por ello, es una víctima idónea, una víctima perfecta.

En estos casos, la pena que debe ser aplicada al infractor, deberá recaer con total severidad. No habrá lugar a atenuaciones o disminución en la dosificación punitiva. Y ello es porque la víctima no ha desarrollado ningún rol, es enteramente inocente de los hechos.

Este concepto se asentó en el imaginario social hasta el segundo período del siglo XIX, donde se abandonó finalmente. Su desalojo fue abrupto, tanto que ello conllevó que se dejara de atender fundamentalmente la importancia de los daños producidos por brindar la atención requerida a la voluntad obrante de la víctima dentro del delito.

Anteriormente no hubo tal distinción, la decisión que determina cuándo un individuo había sido lesionado era un juicio parcializado y totalmente externo a ese individuo, sin corresponder esto a formular siquiera que su opinión y acciones también tienen relevancia para los hechos. Por tanto, hoy se puede considerar un acierto social la inclusión del rol y la actuación de la víctima dentro del hecho criminoso.

\section{Presuntos motivos en idea de abandono al paradigma social}

Lo primero a considerar frente a la pregunta de cuáles podrían haber sido los más acertados motivos para abandonar la idea de presunción de idealidad en una víctima, es que al aludir al proceso de desarrollo de un encuentro delictivo, se debe reconocer la necesidad de empleo de un paradigma integrativo en que los múltiples elementos personales y ambientales den base para que la unidad persona (vulnerable) adquiera la entidad de vector criminógeno. Considerando este punto de vista holístico, podemos aceptar 
que un sujeto que no nació ni se hizo delincuente llegue a cometer un delito determinado, lo que tampoco lo transforma, fatalmente, en un individuo esencialmente distinto, en un ser diverso frente a los demás hombres ${ }^{4}$.

Con esto, se estudia la posibilidad de que todo ser humano tiene la facultad de cometer un delito, es decir, una acción tipificada y que es susceptible de ser sancionada por la ley. Esto, atendiendo a las operables circunstancias en las que cada persona se encuentra, ya sean físicas, biológicas, sociales, económicas, mentales, lingüísticas, etc; y de los factores micro y macro sociales que la rodean.

Estos factores intervienen notoriamente en la actividad criminal, los más operantes socialmente son:

- Factor socioeconómico: Se ha comprobado que los estratos socioeconómicos, el desempleo y, fundamentalmente, la desigualdad social son variables fuertemente asociadas al aumento de los delitos.

- Factor demográfico y socio cultural: Se refiere a factores como el grado de urbanización y variables que obran como barreras de ingreso a la actividad delictiva: familia, escuela y comunidad.

- Factores que se refieren al entorno urbano y físico: Puede referirse al entorno, la urbanización incontrolada, la carencia de servicios públicos, la ausencia de políticas de seguridad efectivas y la ilegalidad en barrios que tienen un bajo nivel en el control de pequeñas mafias locales.

Es por esto que se desplazó esta presunción. La idealidad en las víctimas de todo hecho delictivo no se puede estereotipar y resumir a una sola conducta. No se puede suponer que la víctima desarrolla simplemente el rol de ser afectada por el hecho delictual.

4 ROSAS ORTIZ, Patricio. (2012) Consideraciones Sistematizadas De Criminodinámica: desde el Paradigma Etiológico Multivectorial Integrativo del Profesor Don Marco González Berendique y algunas Teorías Contemporáneas. Santiago de Chile, pág. 95. 
Actualmente existe una amplia y variada tipología en relación a las víctimas, por desarrollarse estudios sobre su conducta y encontrar que, en efecto, ellas también participan activamente y pueden provocar su propia victimización.

\section{Importancia de la víctima en el desarrollo del delito}

La víctima solo empieza a ser un elemento contributivo en el proceso de desencadenamiento del delito o de la génesis del acto criminal en la segunda mitad del siglo XIX. Esto se puede deber a que había un escaso interés científico por su actuación y se profundizó más en el estudio de las conductas de los criminales y su perfil psicológico. Sin embargo, el ilustre autor Mexicano Luis Rodríguez Manzanera ${ }^{5}$, al preguntarse el porqué de este tardío interés, formula una posible respuesta; nos sentimos identificados con el sujeto activo del delito, esto es porque este es capaz de realizar lo que tal vez nos gustaría hacer sin que, desde este ángulo, aparezca atractiva la figura de la víctima. Esto confirma la famosa frase del filósofo griego Platón cuando afirma que "los hombres buenos solo sueñan lo que los malos realizan". Además existiría un descontento de parte del Estado al verificar que fracasa en la protección de los intereses comunitarios y ello inevitablemente conllevaría un alto costo político.

Este desinterés se contrarrestó con el comienzo de la difusión en volúmenes y monografías de estudios sobre Victimología donde se abordaba mucho más el tema del sujeto pasivo del delito, dando pie con ello a Congresos Internacionales de Victimología, la creación de "la Sociedad Mundial de Victimología", y los "Congresos Internacionales Quinquenales sobre Prevención del delito y Tratamiento del delincuente".

Es importante destacar los aportes que ha hecho la Victimología en este aspecto para el Derecho Penal, por estudiar el ángulo crimino-dinámico y por la introducción de conceptos relacionados a la victimización y auto-victimización. Es por esto que hoy se conoce que la víctima puede

${ }^{5}$ MANZANERA, Luis Rodríguez. (1990) "Victimología”, México, Porrúa, pág. 5.

${ }^{6}$ Congresos Internacionales Quinquenales sobre Prevención del delito y Tratamiento del delincuente "Víctimas del delito" (1985). Milán. 
caer en conductas conducentes a su propia victimización, esto es, la propicia, ella misma se hace vulnerable por motivo de sus acciones.

Con las nuevas teorías que se originaron en torno al comportamiento de la víctima frente a la génesis y al desarrollo del delito, se estableció también la responsabilidad que esta asumiría frente al Derecho Penal. Puesto que si la víctima también participa de forma significativa en los hechos criminales, ello puede dar lugar a una disminución en la pena de su agresor.

En cuanto a la dinámica criminal, la víctima se enfrenta a su agresor dentro de diversos factores, por lo cual se puede aducir que, existirán variadas interacciones entre los dos sujetos. Afirma Stephan Hurwitz que, "en muchas ocasiones la constelación de circunstancias que rodea el momento del delito, debe examinarse como la explicación real o primar de un acto delictivo, para el cual se buscan en vano causas más hondas. La situación, en este caso, origina una criminalidad que, puede decirse justamente, depende del azar?.

Esto nos lleva a analizar el aspecto situacional, en el que se pueden distinguir una división de situaciones casuales y provocadas. En las primeras existe un aprovechamiento de oportunidades que propician de manera efectiva el delito a cometer por parte del delincuente. En las segundas, por su parte, existirá una provocación que desencadenará el delito. Esta provocación podrá ser realizada por la misma víctima, que favorecerá el crimen.

Adbel Fattah ${ }^{8}$ clasifica este tipo de víctimas en dos grupos:

- Tipo Pasivo: Que es la víctima que incita al delincuente de forma indirecta por negligencia o por imprudencia.

- Tipo Activo: Que tiene un rol más decisivo en la actuación criminal y a su vez se subdivide en:

Victima consciente: Es consciente de incitar a la acción. Actúa como un agente provocador.

7 HURWITZ, Stephan. (1956) “Criminología”, Barcelona, Ediciones Ariel. Página 383.

8 FATTAH, Abdel Ezzat. (1966) Quelques problèmes posés à la Justice Pénale par la Victimologie. Anales Internacionales de Criminología. Francia 
Victima no consciente: No procura incitar al acto. Sin embargo, por sus acciones lo provoca.

Estas víctimas pueden incluso no tener nexo alguno con su victimario, sin embargo, el acto criminal puede realizarse por la incitación que origina la víctima sobre el futuro ofensor haciendo algo en su contra. En este particular caso, el accionar de la víctima provocará una reacción de venganza por parte de su agresor.

\section{Conclusiones}

El comportamiento de la víctima dentro de los hechos delictivos estuvo relegado durante mucho tiempo. Tuvo su mayor protagonismo en la venganza privada y se olvidó posteriormente durante siglos. Sin embargo, luego de la segunda mitad del siglo XIX se apreció un creciente interés en los estudios sobre la participación de las víctimas en los procesos delictivos y cómo ellas tenían influencia en el desencadenamiento y desarrollo del crimen, lo que le permitió a varios autores atribuir a la víctima también un grado de responsabilidad, que finalmente obraría en la reducción de la pena del infractor de la ley penal. Fue una etapa trascendental en la doctrina victimológica y graduación de la responsabilidad criminal. Los autores procuraban que la víctima recobrase su protagonismo en el proceso y a la vez advertían sobre la importancia de sus acciones. Es por ello que se originó la visión de una legislación futura más orientada a la víctima para no relegarla como sujeto pasivo del delito, sino como agente provocador, interactivo. Ahora habría que considerar todavía más su rol como colaborador en la aparición del delito.

Resulta por tanto innegable hoy que la víctima constituye un elemento significativamente importante al momento de analizar las circunstancias de los hechos delictivos. Sin embargo, esta consideración aún no está suficientemente desarrollada en el ámbito de las ciencias penales, como sí lo está en las ciencias criminológicas. Por ello, se busca orientar en este aspecto a un sistema más razonable al momento de establecer la responsabilidad de los actores en un crimen. Ello daría como resultado la aplicación de medidas más equitativas en la medida en que, cuando la ley deba aplicarse de forma rigurosa, lo hará porque verdaderamente el infractor ha incurrido 
en su rompimiento de manera desproporcionada y osada, lesionando un bien jurídico tutelado, sin la interrupción o participación de la víctima. De manera contraria, actuará conforme a las circunstancias del caso, esto es, si la víctima ha participado ostensiblemente, consciente y de forma voluntaria para producir o provocar su victimización, el agresor podrá beneficiarse de una rebaja en su condena, porque no será enteramente responsable de lo ocurrido.

\section{Referencias}

Beristain, Antonio. (2000) Protagonismo de las víctimas en la ejecución penal (Hacia un sistema penitenciario europeo). Actualidad Penal.

Fatтah, Abdel Ezzat. (1966) Quelques problèmes posés à la Justice Pénale par la Victimologie. Anales Internacionales de Criminología. Francia.

Hurwitz, Stephan. (1956) Criminología. Ediciones Ariel. Barcelona.

Manzanera, Luis Rodríguez (1990) Victimología. México. Porrúa.

Mendelsohn, Beniamin. (1958) "La Victimologie", en Revue Francaise de Psychanalyse, Janvier-Fébrier.

Rosas Ortiz, Patricio. (2012) Consideraciones sistematizadas de criminodinámica: desde el Paradigma Etiológico Multivectorial Integrativo del Profesor Don Marco González Berendique y algunas Teorías Contemporáneas. Santiago de Chile.

\section{Bibliografía}

Congreso de la ONU sobre prevención del delito y tratamiento del delincuente. Séptimo Congreso "Víctimas del delito” (1985), Milán.

LA PROVOCACIÓN AL DELITO Y SU RELACión CON LA Víctima, desde el punto de vista criminológico. «http://www.monografias.com/trabajospdf5/provocacion-al-delito-y-su-relacion-Victima/provocacion-aldelito-y-su-relacion-victima.shtml»

Zaffaroni, Eugenio Raúl: "La cuestión criminal”, suplemento especial de la revista "Página 12", (2011). Argentina. Recopiladas en: "La palabra de los muertos. Conferencias de Criminología Cautelar”. Conferencias reunidas, Editorial Ediar, Buenos Aires. 



\section{CARACTERIZACIÓN DE LOS DERECHOS INDIVIDUALES DE LAS PERSONAS SEXUALMENTE DIVERSAS, VIGENTES EN EL ORDENAMIENTO JURÍDICO COLOMBIANO AL AÑO 2013'}

Yamid Enrique Cotrina Gulfo 2

\section{Resumen}

El presente artículo contiene los resultados parciales del proyecto de investigación en curso, cuya finalidad es analizar los derechos de la población sexualmente diversa en la normatividad colombiana y la efectividad en el goce que tiene esta población sobre los mismos. Para ello, resulta primordial categorizar estos derechos y conceptualizarlos de manera individual e interrelacionarlos en su aplicación a la población sujeta de dicha normatividad. Se caracterizaron en esta oportunidad los derechos del individuo sexualmente diverso, teniendo en cuenta la Constitución Política en paralelo con los Principios de Yogyakarta, también se tuvo en cuenta en la presente producción académica la

1 Artículo de investigación científica presentado como resultado parcial del proyecto de investigación "Análisis Socio Jurídico de Derechos de la Población Sexualmente Diversa en el Ordenamiento Jurídico Colombiano y de su Goce Efectivo por parte de una Muestra Poblacional del distrito de Barranquilla en el año 2013".

2 Estudiante de VI semestre del Programa de Derecho de la Facultad de Ciencias Jurídicas de la Universidad del Atlántico. Miembro y Representante del Semillero General de Investigación y Grupo de Estudio "KALO”. 
Ley 1482 de 2011 (Ley Antidiscriminación) como garantía para el goce efectivo de los derechos anteriormente descritos.

Palabras clave: Derechos Individuales de las personas sexualmente diversas, garantías para el goce efectivo de derechos reconocidos, ordenamiento jurídico colombiano, Principios de Yogyakarta, Constitución Política de Colombia.

\section{Abstract}

In this article is contain the partial results of the research Project in course, its final objective is analyze the sexuality diverse people rights in the Colombian legal system and its effectiveness in the joy this population have about on these. For this is important categorize these rights and conceptualize them individually and interrelate in its application to the population subject of that regulation.

Were characterized the individual rights of sexually diverse people, considering the Constitution, in parallel with the Yogyakarta Principles, also considered in this academic production Law 1482 of 2011 (Antidiscrimination Act) as collateral for the effective enjoyment of the rights described above.

Keywords: Individual Rights of Persons Sexually Diverse, Guarantees for the Effective Enjoyment of Rights Recognized, Colombian legal system, Yogyakarta Principles, Constitution of Colombia.

\section{Introducción}

E1 sistema de protección de derechos de la población sexualmente diversa se encuentra clasificado en las dimensiones socio jurídicas a identificar, por ello se tiene en cuenta de manera específica la forma en como esta población es destinataria de los derechos regulados en el ordenamiento jurídico colombiano. Por medio de la regulación expresa de aquel derecho o recurso creado para obtenerlo, contenido en alguna normatividad jurídica expedida por la entidad del Estado competente para ello. 
Según el objeto legal motivante de la promulgación de dicha normatividad jurídica que contiene regulado en sí misma un derecho, estos pueden clasificarse como lo ilustra el siguiente diagrama.

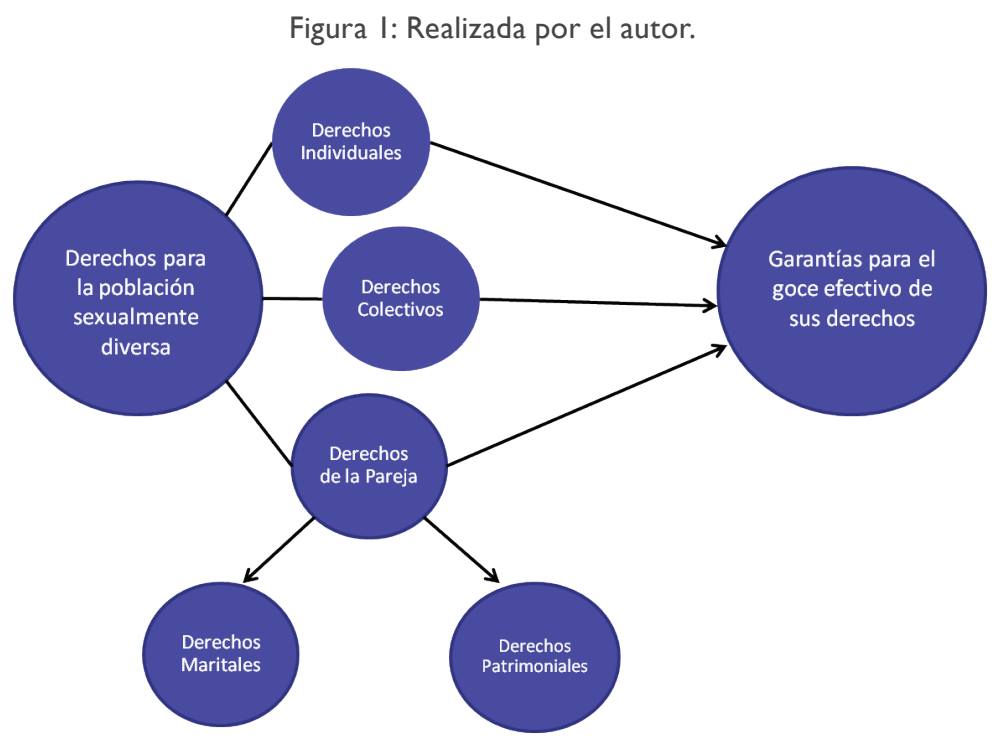

Cuando es el individuo sexualmente diverso destinatario de derechos, la norma jurídica en su función reguladora de los mismos establece los principios y demás presupuestos jurídicos para darle certeza al derecho reconocido careciendo este de ambigüedades y eufemismos que puedan distorsionar su interpretación, dando como consecuencia la obstrucción o en el peor de los casos la negación de un derecho, reconocido de manera difusa en una norma que lo contiene.

Las características que tienen las personas sexualmente diversas para ser objeto de un enfoque diferenciado en lo que al reconocimiento de derechos concierne, parte de su estado de "vulnerabilidad" en el cual se encuentra inmersa dicha población atendiendo a su orientación sexual y/o identidad de género. Estas manifestaciones diversas de la sexualidad se convierten de manera automática en factores de exclusión, al no estar acorde con el paradigma colectivo o imaginario sociocultural vigente de la sociedad, en la que estas personas diversas en su sexualidad hacen presencia. 
La discriminación a la diversidad sexual se concibe como una amenaza a la accesibilidad y al goce efectivo de los derechos reconocidos a la población sexualmente diversa. Visto desde dos perspectivas: cuando una persona diversa en su sexualidad decide acceder a la educación superior, y se le es negado el cupo por su expresión de género. Allí la discriminación opera a través de instituciones, negándole a esta persona el derecho constitucional a la Educación, con base en su identidad de género.

En el caso anteriormente relatado, la persona sexualmente diversa padeció del flagelo social de la discriminación originado por la ausencia de su expresión de género en el paradigma de vida de los administradores de la institución. Sin embargo, en el plano social puede verse bajo la siguiente óptica. Cuando una persona con una orientación sexual diversa a la heterosexual frecuenta un espacio de divertimiento, para departir con algunas personas que se encuentran dentro de dicho establecimiento y se le es prohibido el acceso al local comercial en razón de la manifestación de su sexualidad, por la voluntad individual del funcionario encargado de la seguridad del establecimiento.

En el proyecto de investigación en curso, se clasificó la discriminación de la misma manera como se hizo con las garantías para el goce efectivo de los derechos reconocidos a la población sexualmente diversa. Estas garantías pueden ser jurídicas desde el punto de vista abstracto, en lo que a la regulación normativa concierne. Estas normas, reguladas por sí solas no dan un efecto inmediato, para ello se necesitan acciones subsidiarias a la norma para así poder garantizar un goce efectivo que la población destinataria pueda tener de los derechos reconocidos con posterioridad a la expedición de la normatividad jurídica que los contiene. 
Figura 2: Realizada por el Autor.

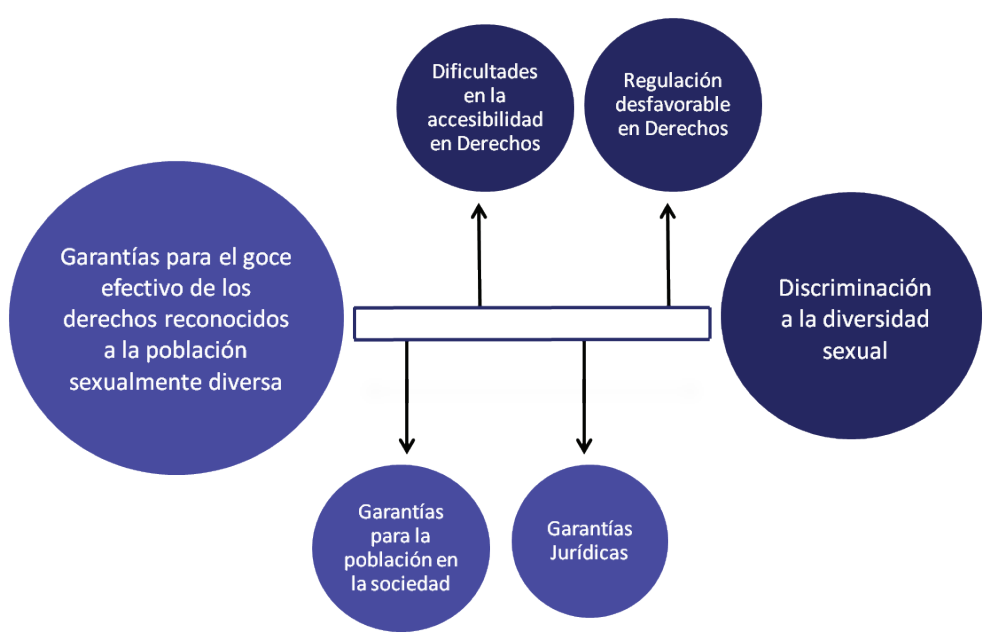

Dichas actuaciones de naturaleza abstracta deben perseguir como fin la erradicación de la discriminación hacia la población sexualmente diversa, y dará como resultado una disminución en la problemática de seguridad de los diversos en su sexualidad. La cultura del odio a la diversidad sexual ha sido una constante en la población barranquillera, así ha estado reposado en muchos informes de derechos humanos, encuestas de percepción y cifras oficiales expedidas por los órganos de seguridad.

La sociedad ejerce un rol importante en el goce efectivo de los derechos reconocidos a la población sexualmente diversa, siendo esta entorpecedora o facilitadora según sea el caso, para el acceso igualitario a derechos por parte de dicha población. La sociedad también la conforman las personas quienes ejercen la envestidura de funcionarios públicos, particulares que ejercen funciones públicas, particulares que ejercen profesiones las cuales tienen naturaleza pública en el sentido de estar abordando una temática relacionada con los derechos fundamentales e imprescindibles de una persona.

Esta persona, al ejercer su función con un prejuicio hacia la persona sexualmente diversa quien requiere aquel servicio público o de tal naturaleza. Entraría a victimizarla por su expresión sexual manifestada por su orientación sexual y/o identidad de género al negarle, condicionarle 
o distorsionarle la realidad de un derecho reconocido en el ordenamiento jurídico de la cual es destinatario.

La regulación desproporcionada, la cual ha venido subsanándose de manera efectiva por vía constitucional, ha sido uno de los logros más significativos en este camino de la igualdad trazado desde la Constitución Política de 1991 y de un estudio jurisprudencial -siguiendo los parámetros establecidos en la Carta Política- se han tomado las determinaciones jurisprudenciales correspondientes para subsanar de manera progresiva este déficit de derechos del cual padeció flagrantemente la población sexualmente diversa en cada una de sus dimensiones sociojurídicas de derechos.

Los derechos colectivos de la población sexualmente diversa tienen como objeto garantizar la asociación de estas personas con el fin de defender sus derechos reconocidos de cualquier circunstancia jurídico-política o social presentada que les afecte como población, siendo a su vez estos derechos una garantía reforzada a los ya reconocidos en el ordenamiento jurídico. La participación en política por parte de la población sexualmente diversa es un tópico también a abordar en esta dimensión de derechos.

Los derechos de la pareja, los cuales corresponden a la asociación intima, marital de dos personas del mismo sexo, quienes por medio de su voluntad responsable de conformar un núcleo de familia homoparental (constituido por lazos de crianza en los términos que lo determina la sentencia T-716 de 2011), deciden asumir esta nueva condición de vida, la cual genera unos derechos/deberes de cumplimiento mutuo. Los derechos maritales de la pareja correspondiente a la relación sostenida entre los dos contrayentes, una concepción del deber ser de la comunidad de vida que conforman.

Así como a los derechos patrimoniales de la pareja corresponde proteger el capital conformado por la pareja del mismo sexo, a su vez son coadyuvantes para el mejoramiento de la calidad de vida de la familia homoparental sujeta de regulación jurídica en esta oportunidad, brindándoles seguridad jurídica de los imprevistos que puedan ser susceptibles de acontecer. 
En especial, la muerte de alguno de estos contrayentes que disuelve de manera inmediata el vínculo que los unió.

En esta oportunidad se caracterizaron los derechos correspondientes al individuo sexualmente diverso, contenidos en la Constitución Política de Colombia, los cuales fueron relacionados con los Principios de Yogyakarta, para así determinar la incidencia que esta normatividad internacional podría dar en el reconocimiento y protección de derechos individuales de las personas sexualmente diversas, en caso de ser ratificada por el Congreso de la República.

\section{Metodología}

La forma correspondiente al desarrollo de la presente producción académica concierne a ser una investigación aplicada, a razón de que busca dar solución a la problemática planteada, la cual es dar un abordaje integral a los derechos de la población sexualmente diversa, expresada en sus múltiples dimensiones, en esta oportunidad en la dimensión sociojurídica del individuo.

El tipo de la presente investigación es descriptiva teniendo en cuenta que se busca analizar de una manera sociojurídica los derechos de la población sexualmente diversa, caracterizándolos luego de haber sido identificados. La recolección de datos se llevó a cabo por medio de las siguientes técnicas: Análisis de contenido de textos donde se abordó la temática de los derechos de la población sexualmente diversa, contenidos en la jurisprudencia, Leyes de la República y referentes doctrinales.

Al tratarse de una investigación en curso, este artículo es resultado parcial del proyecto de investigación que lo antecede. Cumpliendo una parte de un objetivo específico planteado en dicha unidad investigativa, el cual es "Caracterizar el sistema de derechos y garantías de la población sexualmente diversa en el ordenamiento jurídico colombiano" (Cotrina, 2013, p. 9), caracterizando los derechos correspondientes al individuo sexualmente diverso en esta oportunidad. 


\section{Derechos individuales de las personas sexualmente diversas}

Son aquellos que tienen como finalidad, garantizar el mínimo vital de la persona sexualmente diversa para su subsistencia plena, teniendo en cuenta el factor diferenciado que constituye el ser diverso en su sexualidad. Siendo merecedor así de una protección adicional en los términos que especifica el artículo 13 de la Constitución Política de 1991, por el hecho de hacer parte de un grupo social vulnerado y marginado por el imaginario colectivo de la sociedad.

Como referente legal de Derechos de la Población sexualmente Diversa, se tiene en cuenta la Constitución Política de Colombia como la cúspide del Ordenamiento Jurídico, en esta se encuentran reconocidos derechos, los cuales son de carácter universal y vinculante a todos los residentes en Colombia. En la carta magna se encuentran regulados diversos derechos que transversalizan los campos de actuación del ciudadano.

Estos comprenden desde la dimensión más específica que corresponde a ser la del individuo, pasando por la asociación más íntima que puede hacer este con otra persona, abordando así los derechos que se originan en esta unión de la pareja del mismo sexo y los derechos originados cuando esta asociación se hace con fines sociales con el objetivo de defender y promover sus derechos, y perseguir el reconocimiento de otros que no se encuentran regulados para sí en las normas contenidas en el sistema jurídico vigente.

En lo contenido a las leyes expedidas para la protección de los derechos de la población sexualmente diversa, se abordará la Ley 1482 de 2011 más conocida como la "Ley Antidiscriminación", única medida de carácter legislativo que por sí sola regula alguna clase de derechos cuyo destinatario sea la población sexualmente diversa ${ }^{3}$.

3 Sin embargo, en esta disposición legal también se incluyeron de manera expresa a otros grupos sociales conformados por personas con ciertas particularidades que los hacen susceptibles a la discriminación. Una Ley que reguló de manera integral el derecho a la no discriminación de los posibles grupos sociales vulnerables a la exclusión, segregación y discriminación, reglamentando así el artículo 13 de la Constitución Política de 1991, modificando algunas disposiciones normativas vigentes en el Código Penal (Ley 599 de 2000). 
En el contexto internacional, están vigentes los Principios de Yogyakarta, los cuales surgen como resultado de un panel de especialistas en legislación en orientación sexual e identidad de género llevado a cabo en la capital de indonesia. Estos principios acordados en el año de 2006 aún no han sido ratificados por el Congreso Colombiano para que tenga carácter vinculante con las leyes y artículos constitucionales que regulan los principios contenidos en estos.

La Organización de los Estados Americanos (OEA), por medio de propuesta del Estado Brasilero, adoptaron la aplicación de estos principios. Por medio de la resolución AG/RES-2435(XXXVIII-O/08), "Derechos Humanos, Orientación Sexual e Identidad de Género" esta normatividad contiene 28 principios, los cuales en paralelo con la constitución política se encuentran reconocidos en su totalidad a la población en general. Sin embargo, la ratificación de esta normatividad haría del enfoque diferenciado una garantía para el goce efectivo de los derechos constitucionales, por parte de la población sexualmente diversa. Según estos principios, la orientación sexual e identidad de género se definen de la siguiente manera:

La orientación sexual se refiere a la capacidad de cada persona de sentir una profunda atracción emocional, afectiva y sexual por personas de un género diferente al suyo, o de su mismo género, o de más de un género, así como a la capacidad mantener relaciones íntimas y sexuales con estas personas.

La identidad de género se refiere a la vivencia interna e individual del género tal como cada persona la siente profundamente, la cual podría corresponder o no con el sexo asignado al momento del nacimiento, incluyendo la vivencia personal del cuerpo (que podría involucrar la modificación de la apariencia o la función corporal a través de medios médicos, quirúrgicos o de otra índole, siempre que la misma sea libremente escogida) y otras expresiones de género, incluyendo la vestimenta, el modo de hablar y los modales (Yogyakarta, 2006, p. 6). 
Derechos Individuales, Principios de Yogyakarta ${ }^{4}$ y Constitución Política de Colombia 1991

De los 28 principios contenidos en dicha normatividad 26 tienen como finalidad salvaguardar los derechos correspondientes a la dimensión sociojurídica de derechos del individuo sexualmente diverso. De estos 26 derechos 25 se encuentran regulados de manera explícita en la Constitución Política.

\section{Principio $~^{\circ}$ : El derecho universal al disfrute de los Derechos Humanos}

Adaptando la finalidad del citado principio al contexto colombiano, correspondería a ser concordante dicha norma con el artículo 5 de la Constitución Política de 1991 al reconocer la primacía de los Derechos inalienables de la persona. En el inciso "D" de dicho principio se contiene también la toma de decisiones desde un enfoque pluralista tal y como se define a la República de Colombia en su artículo 1 de la Constitución. Así como la implementación de políticas públicas que tienen como fin la promoción y defensa de los Derechos Humanos de las personas independientemente de su orientación sexual y/o identidad de género.

\section{Principio $2^{\circ}$ : Los derechos a la lgualdad y a la no discriminación}

El artículo 13 de la Constitución Política de Colombia provee a los grupos sociales marginados y discriminados por el colectivo social en el cual ejercen su vida en sociedad. En lo que corresponde al derecho a la no discriminación. Este actúa como una garantía reforzada para el acceso igualitario a los derechos reconocidos para la población en general, y los reconocidos específicamente para la población sexualmente diversa. Este artículo se encuentra reglamentado en la Ley 1482 de 2011, cumpliendo

${ }^{4}$ Los principios 20, 24 y 27 no fueron abordados debido a que se desfasa del ámbito de protección de derechos individuales de las personas sexualmente diversas, ya que abordan las temáticas referentes al derecho a la libertad de reunión y de asociación pacíficas, el derecho a formar una familia y el derecho a promover los Derechos Humanos, respectivamente. Con respecto a este último, puede ser ejercido de manera individual o colectiva, pero en el sentido de sus efectos, se asume de naturaleza colectiva ya que los beneficiarios de dicha actuación es el grupo poblacional compuesto por las personas sujetas de regulación normativa. 
así con el literal "C" de este principio, en el que se describe lo siguiente: "Adoptarán todas las medidas legislativas y de otra índole que resulten apropiadas para prohibir y eliminar la discriminación por motivos de orientación sexual e identidad de género en las esferas pública y privada" (Yogyakarta, 2006, p. 11).

\section{Principio $3^{\circ}$. El derecho al reconocimiento de la personalidad jurídica}

En el artículo 14 de la Constitución Política se encuentra regulado este derecho, el cual consiste en dotar al individuo de capacidad jurídica en todos los aspectos de su vida, por medio de su autodeterminación con el fin de no desmejorar su dignidad, ni limitar su libertad. Adaptando este derecho a la orientación sexual e identidad de género del individuo se le garantizaría a este su derecho al goce libre de su sexualidad, la cual no estará sujeta de condicionamiento alguno para tener un goce efectivo de los derechos que tiene como sexualmente diverso.

Así como tampoco podrá ser una persona sexualmente diversa obligada a ocultar, negar o suprimir su orientación sexual o identidad de género en los términos que establece este principio.

\section{Principio $4^{\circ}$. El derecho a la vida}

Regulado en el artículo 14 de la Constitución Política, este derecho es inviolable en los términos que lo establece la normatividad de carácter nacional. En Colombia la pena de muerte está abolida constitucionalmente; sin embargo, las ejecuciones de personas sexualmente diversas por grupos delincuenciales de carácter urbano y rural reposados en los informes de derechos humanos de las organizaciones no gubernamentales, traducen una realidad donde estas colectividades al margen de la Ley emplean mecanismos tales como la "limpieza social" en los barrios de los cascos urbanos municipales y de las grandes ciudades.

Generalmente estos grupos, de corriente paramilitar, atentan contra personas sexualmente diversas de alta influencia en su comunidad, viéndose así afectado el derecho a la vida de este grupo social. Acabar con la vida de la persona diversa en su sexualidad, no es el único presupuesto 
para desmejorar este derecho fundamental en mención. La vida digna y plena se ve desmejorada cuando el Estado por acción u omisión expide normatividad cuya finalidad es desmejorar el mínimo vital del individuo sexualmente diverso, o guarda silencio ante dicha situación causada por determinaciones adoptadas por sus dependencias.

\section{Principio $5^{\circ}$. El Derecho a la seguridad personal}

Aunque el derecho a la seguridad no aparece expresamente nominado como fundamental en la Constitución, sino que ese estatus deriva de una interpretación sistemática de la Carta Fundamental (preámbulo, arts. $2^{\circ}, 12,17$, 18, 28, 34, 44, 46 y 73 C.P.), y de diversos instrumentos internacionales que hacen parte del ordenamiento jurídico interno, en virtud del bloque de constitucionalidad (arts. 93 y 94 C.P.), como son: (i) la Convención Americana sobre Derechos Humanos (art. $7^{\circ}, \mathrm{Nral} .1^{\circ}$ ), incorporada a la legislación colombiana mediante Ley 16 de 1972; y (ii) el Pacto Internacional de Derechos Civiles y Políticos (art. $9^{\circ}$, Nral. $1^{\circ}$ ), aprobada mediante Ley 74 de 1968. Así mismo, la Declaración Americana de los Derechos y Deberes del Hombre (art. $1^{\circ}$ ) y la Declaración Universal de los Derechos Humanos de 1948, aceptada como costumbre internacional a partir de la promulgación de Teherán el 13 de marzo de 1968, aluden al derecho a la seguridad $\left(\operatorname{art.} 3^{\circ}\right.$ ). (Corte Constitucional, 2013).

Este derecho obliga al Estado a salvaguardar al individuo sexualmente diverso de todo acto de violencia originado por cualquier persona. La entidad encomendada para la protección de este derecho es la policía nacional, organismo cívico-militar encargado de la seguridad de los habitantes de Colombia.

Al interior de la Policía Nacional está vigente la Directiva 006 de 2010, la cual tiene como finalidad garantizar el respeto de los derechos de la "comunidad LGBT". Con el fin de proteger a las personas sexualmente diversas de un daño en sus derechos por parte de las autoridades encargadas de velar por su seguridad. 


\section{Principio $6^{\circ}$. El derecho a la privacidad}

Con el fin de velar por la preservación de la honorabilidad del individuo, el Estado colombiano garantiza este derecho por medio del artículo 15 de la Constitución. En los términos establecidos por los Principios de Yogyakarta, se refiere a proteger la opción de revelar o no la orientación sexual del individuo sexualmente diverso; en lo que concierne a la persona con identidad de género distinta a la de su sexo biológico, este derecho no operaría de la siguiente manera debido a que esta identidad aborda rasgos fenotípicos que al asumirla sería evidente.

Sin embargo, sí operaría este derecho en lo que tiene que ver con la información personal del proceso al cual tuvo que someterse para exteriorizar su identidad de género en semejanza física a su sexo opuesto. También sería viable la invocación a este derecho, cuando con el fin de desprestigiar a una persona se acude a la orientación sexual o identidad de género, ya sea por parte de personas particulares como por agentes del Estado.

\section{Principio $7^{\circ}$. El derecho de toda persona a no ser detenida arbitrariamente}

Garantizando, así, el derecho a la libertad. Enunciado en el artículo 28 constitucional concomitante con este principio, enfatiza que solo podrán ser detenidas las personas por medio de una orden judicial, En los principios de Yogyakarta se precisa la independencia de la orientación sexual y/o identidad de género del procesado en lo que respecta al deber que tiene el Estado por medio de sus organismos.

\section{Principio 8. El derecho a un juicio justo}

En la Constitución colombiana, el derecho al debido proceso, estipulado en su artículo 29, especifica que los presupuestos tenidos en cuenta para el juzgamiento de una persona solo deben basarse en las leyes preexistentes a la conducta tipificada, ya sea en disposiciones judiciales o administrativas.

En este principio, se establece la imparcialidad como presupuesto imprescindible para el juzgamiento de una persona que está siendo 
procesada, con independencia de su orientación sexual y/o identidad de género. Estas garantías se encuentran especificadas en la Ley 1482 de 2011 como circunstancia de agravación cuando el acto de discriminación es cometido por un servidor público.

\section{Principio $9^{\circ}$. El derecho de toda persona privada de su libertad a ser tratada humanamente}

Al determinar la orientación sexual y la identidad de género del individuo sexualmente diverso, como conductas propias del ser humano necesarias para su tratamiento digno. El enfoque diferencial de Derechos cumple un papel fundamental en el goce efectivo de este derecho regulado por el artículo 1 constitucional en lo referente a la dignidad humana del individuo, específicamente en lo relacionado con la problemática carcelaria se podrá acudir a la sentencia T851/2004, expedida por la Corte Constitucional.

Protegiendo normativamente a las personas sexualmente diversas de cualquier menoscabo del cual puedan ser vulnerables por parte de otros presos. Adicionándosele la vulnerabilidad en la que estas personas incurren por la manifestación de su sexualidad al ser abusadas sexualmente la gran mayoría de las veces sin la protección adecuada, trayendo como consecuencia la transmisión de enfermedades venéreas.

Principio 10. El derecho de toda persona a no ser sometida a torturas ni a penas $\circ$ tratos crueles, inhumanos o degradantes

Lo contenido en el artículo 12 constitucional, no solo tiene carácter vinculante con las herramientas de carácter coercitivo que pueda emplear el Estado con el fin de reprimir conductas delictivas. También se convierte en sujeto de regulación la sociedad, adaptándola al contexto del individuo sexualmente diverso, el núcleo social en donde este se desenvuelve.

Aunque constitucionalmente están proscritas dichas conductas punibles, la sociedad, por medio de grupos al margen de la Ley, se toman atribuciones que desfasan el objeto lícito de la normatividad jurídica. 
Principio II. El derecho a la protección contra todas las formas de explotación, venta y trata de personas

Al ser abolida la esclavitud, y proscribir todo tipo de trata de seres huma-
nos en el territorio colombiano la Constitución política por medio de su
artículo 17 hace dicha precisión. En este principio, se enuncia que la diver-
sidad sexual del individuo es un factor de vulnerabilidad en lo que respecta
a la discriminación social de la que son víctimas, lo que en muchos casos
los condiciona a aceptar propuestas de trabajo de dudosa procedencia, ter-
minando así en manos de las grandes redes de trata de personas del mundo.

\section{Principio 12. El derecho al trabajo}

Siendo similar la regulación de este principio con el artículo 25 de la Constitución, hace énfasis en el ámbito subjetivo de producción que debe tener este para el individuo y el mejoramiento de su nivel de vida. Garantizando en su regulación la no discriminación a las personas por su orientación sexual y/o identidad de género.

\section{Principio 13. El derecho a la seguridad social}

Se hace precisión en que este derecho debe contar con la naturaleza de ser eficiente, universal y solidario en los términos que establece el artículo 48 de la Constitución Política colombiana de 1991. Adicionándosele a ello, este principio es concomitante con el artículo constitucional citado, en lo que es referente al principio de la universalidad de este derecho en la no discriminación de la que deben estar libres las personas para poder gozar de manera efectiva este derecho, independientemente de su orientación sexual y/o identidad de género.

\section{Principio I4. El derecho a un nivel de vida adecuado}

En el principio constitucional de la Dignidad Humana establecido en su artículo 1, así como en el artículo 366 de la Carta Magna, se establece como objeto fundamental del Estado el mejoramiento de la calidad de vida de la población, teniendo por objeto dar una solución efectiva a las 
necesidades básicas insatisfechas específicamente en saneamiento básico y agua potable.

Tal cual, como es establecido en este principio de Yogyakarta donde las personas con independencia de su orientación sexual y/o identidad de género serán beneficiarias de un nivel adecuado de vida, mejorando así la calidad de la misma.

\section{Principio I5. El derecho a la vivienda adecuada}

En los términos establecidos en el artículo 51 constitucional, la vivienda digna, siendo un derecho de los nacionales, está garantizada por este artículo en el sentido de que el Estado promoverá los planes pertinentes para la masificación de la misma, específicamente la de interés social.

En el contexto de este principio internacional, se tiene en cuenta el desalojo en razón de la orientación sexual y/o identidad de género del propietario del inmueble, como forma de actuación discriminatoria.

\section{Principios 16 y 17. El derecho a la educación y derecho al disfrute del más alto nivel posible de salud}

Concomitantes con los artículos 67 y 49, respectivamente. Son congruentes en su regulación haciendo énfasis en la protección a la discriminación de la que puedan ser víctimas las personas sexualmente diversas. El factor diferenciado en la regulación de estos derechos consiste en el debido respeto a la diversidad sexual en los espacios educativos y a la salud sexual y reproductiva de las personas sexualmente diversas como aspecto fundamental del derecho a la salud respectivamente.

\section{Principio 18. Protección contra abusos médicos}

Protegiendo a toda persona sexualmente diversa, ya sea por su orientación sexual o por su identidad de género de ser obligada a ser sometida a tratamientos médicos, ni ser confinada en algún centro hospitalario con la finalidad de eliminar la manifestación de su sexualidad. El derecho constitucional en el ordenamiento jurídico colombiano que se protege, además del correspondiente a la dignidad humana, el del Libre desarrollo 
de la personalidad, específicamente el de la libre opción sexual, como es establecido en la Sentencia C-075 de 2007.

\section{Principio 19. El derecho a la libertad de opinión y de expresión}

Mientras que en el artículo 20 de la Constitución Política se enuncia el Derecho a la libre expresión con la finalidad de garantizar la libertad de prensa y del derecho que tiene toda persona de expresar sus ideas. En el contexto de los Principios de Yogyakarta se protege el derecho de toda persona diversa en su sexualidad de expresar sexualmente sus emociones, por medio de la indumentaria que pueda esta portar, el comportamiento que dicha persona pueda asumir, así como también el derecho que tiene de difundir los derechos humanos de la población que conforma.

Principio 2I. El derecho a la libertad de pensamiento, de conciencia y de religión

En lo que concierne a la relación de la diversidad sexual con la religión resulta compleja su concepción, debido a las desavenencias que manifiesta esta conducta propia del ser con los principios y dogmas eclesiásticos de estas congregaciones religiosas que en muchos de los casos estigmatizan a las personas sexualmente diversas, promoviendo su discriminación.

En lo que se relaciona con los pensamientos y las convicciones de la persona sexualmente diversa que construyen su paradigma de vida, el Estado no podrá inmiscuirse expidiendo leyes que tengan como fin erradicar dicho imaginario.

El artículo 18 constitucional establece el derecho a la libertad de conciencia y pensamiento y el artículo 19 el derecho a la libertad de cultos. Sin embargo, no se hace alusión a la protección que tiene esta población sobre los ataques que frecuentemente realizan estas congregaciones religiosas sobre esta población.

\section{Principio 22. El derecho a la libertad de movimiento}

La orientación sexual y la identidad de género de las personas no podrán ser tomadas como impedimento para la libre circulación del individuo por 
el territorio colombiano, permitiéndole escoger libremente su lugar de residencia en cualquier municipio del país con las limitaciones que determina la ley, generalmente estas limitaciones versan sobre asuntos de seguridad nacional.

Ninguna entidad territorial podrá restringir el acceso a una persona por las características anteriormente especificadas, en lo que respecta a la diversidad sexual. En el ordenamiento jurídico colombiano el artículo 24 de la Constitución Política es la norma concordante con este principio internacional.

\section{Principio 23. El derecho a procurar asilo}

Constitucionalmente en Colombia el derecho al asilo es apenas enunciado en la redacción del artículo que corresponde a su regulación: el artículo 36. En este principio, se establece la orientación sexual y la identidad de género de la persona como generador de vulnerabilidad en lo que a la degradación de derechos respecta, por ende se establece que no podrá ser sujeto de extradición una persona por su sexualidad a su país de origen, cuando este individuo se vea amenazado de padecer tratos inhumanos por parte de los agentes del Estado o de la sociedad regulada por el mismo.

Principios 25 y 26 . El derecho a participar en la vida pública y el derecho a participar en la vida cultural

Nuevamente haciendo referencia al derecho a la no discriminación como garantía para el goce efectivo de estos derechos, en los Principios de Yogyakarta se establecieron la orientación sexual e identidad de género del individuo como factores de protección por parte de los Estados que se acojan a dichos lineamientos internacionales sobre la aplicación de legislación en diversidad sexual.

E1 derecho a elegir y ser elegido, consagrado constitucionalmente en el artículo 40 de la Constitución Política, establece una garantía universal para que todo colombiano pudiera hacer parte del proceso electoral, incluyendo a las personas sexualmente diversas a las cuales no se les puede negar su derecho a ejercer cargos públicos de elección popular, ni los obtenidos 
por concurso de méritos, así como tampoco los relacionados con la seguridad nacional tales como la policía y las fuerzas militares.

Sin embargo, esta garantía constitucional no es suficiente para garantizar la elección de representantes de la población sexualmente diversa en las corporaciones públicas, y cargos de naturaleza ejecutiva (Presidencia, Gobernación, Alcaldía), ya que el constituyente primario en el pleno uso del voto puede abstenerse de elegir a personas que no se acoplan a su paradigma de vida.

En cambio en lo referente al derecho que tienen las personas sexualmente diversas a participar en la vida cultural, regulada también en el artículo 70 constitucional, establece que no puede limitarse a causa de su orientación sexual e identidad de género. La cultura como construcción del imaginario colectivo de un grupo poblacional determinado es diversa, pluriétnica y multicultural. Sin embargo, el paradigma de diversidad en la sexualidad no se ve reflejado en el mismo, siendo este el motivante en muchas de las ocasiones del rechazo de la población a la participación de esta población en sus muestras culturales representativas.

\section{Principio 28. El derecho a recursos y resarcimientos efectivos}

En caso de que se le hayan violentado los derechos a la persona sexualmente diversa, por su orientación sexual y/o identidad de género, el Estado será obligado a resarcir el daño causado por sus determinaciones causadas o por las omisiones incurridas.

En la Constitución Política de Colombia, existen tres artículos que regulan estos recursos para la reparación de los daños causados a los ciudadanos. La acción de tutela, regulada por el artículo 86 de la Constitución, tiene como finalidad la protección de los derechos fundamentales de la persona; estos, al servulnerables por acción u omisión de cualquier autoridad encargada de la prestación de un servicio de naturaleza pública que tiene como finalidad hacerle llegar el derecho constitucionalmente otorgado al ciudadano. 
En caso de que por el incumplimiento de la normatividad jurídica vigente, por parte de cualquier entidad. El ciudadano podrá acudir ante la autoridad judicial para su inmediato cumplimiento, en los términos establecidos por el artículo 87 constitucional. Como norma subsidiaria, el artículo 90 de la constitución asume al Estado como responsable de los daños antijurídicos causados por sus entidades, las cuales entrarán a reparar patrimonialmente a los afectados.

\section{Conclusiones}

Al abordar de manera específica la dimensión sociojurídica de los derechos individuales de las personas sexualmente diversas, tomando como referentes la Constitución Política de Colombia de 1991 y los Principios de Yogyakarta, pudo encontrarse un alto grado de similitud en los derechos regulados. Sin embargo, la diferencia radica en los destinatarios de ambas normas. Mientras que la Constitución por su carácter imperativo y universal regula derechos para la población en general, los Principios de Yogyakarta hacen lo suyo con la población sexualmente diversa atendiendo a su orientación sexual y/o identidad de género.

La diversidad en la sexualidad implica muchas consecuencias jurídicas, teniendo en cuenta la discriminación originada por la ausencia de esta conducta propia del ser humano en el imaginario colectivo de la población en la que se desenvuelve. Los derechos regulados en los Principios de Yogyakarta tienen en cuenta la discriminación como una amenaza, la cual tiene por objeto contrarrestar por medio de medidas específicas en cada uno de los principios regulados. El derecho a la no discriminación es concebido como una garantía para la protección de los derechos reconocidos, siendo esta una gran facilitadora para su goce efectivo.

Teniendo el mínimo vital garantizado por medio de la regulación constitucional de los derechos que son inherentes a su vida, la persona sexualmente diversa se ve expuesta por su orientación sexual y/o identidad de género a la discriminación de la que puedan ser objeto en su colectivo social. En el caso de Colombia, existen derechos reconocidos a toda la población en sus diferentes campos de aplicación, a su vez, existe una ley 
antidiscriminación que les da las garantías legales para el resarcimiento de sus derechos cuando estos sean vulnerados, tanto por miembros de la sociedad como por determinaciones proferidas por agentes del Estado.

El enfoque diferenciado en la expedición de normatividad jurídica es determinante al momento de ser garantía para el goce efectivo de la misma. Es por ello que la ratificación de los Principios de Yogyakarta por parte del Congreso Colombiano debe de realizarse con el fin de dar cumplimiento a los múltiples exhortos que ha emitido la Corte Constitucional en sus sentencias, en lo que a Derechos de la población sexualmente diversa respecta. Contribuyendo a subsanar progresivamente el déficit de regulación legislativa en Derechos que tiene la población sexualmente diversa.

La criminalización de la discriminación en el ordenamiento jurídico colombiano es una herramienta que se emplea para garantizar el libre desarrollo de la personalidad de las "minorías" de todo tipo en la demografía colombiana. Sin embargo, si no se emplea la ejecución de normas subsidiarias para cumplir con la finalidad de la ley antidiscriminación, se tendrá un resultado mucho más disociador del que se tenía anterior a la expedición de la ley mencionada, ya que habrá una indiferencia hacia la diversidad. Esto, en cuanto que la población que comparte el imaginario colectivo dominante, en vez de actuar por las vías de hecho para discriminar a una persona en razón de la diversidad en su sexualidad cuando esta desfase lo contemplado en su paradigma de vida, optará por marginarla con su silencio.

Por ello las medidas actuales deben ir acompañadas con la implementación de políticas públicas que tengan como fin proteger de manera reforzada los derechos ya reconocidos de la población sexualmente diversa. Muchas veces el efecto constitucional de las normas contenidas en la Carta política de 1991 no es suficiente para permear todos los entornos en donde actúa el individuo para protegerle de cualquier vulneración en sus derechos que pueda padecer, muchas veces la soberbia de algunas personas que por circunstancias tienen bajo su poder funciones específicas y sus decisiones puedan afectar el mínimo vital de la persona a quien valla proferida dicha determinación. Es el origen de los recursos judiciales para la exigibilidad 
de derechos y por medio de la ejecución de políticas públicas que se puede incidir en la descongestión del aparato judicial.

\section{Referencias}

Colombia (1991). Constitución Política de Colombia, 1991.

Cotrina Gulfo, Yamid Enrique (2013), "Análisis socio jurídico de derechos de la población sexualmente diversa en el ordenamiento jurídico colombiano y de su goce efectivo por parte de una muestra poblacional del Distrito de Barranquilla en el año 2013" [Proyecto de investigación dirigido] Universidad del Atlántico, Facultad de Ciencias Jurídicas, Centro de Investigaciones Socio Jurídicas "Luis Eduardo Nieto Arteta”.

Colombia (2011). Congreso de la República, Ley 1482 de 2011, "Por medio de la cual se modifica el Código Penal y se dictan otras disposiciones" [Ley Antidiscriminación].

Colombia (2011). Corte Constitucional, Sala Plena, Sentencia T-716 de 2011, M.P. Luis Ernesto Vargas Silva.

Colombia (2013). Corte Constitucional, Sala Plena, Sentencia T-078 de 2013, M.P. Gabriel Eduardo Mendoza Martelo. COLOMBIA, (2004) Corte Constitucional, Sala Plena, Sentencia T-851 de 2004, M.P. Manuel José Cepeda Espinosa.

Colombi a (2010). Policía Nacional, Directiva Administrativa Permanente 006/DIPON INSGE 23.1, 2010 "Garantías y respeto a los derechos de la comunidad LGBT".

Indonesia (2006). Panel Internacional de Especialistas en Legislación Internacional de Derechos Humanos y en Orientación Sexual e Identidad de Género, Principios de Yogyakarta.

Organización de los Estados Americanos (2008). Resolución AG/ RES-2435(XXXVIII-O/08) "Derechos Humanos, orientación sexual e identidad de género". 


\section{MARCO NORMATIVO. ASOCIACIONES PÚBLICO-PRIVADAS: ANÁLISIS DE LA LEY I508 DE 2012}

Eddi Leonardo Molina Franky'

\section{Introducción}

Con este trabajo se pretende exponer cómo está concebida la Ley 1508 de 2012, la cual crea la figura de las Asociaciones Público-Privadas, que son una gran innovación en nuestro ordenamiento jurídico, ya que permite formar un lazo entre el Estado y un particular para desarrollar proyectos de infraestructura o prestación de servicios que tienen como fin último la satisfacción de las necesidades de todos los ciudadanos.

Esta ley propone vincular al sector privado, para que este se inmiscuya, con el desarrollo de las políticas sociales del Estado, pues les da la posibilidad de asociarse cuando el Estado tiene una iniciativa de proyecto o cuando el particular desarrolla un proyecto y la entidad estatal competente lo acepta.

De igual manera, la Ley 1508 trae una serie de innovaciones y cambios en el tema de contratación, ya que desarrolla de una manera distinta la asignación y distribución de riesgos; la manera como el Estado le va a retribuir al contratista el proyecto ejecutado; revoluciona el tema de los anticipos que el Estado le concede a los contratistas para que estos desarrollen el

1 Alumno de décimo semestre de la Universidad Sergio Arboleda, adscrito al semillero de investigación de Derecho Privado e integrante de la Clínica de Interés Público, Línea de trabajo en Derecho Privado. 
proyecto; otorga una serie de incentivos a los empresarios y/o inversionistas que tienen iniciativa, entre otros.

Así mismo, se procederá a realizar una comparación en el concepto de esta institución jurídica, que ya está en rigor en nuestra legislación, con distintos países que igualmente la han consagrado en su régimen normativo, para poder establecer sus similitudes y diferencias.

Se establecerá qué exigencias y requisitos deben tener los empresarios y/o inversionistas para llegar a contratar con el Estado bajo los términos señalados por esta ley.

Por último, se analizará el tratamiento que la ley dispone para la postulación y elección del contratista, ya que la simple iniciativa privada de propuesta de proyecto con aceptación de la entidad estatal competente, no supone la celebración del contrato que crea la Asociación Público-Privada.

\section{Marco normativo asociaciones públicoprivadas}

Esta modalidad de asociación surge con motivo de la Ley 1508 de $2012^{2}$ y del Decreto Reglamentario $1467^{3}$ del mismo año, que tiene como fin crear un lazo de cooperación entre las entidades estatales y las empresas y/o inversionistas. En esta ley se encuentran delimitados los convenios de colaboración que pueden surgir entre las partes contratantes, así como los requisitos y procedimientos para contratar con el Estado y desarrollar obras que están dirigidas única y exclusivamente a la satisfacción de las necesidades de los ciudadanos.

Esta figura jurídica aunque es nueva en nuestro ordenamiento jurídico, no lo es así para otras legislaciones como son en el Reino Unido, España, Francia, Grecia, entre otros países. Es una innovación jurídica que le permite al Estado reunir a los empresarios con un fin específico para proveer bienes públicos y sus servicios relacionados, como solución a una necesidad

\footnotetext{
2 Por la cual se establece el régimen jurídico de las Asociaciones Público-Privadas, se dictan normas orgánicas de presupuesto y se dictan otras disposiciones.

3 Por la cual se reglamenta la Ley 1508 de 2012.
} 
identificada dentro de las políticas o planes de desarrollo pautados por el gobierno.

La ley en su artículo $1^{\circ}$ define estas asociaciones de la siguiente manera:

"Las Asociaciones Público Privadas son un instrumento de vinculación de capital privado, que se materializan en un contrato entre una entidad estatal y una persona natural o jurídica de derecho privado, para la provisión de bienes públicos y de sus servicios relacionados, que involucra la retención y transferencia de riesgos entre las partes y mecanismos de pago, relacionados con la disponibilidad y el nivel de servicio de la infraestructura y/o servicio".

Esta definición, a mi modo de ver extremadamente amplia, no indica una verdadera definición de esta institución, ya que para poder lograr una verdadera acepción, esta debe responder a la pregunta "Qué es", y ante esto el legislador únicamente dispone "que son un instrumento de vinculación de capital privado, que se materializan en un contrato entre una entidad estatal y una persona natural o jurídica de derecho privado". Se establecen muy bien sus características pero no una verdadera significación de esta institución de reciente incorporación.

\section{Denominaciones de la asociación público-privada en las distintas legislaciones}

En cuanto a definiciones dadas por doctrinarios no se encuentran muchos aportes, esto debido a su entrada en vigencia hace poco más de un año. El gobierno entiende estas asociaciones como "una herramienta contractual de largo plazo a disposición del sector público, en cualquier nivel de gobierno, que le permite vincular al sector privado con un objeto específico para proveer bienes públicos y sus servicios relacionados, como solución a una necesidad identificada dentro de las políticas o planes de desarro1lo correspondientes. La Asociación Público-Privada involucra, dentro del contrato de largo plazo, la retención y transferencia de riesgos entre las partes y la definición de los mecanismos de pago, relacionados con la disponibilidad y el nivel de servicio del bien provisto." 
Así mismo, la posición mayoritaria en España, aunque ha sido muy debatida esta definición, la define como "un contrato esencialmente complejo, ya que implica la participación del sector privado en la financiación y distribuye los riesgos de la operación entre el socio privado y el socio público"4.

Este contrato ha sido de igual manera desarrollado por la totalidad de los países que conforman la Unión Europea, y para esta comunidad política esta asociación público-privada es concebida como "las diferentes formas de cooperación entre las autoridades públicas y el mundo empresarial, cuyo objetivo es garantizar la financiación, construcción, renovación, gestión o el mantenimiento de una infraestructura o la prestación de un servicio"s.

La legislación española implantó esta institución jurídica en el año 2011 y denomina este acuerdo como contrato de colaboración público-privada, y es comprendido como "contratos de colaboración entre el sector público y el sector privado aquellos en que una Administración Pública o una Entidad pública empresarial u organismo similar de las Comunidades Autónomas encarga a una entidad de derecho privado, por un período determinado en función de la duración de la amortización de las inversiones o de las fórmulas de financiación que se prevean, la realización de una actuación global e integrada que, además de la financiación de inversiones inmateriales, de obras o de suministros necesarios para el cumplimiento de determinados objetivos de servicio público o relacionados con actuaciones de interés general"'.

En la legislación uruguaya se implementó este modelo de contrato a finales del año 2011. En este régimen jurídico este contrato es denominado como contrato de participación público-privado, distinta acepción al dispuesto en el régimen colombiano, pero de igual contenido, y es definido como "Contratos de Participación Público-Privada aquellos en que una

${ }^{4}$ Cf. José Valles Ferrer y Ana María Collazo Antúnez, Los contratos de colaboración público-privado, en Reflexiones, revistas de obras públicas, transportes y ordenación territorial, núm. 8 IV/2008. Sevilla, 2008.

${ }^{5}$ Libro verde de la Comisión Europea sobre las asociaciones público-privadas y el derecho comunitario en materia de contratación pública, COM (2004) 327.

${ }^{6}$ Artículo 11', Real Decreto Legislativo 3/2011, de 14 de noviembre, por el que se aprueba el texto refundido de la Ley de Contratos del Sector Público. 
Administración Pública encarga a una persona de derecho privado, por un período determinado, el diseño, la construcción y la operación de infraestructura o alguna de dichas prestaciones, además de la financiación”7.

En el ordenamiento jurídico peruano también está consagrada la asociación público-privada. Allí es entendida por esta legislación como "modalidades de participación de la inversión privada en las que se incorpora experiencia, conocimientos, equipos, tecnología, y se distribuyen riesgos y recursos, preferentemente privados, con el objeto de crear, desarrollar, mejorar, operar o mantener infraestructura pública o proveer servicios públicos"

Actualmente este contrato que regula las asociaciones público-privadas se encuentra integrado en más de 120 legislaciones alrededor del mundo, en donde se encuentran países como Kosovo, Polonia, Francia, Croacia, Bulgaria, Macedonia, Brasil, República Checa, Irlanda, India, Egipto, Madagascar, entre otros países.

\section{Elementos esenciales del contrato de asociación}

La doctrina que se ha referido a este nuevo contrato que ha tenido una muy buena acogida alrededor del mundo, ha discutido acerca de cuáles son los elementos esenciales que conforman el contrato de asociación público-privada o entendido en el lenguaje anglosajón como Public-Private Parnership o PPP, y a pesar de no haber convergencia en este tema, la posición mayoritaria que está en cabeza del profesor García Capdepon ${ }^{9}$ indica que son los siguientes:

1. Estos contratos deben ser complejos, tanto en las prestaciones que incorporan como en los sujetos participantes, ya que estos deben

7 Artículo 2º Ley no 18.786 Contratos de Participación Público-Privada para la realización de obras de infraestructura y prestación de servicios conexos.

8 Artículo $3^{\circ}$ del Decreto Legislativo No 1012, que aprueba la Ley Marco de Asociaciones Público-Privadas para la generación del empleo productivo.

9 P. García Capdepon, El Contrato de Colaboración Público-Privado, en revista de la función consultiva, núm. 3 ene-jun. 2005. 
ser por un lado, entidades públicas, y por el otro, empresarios o inversionistas.

2. Este contrato exige un adecuado reparto de riesgos, entre el contratista y la administración ${ }^{10}$.

3. En este contrato los pagos no se producen como contraprestación por la construcción de una determinada obra, sino por la utilización de la misma o la explotación del servicio de mantenimiento, incluso en aquellas supuestas en los que es la propia administración la que abona la cuantía debida al socio privado, v. gr. peajes.

Son estos los elementos que se estiman como esenciales para la existencia de este contrato, en donde debe haber una bilateralidad de partes conformada por una entidad estatal propiamente dicha y un particular. Además, este acuerdo de voluntades debe ser solemne, sinalagmático, oneroso.

En cuanto a los riesgos compartidos, es un gran cambio que se presenta teniendo como punto de referencia la Ley 80 de $1993^{11}$ y la Ley 1150 de $2007^{12}$, ya que por medio de esta regulación normativa no se hacía una eficiente asignación del riesgo, mientras que con la Ley 1508 de 2012 la asignación de riesgos se analiza ex-ante ${ }^{13}$ al proceso de selección.

En lo concerniente al pago por explotación del servicio o por utilización de la infraestructura, en el artículo 5o de la Ley 1508 se encuentra estipulado en los siguientes términos: "El derecho al recaudo de recursos por la explotación económica del proyecto, a recibir desembolsos de recursos públicos o a cualquier otra retribución, en proyectos de asociación público privada, estará condicionado a la disponibilidad de la infraestructura, al

${ }^{10}$ Debido a la novedad de este contrato, los riesgos deber ser detallados y explícitos.

${ }^{11}$ Por la cual se expide el Estatuto General de Contratación de la Administración Pública.

12 Por medio de la cual se introducen medidas para la eficiencia y la transparencia en la Ley 80 de 1993 y se dictan otras disposiciones generales sobre la contratación con Recursos Públicos

${ }^{13}$ Esta acepción hace referencia a que el análisis debe hacerse con antelación a la obra que se pretende desarrollar. 
cumplimiento de niveles de servicio, y estándares de calidad en las distintas etapas del proyecto, y los demás requisitos que determine el reglamento". Estamos en este punto ante una gran innovación en este tipo de contratos, ya que antes de la expedición de esta Ley 1508, el Estado pagaba por las obras y concedía anticipos en proyectos de concesión, y ahora el Estado paga por los servicios que presta la infraestructura y no otorga anticipos durante la fase de construcción.

\section{Concesiones para la formación de una APP}

En la Ley 1508 de 2012 se establecen de manera taxativa las concesiones por las cuales se puede llegar a crear una alianza contractual público-privada con el fin de satisfacer las necesidades sociales. El artículo $2^{\circ}$ nos remite al artículo 32 de la Ley 80 de 1993 que dispone de las siguientes concesiones:

1. Contratos de Obra: Son aquellos en los que se establezca la construcción, mantenimiento, instalación y, en general, para la realización de cualquier otro trabajo material sobre bienes inmuebles, cualquiera que sea la modalidad de ejecución y pago.

2. Contrato de Consultoría: Son aquellos que se refieren a los estudios necesarios para la ejecución de proyectos de inversión, estudios de diagnóstico, prefactibilidad o factibilidad para programas o proyectos específicos, así como a las asesorías técnicas de coordinación, control y supervisión.

3. Contrato de Prestación de Servicios: Son aquellos que desarrollan actividades relacionadas con la administración o funcionamiento de la entidad pública.

4. Contrato de Concesión: son aquellos que tienen el objeto de otorgar a una persona llamada concesionario la prestación, operación explotación, organización o gestión, total o parcial, de un servicio público, o la construcción, explotación o conservación total o parcial, de una obra o bien destinados al servicio o uso público, así como todas 
aquellas actividades necesarias para la adecuada prestación o funcionamiento de la obra o servicio.

La legislación española ${ }^{14}$ no desvaría de lo estipulado en el régimen jurídico Colombiano, ya que el legislador español ha dispuesto los siguientes casos en los cuales se puede presentar la APP, estos son:

1. La construcción, instalación o transformación de obras, equipos, sistemas, y productos o bienes complejos, así como su mantenimiento, actualización o renovación, su explotación o su gestión.

2. La gestión integral del mantenimiento de instalaciones complejas.

3. La fabricación de bienes y la prestación de servicios que incorporen tecnología específicamente desarrollada con el propósito de aportar soluciones más avanzadas y económicamente más ventajosas que las existentes en el mercado.

4. Otras prestaciones de servicios ligadas al desarrollo por la Administración del servicio público o actuación de interés general que le haya sido encomendado.

La legislación Uruguaya establece de igual manera los casos en los que esta colaboración Público-Privado se puede efectuar. Es por eso que en el artículo $3^{\circ}$ de la Ley No 18.786 decreta lo siguiente:

Los contratos de colaboración Público-Privada podrán celebrarse para el desarrollo de obras de infraestructura en los siguientes sectores de actividad:

1. Obras viales, ferroviarias, portuarias y aeroportuarias. Se considerarán incluidas dentro de las obras viales las de caminería rural ${ }^{15}$.

2. Obras de infraestructura energética, sin perjuicio de lo establecido en el Decreto-Ley No 14.694, de 1o de setiembre de 1977 (Ley Nacional de Electricidad) y Ley No 8.764, de 15 de octubre de 1931 (Creación de ANCAP).

${ }^{14}$ Artículo 11\%, Real Decreto Legislativo 3/2011, de 14 de noviembre, por el que se aprueba el texto refundido de la Ley de Contratos del Sector Público.

${ }^{15}$ Entiéndase como los caminos que se trazan entre veredas. 
3. Obras de disposición y tratamiento de residuos.

4. Obras de infraestructura social, incluyendo cárceles, centros de salud, centros de educación, viviendas de interés social, complejos deportivos y obras de mejoramiento, equipamiento y desarrollo urbano.

Este ámbito de aplicación es limitado teniendo como punto de referencia la legislación Colombiana, ya que estas APP solo surgen para ejecución de obras e infraestructura, y no para casos como el de la prestación de servicios, consultoría y los contratos de concesión.

\section{Disposiciones generales de las APP}

Solo se podrán realizar proyectos bajo esquemas de APP cuyo monto de inversión sea superior a seis mil $(6000)^{16} \mathrm{smmlv}$. Para los APP de iniciativa privada, los recursos públicos totales no podrán ser superiores al 20\% del presupuesto estimado de inversión del proyecto.

En los esquemas de asociación público-privadas podrán efectuarse aportes en especie por parte de las entidades territoriales.

Solo se podrán hacer adiciones y prórrogas después de transcurridos los tres primeros años de su vigencia y hasta cumplir las 3/4 partes del plazo inicialmente pactado. Las adiciones y prórrogas no podrán superar el 20\% del valor del contrato en las APP de iniciativa pública, ni el 20\% de los recursos públicos originalmente pactados en las APP de iniciativa privada.

El Plazo máximo es de $30^{17}$ años, incluidas prórrogas. Si de la estructuración financiera, y antes de la selección, resulta que el proyecto tendrá un plazo de ejecución superior al previsto en el inciso anterior, se requiere concepto previo favorable del $\mathrm{CONPES}^{18}$.

\footnotetext{
${ }^{16}$ Únicamente se podrán presentar proyectos de mínimo $\$ 3.400$ millones.

${ }^{17}$ Plazo superior solo cuando se cuente con concepto previo favorable del CONPES.

${ }^{18}$ Consejo Nacional de Política Económica y Social. Es la máxima autoridad nacional de planeación y se desempeña como organismo asesor del Gobierno en todos los aspectos relacionados con el desarrollo económico y social del país.
} 
Ya se analizó con anterioridad que la retribución que se le hace a los inversionistas y/o empresarios no se presenta por la construcción de una determinada infraestructura, sino por los servicios que preste dicha infraestructura.

\section{Tipos de APP}

Estos contratos convenidos entre una parte privada y una pública pueden surgir a la vida jurídica mediante dos formas, estas son:

Por Iniciativa Privada: Cuando son los inversionistas y/o los empresarios quienes deciden manifestar la voluntad de asociarse con el Estado para desarrollar alguna infraestructura o la prestación de algún servicio, según el ámbito de aplicación de la Ley 1508 de 2012, se pueden presentar dos escenarios, estos son:

I. Iniciativas Privadas en las cuales se asume la totalidad de los costos.

II. Iniciativas Privadas que requieren desembolsos de recursos públicos.

Los particulares podrán presentar ante la entidad estatal competente el proyecto de infraestructura pública o la prestación de sus servicios asociados, en donde la entidad pública los analizará y afectará como documentos de reserva que deberán ser confidenciales.

Los particulares deberán surtir un proceso de estructuración del proyecto, el cual cuenta con dos etapas, la primera de prefactibilidad y la segunda de factibilidad.

\section{Etapa de prefactibilidad en los proyectos de iniciativa privada}

En esta fase, el particular creador de la proposición de contrato de APP deberá de manera clara y precisa explicar el proyecto que se pretende dar a consideración, vinculando el diseño mínimo en etapa de prefactibilidad, construcción, operación, mantenimiento, organización y explotación del 
mismo, así como el análisis del alcance del proyecto, investigaciones de la demanda en etapa de prefactibilidad, el valor calculado para la ejecución del proyecto y su fuente de financiación.

Una vez presentada esta iniciativa, la entidad pública competente procederá a verificar la propuesta ${ }^{19}$, en donde debe establecer si el proyecto es de interés de la entidad competente, ponderar si es de carácter prioritario la ejecución del proyecto en estudio y finalmente concluir que dicha propuesta contiene los elementos que la permitan llegar a ser viable.

Cuando la entidad competente se remita a dar un concepto, está podrá establecer si acepta o rechaza la propuesta del particular, en caso de rechazar la propuesta ${ }^{20}$, el proyecto presentado se archiva; pero si el concepto es favorable, se le solicita al particular que presente el estudio de factibilidad, sin que ello genere compromiso de aceptación del proyecto u obligación de cualquier orden para el Estado.

\section{Etapa de factibilidad en los proyectos de iniciativa privada}

En esta etapa el particular debe presentarle datos reales de los datos que se estimaron en la etapa de prefactibilidad, es decir, se deberá incluir el modelo financiero de la obra o prestación de servicio asociado en el que se relacione el valor del proyecto, descripción detallada de las fases y el tiempo máximo de entrega de este, además de la justificación de este plazo. Se deberán de igual manera incluir la totalidad de estudios asociados a los riesgos del proyecto y los estudios correspondientes al impacto ambiental, social y económico.

Por último, se deberán anexar los estudios de factibilidad técnica, económica, ambiental, predial, financiera y jurídica del proyecto.

${ }^{19}$ La entidad competente tendrá un plazo legal de máximo tres meses para estudiar el proyecto presentado, el cual puede ser aceptado o rechazado.

${ }^{20}$ La entidad competente podrá rechazar la propuesta proponiendo argumentos como que el proyecto no es de interés público; o requiere más de un $20 \%$ de desembolso de recursos públicos; o que la entidad estatal ha adelantado la estructuración; o que existe un contrato de obra o concesión. 
En esta fase de factibilidad el creador del proyecto deberá incorporar todos los documentos relacionados con su capacidad jurídica, financiera o de potencial financiación, de experiencia en inversión o de estructuración de proyectos o para desarrollar el proyecto, el valor de la estructuración del proyecto y una minuta del contrato a celebrar que incluya entre otros, la propuesta de distribución de riesgos.

En esta etapa se deberá certificar que la información que entrega es veraz y es toda de la que dispone sobre el proyecto. Esta certificación deberá presentarse mediante una declaración juramentada.

No podrán presentarse iniciativas en los casos en que correspondan a un proyecto que, al momento de su presentación modifiquen contratos o concesiones existentes o para los cuales se haya adelantado su estructuración por parte de cualquier entidad estatal. Tampoco se aceptarán aquellas iniciativas que demanden garantías del Estado o desembolsos de recursos del Presupuesto General de la Nación, las entidades territoriales o de otros fondos públicos, superiores a los establecidos en la presente ley.

Cuando existan varios originadores para un mismo proyecto tendrá prioridad para su estudio el primero que radique una oferta ante la entidad estatal competente y que posteriormente sea declarada por esta como viable $^{21}$.

Una vez radicado el estudio de factibilidad, la entidad estatal competente tendrá un plazo de hasta seis meses para decidir sobre la propuesta presentada por el inversionista y/o empresario. Durante este término legal, la entidad evaluará el proyecto en conjunto y podrá acudir a terceros y autoridades competentes para que estos la asesoren y emitan un concepto. Este periodo de 6 meses podrá prorrogarse hasta 3 meses más, con el fin de profundizar investigaciones o solicitarle al particular creador de la propuesta estudios complementarios sobre el tema.

Una vez surtido este estudio, la entidad estatal competente procederá a emitir su concepto, ya sea favorable o de rechazo de la propuesta. Si la enti-

${ }^{21}$ Artículo 14 de la ley 1508 de 2012. 
dad estatal competente emite una decisión negativa ${ }^{22}$, deberá comunicarlo al particular por medio de acto administrativo debidamente motivado, y en todo caso, no se le reconocerá ningún valor por los estudios que haya previamente adelantado.

En caso de emitir un concepto favorable, la entidad le comunicará al creador de la propuesta y le indicará las condiciones para la aceptación de la propuesta, en donde se incluirá el monto que acepta como valor de los estudios realizados, teniendo como base de estimación los costos demostrados en tarifas de mercado para la estructuración del proyecto.

Notificada la aceptación de la propuesta, la entidad le presentará al creador del proyecto una serie de condiciones para que este las acepte o proponga alternativas, para que en un plazo no superior a dos meses contados desde el momento de la notificación, la administración se pronuncie al respecto. Si en este término la entidad pública no llega a un acuerdo con el particular, se entenderá que el proyecto ha sido negado.

Una vez que las partes contratantes hayan acordado las condiciones del proyecto, el paso a seguir es dirigirse a las tratativas que convinieron con anterioridad las partes para poder establecer si el proyecto requiere o no desembolso de dinero por parte de la entidad estatal competente.

Luego surgen dos escenarios en este tema específico de las Asociaciones Público-Privadas de iniciativa privada, estas son:

\section{Iniciativas privadas que requieren desembolsos de recursos públicos}

La entidad estatal abrirá un proceso de licitación con el fin de elegir al contratista que desarrollará y ejecutará la idea presentada por el creador del proyecto $^{23}$. En el proceso de selección se le otorgará una bonificación en la

${ }^{22}$ La propiedad sobre los estudios será del originador, pero la entidad pública tendrá la opción de adquirir aquellos insumos o estudios que le interesen o sean útiles para los propósitos de la función pública.

${ }^{23} \mathrm{Si}$ la entidad estatal que tiene a su cargo la selección del contratista no elige al creador de la propuesta, el adjudicatario tendrá que pagarle al proponente del proyecto el valor dispuesto por la entidad competente por concepto de estudios realizados para la estructuración del proyecto. 
calificación al creador de la propuesta. Esta bonificación oscilará entre un $3 \%$ y un $10 \%$ sobre su calificación inicial ${ }^{24}$.

La financiación que el Estado otorga para la ejecución de este proyecto no podrá superar el 20\% del total del presupuesto destinado para la obra ${ }^{25}$.

\section{Iniciativas privadas que no requieren desembolsos de recursos públicos}

Habiendo acordado las condiciones entre el creador de la propuesta y la entidad pública, y sin que el originador de la propuesta haya expresado que requiere desembolso de dineros públicos para la ejecución del proyecto, la entidad competente publicará el acuerdo, los estudios y la minuta del contrato con sus anexos en un término no inferior a un mes ni superior a seis meses en la página del "SECOP" 26.

Según la Ley 1508 de 2012, "en esta publicación la entidad estatal competente señalará las condiciones que deben cumplir eventuales interesados en participar en la ejecución del proyecto y anunciará su intención de adjudicar un contrato al proponente originador, en las condiciones acordadas, si no existieren otros interesados en la ejecución del proyecto.

Transcurrido el plazo de la publicación anteriormente referida, sin que ningún interesado distinto al originador del proyecto manifieste a la entidad estatal competente, su interés de ejecutarlo o cumpla las condiciones para participar en su ejecución, se podrá contratar con el originador, de manera directa en las condiciones pactadas".

Una vez publicado en el "SECOP" este proyecto que se pretende realizar, los terceros interesados podrán manifestar su voluntad en ejecutar este proyecto presentado una propuesta para su ejecución y, por supuesto, manteniendo la condición de no requerir recursos públicos; para ello de-

\footnotetext{
${ }^{24}$ La entidad se basará en criterios de tamaño y complejidad del proyecto para otorgarle al creador de la idea la bonificación. Esta bonificación tiene como finalidad compensar la actividad previa del particular.

${ }^{25} \mathrm{E}$ l contratista podrá solicitarle a la entidad estatal una adición en tiempo o en financiación. Esta no podrá ser superior al 20\% del tiempo y del monto de desembolso pactado en el contrato.

${ }^{26}$ Sistema Electrónico para la Contratación Pública.
} 
berá sustentar ante la entidad compete la iniciativa mediante una póliza de seguros, un aval bancario u otro medio autorizado por la ley. Además, deberá anexar los documentos en donde se acredite su capacidad jurídica, financiera, la experiencia en inversión o en estructuración de proyectos.

Ante esta situación, la entidad deberá abrir un proceso de selección abreviado con la metodología de menor cuantía con precalificación, para de esta manera seleccionar entre el creador de la propuesta y los proponentes al contratista que ejecutará el proyecto.

Si la entidad que tiene a su cargo la selección elige a un proponente distinto al creador del proyecto, este tendrá un término de hasta diez días para presentar otra oferta que mejore la del proponente mejor calificado. Si el originador del proyecto mejora la oferta, se le adjudicará el contrato, de lo contrario, se le adjudicará al mejor calificado, quien tendrá que retribuirle los costos de los estudios realizados para la estructuración del proyecto.

En cuanto a las adiciones contractuales, el contratista no le podrá solicitar adición de presupuesto a la entidad estatal, pues este contrato se ejecuta sin ningún desembolso del Estado, mientras que si se solicita una adición por concepto de tiempo, el contratista podrá conceder de hasta un 20\% de tiempo más del pactado en el contrato.

Por iniciativa pública: Cuando sea el Estado por razones de políticas públicas el encargado de ofertar, ya sea la construcción, el mantenimiento, renovación, gestión de una infraestructura o la prestación de un servicio, deberá indicar de manera pública la idea o proyecto conceptual en donde ya consten los estudios vigentes de carácter técnico, socioeconómico, a mbiental, predial, financieroy jurídico acordes con el proyecto, la descripción completa del proyecto incluyendo diseño, construcción, operación, mantenimiento, organización o explotación del mismo, el modelo financiero detallado y formulado que fundamente el valor del proyecto, descripción detallada de las fases y duración del proyecto y justificación del plazo del contrato ${ }^{27}$. Así mismo, la entidad deberá realizar un estudio de costo y beneficio del

${ }^{27}$ Se deberá igualmente haber desarrollado el modelo financiero estatal, pero este estará afectado de reserva legal. 
proyecto que se pretende desarrollar, incluyendo de igual manera el impacto social y las repercusiones que va a tener lo que se pretende desarrollar.

Además, antes de iniciar el proceso de selección de los proponentes, la entidad deberá incorporar una adecuada tipificación, estimación y asignación de los riesgos, posibles contingencias y la respectiva matriz de riesgos asociados al proyecto.

Por último, en esta propuesta que hace la entidad pública de asociarse con un privado, la financiación del proyecto podrá ser pública y/o privada, quiere esto decir, que la misma entidad estudiará el proyecto y decidirá si va a aportar fondos para la realización de esta obra, de ser así, será menester la solicitud de aval fiscal y aprobación de vigencias futuras ${ }^{28}$ ante la CONFIS $^{29}$.

En cuanto a la selección de los proponentes, la entidad deberá seleccionar al particular que presente la mejor propuesta ${ }^{30}$, valiéndose de un criterio objetivo y se efectuará mediante la selección del ofrecimiento más favorable a la entidad y a los fines que ella busca. Esta selección se realizará por medio de licitación pública y los recursos destinados para la infraestructura serán tanto públicos como privados.

La entidad deberá otorgar puntaje a cada proponente que se presente a la licitación, y los criterios de calificación serán, tal como se encuentran consagrados en la Ley 1508 de 2012, "La capacidad jurídica, la capacidad financiera o de financiación y la experiencia en inversión o en estructuración de proyectos, serán objeto de verificación documental de cumplimiento por parte de las entidades estatales como requisitos habilitantes para la participación en el proceso de selección y no otorgarán puntaje. En estos casos no se exigirá Registro Único de Proponentes y la presen-

${ }^{28}$ El artículo 6 del Decreto 1610 del 30 de julio de 2013. Por el cual se reglamenta el artículo 26 de la Ley 1508 de 2012, establece los requisitos para la presentación de esta solicitud.

${ }^{29}$ Consejo Superior de Política Fiscal.

${ }^{30}$ La oferta más favorable será aquella en la que el proponente logre cumplir con todas las exigencias propuestas en el pliego de condiciones, además de presentar la mejor propuesta en términos económicos o la mejor relación costo beneficio. 
tación de esta documentación será subsanable, en los términos establecidos en el Estatuto General de Contratación."

Una vez que el proponente haya sido elegido como ganador en la licitación pública, se le notificará y se ajustará fecha y hora para la celebración del contrato de asociación público-privado, en donde se estipularán de manera clara y precisa aspectos como el valor total que se tiene dispuesto para la realización de la obra, y el tiempo máximo para la entrega de esta, ya que si el contratista pretende solicitar una adición, ya sea de dinero o tiempo, la entidad deberá estudiar esta petición y solo podrá conceder hasta un $20 \%$ de tiempo o dinero del total que había sido acordado en el contrato.

\section{Referencias}

LeY I508 DE 20I2, Por la cual se establece el régimen jurídico de las Asociaciones Público-Privadas, se dictan normas orgánicas de presupuesto y se dictan otras disposiciones.

Decreto Reglamentario 1467, Por la cual se reglamenta la Ley 1508 de 2012.

LEY 80 DE I993, Por la cual se expide el Estatuto General de Contratación de la Administración Pública.

LEY II5O DE 2007, Por medio de la cual se introducen medidas para la eficiencia y la transparencia en la Ley 80 de 1993 y se dictan otras disposiciones generales sobre la contratación con Recursos Públicos.

Decreto I6Io Del 30 De JUlio De 20I3, por el cual se reglamenta el artículo 26 de la Ley 1508 de 2012, establece los requisitos para la presentación de esta solicitud.

Londoño Ayala (2005). Bloque de Constitucionalidad. Bogotá: Editorial Ediciones Nueva Jurídica.

Valles Ferrer y Collazo Antúnez (2008). Los contratos de colaboración público-privado. Sevilla: núm. 8. 
Libro verde de la Comisión Europea sobre las asociaciones PÚBLICO-PRIVADAS Y EL DERECHO COMUNITARIO EN MATERIA DE CONTRATACIÓN PÚBLICA, (2004).

Real Decreto Legislativo 3/20ir, de 14 de noviembre, por el que se aprueba el texto refundido de la Ley de Contratos del Sector Público.

Ley i 8.786. Contratos de Participación Público-Privada para la realización de obras de infraestructura y prestación de servicios conexos.

Decreto Legislativo No 1012, que aprueba la Ley Marco de Asociaciones Público-Privadas para la generación del empleo productivo.

García Capdepon (2005). El Contrato de Colaboración Público-Privado, núm. 3.

Decreto i6io Del 30 De Julio De 20I3, Por el cual se reglamenta el artículo 26 de la Ley 1508 de 2012, establece los requisitos para la presentación de esta solicitud. 


\section{EL MODELO ECONÓMICO CONSTITUCIONAL: UN ANÁLISIS JURSIPRUDENCIAL'}

Beliña Herrera Tapias², María Claudia Boneu Cantillo

\section{Resumen}

Los Estados dentro de sus fines conciben la satisfacción de las necesidades del ser humano así como el ejercicio de sus libertades. Para este fin, la economía juega un papel fundamental, razón por la cual históricamente las constituciones modernas consagran de manera tácita o expresa el modelo económico adoptado por dicho Estado que se circunscriben hoy por hoy en el campo de la economía liberal contrarrestado por un Estado Interventor, y principios de solidaridad dentro de un contexto democrático, que oriente la ejecución de un orden

1 Este documento es producto de los avances de investigación titulada "Un Estado de arte a la protección a los pequeños empresarios", desarrollada en el marco de la línea de investigación de asuntos mercantiles del grupo de investigación en Derecho, Política y Sociedad, de la Facultad de Derecho de la Universidad de La Costa.

2 Abogada, magíster en Derecho de la Universidad del Norte, doctorando en Derecho de la Universidad Externado de Colombia. Director del Centro de Investigaciones Socio Jurídicas, Universidad de la Costa, Investigador del Grupo de Investigaciones en Derecho, Política y Sociedad, de la Facultad de Derecho de la Universidad de La Costa (bherrera3@cuc.edu.co)

3 Estudiante de segundo semestre del programa de Derecho de la Universidad de la Costa, miembro del semillero de investigación adscrito al grupo de investigaciones en Derecho, Política y Sociedad, de la Facultad de Derecho de la Universidad de La Costa (mboneu1@cuc.edu.co). 
económico y social justo. Es así como se pretende con este estudio determinar el modelo económico constitucional colombiano, aplicando una metodología de corte jurídico con un enfoque cualitativo y del tipo descriptivo-analítico.

\section{Abstract}

States in their late conceive the satisfaction of human needs and the exercise of their freedoms, to which economics plays a key role, which is why modern constitutions enshrine historically so tacit or explicit economic model adopted by the State that are limited today in the field of liberal economy offset by a State Auditor, and principles of solidarity within a democratic context, to guide the implementation of a just economic and social order. Since then, as the aim of this study to determine the economic model Colombian constitutional court applying legal methodology with a qualitative approach and descriptive-analytical.

Palabras clave: Modelo económico, mercado, consumo, libertades, Constitución.

Key words: Economic model, market, consumption, liberties, Constitution.

\section{Introducción}

Los modelos económicos adoptados por los Estados históricamente se han fundamentado bajo criterios de libertad económica o de intervención estatal, en los que se identifica cuatro elementos básicos: (i) un orden fundamental, como una serie de derechos dirigidos a garantizar la seguridad económica de las personas consagradas en una Constitución y que posteriormente son desarrolladas mediante normas; (ii) los valores y los principios, que confluyen en conceptos de justicia social y ética; (iii) la dignificación de la persona, como elemento esencial e indispensable de un Estado social de derecho, y, por último, (iv) un mejor vivir, como razón de ser de la sociedad política y dentro de un contexto de bien común ${ }^{4}$.

${ }_{4}$ Entendiendo esta expresión de bien común en términos de Santo Tomás de Aquino, que la empleaba para referirse a los fines del Estado. 
Ahora bien estos elementos básicos, sumado al deber de cumplimiento por parte del Estado de los objetivos y prestaciones trazadas en la Carta Fundamental en pro de los titulares de la soberanía, nos señala que la esfera constitucional debe contener a su vez un marco de la actividad económica, en la que se reflejen una serie de derechos que permitan ajustar al Estado y a la vida social un modelo económico que permita el desarrollo de las actividades de producción, distribución, cambio y consumo en aras de la satisfacción de las necesidades humanas y el bien común.

La constitución cumple una de sus funciones capitales al configurar el escenario para el desarrollo del individuo, y de este modo se entiende que las libertades económicas quedan comprendidas dentro de las libertades políticas (BASSOLS, 1985, p. 21). Sin embargo, en Colombia no podríamos decir con certeza que existe un modelo económico constitucional expreso, sino que se colige de la interpretación de diferentes articulados de la Carta Superior, entre ellos los que se refieren a la propiedad, la libertad económica, la libre competencia, derecho a la legalidad de las contribuciones fiscales y parafiscales, a la prestación eficiente de los servicios públicos, al trabajo, a escoger profesión u oficio, a la libre asociación, y los derechos de los consumidores. Colombia en la vigencia de su Constitución de 1991 ha sufrido un proceso de transformación para articular a la norma fundamental con los cambios históricos, sociales y económicos que se han dado, y más aún con la imperiosa necesidad de establecer una estructura económica que se ajuste a la globalización de los mercados.

Por lo anteriormente expuesto es necesario hacer un análisis de las sentencias de la Corte Constitucional relacionadas entre sí, apartándonos del modelo de línea jurisprudencial propuesto por Diego López, para poder comprender en términos precisos la interpretación que la Alta Corte ha hecho sin que se desnaturalice la realidad que el concepto pretende contener en un momento dado con respecto a los principios estipulados en la carta de 1991 con el fin de dar respuesta al siguiente problema jurídico: ¿Cuál es la posición de la corte Constitucional respecto a determinar el modelo económico constitucional colombiano? 
Circunscrito el problema a este interrogante se buscaron las sentencias que aborden el problema desde la naturaleza y el contenido del modelo económico constitucional y luego a través de la metodología descriptivaanalítica y con un enfoque cualitativo comenzamos a revisar las sentencias que se consideraban más relevantes y que se mencionaban o referenciaban en problemáticas relativas al cuestionamiento aquí planteado y que resolvían el mismo problema en la Línea Jurisprudencial.

\section{Naturaleza del modelo económico constitucional}

\section{Sentencia T-505, agosto 28 de 1992:}

E1 Estado Colombiano ha encontrado en los principios rectores y en los valores consagrados en el preámbulo el fundamento necesario como Estado Social de Derecho, para la creación del régimen económico y de la hacienda pública estatuido en el Título XII de la Constitución y que a criterio de la Corte Constitucional, esté no podría aislarse del mismo fundamento, pues para su correcta interpretación y adecuación es menester enlazarlas, pues así lo ha dado a entender en esta sentencia:

"E1 Estado Social de Derecho, los principios de dignidad humana y de solidaridad social, el fin esencial de promover la prosperidad general y garantizar la efectividad de los derechos, deberes y principios constitucionales y el derecho fundamental a la igualdad de oportunidades, guían la interpretación constitucional económica e irradian todos los ámbitos de su regulación - propiedad privada, libertad de empresa, explotación de recursos, producción, distribución, utilización y consumo de bienes y servicios, régimen impositivo, presupuestal y de gasto público".

\section{Sentencia T-265 de Junio 2 de 1994:}

La Corte Constitucional ha dicho que las libertades económicas y el resto de libertades políticas no están sometidas a una misma regulación constitucional; la Constitución confiere un mayor valor a los derechos y libertades de la persona que a los derechos y libertades de contenido puramente patrimonial, ya que expresamente establece el dirigismo económico, es 
decir, consagra un mercado de bienes y servicios pero bajo la dirección del Estado, mientras que proscribe todo el dirigismo en materia política, ética o intelectual, por lo cual se puede decir que estatuye una libre circulación de ideas, por lo cual es lícito concluir que, en términos generales, las libertades de las persona y los derechos de participación ocupan en la Constitución Colombiana una posición preferente a las libertades puramente económicas.

\section{Sentencia C7I3 de 1998:}

E1 Estado Social de derecho, por definición, interviene en el entero proceso económico y social, lo que lleva a cabo no de manera puntual sino como función suya típica y constante, sin necesidad de que para hacerlo deba primero conceder ventajas a los particulares comprometidos con una determinada actividad social... Esta forma de Estado supera la visión de la economía y de la sociedad como esferas puramente fácticas externas al derecho. La consagración de un título de la Constitución, dedicado al régimen económico, pone de presente que en las normas constitucionales puedan encontrarse los criterios superiores llamados a orientar positivamente la vida económica y social, en modo alguno ajena al ordenamiento jurídico. Por consiguiente, los principios constitucionales en asuntos ligados a la economía, por establecer el marco para el ejercicio de la actividad económica, tienen carácter vinculante tanto para las autoridades públicas como para los particulares.

\section{Sentencia 830 de 2010:}

De la misma forma y con mayor especificidad en demanda de inconstitucionalidad contra los artículos 14, 15, 16 y 17 de la Ley 1335 de 2009, y como magistrado ponente el Dr. Luis Ernesto Vargas Silva, la Corte sostiene que: ya es un tópico suficientemente definido en la jurisprudencia constitucional que la Carta Política no ofrece una perspectiva neutra frente al modelo económico aceptable, sino que toma partido por una régimen de economía social de mercado, el cual tiene entre sus características definitorias (i) el reconocimiento constitucional de la libertad de empresa y la libre iniciativa privada, en tanto garantías indispensables para el logro del desarro- 
1lo económico y la prosperidad general. Para ello se impone una cláusula general compleja, la cual impide la exigencia de permisos previos o requisitos, al igual que la obligación estatal de promover la libre competencia y la libertad económica (Art. 333 C.P.); y (ii) la adscripción al Estado de la función de dirección general de la economía, tarea que se expresa en diversos planos, como son la verificación que la libre empresa se ejerza en los límites del bien común y la potestad de imponer limitaciones a esa libertad cuando lo exijan el interés social, el ambiente y el patrimonio cultural de la Nación (Art. 333 C.P.).

Sobre el particular, decisiones recientes de la Corte han contemplado que "el Estado Constitucional colombiano es incompatible tanto con un modelo del liberalismo económico clásico, en el que se proscribe la intervención estatal, como con modalidades de economía de planificación centralizada en las que el Estado es el único agente relevante del mercado y la producción de bienes y servicios es un monopolio público. En contrario, la Carta adopta un modelo de economía social de mercado, que reconoce a la empresa y, en general, a la iniciativa privada, la condición de motor de la economía, pero que limita razonable y proporcionalmente la libertad de empresa y la libre competencia económica, con el único propósito de cumplir fines constitucionalmente valiosos, destinados a la protección del interés general."

La dirección general de la economía, según lo planteado, se expresa de forma más amplia a partir de dos aspectos definidos. En primer término, corresponde al Estado ejercer las medidas dirigidas a que las empresas, habida cuenta su condición de expresiones de la propiedad privada, cumplan las obligaciones que se derivan de su función social y ecológica (Art. 58 C.P.) En segundo lugar, dicha dirección general involucra un grupo de competencias estatales referidas a la intervención, por mandato legal, en aras de regular la explotación de los recursos naturales, el uso del suelo, la producción, distribución, utilización y consumo de los bienes y servicios públicos y privados, con el fin de conseguir el mejoramiento de la calidad de vida de los habitantes, la distribución equitativa de las oportunidades y los beneficios del desarrollo y la preservación de un ambiente sano (Art. 334 C.P.). Asimismo, la norma constitucional prevé que la interven- 
ción estatal en la economía debe estar dirigida al aseguramiento del pleno empleo a los recursos humanos, el acceso efectivo a los bienes y servicios básicos por parte de las personas con menores ingresos, al igual que la promoción de la productividad y la competitividad y el desarrollo armónico de las regiones.

Estas previsiones constitucionales llevan a concluir que la delimitación conceptual de las libertades económicas se insertan en el equilibrio entre el reconocimiento de las garantías necesarias para el intercambio económico y la obligación estatal correlativa de intervenir en el mercado con el fin de (i) garantizar la supremacía del bien común, representado en los objetivos identificados por el Constituyente como propios de ese interés general; y (ii) corregir, en el marco de la protección de la igualdad de oportunidades, las imperfecciones de dicho mercado que se conformen como barrera para el acceso de los bienes y servicios de las personas de menores ingresos o en condiciones de debilidad manifiesta.

De la misma manera, las citadas disposiciones implican que la libertad de empresa y la libre iniciativa económica deban entenderse como garantías constitucionales, que carecen en sí mismos de connotación iusfundamental y, en tal sentido, incorporan en su definición las restricciones e intervenciones legítimas que la Carta Política impone, razón por la cual, como sucede con los demás derechos y garantías, no tienen carácter absoluto. Se trata, en cualquier caso, de libertades de raigambre constitucional que, merced su vinculación con la función social y ecológica de la propiedad y la dirección general de la economía por parte del Estado, son de naturaleza autorrestringida.

\section{Sentencia C-197 de 2012}

En una de sus más recientes decisiones la Corte precisó que: "La Constitución de 1991, especialmente al adoptar un modelo de Estado Social de Derecho, introdujo un modelo de economía social de mercado en el que, de un lado, se admite que la empresa es motor de desarrollo social (artículo 333 superior), y por esta vía, se reconoce la importancia de una economía de mercado y de la promoción de la actividad empresarial, pero por otro, 
se asigna al Estado no sólo la facultad sino la obligación de intervenir en la economía con el fin de remediar las fallas del mercado y promover el desarrollo económico y social (artículos 333, 334 y 335 constitucionales)”.

Para compatibilizar el régimen de libertades económicas con la cláusula de Estado social de derecho existen diversos mecanismos de intervención en la economía. El Estado tiene a su cargo la dirección general de la economía y, en esa medida, es no solo legítima su intervención en ciertos sectores, sino que en algunos eventos se hace necesaria con el fin de racionalizarla y conseguir el mejoramiento de la calidad de vida de la población, la distribución equitativa de oportunidades y los beneficios del desarrollo.

\section{Sentencia 263 del 8 de mayo de 2013}

Continuando la línea de pensamiento la corte en demanda de inconstitucionalidad contra el artículo 74 (parcial) de la Ley 142 de 1994, y con ponencia del magistrado Jorge Iván Palacio Palacio, precisó que para la realización efectiva de los cometidos estatales, "la Constitución acogió lo que se ha llamado un modelo de "economía social de mercado", que propende por armonizar el derecho a la propiedad privada y el reconocimiento de libertades económicas, como la libertad de empresa, la libre competencia yla iniciativa privada, con la intervención del Estado en la economía, de manera que confluyen "la mano invisible del mercado y el brazo visible del Estado". Advirtiendo además la Corte de manera muy puntual que "el papel del mercado como instrumento de asignación de recursos se concilia con el papel económico, político y social del Estado redistribuidor de recursos".

\section{Contenido de los principios del modelo económico constitucional}

\section{Sentencia C524, noviembre 16 de 1995}

Con ponencia del magistrado Carlos Gaviria Díaz, expresó la Corte que la libertad económica tal como se concibe en la Constitución de 1991, que quiso perfeccionar los instrumentos propios de la economía de mercado contiene a su vez la libertad de empresa y la libre competencia. Entendiendo como libertad de empresa "aquella libertad que se reconoce a los ciudadanos para 
afectar o destinar bienes de cualquier tipo (principalmente de capital) para la realización de actividades económicas para la producción e intercambio de bienes y servicios conforme a las pautas o modelos de organización típicas del mundo económico contemporáneo con vistas a la obtención de un beneficio o ganancia.

"El término empresa en este contexto parece por lo tanto cubrir dos aspectos, el inicial - la iniciativa o empresa como manifestación de la capacidad de emprender y acometer- y el instrumental -a través de una organización económica típica-, con abstracción de la forma jurídica (individual o societaria) y del Estatuto jurídico patrimonial y laboral"5.

La libertad de empresa le otorga a toda persona el derecho de ejercer y desarrollar una determinada actividad económica, de acuerdo con el modelo económico u organización institucional que, como ya se anotó, en nuestro país lo es la economía de mercado, libertad que al tenor del Estatuto Supremo no es absoluta, ya que el legislador está facultado para limitar o restringir su alcance cuando así lo exijan "el interés social, el ambiente y el patrimonio cultural de la Nación”. Además, no puede olvidarse que la empresa, como base del desarrollo, tiene una función social qué cumplir, la que implica ciertas obligaciones, y que la libre competencia económica "supone responsabilidades". Así las cosas, el Estado al regular la actividad económica cuenta con facultades para establecer límites o restricciones en aras de proteger la salubridad, la seguridad, el medio ambiente, el patrimonio cultural de la Nación, o por razones de interés general o bien común.

Con respecto a las limitaciones que según nuestro Estatuto Supremo se permite imponer a la libertad económica, ha dicho la Corte que "en el marco de un Estado Social de Derecho (CP art.1), fundado en la dirección general de la economía por parte del Estado (CP art.334), -tal libertad- está sometida a limitaciones potenciales más severas que las otras libertades y derechos constitucionales", pues como se dejó establecido en pronunciamiento anterior, "la Constitución confiere un mayor valor

5 CORTE CONSTITUCIONAL, Sentencia C-524, noviembre 16 de 1995. M.P. Carlos Gaviria Díaz. 
a los derechos y libertades de la persona que a los derechos y libertades de contenido puramente patrimonial, ya que expresamente establece el dirigismo económico, es decir, consagra un mercado de bienes y servicios pero bajo la dirección del Estado, mientras que proscribe todo dirigismo en materia política, ética o intelectual" y, en consecuencia, debe hacerse una interpretación más amplia de las facultades regulatorias del Estado en relación con las libertades económicas.

"Las limitaciones que la ley imponga a la actividad económica y a la libre competencia, habrán de ser serias y razonables. Se trata de dos derechos constitucionales que si bien son de configuración legal, describen un ámbito de actuación privada que, a partir de un cierto límite, no es susceptible de ser restringida adicionalmente, so pena de vulnerar sus núcleos esenciales. En este sentido, aparte de los fines propios de la intervención del Estado en la economía que se señalan en el artículo 334 de la C.P., la libertad de empresa, en el lenguaje de la Constitución Política la actividad económica y la iniciativa privada y la libre competencia, pueden ser delimitadas por la ley cuando así lo exijan el interés social, el ambiente y el patrimonio cultural de la Nación (CP art. 333). La seriedad y razonabilidad de las medidas legales limitativas de la actividad económica no la coartan. Por el contrario, la restricción legal persigue conciliar los intereses de la actividad económica libre con los que demanda la atención del bien común, en un sistema que en razón de sus fundamentos debe guiarse por el principio pro libertate. De ahí que, a título de garantía adicional, se disponga que "las leyes de intervención económica, previstas en el artículo 334 (...) deberán precisar sus fines y alcances y los límites a la libertad económica”.

\section{Sentencia C-624, noviembre 4 de 1998}

En esta providencia se amplía un poco la interpretación al considerar que la libertad económica ha sido concebida como "la facultad que tiene toda persona de realizar actos de carácter económico, según sus preferencias o habilidades con miras a crear, mantener o incrementar su patrimonio. Las actividades que conforman dicha libertad están sujetas a las 
limitaciones impuestas por la Constitución y las leyes, por razones de seguridad, salubridad, moralidad, utilidad pública o interés social”'.

"El artículo 333 de la Constitución acoge esos valores y propende entonces por el equilibrio entre el reconocimiento de la libertad económica y la protección del interés general, no sólo para lograr eficiencia y garantías para el sistema económico sino también debido a la incorporación de la fórmula del Estado Social de Derecho (CP art. 1\%), en virtud de la cual el poder público debe, entre otros fines, servir a la comunidad, promover la prosperidad general y garantizar los principios y deberes de la Constitución (C.P. art. 2). Esto explica que el artículo 333 superior establezca límites a la libertad económica, como el bien común y la propia función social de la empresa, e incorpore herramientas para que el Estado evite que se obstruya la libertad económica y el abuso de las personas o empresas de su posición dominante en el mercado. En el mismo sentido, el artículo 334 consagra la dirección estatal de la economía y fija los objetivos de su intervención, como son la racionalización de la economía, el mejoramiento de la calidad de vida de los habitantes, la distribución equitativa de las oportunidades $\mathrm{y}$ los beneficios del desarrollo y la preservación de un ambiente sano, los cuales van asociados, como se dijo, a los fundamentos mismos del Estado Social de Derecho, que irradia toda la normativa constitucional, a la cual no escapan los artículos relacionados con el régimen económico y con la actividad empresarial. Conforme a lo expuesto, es innegable que la libertad del individuo en materia económica, si bien está protegida por la Constitución, también se encuentra limitada por la prevalencia del interés general (artículo 1 C.P.), por las competencias de intervención y regulación a cargo del Estado (artículos 333, 334 y 335 de la C.P.) y por los principios de razonabilidad y proporcionalidad que esta Corte ha desarrollado. Por ello esta Corporación ha señalado que "la libre competencia económica no puede erigirse como una barrera infranqueable para la actividad de intervención del Estado, en ejercicio de su básica de dirección general de la economía". En ese mismo orden de ideas, así como la Carta ampara la libertad contractual, también le impone límites, que son los mismos de la

${ }^{6}$ CORTE CONSTITUCIONAL, Sentencia C-624, Noviembre 4 de 1998. M.P. Alejandro Martinez Caballero. 
libertad económica, y que pretenden que su ejercicio en el mercado no sea arbitrario ni desconozca principios constitucionales. Por ello, si bien la Constitución ha elevado la libertad empresa -y junto a ella la libertad de contratar-, a la calidad de principio rector de la actividad económica, el Legislador se encuentra facultado para establecer restricciones en este campo, pues la Constitución lo habilita para desarrollar y concretar la sanción o el límite frente a actividades que incumplan los parámetros básicos de conducta fijados por el Constituyente o que sean susceptibles de ello. Además, la Corte recuerda que es precisamente en el ámbito económico en donde el interés general prima con claridad sobre el interés particular (C.P. art. $1^{\circ}$ y 58), puesto que solo limitando, de manera razonable y proporcional, las libertades económicas, puede el Estado contribuir a realizar un "orden político, económico y social justo" (Preámbulo) y a hacer efectivos los llamados derechos humanos de segunda generación o derechos prestacionales de las personas".

\section{Conclusiones}

De los pronunciamientos e interpretaciones de la Corte Constitucional podemos concluir que la Carta de 1991 se ha fundamentado bajo principios económicos que ubican al Estado colombiano dentro de un modelo mixto que mezcla elementos de naturaleza liberal como son la libre iniciativa privada, la libertad económica y la libre competencia, con otros de mayor primacía que son clásicos del Estado social y de una economía dirigida. Postura que sin duda alguna nos coloca dentro del grupo de los países capitalistas, que en parte surte su desarrollo en el libre mercado y la libertad económica, principios a los que se ponen de colorario la intervención del Estado en la actividad económica. Sistema complejo en el que los diversos elementos que lo componen cumplen funciones distintas: por una parte, las libertades económicas clásicas ponen límites a la actuación de los poderes públicos; los valores y principios, de otro lado, además de ese papel cumplen la función de mandatos informadores de la actividad de las instancias estatales con competencias en la materia, al establecer el sentido de cómo deben utilizar los diversos instrumentos de intervención en la economía. 


\section{Referencias}

Acción de tutela (1992, agosto, 28). Sentencia T-505, (Corte Constitucional).

Acción de tutela (1994, junio, 2). Sentencia T-265, (Corte Constitucional).

Acción de inconstitucionalidad (1995, noviembre, 16). Sentencia C-524, (Corte Constitucional).

Acción de inconstitucionalidad (1998, noviembre, 4). Sentencia C-624, (Corte Constitucional).

Acción de inconstitucionalidad (1998, noviembre, 25). Sentencia C-713, (Corte Constitucional).

Acción de inconstitucionalidad (2010, octubre, 20). Sentencia C-830 (Corte Constitucional).

Acción de inconstitucionalidad (2012, marzo, 14). Sentencia C-197, (Corte Constitucional).

Acción de inconstitucionalidad (2013, mayo, 8). Sentencia C-263, (Corte Constitucional).

Bassols Coma, M. Constitución y Sistema Económico. Editorial Tecnos, Madrid, 1985, p. 21. 



\section{MIRADA JURISPRUDENCIAL DE LA PARTICIPACIÓN CIUDADANA EN LA POLÍTICA AMBIENTAL DE LA CONSTITUCIÓN POLÍTICA DE COLOMBIA DE I99|}

Roberto Jiménez González'

\section{Resumen}

El presente artículo es producto de una propuesta investigativa encaminada a determinar la importancia de la política ambiental basada en los lineamientos expresados por la Constitución Política de 1991, circunstancia que según el Tribunal Constitucional como intérprete auténtico del Estatuto Básico, tiene una relación inescindible con la vida digna, el derecho a la salud y a la participación ciudadana y otros aspectos de no menos valía, en el marco que caracteriza a nuestro medio jurídico como Estado social de derecho.

\section{Abstract}

This article is a proposed product research aimed at determining the importance of environmental policy based on the guidelines established by the Constitution of 1991, a fact that according to the Constitutional Court as authentic interpreter of the Basic Statute, has an inseparable relationship with a decent life, the right to health and public participation and other aspects of

1 Docente Investigador CUC Sergio Escalante Hernández, Estudiante Semillero de Investigación CUC. 
no less value, in the context that characterizes our legal environment and rule of law.

Palabras clave: Ambiente, derechos fundamentales, Constitución, Estado.

Keywords: Environment, rights, Constitution, State.

Se acepta al medio ambiente sano como un derecho del cual son titulares todas las personas, quienes a su vez se encuentran legitimadas para participar en las decisiones que puedan afectarlo y deben colaborar en su conservación. En suma, el medio ambiente es un bien jurídico constitucionalmente protegido cuya preservación debe procurarse no sólo a través de acciones aisladas del Estado, sino con la concurrencia de los individuos, la sociedad, la empresa y demás autoridades.

Corte Constitucional, Sentencia C-595 de 2010

Los problemas ambientales como la contaminación de cuerpos de agua como lagunas, ríos y mares, la progresiva desaparición por extinción de la fauna y la flora, la conversión y alteración irrespirable de la atmósfera de muchas grandes ciudades industrializadas y con polución, la disminución de la capa de ozono, el sobrecalentamiento global o efecto invernadero, los niveles excesivos de ruido, la deforestación masificada, el aumento de la erosión, la utilización de productos químicos, el manejo irresponsable de desechos industriales, la creciente lluvia ácida, los melones nucleares, el empobrecimiento de los bancos genéticos del planeta, etc., hacen parte integral de los asuntos que de forma integral merecen la atención responsable de todas las personas y los Estados. Máxime cuando en un país como $\mathrm{Co}_{-}$ lombia hay un patrimonio natural que es parte de lo que podríamos llamar una riqueza natural de carácter universal, nos pertenece y debemos presérvalo para las generaciones futuras, pues de dichas condiciones pende la calidad de vida de nuestros descendientes.

Para abordar la presente temática, que también es un problema para el derecho, resulta interesante lo planteado respecto a la definición de derecho por diversos autores: Fernando Hinestrosa en su texto Manual de Obligaciones (pp. 37 y 38) sostiene que "el derecho es un conjunto de normas 
o preceptos de conducta cuya existencia y efectividad son indispensables para la solidez y a armonía de las relaciones sociales. Dictados que surgen espontánea o deliberadamente de la vida en común y cuya vigencia está garantizada por el poder coercitivo del Estado. El derecho no es un fin en sí mismo, sino un medio emanado de la sociedad para mantener un equilibrio entre los hombres y proveer a la realización de un ideal de justicia”. Niklas Luhmann, citado por Habermas, Jürgen. Facticidad y Validez, (Madrid, Trotta, 2000, p. 264), expresa que "el derecho en sentido lato es el subsistema social que está especializado en la estabilización de las expectativas de comportamiento y el derecho en sentido estricto son todas aquellas interacciones que no sólo se orientan por el derecho (en el sentido lato), sino que también se enderezan, a producir nuevo derecho y a reproducirlo como derecho".

Immanuel Kant en su conocida obra Metafísica de las costumbres (Madrid, Tecnos, 2002, p. 39), apunta que "el derecho es el conjunto de condiciones bajo las cuales el arbitrio de uno puede conciliarse con el arbitrio del otro según una ley universal de la libertad".

El tratadista Luis Recances Shichet, Tratado General de la Filosofía del Derecho, dice que le derecho es el agente garantizador de la paz entre los hombres, del orden social, de la libertad de la persona, el defensor de sus posesiones y su trabajo, el órgano que ayuda a llevar a cabo grandes empresas y realizar importantes ideales, cuya puesta en práctica no sería posible sin intervención jurídica.

Para el reputado tratadista Eduardo García Máynez, en Introducción al Estudio del Derecho (México, 1999, KC300G37I5 USBI -X), sostiene que el derecho es "el conjunto de normas jurídicas imperativas y atributivas (esto implica que es derecho y obligaciones), con la finalidad de hacer, no hacer y tolerar".

Para Radbruch, G., en Filosofía del Derecho(Revista de Derecho Privado, Madrid 1933, p. 44), afirma que el derecho es un concepto cultural, o, lo que es lo mismo, un concepto de una realidad referida a valores, una realidad cuyo sentido consiste en estar al servicio de los valores. El derecho es la realidad que tiene el sentido de servir al valor jurídico, a la idea del derecho. 
Se deduce en todas las definiciones un fuerte relacional que no solo acoge a las personas sino también a su entorno o contexto, ello se macroamplifica no solo a la sociedad sino que también entra a condicionar el concepto de soberanía, según el cual la soberanía de los Estados involucra su autodeterminación e invariable defensa de intereses particulares,enmarcados dentro del límite de las respectivas fronteras políticas. No obstante, la degradación del ecosistema desborda estos límites llegando a ser una problemática de orden global requiriendo para su protección de la voluntad conjunta de todos los Estados, para enfrentar un futuro común. Se debe trabajar para propiciar un medio ambiente sano, desarrollando simultáneamente instrumentos de derecho interno y tratados internacionales, para afrontar y contrarrestar la degradación creciente y las amenazas de cambios climáticos y extinción de especies de fauna y flora que desmejoran la calidad de vida de los seres humanos y la responsabilidad que le debemos a las próximas generaciones en el cuidado del planeta.

Es un axioma que la mayor afectación al ambiente está generado en actividades que tienen causales antropogénicas, es decir, originadas de la actividad humana interesadas en la satisfacción de necesidades, eventos que siempre han existido, mas sin embargo, incrementados a partir de la industrialización de los procesos de producción y el aumento de la población mundial que aceleraron la pérdida de equilibrio y sostenibilidad del ecosistema generando un impacto negativo sobre los recursos naturales afectando la calidad de vida.

Uno de los aspectos innovadores de la Carta Política de 1991, y que va en concordancia con las modernas exigencias sociales y constitucionales, es la que hace referencia al tratamiento y conservación del patrimonio natural de la Nación y el medio ambiente, mediando una nueva conciencia que ha de reflejar claros compromisos tanto para el Estado como roles participativos para la comunidad en general, todo ello tendiente a la conservación y protección, del patrimonio natural y común.

El Medio ambiente o el ambiente ocupa en la Constitución política de 1991, un lugar relevante correspondiéndole al legislador, dentro de los límites que imponen los mandatos superiores, la configuración de cada uno de 
los mecanismos e instrumento para la efectiva gestión ambiental, desde los postulados del artículo sexto superior, se le asignan a las autoridades unas obligaciones que igualmente cobijan a la administración pública en general, incluidos los aspectos ambientales, políticas y acciones administrativas que parten de la planificación como elemento fundamental para una eficiente y efectiva concreción de sus metas o cometidos estatales. Bajo esta dinámica se incluye igualmente la temática ambiental que permite fijar parámetros y desarrollar actos puntuales para materializar el desarrollo social, protegiendo y mejorando el medio ambiente.

La conservación del medio ambiente constituye un objetivo transversal y básico que tiene la categoría de Principio Constitucional dentro de la actual estructura de nuestra Carta Política y del Estado social de derecho, en razón a que el ambiente se debe entender como el entorno vital del ser humano, imprescindible para su supervivencia y la de las generaciones futuras. El medio ambiente se encuentra tutelado por lo que en los pronunciamientos de la Corte Constitucional se ha denominado "Constitución Ecológica”, estructurada por el conjunto de disposiciones superiores que precisan los supuestos fácticos y jurídicos a partir de los cuales han de entenderse las relaciones de la comunidad con el entorno y que, en gran medida, propugnan por su conservación y protección ambiental.

De un lado, se registra el ambiente sano como una garantía de la cual son titulares todas las personas, sujetos que a su vez en su rol de ciudadanos están legitimados y llamados a participar en las decisiones que puedan afectarles y debiendo colaborar en la conservación del mismo. Por otro lado, a la organización estatal se le asignan según la Sentencia C-431/00 "los deberes correlativos de: 1) proteger su diversidad e integridad, 2) salvaguardar las riquezas naturales de la Nación, 3) conservar las áreas de especial importancia ecológica, 4) fomentar la educación ambiental, 5) planificar el manejo y aprovechamiento de los recursos naturales para así garantizar su desarrollo sostenible, su conservación, restauración o sustitución, 6) prevenir y controlar los factores de deterioro ambiental, 7) imponer las sanciones legales y exigir la reparación de los daños causados al ambiente y 8) cooperar con otras naciones en la protección de los ecosistemas situados en las zonas de frontera". 
La importancia de dicha interpretación concordante con las normas que de nuestra actual Constitución Política regulan la materia ambiental o ecológica, estriba en que dichas apreciaciones son concomitantes con el derecho a la vida cuya protección consagra el artículo 11 del mismo ordenamiento. El tribunal constitucional entiende que el medio ambiente es un derecho constitucional fundamental para la existencia y desarrollo del hombre y que el Estado, con la participación de la comunidad, está llamado a guardar por su conservación y debida protección, procurando políticas de desarrollo sostenible compatibles con la protección de las riquezas naturales de la Nación.

Colombia es una organización política personalista fundada en el respeto de la dignidad humana tal como se desprende taxativamente del artículo primero superior, la vigente Constitución en una característica pro hominie reconoce como principio del Estado en su artículo quinto la primacía de los derechos inalienables del ser humano.

El amparo del medio ambiente constituye un fin de la forma organizativa de Estado social de derecho. Según la Corte Constitucional, este concepto abarca aspectos relacionados con "el manejo, uso, aprovechamiento y conservación de los recursos naturales, el equilibrio de los ecosistemas, la protección de la diversidad biológica y cultural, el desarrollo sostenible, y la calidad de vida del hombre entendido como parte integrante de ese mundo natural, temas, que entre otros, han sido reconocidos ampliamente por nuestra Constitución Política en muchas normas que establecen claros mecanismos para proteger este derecho y exhortan a las autoridades a diseñar estrategias para su garantía y su desarrollo. En efecto, la protección del medio ambiente ha adquirido en nuestra Constitución un carácter de objetivo social, que al estar relacionado adicionalmente con la prestación eficiente de los servicios públicos, la salubridad y los recursos naturales como garantía de la supervivencia de las generaciones presentes y futuras, ha sido entendido como una prioridad dentro de los fines del Estado y como un reconocimiento al deber de mejorar la calidad de vida de los ciudadanos".

Colombia ostenta el reconocimiento mundial como uno de los centros biológicos de mayor biodiversidad -es el segundo país después de Brasil- 
y en esa misma vía por la responsabilidad que implica esta condición, es uno de los países que mayor interés debe tener respecto a los acuerdos internacionales en materia de biodiversidad, lo cual se evidencia en ventajas comparativas en aspectos críticos para las relaciones internacionales y la economía del siglo XXI: los recursos genéticos y la diversidad biológica. En muchos casos, esta ventaja es absoluta cuando se trata de especies endémicas, es decir únicas y no repetidas en lugar alguno del planeta: "Colombia es uno de los 13 países del planeta que concentran el 60 por ciento de la riqueza biológica. [...] Colombia congrega aproximadamente el 10 por ciento de todas las especies de fauna y flora del planeta, aunque representa menos del 1 por ciento de la superficie del planeta.

La anterior particularidad sitúa a nuestro país en los primeros lugares en diversidad de especies por unidad de área, y número total de especies. "Un tercio de las 55.000 especies de plantas de Colombia son endémicas, lo que se considera un recurso sin igual, equivalente al 10\% del total identificado (Bundestag, 1990). El país cuenta, por ejemplo, con el 15\% de las especies de orquídeas clasificadas mundialmente; con más de 2.000 plantas con propiedades medicinales identificadas y con una cifra muy alta de especies de frutos comerciales, silvestres o apenas localmente cultivados, que son comestibles o que pueden ser utilizados para el mejoramiento genético de especies cultivadas. "En el país se han clasificado 338 especies de mamíferos, lo que representa un $8 \%$ del total de las conocidas en el Planeta; el 15\% de las especies primates vivientes; 1.754 especies de aves (18\%); y casi 3.000 vertebrados terrestres". En tiempos modernos se ratifican las conclusiones de la Expedición Botánica dirigida en tiempos coloniales por José de Celestino Mutis.

Para manejar los aspectos ambientales es necesario tener en cuenta la precaución de los efectos que la actividad humana conlleva en especial aquellos hechos que impactan el ambiente, sin embargo, se reconoce que la contingencia de anticipación de los efectos en el ecosistema es limitada por estar basada en nuestro grado o estadio de conocimientos científicos, los cuales son imperfectos o variables. Ello se incrementa a largo plazo, dado que los efectos de la interacción de los efectos del ser humano sobre la naturaleza y viceversa no pueden ser determinados con total exactitud. 
Bajo la consideración de que la existencia de la especie humana estriba en gran medida en el respeto y guarda incondicional al medio ecológico, y de la defensa a inamovible del medio ambiente sano, como elemento insustituible que garantiza la subsistencia y vida digna, que sea compatible con un desarrollo sostenible, comprendido cómo las acciones que satisfacen las necesidades del ser humano en el presente, sin condicionar de forma negativa la capacidad de que las futuras generaciones puedan satisfacer sus propias necesidades. Las relaciones de producción para el crecimiento económico, la investigación tecnológica, son necesarias y bienvenidas, sin sacrificar el ecosistema; es más, deben propender al mejoramiento ambiental, de manera que se materialice la primacía del interés general y del bienestar comunitario, dentro de los referidos postulados constitucionales.

Las relaciones ecológicas se han venido internacionalizando, mediante una serie de instrumentos de derecho internacional, cuya finalidad es la de establecer políticas comunes en torno a una cooperación y alianza mundial, y entre los Estados, en pos de proteger la integridad del sistema ambiental, como medida para enfrentar la degradación ambiental. Ejemplo, aunque no suficiente, de estos esfuerzos son los convenios, tratados y demás instrumentos internacionales que se han signado con los referidos enunciados, entre los cuales cabe resaltar los siguientes: La Declaración de Estocolmo sobre el Medio Ambiente Humano, adoptada en la Conferencia de las Naciones Unidas sobre el Medio Ambiente Humano de 1972; La Carta Mundial de la Naturaleza de las Naciones Unidas de 1982; E1 Protocolo de Montreal, relativo a las sustancias que agotan la capa de ozono, adoptado en 1987; La Declaración de Río sobre el Medio Ambiente y Desarrollo de las Naciones Unidas de 1992; La Convención Marco de las Naciones Unidas sobre Cambio Climático de 1992; E1 Protocolo de Kyoto de las Naciones Unidas a la Convención Marco de las Naciones Unidas sobre Cambio Climático de 1997; La Cumbre del Milenio de las Naciones Unidas de 2000, además del Acuerdo de Copenhague de 2009.

No obstante esta política tiene sus puntos de no colaboración como debiera ser por parte de los países más industrializados, es decir, los máximos contaminadores, a saber, China, Estados Unidos y Rusia, quienes se rehúsan a incorporar algunos de los mencionados documentos 
en su legislación interna lo cual es plenamente censurable por la mayoría de los países y un contrasentido en los referidos esfuerzos ambientales conservacionistas. En este frente siguen adicionando esfuerzos. Hoy día escasos países consideran la política medioambiental, en sentido estricto, un asunto interno, debido al crecimiento de la conciencia sobre la protección del medio ambiente y la necesidad de una normatividad internacional que permita consolidar instrumentos bilaterales y multilaterales entre los Estados para colocar dicho propósito en común de manera exitosa, en los planos jurídico, social, político y económico.

La Corte Constitucional desde sus inicios viene sosteniendo que "el derecho al medio ambiente no se puede desligar del derecho a la vida y a la salud de las personas. De hecho, los factores perturbadores del medio ambiente causan daños irreparables en los seres humanos y si ello es así habrá que decirse que el medio ambiente es un derecho fundamental para la existencia de la humanidad. A esta conclusión se ha llegado cuando esta Corte ha evaluado la incidencia del medio ambiente en la vida de los hombres y por ello en sentencias anteriores de tutelas, se ha afirmado que el derecho al medio ambiente es un derecho fundamental" (Sentencia T-092 de 1993). Además, continua expresando la referida providencia de la Corte que "dados los efectos perturbadores y el riesgo que enfrenta el medio ambiente, que ocasionan daños irreparables e inciden nefastamente en la existencia de la humanidad", los derechos al ambiente sano se consideran de categoría fundamental por conexidad, al resultar enlazados indefectiblemente con los derechos individuales como la vida y la salud de los seres humanos.

Es tal la necesidad y relevancia de estos derechos que nuestro Tribunal Constitucional en su rol de intérprete auténtico de la vigente Carta Política ha clasificado los derechos medioambientales como derechos humanos de tercera generación o derechos de las generaciones que están por nacer. Según la Alta Corte, se le deben a toda la humanidad, es decir, en cuanto son protegidos por el interés universal, las generaciones futuras tienen derecho a que se le conserve el planeta desde hoy, en un ambiente adecuado a la dignidad del hombre como sujeto universal del derecho. 
Estos conceptos tienen la connotación de colectivos. Cierto es que la Constitución cataloga el medio ambiente en el conjunto de los denominados derechos colectivos en el artículo 79, conforme a los principios de universalidad y solidaridad, los cuales son objeto de amparo judicial directo por vía de las acciones populares establecidas como su garantía en el artículo 88 de la Constitución Política de 1991. Para la Asamblea Nacional Constituyente redactora de nuestro Estatuto Básico, se desprende que es responsabilidad del Estado custodiar y garantizar el derecho al saneamiento ambiental como un derecho de prestación efectiva -servicio comunitario- dicha obligación estatal va dirigida a la preservación, conservación y protección del medio ambiente.

Sin despreciar lo anterior, la acción de tutela es un mecanismo consagrado en el artículo 86 de la vigente Carta Política para salvaguardar derechos constitucionales fundamentales de carácter individual, sin embargo, es procedente por vía del mencionado amparo constitucional, cuando se trata de la probable transgresión o amenaza de un derecho relativo al ambiente sano, ya que en estas situaciones se está ante la presencia de la conexidad de los derechos colectivos y fundamentales vulnerados. Debido a lo anterior, es prevalente la acción de tutela sobre las acciones populares, tornándose así en el mecanismo judicial adecuado para la protección oportuna de los derechos amenazados.

Este derecho, ha dicho la Corte Constitucional, se concibe como un conjunto de condiciones básicas que rodean a la persona, permitiendo la supervivencia biológica e individual, lo que garantiza el desempeño normal y la mejora integral en el medio social. Por lo anterior, el Estado debe garantizar el derecho a un ambiente sano regulando esta situación con las medidas pertinentes a obtener el mejoramiento de la calidad de vida de la comunidad para el aseguramiento del bienestar general. El Estado como administrador de la sociedad ha de velar por que no se causen daños irreparables a la persona ni a su entorno. En tal hipótesis o eventualidad, dicho derecho constitucional amenazado o vulnerado es susceptible de ser amparado a través del ejercicio de la acción de tutela.

Un capítulo especial en esta temática es el constate riesgo ante actos que propenden por una actividad económica, como es el caso de la minería 
o el procesamiento de basuras, desechos o residuos, procesos que pueden generar contaminación del medio ambiente. Cuando dichas actividades se presenten la autoridades estatales han de tomar las medidas administrativas o de policía que resulten eficaces o suficientes para implantar controles que correspondan para mantener las condiciones básicas ambientales que coadyuven el derecho fundamental a la igualdad de aquellas personas que resultaren afectadas por las actuaciones contaminantes, evitándose una especie de trato discriminatorio con los demás miembros de la población en general.

La reglamentación ambiental contenida en diferentes estatutos, respeta la libertad de la actividad económica desarrollada por los particulares, no obstante ante la no existencia de derechos absolutos, a la misma libertad se aplican una serie de condicionamientos para su ejercicio con la finalidad de hacer compatible el desarrollo económico sostenido con la preservación de un ambiente sano. La referida normatividad supedita el interés privado representado en la actividad económica a la supremacía del interés público o social que exige la preservación del ambiente del cual penden otros derechos, de manera que el particular puede ejecutar su respectiva actividad económica enmarcada en los postulados que le señala la ley ambiental, los reglamentos y las actos administrativos expedidos de conformidad con el marco jurídico por las entidades correspondientes del manejo de los recursos naturales.

En esa interacción empresarial, las autoridades ambientales deben admitir el accionar de los particulares actividad económica legítima, cuando su ejercicio no comprometa los niveles topes de la contaminación, pues si los rebasa la primacía del bien común requerirá que se restrinja o se prohíba el ejercicio de la actividad empresarial del particular. Lo anterior, parte de la base reglamentaria y funcional que ostenta la autoridad pública, que debe velar por que se asegure el establecimiento y la efectividad de los respectivos controles técnicos, adecuados y eficaces de la contaminación, de forma que la actividad económica no se convierta en un peligro o amenaza para la vida humana o la preservación del patrimonio natural. 
Las autoridades administrativas, acorde a los postulados consagrados en los artículos $1^{\circ}, 2^{\circ}, 4^{\circ}, 5^{\circ}, 6^{\circ}$ y 209 de la Constitución Política, que respectivamente enmarcan la actuación estatal en el Estado social de derecho, la participación ciudadana, la solidaridad, la dignidad humana, la defensa y realización de los cometidos estatales entre los cuales se encuentra la prestación eficiente de los servicios públicos y la garantía de los derechos fundamentales, así como el principio de responsabilidad oficial y la primacía del interés general, deben actuar acorde al principio constitucional de la eficacia de la función administrativa que orienta a no esperar que los ciudadanos instauren acciones judiciales o administrativas para poner en marcha las medidas que hagan efectivos los derechos, incluidas las garantías relacionadas con el ambiente.

Tal es la importancia que amerita esta situación en nuestro medio que la Ley 99 de 1993 instituyó el Ministerio del Medio Ambiente, asignándole competencias en materia ambiental. Esta disposición ordenó que en las entidades territoriales a las autoridades locales les corresponde otorgar licencias ambientales, permisos, concesiones y autorizaciones cuya expedición no esté a cargo del Ministerio del Medio Ambiente según lo regulado por el artículo 55 de la norma antes referida. Por su cercanía a las comunidades, se dispuso que las autoridades municipales deben "efectuar el control de vertimientos y emisiones contaminantes, disposición de desechos sólidos y de residuos tóxicos y peligrosos, dictar las medidas de corrección o mitigación de daños ambientales y adelantar proyectos de saneamiento y descontaminación", para lo cual ostentan funciones y amplias atribuciones de policía administrativa.

Uno de los aspectos más importantes del ordenamiento constitucional que data de 1991 tiene que ver con la participación democrática que involucra una serie de múltiples aspectos del rol de la ciudadanía. En efecto, la participación ciudadana ha sido concebida como estructural para el sistema democrático e involucra en simultánea derechos y deberes; ello no solo es de aplicación exclusiva para la esfera electoral. Comprende también una serie numerosa y cualif icada de campos en los que las medidas u órdenes de la administración tienen relevancia para la 
ciudadanía en materias económicas, sociales, familiares y por supuesto ambientales, entre otras.

En ese orden de ideas, el derecho a la participación ciudadana evidencia y materializa la posibilidad que tienen los sujetos pertenecientes a una comunidad determinada titular de derechos y deberes que implican un ejercicio consciente y responsable. Es el resultado de los procesos evolutivos de la consecución de garantías frente al poder, según lo cual los ciudadanos puedan y deben ejercer adecuadamente su participación y control dentro del medio social político y económico con las herramientas que brinda la legalidad; en ello coincide Gloria Amparo Rodríguez y Lina Marcela Múñoz Ávila, en la obra La participación en la Gestión Ambiental. Un reto para el nuevo Milenio (Colección de textos de jurisprudencia, Ed. Universidad del Rosario, 2009).

El derecho a la participación se convierte en la prerrogativa que tienen los ciudadanos de conocer las propuestas de las entidades estatales que tengan relación directa o indirecta con ellos en cualquier manifestación o forma, e intervenir. Implica el derecho a informarse y estar al tanto sus intereses frente a los asuntos de su interés. Este concepto es aplicado totalmente en los temas ambientales. El derecho a la participación es aplicable en el ámbito particular como en el colectivo y su finalidad es influir en la toma de decisiones que de manera directa o indirecta, total o parcialmente, vinculan los intereses de los participantes.

En consonancia con lo anterior, la Constitución Política de 1991 es generosa en medios para garantizar el derecho a la participación, según el ámbito en el que se vaya presentar la intervención del Estado, desde las iniciativas populares en aspectos legislativos así como las consultas populares para legitimar la actuación de las autoridades políticas.

En la temática ambiental concretamente se exige la aplicación de medidas que garanticen la participación ciudadana antes de implementar los actos administrativos, dentro de los cuales se encuentran la audiencia pública ambiental, la consulta previa, la intervención en los procedimientos administrativos ambientales, las veedurías ciudadanas en asuntos ambien- 
tales, el derecho de petición, y la participación en los procesos de planificación ambiental, entre otros.

Lo anterior es aplicable en la toma de decisiones sobre megaproyectos que comporten impacto ambiental o compromiso de los recursos naturales, mecanismo expresamente reconocido por misma Constitución Política. En efecto, el artículo 79 Superior dice al respecto lo siguiente:

Todas las personas tienen derecho a gozar de un ambiente sano. La ley garantizará la participación de la comunidad en las decisiones que puedan afectarlo.

Es deber del Estado proteger la diversidad e integridad del ambiente, conservar las áreas de especial importancia ecológica y fomentar la educación para el logro de estos fines.

En el mismo sentido, la Declaración de Río sobre el Medio Ambiente y el Desarrollo hace mención a que siempre se deben garantizar mecanismos de participación cuando las comunidades puedan verse afectadas con la ejecución de un proyecto de infraestructura, teniendo en cuenta sus oficios e intereses sobre los recursos naturales que se verán intervenidos. Por ello y en virtud de la especial protección que se les debe, dicho documento expresa en su artículo 22:

Los pueblos indígenas y sus comunidades, así como otras comunidades locales, desempeñan un papel fundamental en la ordenación del medio ambiente y el desarrollo debido a sus conocimientos y prácticas tradicionales. Los Estados deberían reconocer y prestar el apoyo debido a su identidad, cultura e intereses y velar por que participaran efectivamente en el logro del desarrollo sostenible.

Lo relevante de garantizar medios eficientes para la participación de la ciudadanía y la comunidad en el diseño y ejecución de megaproyectos que intervienen recursos del medio ambiente, estriba en darle un blindaje jurídico, es decir, incorporarle el principio y derecho del debido proceso a esta garantía social que se fundamenta además en que el medio ambiente es un bien jurídico constitucionalmente que debe ser privilegiado, en el cual concurren varias dimensiones. Según ha dicho la Corte Constitucional 
"Es un principio que irradia todo el orden jurídico en cuanto se le atribuye al Estado la obligación de conservarlo y protegerlo", procurando que el desarrollo económico y social sea compatible con la protección de los recursos naturales, es un derecho constitucional de cada individuo como ciudadano y puede ser exigido por vía judiciales, es origen de la obligación a cargo del Estado de prestar saneamiento ambiental como un servicio público, como la salud, la educación y el agua, cuya protección garantiza al mismo tiempo la calidad de vida de los habitantes, y finalmente, es "una prioridad dentro de los fines del Estado, comprometiendo la responsabilidad directa del Estado al atribuirle los deberes de prevención y control de los factores de deterioro ambiental y la adopción de las medidas de protección” (Sentencia C-632 de 2011 M.P. Gabriel Eduardo Mendoza Martelo).

La participación comunitaria tiene como requisito sine qua non que debe preceder a la actuación administrativa que se propone ejecutar, pues es la mejor forma de armonizar o legitimar las obligaciones estatales, lo cual justifica la existencia de figuras como la licencia ambiental, la cual prevé durante el respectivo trámite una importante participación de la sociedad civil en aquellos hechos en que la actividad pueda ocasionar un daño considerable o irreversible al ambiente o que siendo el caso de las comunidades indígenas, para no variar su entorno y con ello la identidad cultural y existencia de las mismas.

Con fundamento en las anteriores consideraciones, en sentencias C-328 M.P. Eduardo Cifuentes Muñoz, C-593 de 1995 M.P. Fabio Morón Díaz, y C-535 de 1996 M.P. Alejandro Martínez Caballero, el Tribunal Constitucional analizó la participación ciudadana y comunitaria en los procesos de licenciamiento ambiental, y en general, en las decisiones y procesos de planificación de políticas que puedan afectar el ambiente sano. En la última providencia mencionada, la Corte Constitucional determinó que la participación comunitaria debe ser previa y es acorde con la Constitución Política; con ello se adquiere mayor preminencia en los eventos en que la decisión o intervención administrativa pueda ocasionar un deterioro considerable o irreversible al ecosistema, para concertar medidas de compensación y de reparación acordes con la naturaleza de la comunidad afectada. 
Por todo lo anterior, concluimos que por la relevancia del derecho al ambiente sano, su significado multivalorativo, polifuncional, su relación con el derecho a la vida y el rol en el presente y futuro de la humanidad, los tratados que versen sobre asuntos ambientales o ecosistémicos debidamente aprobadas mediante ley por Congreso de la República de Colombia deben hacer parte del bloque de constitucionalidad.

\section{Referencias}

Bakker, J. y Valderrama, M.L. Normatividad colombiana en materia de fauna silvestre. Latin América Environmental Society. Bogotá. 1999. Pp. 7-52.

Cites. Convención internacional sobre el tráfico de especies silvestres. República de Colombia Ministerio del Medio Ambiente.

Departamento Nacional de Planeación - Instituto de Investigación de Recursos Biológicos Alexander von Humboldt - Ministerio del Medio Ambiente. 1998. Colombia biodiversidad siglo XXI. Propuesta técnica para la formulación de un plan de acción nacional en biodiversidad. Santafé de Bogotá, Colombia.

González Ladrón De Guevara, Francisco. Ecosistema, Cultura y Desarrollo Sostenible. En: Ecos \# 1 .Ecofondo. Bogotá. 1994. P. 130156.

Instituto de Investigaciones de Recursos Biológicos Alexander Von Humboldt. Informe nacional sobre el estado de la biodiversidad. Colombia. Tomo I. Diversidad biológica. 1997.

Instituto de Investigaciones de Recursos Biológicos Alexander Von Нumboldt.. Colombia megadiversa, cinco años explorando la riqueza de un país megadiverso. 2000. Santafé de Bogotá.

Mast, Roderic; Rodríguez, José Vicente; Gómez, Raquel \& Mittermeier, Russell A. 1993. Prioridades para la conservación de la biodiversidad a nivel mundial, con especial énfasis en Colombia. Nuestra Diversidad Biológica. Fundación Alejandro Ángel Escobar CEREC. Bogotá, Colombia. 
República de Colombia - Ministerio del Medio Ambiente - Banco Mundial - Área metropolitana del valle de Aburrá - Programa de fortalecimiento institucional para la gestión a mbiental Urabá (FIGAU). Manual sobre procedimientos de decomisos de especies y productos de fauna y flora silvestres.

República de Colombia - Sistema Nacional Ambiental - Ministerio del Medio Ambiente. Gestión ambiental para la fauna silvestre en Colombia. Santafé de Bogotá. 1997.

\section{Legislación}

Ley 99 diciembre 22 de 1993.

Resolución 00208 agosto $1^{\circ}$ de 1994.

Resolución 00215 agosto 2 de 1994.

Decreto-Ley 2811 diciembre 18 de 1974.

Decreto 133927 de junio de 1994.

Decreto 18653 de agosto de 1994.

Decreto 17683 de agosto de 1994.

Decreto 19335 de agosto de 1994.

Decreto 1753 de agosto 3 de 1994.

Resolución 655 junio 21 de 1996

\section{CONSTITUCIÓN POLÍTICA DE COLOMBIA JURISPRUDENCIA CORTE CONSTITUCIONAL}

Sentencia T-092 de 1993 M.P. Simón Rodríguez Rodríguez.

Sentencia C-519 de 1994 M.P. Vladimiro Naranjo Mesa.

Sentencia C-332 de 1996 M.P. Julio Cesar Ortiz Gutiérrez.

Sentencia C-535 de 1996 M.P. Alejandro Martínez Caballero.

Sentencia C-401 de 1997 M.P. Hernando Herrera Vergara.

Sentencia T-550/00 M.P. Antonio Barrera Carbonell. 
Sentencia C-293 de 2002 M.P. Alfredo Beltrán Sierra.

Sentencia C-339 de 2002 M.P. Jaime Araujo Rentería.

Sentencia C-012 de 2004 M.P. Clara Inés Vargas Hernández.

Sentencia C-431/00 M.P. Iván H. Sierra Porto.

Sentencia T-851 de 2010 M.P. Humberto Antonio Sierra Porto.

Sentencia T-608/11 M.P. Juan Carlos Henao Pérez.

Sentencia T-348/12 M.P. Jorge Ignacio Pretelt Chaljub.

Sentencia C-632 de 2011 M.P. Gabriel Eduardo Mendosa Martelo. 


\section{LA INEJECUCIÓN DE LAS OBLIGACIONES POR LA CULPA DEL DEUDOR EN EL DERECHO ROMANO Y EN EL DERECHO CIVIL COLOMBIANO}

Mavelin Cantillo Gómez', Jassir Alvarez Estrada²

\section{Resumen}

La teoría de las obligaciones fue sin duda alguna uno de los más grandes aportes, entre los muchos que hizo, el derecho romano a toda la tradición jurídica occidental. El rigorismo y la minuciosidad de la casuística de los jurisconsultos romanos permitieron la elaboración de importantes figuras para la ciencia del derecho, que muchos siglos después conservan su primitivo fundamento y conservan vigencia en muchos de los ordenamientos jurídicos que han seguido la tradición romano-germánica del derecho. En las siguientes líneas intentaremos sustentar estas aseveraciones, limitándonos, por lo extenso del tema, al estudio del incumplimiento de las obligaciones producido por la culpa del deudor, haciendo una comparación del desarrollo del mismo en el derecho romano y en los postulados vigentes actualmente en la legislación colombiana.

1 Estudiante de segundo semestre de derecho Corporación Universidad de la Costa -CUC-, integrante del Semillero de Investigación en Derecho Privado "Joaquín Garrigues".

2 Abogado, Esp. En derecho mercantil, Mg. En derecho mercantil, docente investigador en Derecho Comercial de la Corporación Universidad de la Costa-CUC-. 


\section{Abstract}

The theory of obligations was without a doubt one of the most important contributions, among the many, who did the Roman law to the Western legal tradition. The rigor and thoroughness of the casuistry of the Roman jurists allowed the development of important figures for the science of law, preserved many centuries after its original foundation and still relevant in many of the jurisdictions that have followed the Roman-Germanic law tradition. In the following paper we will try to support these claims, limiting, by the extent of the subject, the study of the breach of duty caused by the fault of the debtor, making a comparison of the development of the figure in Roman law and the same subject currently in force in the Colombian civil code.

Palabras clave: Obligación, culpa, responsabilidad, incumplimiento.

Keywords: Obligation, fault, liability, breach.

\section{La inejecución de las obligaciones por culpa en Roma}

E1 efecto natural de las obligaciones es el cumplimiento de las mismas, si la obligación se ejecuta o realiza de forma completa y en la época en que el acreedor tiene derecho a exigirla, la deuda se extingue y el deudor se libera. Ya era así desde los tiempos de Roma, los romanos acuñaron la expresión solutio, para referirse al pago o cumplimiento del deudor; es más, en principio dicho término, que proviene del vocablo solvere, lo contrario a ligare, significaba ad omnem liberationem quo modo factam (Digesto, L. 46, 3, 54) la liberación del deudor, la extinción de la obligación, sin tener en cuenta la forma en que se verificaba.

Sin embargo, no siempre el cumplimiento es el destino final de las obligaciones. Puede resultar que tal cumplimiento fuera imposible objetivamente, y en tal caso se disuelve el vínculo -tema del que no trata este estudio-, o en otros casos puede que la inejecución o incumplimiento de la obligación tenga su origen en el comportamiento del deudor. Los juristas romanos estudiaron este segundo supuesto con prolijidad, aunque resulta difícil para nosotros conocer los límites dentro de los cuales se mueve histórica y dogmáticamente la responsabilidad del deudor. 
Ante todo, conviene advertir que la cuestión de la responsabilidad no es resuelta por los clásicos al dictado de un criterio preciso y uniforme, las muchas posibilidades de la casuística romana y las particularidades propias de cada negocio no permiten deducir un criterio rígido o definitivo, además está el problema de las alteraciones hechas por los compiladores justinianeos en los textos clásicos, y que generan todo tipo de cuestionamientos entre los doctos en la materia.

Lo cierto es que, en orden al desenvolvimiento histórico de la responsabilidad civil solo conocemos con bastante certeza el comienzo y el fin: la oposición originaria entre dolos y casus y el sistema articulado de la compilación justinianea (Giorgi, 1939). En lo restante, sobre todo en lo que toca al nacimiento y desarrollo del concepto de culpa, existe gran incertidumbre.

En los contratos primitivos no se conocía la noción de culpa, debido más que todo a lo estricto del formalismo. Si el deudor se había comprometido mediante una estipulación a entregar a un esclavo, si no lo entregaba no importaba la razón, debía ser condenado porque lo había prometido mediante el ritual sacramental.

La mayoría de las opiniones se inclinan por la probabilidad de que el concepto de culpa surgiera en el campo de los delitos, en el curso de la aplicación del damnum iniuria datum de la Ley Aquilia, y que de aquí pasara al campo contractual. Lo cierto es que los fragmentos relativos a dicha ley demuestran que los juristas examinaron el problema de la negligencia y distinguieron entre esta y el dolo, además el término ya era conocido en tiempos de Gayo (Digesto, L. 2, 202, 211).

Otros consideran que el elemento culpa aparece en los contratos el día que los romanos admitieron que el deudor no es siempre automáticamente responsable por la no ejecución, es decir junto con la aparición del caso fortuito y la fuerza mayor (Medellín, 1995). Si, por ejemplo, el esclavo prometido mediante stipulatio había perecido por fuerza mayor, el amo que debía entregarlo no era responsable, pero sí lo era cuando había perecido por su culpa. 
Ahora, ahondando más en la cuestión de la culpa y dejando de lado sus orígenes históricos, los juristas romanos distinguieron entre la infracción intencionada de la obligación contractual (dolo) y la inobservancia de un deber de prudencia que pesa sobre cada miembro de la comunidad ciudadana en la vida de relación; la culpa fue concebida como la desviación de un modelo ideal de conducta (Arangio-Ruiz, 1965). Este modelo, en opinión del profesor Bassurto Scarpetta, estaba representado unas veces por la bona fides, y otras, por la diligencia de un pater familia cuidadoso.

El contrato de buena fe, por su definición misma, exigía de parte del deudor una atención especial sobre la cosa que debía entregar, era preciso entonces que el deudor se comportará de la manera más correcta posible en aras al cumplimiento efectivo de la prestación debida. Toda conducta reprensible del deudor que provocara incumplimiento sin mediar su intención originaba una responsabilidad que se debía resarcir. Obedecía a impericia o negligencia, y era indiferente si consistía en acción-culpa in faciendo-o en una omisión -culpa in ommitendo- (Arangio-Ruiz, 1965). O sea, incurría en culpa quien dejaba de cumplir la prestación no por malevolencia o por una conducta fraudulenta, sino por la inobservancia de una determinada diligencia y cuidado, llegando a consecuencias que debía haber previsto y por consiguiente evitado.

Los romanos idearon también la clasificación de los grados de culpa, de acuerdo a la gravedad de la acción o descuido generador de la falta; esta clasificación tampoco está exenta de controversia y los diversos estudiosos del derecho romano suelen tener posiciones encontradas al respecto.

La idea más extendida es la de las dos clases de culpa de la compilación justinianea. Este sistema distinguía entre dos tipos de culpa:

a) Culpa Lata: lata culpa est nimia neglegentia, id est non intelligere quod omnes intellegunt, es decir, es culpa lata la negligencia excesiva, esto es, no entender lo que todos entienden (Digesto, L. 16, 212, 3). Es la negligencia extrema, en otras palabras: es la falta que no cometería un individuo de inteligencia mediocre (Di Francisci, 1959). Sabemos por la célebre sentencia de Ulpiano que los romanos la equiparaban al dolo -culpa lata dolo aequiparatur-(Digesto, L.16, 3, 32). 
Solo en los contratos que reportaban utilidad exclusiva al acreedor, el deudor incumplido respondía por la culpa grave (utilitas contrahetium). A este respecto, se citan como ejemplo los contratos de depósito y de donación (Digesto, L. 13, 6, 5).

b) Culpa Levis: Que implicaba la inobservancia de la diligencia propia de un hombre normal, el descuido ordinario o mediano (Ihering) que se determina comparándolo con la diligencia de un buen padre de familia. Los comentaristas derivaron de esta culpa leve dos subcategorías: la culpa in abstracto, en la que como elemento de referencia de la conducta del deudor se tomó como modelo la diligencia de un buen padre de familia; y la culpa in concreto, en la que al deudor se le imponía el cuidado que empleaba en sus propios negocios -iligentia quam suis rebus adbibere solet- (Digesto, L. 9, 2, 44).

Algunos autores mencionan una tercera clase de culpa a la que denominan levísima, este es por ejemplo el caso de Pothier y su doctrina de las tres culpas. Esta opinión no es compartida por opiniones bastante autorizadas, como la de Francisci y la de Biscardi. La diferencia tiene su origen en un texto de Ulpiano en el Digesto (L. 9, 2, 44), que se refiere a la Ley Aquilia -in lege Aquilia et levísima culpa venit-. Habría consistido en una falta de diligencia extremadamente cuidadosa, valga la paradoja, solo concebible en hombres bastante inteligentes. Al respecto, podemos destacar la opinión de Biscardi (1987): "El reconocimiento de 3 categorías de culpa no quiere decir que haya 3 especies de culpa, contrario a lo que dice Pothier, esta teoría no es romana. La culpa levísima solo existe en función de la Ley Aquilia. La jurisprudencia francesa ha reaccionado acertadamente, volviendo a aplicar -a propósito del art. 1137 del código francés-los principios romanos".

Al sistema justinianeo de la culpa se opone otro sistema basado en un texto-testigo, es decir, un texto que se encuentra por fuera de la compilación justinianea. Pertenece a Modestino, uno de los últimos jurisconsultos clásicos, y se halla en la collatio legum mosaicarum, según Modestino existe una diferencia básica que se debe establecer entre los deudores: 
a) Los que responden por el dolo: Algunos deudores estarían obligados únicamente en razón del dolo que hubieran cometido y en consecuencia carecen de dicha obligación si la cosa ha perecido, no por dolo de su parte, aunque sí por culpa (González de Cancino, 1996).

b) Los que responden por dolo y culpa in abstracto: Otros deudores debían responder del dolo y de la culpa, entendiéndose por esta última la noción de culpa in abstracto. ¿YY por qué están obligados de esta forma? Porque tienen intereses en el contrato o en el cuasicontrato.

c) Los que responden de la custodia: Desde la época clásica algunos autores estaban obligados en virtud de la custodia, es decir, en virtud de una supervigilancia especial de la cosa objeto del contrato (González de Cancino, 1996). Dicha custodia implicaba la responsabilidad por el caso fortuito (casus minores), pero la excluía para la fuerza mayor (casus majores). Ej.: el individuo está obligado en caso de muerte natural del esclavo, aún sin su culpa, pero no es responsable si ha perecido calcinado en un incendio (González de Cancino, 1996).

A hora bien, independientemente de la corriente a la que se quiera seguir surge una pregunta: ¿cuándo es responsable el deudor por su culpa?

En principio, todo deudor respondía de la culpa grave, que como ya se dijo era asimilada al dolo, y ninguna convención podía exonerarlo de esta responsabilidad (Petit, 1982), ya que aunque las normas sobre la responsabilidad eran de carácter dispositivo -y por consiguiente- podían ser agravadas o atenuadas por las partes, se le negaba toda eficacia al pactum de dolo non praestando.

En cuanto a la culpa leve, existían varios supuestos, pues era lógico que todos los deudores no estuvieran obligados al mismo grado de diligencia. Además se diferenciaba entre las obligaciones de buena fe y las de estricto derecho.

En las primeras, las de buena fe, se aplicaba esta máxima: "E1 deudor solo es responsable de culpa leve si saca ventaja de la obligación que lo vincula al acreedor" (Africano, L. 108, 12 , 30 D. sicut en contractibus fidei bonai....) de lo que se derivaban dos supuestos: 
- Si solo el acreedor estaba interesado, la responsabilidad del deudor se reducía al mínimo.

- Si también el deudor estaba interesado, estaba sujeto al máximo de responsabilidad. Debía responder por las consecuencias de la culpa leve, sin que haya que distinguir si el acreedor mismo estaba o no interesado en el negocio.

Por su parte, en las obligaciones sricto iuris, cuando la obligación tenía por objeto un hecho (facere), el deudor respondía de toda la culpa; solo el caso fortuito puede liberarle. El carácter de la obligación impedía cualquier tipo de atenuación de la responsabilidad (Digesto, L. 3, 137, 44). Cuando por el contrario el objeto de la obligación consistía en la datio de un cuerpo cierto, el deudor nunca era responsable de las acciones u omisiones cometidas, aun cuando estas originaran la pérdida de la cosa debida, puesto que había prometido dar, no hacer. Pero, si es por su hecho por lo que la cosa ha perecido y la datio se ha hecho imposible, es responsable ya haya dolo o culpa de su parte, como en el ejemplo del esclavo que muere por culpa de la medicina recibida de manos de su amo. Petit (1982) sobre esta materia cita un pasaje del jurista Paulus (Paulo, L. 91, pr., D., de verb. oblig., XLV, 1....an culpa quod ad stipulationis...).

Los efectos del incumplimiento eran también diversos: siempre que el deudor debía responder por los criterios antes anotados, la obligación subsistía - perpetuatio obligationis- (Digesto, L. 45, 1, 91, 3) y el acreedor podía pedir en juicio la cosa debida si esta no hubiere perecido. A falta del cumplimiento de la obligación, entonces la condena consistía en una suma de dinero a título de pena, cuyo monto determinaba el mismo acreedor bajo juramento o en su defecto el juez. El contenido de la condena dependía de la modalidad de fórmula de la que se tratará el caso subjudice y había que distinguir si se trataba de intentio certa o incerta. En los contratos de buena fe la condena tendía al quidquid dare facere oportet ex fide bona. Y comprendía tanto el daño en sí causado (daño emergente) y las ganancias frustradas (lucro cesante), pero solo si era demostrable que el daño sufrido por el acreedor derivaba del incumplimiento. 


\section{El régimen de la culpa en el derecho civil colombiano}

Apenas con un ligero análisis de nuestro Código Civil vigente en la actualidad salta a la vista la total analogía de las normas sobre la culpa con lo estipulado anteriormente por los juristas romanos. El art. 63 del C.C. establece el concepto y la clasificación de la culpa, e incurre en el error en mi opinión personal- de adoptar la clasificación tripartita de la culpa atribuida a la compilación justinianea, y que como vimos en su momento, es bastante criticada por los tratadistas de la materia, ya que es atribuida a las interpelaciones hechas por los comentaristas sobre el texto original, y donde predominan demasiados elementos subjetivos antes que los hechos propiamente establecidos que configurarían o no la culpa del deudor.

El texto del art. 63 es como sigue:

Art. 63: Clases de Culpa y Dolo: La ley distingue 3 especies de culpa o descuido.

Culpa Grave, negligencia grave, culpa lata, es la que consiste en no manear los negocios ajenos con aquel cuidado que aún las personas negligentes suelen emplear en sus negocios propios. Esta culpa en materia civil se asimila al dolo.

Culpa Leve, descuido leve, es la falta de aquella diligencia y cuidado que los hombres emplean ordinariamente en sus negocios propios. Culpa o descuido, sin otra clasificación, significa culpa leve...el que debe administrar un negocio como un buen padre de familia, es responsable de esta especie de culpa.

Culpa Levísima, descuido levísimo, es la falta de aquella esmerada diligencia que un hombre juicioso emplea en la administración de sus negocios importantes...

Es decir, el sistema que al respecto defienden entre otros Pothier y Desmoullins, pero que es en realidad inexacto. Por su parte la jurisprudencia nacional ha desarrollado en sus diferentes sentencias la explicación respecto del art. 63, haciendo aclaraciones al respecto sobre este punto en particular, la mayoría de las cuales también han sido esbozadas por algunos doctrinantes de la materia. 
Ha dicho por ejemplo nuestra Corte Suprema ${ }^{3}$ :

La culpa, pues, se presenta en 2 casos:

a) Cuando el autor conoce los daños que pueden ocasionarse con un acto suyo pero confió imprudentemente en evitarlos. Esta es la llamada culpa consciente y es desde luego la más grave.

b) Cuando el autor no prevé el daño que pueda causarse con un acto suyo, pero hubiera podido preverlo, dado su desarrollo mental y conocimiento de los hechos. Aquí se trata de negligencia o culpa inconsciente.

...el Art. 63 consagra 3 clases de culpa, con referencia al tipo de conducta de 3 categorías abstractas de personas: las negligentes, las ordinarias y las diligentes....para definir el tipo de culpa en el que se ha incurrido es necesario comparar la conducta del actor con la de estas categorías abstractas... circunstancia que excluye el examen de elementos objetivos de gran significación, que le quita a la noción de culpa civil su verdadero alcance científico, al contrario de la culpa penal, para la cual el C.P trae una definición más clara y precisa ${ }^{4}$.

Aparte del art. 63, la ley civil colombiana sigue manteniendo prácticamente la totalidad de las argumentaciones romanas al respecto, por ejemplo: la presunción de culpa por el incumplimiento contractual art. 1604 C.C., presunción legal que puede ser controvertida por el deudor, las obligaciones de custodia y cuidado de la cosa debida art. 1606 C.C., la posibilidad de que las partes puedan agravar o atenuar los diversos grados de culpa art. 1604 C.C., la imposibilidad de condonar la culpa grave equiparable al dolo (solo se puede condonar la pretérita) art. 1522 C.C. y las normas que regulan los efectos del incumplimiento por culpa art. 1613 C.C. daño emergente y lucro cesante, art. 1614 y art. 1615 del Código Civil.

${ }^{3}$ Corte Suprema: Sentencia, marzo 28 de 1957.

4 Ibid. Subrayado fuera del texto original. 


\section{Referencias}

Arangio-Ruiz, V., Las Acciones en el Derecho Privado Romano, Ed. FCA, México, 1965.

Digesto, Institutas, Derecho Romano, Universidad del Norte, Barranquilla, 1989.

Di Francisci, P., Derecho Romano, Ed. ESA, Bogotá, 1959.

D’Ors, A., Derecho Romano Privado, Ed. Universidad de Navarra, EUNSA, Pamplona, 1977.

Giorgi, J., Teoría de las Obligaciones en Roma, Ed. Depalma, Bs. As, 1939.

Gayo, Las Institutas, Ed. Librería Jurídica la Plata, La Plata, 1985. González De Cancino, E., Manual de Derecho Romano, Ed. U. Externado, Bogotá, 1990.

Medellín, C., Lecciones de Derecho Romano, Ed. Temis, Bogotá, 1996.

Petit, E., Tratado de Derecho Romano, Ed. Abeledo-Perrot, Bs. As, 1982. 


\section{FORTALECIMIENTO LOCAL DE LOS DERECHOS DE LOS CONSUMIDORES: PROMOCIÓN Y PROTECCIÓN DE LOS DERECHOS DEL CONSUMIDOR, EN LA CIUDAD DE SANTA MARTA (COLOMBIA), EN EL MARCO DEL NUEVO ESTATUTO DEL CONSUMIDOR}

Edimer Leonardo Latorre Iglesias', Cindy Caterine Díaz Areiza ${ }^{2}$

\section{Resumen}

El nuevo Estatuto del Consumidor (Ley 1480 de 2011) se expide en Colombia para lograr unas relaciones más equitativas y dignas en la cadena de consumo, teniendo en cuenta las asimetrías del mercado. El objetivo general de la ponencia es analizar la forma como se pueden orientar y fortalecer las capacidades locales de los consumidores y colectivos de consumidores en la ciudad de Santa Marta, a través del acompañamiento a las asociaciones de consumidores, servicios jurídicos y articulación entre la Universidad Sergio Arboleda Seccional Santa Marta,

1 El autor Edimer Leonardo Latorre Iglesias es doctor en Sociología Jurídica e Instituciones Políticas. Docente investigador de la Escuela de Derecho de la Universidad Sergio Arboleda Seccional Santa Marta. Dirige el grupo de investigación Joaquín Aarón Manjarrés de la misma Universidad.

2 Cindy Caterine Díaz Areiza es abogada especialista en Derecho Penal y Criminología, especialista en Derecho Constitucional. Actualmente es candidata a magíster en Teoría del Derecho de la Universidad Externado de Colombia y directora del Centro de Investigación Sociojurídica de la Corporación Universitaria del Caribe CECAR. Contacto: cindy.diaza@cecar.edu.co 
entes territoriales, Confederación Colombiana de Consumidores y la Red Nacional de Ligas Colombianas de Consumidores de la Superintendencia de Industria y Comercio, para empoderar al ciudadano y a sus asociaciones en el manejo y dominio de la política nacional de consumo.

Palabras clave: protección del consumidor, regionalización, política pública, asociaciones de consumidores, ligas universitarias de consumidores.

\section{Summary}

The new Consumer Statute (Law 1480 of 2011) is issued in Colombia to achieve more equitable and humane conditions in the consumption chain relations, taking into account the asymmetries in the market. The overall objective of the paper is to analyze the way they can guide and strengthen local capacities of consumers and consumer groups in the city of Santa Marta, through support to consumer associations, legal services and coordination between the University Sergio Arboleda Sectional Santa Marta, local authorities, Colombian Confederation of Consumers and the National Network of Colombian League of Consumers of the Superintendency of industry and Commerce, to empower citizens and their associations in the management and control of national consumer policy.

Keywords: Consumer protection, regionalization, public policy, consumer associations, leagues university of consumers.

Contexto problematizador: el rol del consumidor en los estados reguladores

El paso del estado del bienestar a un estado regulador de riesgos está enmarcado en las revoluciones que han logrado permear la vida social: fordismo y toyotismo. Estas dos formas de hacer empresa, implican el paso de la gran cadena de montaje (fordismo) a grandes sistemas especializados en función del cliente (toyotismo). Este paso, del estado de bienestar al estado regulador de riesgos y del fordismo al toyotismo, gira en torno a una gran construcción societal: la sociedad de consumo. 
Las grandes fuerzas globales que se han desarrollado en función de la sociedad de consumo hacen que vivamos una era donde el consumismo es la clave y donde todo, absolutamente todo, podría ser comprado. La colonización de las leyes del mercado hacen que estemos padeciendo como nunca el problema de pasar de una economía de mercado a una sociedad de mercado, donde las reglas del mercado colonizan la interacciones sociales (Sandel, 2011). Este fenómeno de hiperconsumismo o capitalismo cultural (Žižek, 2013) hace que los consumidores sean el eslabón más débil ante el cada vez más poderoso sistema global empresarial que se desarrolla en el capitalismo actual, de ahí la importancia de revisar los derechos de los consumidores en el marco de este fenómeno global que cada vez se materializa en el ámbito de lo local.

La Constitución colombiana de 1991 no ha sido ajena a entender las asimetrías del mercado y su afectación a los consumidores; en su artículo 78 , dispone que el legislador a través de sus normas debe ejercer el control de calidad de bienes y servicios ofrecidos a la comunidad, así como darle un realce significativo a la importancia de la información que se le debe suministrar a los consumidores durante su comercialización. En consonancia con este imperativo, el legislador ha expedido una normatividad tendiente a proteger los derechos de los consumidores, como es el nuevo Estatuto del Consumidor o Ley 1480 de 2011.

Para que las normas puedan ser efectivas se necesita una sociedad organizada alrededor de estas. Lo mismo ocurre con este nuevo estatuto. Se hace vital el papel dinámico y real en el mundo de lo fáctico de las instituciones que tienen el rol de velar por un cumplimiento efectivo y oportuno de la normatividad, así como una ciudadanía organizada y legalmente constituida que, a través del activismo judicial, logre un protagonismo mediante su participación.

El nuevo Estatuto del Consumidor gira en torno a tres pilares básicos: 1) la necesidad de reivindicar como derecho la información oportuna en el momento de la compra; 2) la necesidad de educar al consumidor sobre los derechos que posee antes de la compra, durante y después de esta; y 3) la necesidad de que los ciudadanos se organicen para constituir asociaciones 
que posibiliten una defensa mancomunada de sus derechos. Ante la ausencia de una visibilización de las acciones propias de las ligas de consumo y ante la necesidad actual de generar el empoderamiento ciudadano, se hace necesario asumir un proceso que posibilite la reinvención de estas organizaciones.

En la ciudad de Santa Marta, después de una exploración inicial sobre la temática, se evidencia que existe una liga distrital de consumidores, pero la ausencia de unos canales efectivos de comunicación y de una visibilización de su impacto es notoria. No maneja redes sociales que permitan una canalización efectiva de las denuncias de los consumidores, no existe una visibilización en medios masivos de comunicación, solo existen dieciocho entradas para las palabras claves (liga distrital de consumidores en Santa Marta), y al referirse a la temática en metabuscadores aparece un liderazgo mesiánico evidenciado en su director. No fue posible evidenciar procesos de construcción y empoderamiento educativo de los ciudadanos del Distrito de Santa Marta. De ahí que redefinir procesos que giren en torno a organizar y empoderar comunidades para hacer valer los derechos sean pertinentes y necesarios en el contexto local de la ciudad de Santa Marta.

Teniendo en cuenta lo anterior se plantea la siguiente pregunta que guía la investigación: ¿qué tipo de relaciones existen en el entramado local de la ciudad de Santa Marta en torno a los entes territoriales, locales y de las asociaciones civiles de consumidores, relativas a la protección y promoción de los derechos de los consumidores, en el marco de la política pública nacional de consumo?

\section{Aproximación desde lo normativo: un derecho del consumo para una sociedad de consumo}

Plantear una definición de derecho del consumo y, en consecuencia, de derecho de los consumidores no ha sido una tarea fácil, teniendo en cuenta la desprotección que siempre ha tenido el consumidor como la parte más débil en la cadena de consumo. Hoy tenemos definiciones que lo ilustran, por ejemplo, Juan Carlos Villalba (2009) expresa que el derecho del consumidor no busca inclinarse del todo hacia el consumidor, su finalidad es 
corregir los desequilibrios que se presentan en la relación de consumo, suministrándole herramientas de protección al consumidor, siendo innegables las diferentes posiciones que ostentan el consumidor y el productor en la dinámica del libre mercado.

En cuanto a su autonomía como área del derecho, autores como Witker y Valera (2003) argumentan la imposibilidad de considerar al derecho del consumo como ciencia autónoma por carecer de una parte general que la sustente. En contrario sentido, Villalba (2009) considera el derecho del consumo como una disciplina autónoma por erigirse como un microsistema de reglas y principios, que solo regula algunas materias o situaciones en que se considera que eventualmente el consumidor puede verse en desventaja.

En otras palabras, el conjunto normativo que enmarca la protección del consumidor dentro de la relación del consumo, en su sentido amplio, constituye la disciplina del derecho del consumidor.

En torno a esta materia, en Colombia tenemos las siguientes normativas: - Constitución Política de 1991

- Decretos 2152 y 2153 de 1992 (hoy parcialmente derogados)

- Decreto 2269 de 1993

- Ley 100 de 1993

- Ley 472 de 1994

- Ley 256 de 1996

- Ley 1328 de 2009 (establece claras disposiciones en materia del consumidor financiero)

- Ley 1480 de 2011, nuevo Estatuto del Consumidor

La Corte Suprema de Justicia colombiana, en providencia de fecha del 30 de abril de 2009, definió la relación de consumo como aquella que "constituye una particular categoría que surge entre quienes se dedican profesionalmente a elaborar o proveer bienes o prestar servicios con quien 
los adquiere con el fin de consumirlos”. En esta relación, se constituyen en sujetos el consumidor, el productor, el proveedor, el expendedor y todo aquel que intervenga en la cadena de comercialización.

Visto lo anterior, la relación de consumo no debe entenderse como un vínculo contractual, porque cobija otras relaciones de tipo extracontractual, ya que en esta relación lo central no es el acto de contratar, sino el de consumir. En este mismo sentido lo explica Villalba (2009, 92):

"Sin embargo, debe advertirse que la relación de consumo no es de naturaleza exclusivamente contractual. Para la doctrina Argentina, la relación de consumo cobija vínculos jurídicos extracontractuales. La relación de consumo es más amplia que la noción de contrato, que solo incluye al consumidor individual, mientras que la primera cobija al consumidor o usuario individual o colectivamente considerados".

En este orden de ideas, se puede afirmar que la relación de consumo es un vínculo jurídico obligacional de carácter especial propio de las relaciones económicas capitalistas de la vida moderna, que se puede configurar en las fases precontractual, contractual o extracontractual, y que además rompe con los esquemas tradicionales del derecho privado.

\section{Propuesta metodológica y posibles hallazgos}

Los posibles resultados se darían a partir de un análisis de derecho comparado y de su funcionamiento en realidades locales similares pero con problemas disímiles. Esto implica analizar contextos propios de la ciudad de Santa Marta, la ciudad de Cartagena y la ciudad de Sincelejo. A pesar de ser ciudades enmarcadas en la cultura caribe, sus formas de asumir la defensa de los derechos de los consumidores es totalmente diferente.

La metodología propuesta, que consiste en la realización de mapas de actores sociales, empoderamiento ciudadano y organización efectiva como resultados a largo plazo, hace que la investigación muestre pertinencia con el contexto social e incida en la transformación y solución de una problemática real. 
Se busca desde el escenario mismo de los consultorios jurídicos propiciar sistemas organizacionales efectivos, que logren empoderar a los actores sociales y ligas de consumidores para que se fortalezcan jurídicamente y se apalanquen organizacionalmente (empresas spin off). De igual forma, con el proyecto se pretende empoderar a la ciudadanía en la defensa de sus derechos como consumidores y establecer canales efectivos entre las organizaciones de defensa de los derechos de los consumidores y las instituciones encargadas de regular dichos derechos.

Así las cosas el proyecto que se propone es pertinente ya que busca empoderamiento ciudadano y organización efectiva como resultados a largo plazo, e interacción de actores con instituciones; por ello, además de solucionar una necesidad real del Estado alrededor de la política pública de consumo, hace que la propuesta de investigación muestre pertinencia con el contexto social e incida en la transformación y solución de una problemática real.

\section{Objetivo general}

Promover las capacidades locales de los ciudadanos consumidores y colectivos de consumidores en la ciudad de Santa Marta, a través del fortalecimiento y promoción de sus derechos, a partir de la educación, protección, garantía y defensa en el ejercicio de sus derechos económicos como ciudadanos, para contribuir al desarrollo y sostenibilidad de la política pública de consumo en el marco de las normas rectoras establecidas en el nuevo Estatuto del Consumidor en el periodo 2015-2016.

\section{Objetivos específicos}

1. Promover el fortalecimiento de las asociaciones de ciudadanos consumidores (asociaciones y ligas universitarias) en la ciudad de Santa Marta.

2. Promover en Santa Marta la articulación de las autoridades nacionales, territoriales y locales en materia de protección, garantía y defensa de los consumidores. 
3. Diseñar un modelo de atención jurídico integral para los consumidores quejosos a partir de las plataformas tecnológicas integradas desde el consultorio jurídico.

4. Caracterizar las reclamaciones de los consumidores para determinar pautas de comportamiento de los oferentes de bienes y servicios y de los consumidores en el periodo de duración del proyecto.

\section{Conclusiones}

Del proyecto para la promoción y el fortalecimiento de las organizaciones de consumidores se espera lo siguiente:

1. Nueva metodología de regionalización de la política pública de consumo en la estrategia de regionalización de la Superintendencia de Industria y Comercio a partir de la articulación de Estado, academia y sociedad civil.

2. Apertura para nuevos espacios de gestión de la proyección social universitaria desde la solución de una necesidad para la población de consumidores en el territorio de la ciudad.

3. Generación de un núcleo de estudios teórico-práctico sobre la práctica del derecho del consumo y sobre la praxis cotidiana de los consumidores desde los colectivos de consumidores y desde las ligas universitarias de consumidores.

4. Generación de un protocolo de procedimientos para los comités regionales y locales de consumidores.

5. Diseño de nuevo software para la atención de usuarios quejosos que puede ser usado y replicado para caracterizar patrones de comportamientos de consumidores y de productores.

6. Generación de capital social y confianza en los ciudadanos en sus instituciones, desde la manera como se direcciona una política pública al ciudadano y a los territorios. 
7. Contribución en la dinámica local de la cadena de consumo a partir de ciudadanos informados y educados como consumidores.

\section{Bibliografía}

Barrera de Hurtado, Jacqueline (2010). Metodología de la investigación: guía para la comprensión holística de la ciencia. Venezuela: Quirón.

Bernal, César Augusto (2010). Metodología de la investigación.Colombia: Pearson, 2010.

Gusdorf, G. (1998). Pasado, presente y futuro de la investigación interdisciplinaria. Washington: Unesco.

Morin, Edgar (1994). Introducción al pensamiento complejo. Barcelona: Gedisa.

Rossati, Horacio; et al (1994). La reforma de la constitución. Argentina: Editorial Rubinzal.

SAndel, Michael (2011). Justicia ¿̈hacemos lo que debemos? Barcelona: debate.

Villalba, Juan Carlos (2009). Aspectos introductorios al derecho del consumo. En Prolegómenos - Derechos y Valores. 2009. Vol. XII No. 24.

Witker, Jorge; Valera, Angélica (2003). Derecho de la competencia económica en México. México: Universidad Autónoma de México.

ŽıžEк, Slavoj (2013). El año que soñamos peligrosamente. Madrid: Akal. 



\title{
TEJEDORAS DE RECONCILIACIÓN PARA CONSTRUIR LA PAZ. MUJERES VÍCTIMAS: UN EJEMPLO PARA LA REGIÓN Y EL PAÍS
}

\author{
Katherine Paola Castro Molina', Carlos Alberto Peña Orozco ${ }^{2}$
}

\section{Resumen}

Las mujeres tienen actualmente un papel relevante en el marco del evento que tiene tanta trascendencia para el país y el mundo como son los acuerdos de paz que se realizan para darle fin al conflicto armado entre el Gobierno y las FARC; ellas tienen la misión de convertirse en tejedoras de paz con el objetivo de minimizar las consecuencias que deja la desgarradora violencia de una nación que ha sufrido este flagelo durante tantas décadas y que, a su vez, ha vulnerado la dignidad física y moral de gran parte de la población femenina.

Palabras clave: mujer, reconciliación, conflicto armado, víctimas.

1 Comunicadora social y periodista con énfasis en Comunicación Organizacional de la Universidad Sergio Arboleda. Especialista y magíster en Docencia e Investigación Universitaria. Estudio realizado en la Escuela de Postgrados de la Universidad Sergio Arboleda. Doctoranda en Ciencias Políticas.

2 Filósofo, magíster en Educación, Universidad del Norte. Doctorando en Ciencia Política, Universidad del Zulia. Docente Investigador Universidad Sergio Arboleda Sede Santa Marta. carlosal.pena@usa. edu.co 


\section{Abstract}

Women now have a role as part of the event that is so important for the country and the world as peace agreements are being made to put an end to the armed conflict between the government and the FARC; they have the mission to become weavers of peace in order to minimize the consequences left by the harrowing violence of a nation that has suffered this scourge for so many decades and which in turn, has violated the physical and moral dignity largely of the female population.

Keywords: women reconciliation, armed conflict victims.

\section{Introducción}

En La Habana, Cuba, una región caracterizada por el maltrato a la mujer, según datos de "investigaciones de Medicina Legal, reportan un comportamiento homicida contra el sexo femenino, en el que 45 por ciento de las mujeres murió a manos de su pareja y 52 por ciento de los casos ocurrió en el hogar, en la capital cubana" (Más, 2015). Es en este escenario donde se está desarrollando el proceso de resolución de conflicto realizado entre el Gobierno de Colombia y las Fuerzas Armadas Revolucionarias, FARC. En las fases proyectadas para el logro de los objetivos intervienen comisiones de las partes para desarrollar la agenda compuesta por cinco puntos en los cuales está ausente el tema de la vulneración de los derechos de la mujer víctima de la violencia a causa del conflicto interno.

Las universidades en su condición de academia tienen como responsabilidad universitaria la formación de las nuevas generaciones de profesionales para el país y para esta región Caribe en particular, en este sentido y como complemento a este proceso pedagógico han querido sumarse por medio de procesos investigativos a los cientos de voces institucionales y sociales que desde distintas orillas, indagan las particularidades y su diversidad de los contextos sociales con el fin de reconocer el valor de la mujer, su lugar en la sociedad y el ejemplo de superación que le aportan a Colombia, en especial a las personas, que aún en medio del sufrimiento y de la pérdida han reconstruido sus vidas, edificando junto con ellas las claves hacia la 
reconciliación, la convivencia pacífica y la construcción de una paz estable, justa y duradera para todas y todos los colombianos.

Desde la Escuela de Comunicación Social y Periodismo de la Universidad Sergio Arboleda en Santa Marta se aporta, desde las investigaciones hechas en el grupo Comunicación y Sociedad, el respeto y admiración a las miles de víctimas que hoy, en el departamento del Magdalena y en el Distrito de Santa Marta, nos enseñan con su esfuerzo y tesón del día a día cómo se reconstruyen los tejidos sociales, cómo se transforman los imaginarios y cómo se teje la reconciliación.

$\mathrm{Y}$ de entre todas las víctimas, queremos referirnos en este capítulo haciendo una mención especial a las mujeres, a las mujeres victimas, a todas a aquellas abuelas, madres, esposas, hijas, que son al mismo tiempo diligentes trabajadoras rebuscándose el día a día, comprometidas lideresas en sus comunidades, ya sea urbanas o rurales, solidarias compañeras o esposas y amorosas madres, que le apuestan buena parte de sus vidas a hacer de sus hijas e hijos personas de bien.

El desarrollo epistémico en el presente texto se mueve en el marco de una hipótesis central: las mujeres víctimas han aportado, están aportando y seguirán aportando, casi sin saberlo, a la construcción de escenarios de reconciliación en Colombia. Su manera particular de levantarse de entre la tragedia, el sufrimiento, la pérdida o la orfandad, y de reconstruir poco a poco la vida, los espacios, las rutinas, las relaciones, nos enseña, nos muestra las claves, o mejor, nos da lecciones, acerca de las rutas posibles hacia la paz y el escenario futuro del postconflicto.

\section{La Universidad Sergio Arboleda y las mujeres víctimas}

En primer lugar, una rápida explicación del porqué para la Academia, o más específicamente, para la Universidad Sergio Arboleda, las mujeres víctimas son tan importantes. El asunto se resume en el hecho de que una de las políticas de apoyo a la población femenina vulnerable se hace por medio del Centro de Emprendimiento Femenino. En dicha política la mujer tiene un rol primordial como base de la familia; en este sentido, se concibe como el punto de partida para la proyección de diferentes acciones, sujeto eje en 
la transformación social y actora con un rol clave en el desarrollo social nacional, regional y local.

Esta definición programática nos conduce al desarrollo de acciones permanentes para la generación de oportunidades de acceso equitativo de las Mujeres a una educación de calidad. Realizando actividades para ellas como el Foro de Emprendimiento Femenino, propósito este en el que la académica se encuentra radicalmente comprometida y que conduce de manera constante a la creación de escenarios de formación desde un enfoque diferencial, tanto de género como cultural.

Según las cifras que aporta la organización Global Entrepreneurship Monitor GEM, entidad que hace un proceso de análisis a través de la académica de la dinámica del emprendimiento a nivel mundial, en su informe 2006-2013 para el caso de Colombia arrojó como resultado que el 30\% de los empresarios nacientes son hombres y $17 \%$ mujeres, tal como se indica en la siguiente gráfica:

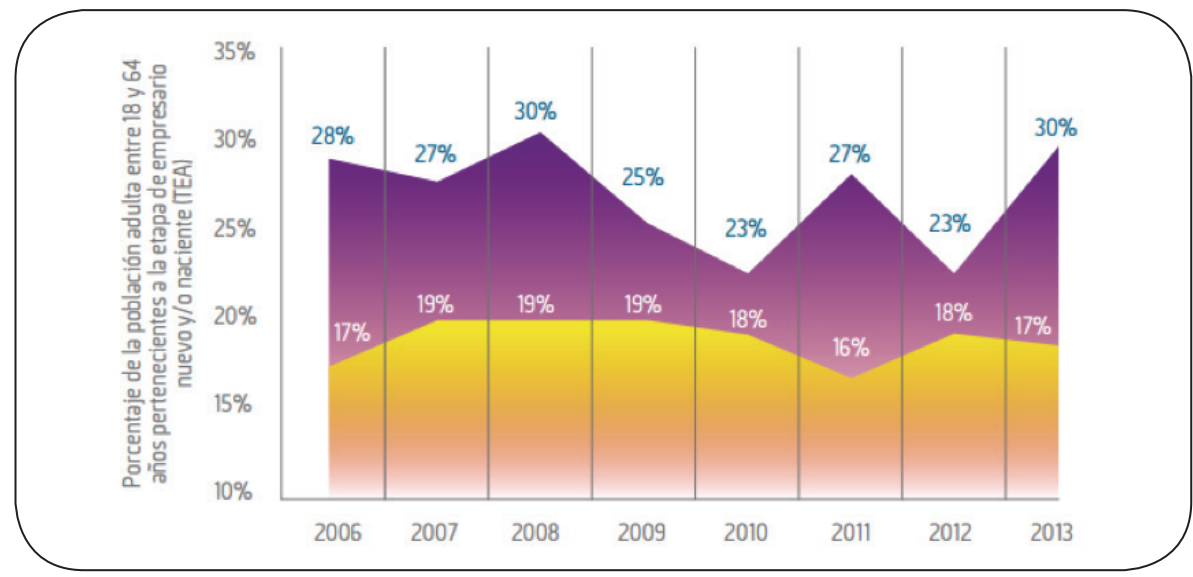

Gráfica tomada del informe 2006-2013. GEM, Colombia.

Este dato evidencia la necesidad que tienen las entidades gubernamentales y la empresa privada de desarrollar e incentivar a la población femenina con programas para mejorar las habilidades empresariales básicas. Por esta razón, la Universidad Sergio Arboleda es una entidad académica particularmente sensible a la realidad de las miles de mujeres víctimas por 
hechos ocurridos en el marco del conflicto armado interno, en Colombia y en la Región Caribe.

\section{El panorama del conflicto armado sobre las mujeres}

En tal sentido, desde un mandato institucional, la Universidad Sergio Arboleda se asoma a las dinámicas del conflicto armado interno en Colombia y de sus consecuencias, particularmente, sobre las mujeres. Y al hacerlo encontramos un panorama arrasador, tal como se indica a continuación.

En cifras oficiales del 2009, se señalaba que del total de población víctima del desplazamiento forzado en Colombia, el 50.5\% eran mujeres y casi el 25\% de los hogares que habían sufrido el flagelo del desplazamiento tenían jefatura femenina. Adicionalmente, las cifras de ese año nos revelan a la Región Caribe, como la región con mayor cantidad de personas desplazadas, con un $20 \%$ del total nacional.

Ahora bien, en el lapso de cuatro años, las cifras, lejos de disminuir, siguen develando la condición de extrema vulnerabilidad de las mujeres y la ferocidad con la que fueron golpeadas por la violencia y el conflicto. El reciente Informe Basta Ya, del Centro de Memoria Histórica, publicado en agosto de 2013, registra cómo las mujeres "fueron víctimas de múltiples, atroces y sistemáticos crímenes del conflicto armado", problemática de la cual se mostrará a continuación los escalofriantes datos.

En las Cifras del Registro Único de Víctimas con corte a marzo de 2013, se evidencia que entre 1985 y 2012, es decir, en un lapso de 27 años:

- $\quad 2.420 .887$ mujeres fueron víctimas de desplazamiento forzado

- 1.431 de violencia sexual

- 2.601 de desaparición forzada

- 12.624 de homicidio

- 592 de minas antipersona

- $\quad 1.697$ de reclutamiento ilícito

- 5.873 de secuestro 
Conforme a las anteriores cifras, se evidencia cómo estas mujeres han sido vulneradas, y hoy en día hay muchas de ellas que siguen recordando los hechos como una huella indeleble del pasado que se manifiesta en el presente, que las perturba y las posee, lo cual representa, en sentido estricto, una situación de estrés postraumático para quienes se han quedado con la tragedia en su memoria y continúan siguen viviéndola de alguna manera; son personas que no han logrado la resiliencia. En cambio, quienes miran su experiencia trágica como un episodio que, aunque doloroso, saben que pertenece al pasado y lo resignifican desde su presente, esto es, quienes desde su presente logran una comprensión crítica de los hechos del pasado, son personas que han logrado la resiliencia.

\section{Memorias de dignidad y resistencia}

Pese a lo anterior, las mujeres víctimas han mostrado una enorme capacidad para sobreponerse a los estragos del conflicto, evidenciando un proceso resiliente, en el cual, la memoria ha sido una de las rutas hacia la verdad, la justicia y la reparación integral, y sobre todo, esperamos, una ruta hacia la no repetición del horror del conflicto. Un ejercicio de memoria que nos devuelve las voces de miles de mujeres, voces de resistencia y de dignidad que han tejido la vida de esta región y del país entero. Sin embargo, no hay que dejar de lado que las secuelas de la violencia no son fáciles de sobresalir y en muchos casos nunca llega a superarse, por tal motivo:

La violencia de género comporta graves consecuencias para la salud física y psicológica de quienes la padecen, que son las mujeres y sus hijos e hijas. Los niños y niñas van a sufrir de manera importante por el hecho de convivir en el ambiente de violencia hacia su madre. Aunque no experimenten malos tratos directamente, incluso aunque no los presencien, los/as niños/as viven el impacto y las consecuencias que estos malos tratos dejan en su madre, por eso se les considera víctimas directas siempre (Sánchez, 2015).

Con esa capacidad que tienen las personas resilientes de hacer frente a las adversidades, superando las acciones o eventos traumáticos a los cuales han sido sometidas, para posteriormente lograr salir favorecidas de esa etapa oscura de la vida. En este proceso hacen parte los diferentes actores 
resilientes; personas, grupos, organizaciones y comunidades de las cuales las mujeres hacen parte activa y organizan actividades donde sistematizan las experiencias vividas para afrontarlas a la nueva vida que tienen luego de la tragedia.

Muchas mujeres maltratadas rompen con el maltrato y se recuperan. Sin embargo, no se ha indagado suficientemente sobre los factores que les ayudan a recuperarse ni las relaciones entre ellos. Las investigaciones sobre la influencia de factores protectores en la salud física y mental de las mujeres y los estudios sobre resiliencia en mujeres maltratadas aportan elementos para comprender la adaptación eficaz de estas mujeres y muestran cómo se recuperan del trauma y logran vidas y relaciones personales exitosas (Jaramillo, Ospina, Cabarcas \& Humphreys, 2005).

En este punto, es posible afirmar lo dicho, con una frase que nos obsequia el texto de la Asociación Colectivo Mujeres al Derecho, en su segundo Informe sobre la situación de las mujeres víctimas del conflicto armado en la Región Caribe: departamentos del Magdalena y el Atlántico, en la cual refiere que "del lado de la memoria del sufrimiento, también se registra la memoria de la dignidad y de la resistencia” (López, 2013).

Una de las características de la mujer caribe es su dignidad y su resistencia frente a un hecho violento, además de ser socialmente líder, no se deja llevar por las adversidades y está dispuesta a la superación de los obstáculos por medio de actividades que le generen una alta autoestima, desarrollando proyectos innovadores que le permitan sacar adelante a su familia y ser objeto de la sociedad para la superación personal y comunitaria como generadoras de cambio social.

\section{Aportes de las mujeres víctimas}

Si desde esta frase: "Del lado de la memoria del sufrimiento, también se registra la memoria de la dignidad y de la resistencia", nos aproximamos a las evidencias que la realidad nos muestra en relación con las mujeres víctimas, a quienes encontramos allí, en la ciudad, en la parcela, en el barrio, o en su vida en familia, desplegando una enorme capacidad para: 
Resistir - Sobrevivir - Adaptarse - Reconstruir - Perdonar Emprender - Transformar

Estas capacidades han significado que la mujer víctima con su proceso resiliente ha mostrado una evolución en la sociedad con una serie de aportes en lo socio-cultural, en lo político, y en lo económico, solo por mencionar tres ámbitos, tanto para el país como para la Región Caribe y su departamento del Magdalena.

Con respecto a sus aportes en lo $\underline{\text { Socio-Cultural, }}$ señalaremos solo dos, entre muchos otros, que nos parecen supremamente importantes:

- Las mujeres víctimas han reconstruido el tejido comunitario y social en los territorios donde llegaron, y hablamos tanto de mujeres víctimas del desplazamiento como de otros hechos victimizantes. Y lo han hecho tejiendo relaciones y redes de vecindad, de solidaridad y de generosidad; animando y participando en la creación de grupos, de colectivos y de organizaciones.

- Con su fuerza y su entereza frenaron el colapso de la familia y de la comunidad ante el horror. Y en medio del dolor, e incluso, en ocasiones, de la desestructuración de sus familias, rescataron a sus hijos, impulsándolos, exigiéndoles y articulándolos en las rutinas de todos los demás niños, niñas y jóvenes, visionando para ellos una vida útil y grata. Y abrieron entonces las oportunidades de la escuela, del barrio, del círculo de amigos.

Convirtiéndose de esta manera en el eje sobre el que gravita y descansa la unión familiar, que es la base de la sociedad. Conforme a esta premisa, actualmente son palpables los casos de éxitos donde las madres que han sido violentadas en su integridad en medio del conflicto armado, luego de superar los hechos violentos, se reintegran a la sociedad impulsando a sus hijos a vivir una etapa nueva dejando de lado las secuelas de la violencia y empoderándolos a subsistir en la sociedad.

Desde el ámbito Político, sus aportes han sido también claves, entre ellos: 
- El surgimiento de nuevos liderazgos, edificados, muchos de ellos, sobre nuevos principios, nuevas acciones, nuevos comportamientos y, por qué no, nuevas éticas.

- Incidencia para hacer realidad el enfoque diferencial en la vida social e institucional del país, enriqueciendo de esta manera tanto a la sociedad como al Estado en su conjunto.

- Incidencia en la definición de políticas públicas desde un enfoque de derechos, que visibilizan y favorecen a las mujeres.

- Transformaciones en los escenarios de participación política y representación de intereses.

Finalmente, en lo Económico no han sido menores sus aportes. Y como preámbulo, es importante hacer referencia a una frase que contextualiza bastante bien lo que ha sido el esfuerzo de las mujeres, aun en medio de múltiples circunstancias adversas:

"La discriminación y desconocimiento histórico del papel de las mujeres rurales en la economía campesina y la lucha por la tierra, hace que en un contexto de conflicto armado como el colombiano se agudicen las violaciones y discriminaciones sobre ellas" (Asociación Colectivo Mujeres al Derecho, 2013). Y es que, en realidad, a pesar de esta discriminación histórica y su especial vulnerabilidad frente a las dinámicas del conflicto armado, las mujeres víctimas nos siguen mostrando aportes:

- Cambio de paradigmas en Políticas Públicas en cuanto a su reconocimiento como sujetos de derechos en temas de tierras, producción, créditos, entre otros.

- Inclusión laboral de las mujeres en escenarios de desarrollo económico urbano.

- Presencia y visibilidad de las mujeres en procesos de formación y cualificación para el trabajo.

- Protagonismo y reconocimiento de las mujeres en temas de seguridad y soberanía alimentaria. 


\section{¿Qué nos han enseñado las mujeres víctimas?}

Desde todos estos aportes, las mujeres víctimas nos entregan numerosas enseñanzas. Y por eso, su contribución debe ser visibilizada y reconocida. Sin duda alguna, han dado lecciones tanto a las demás mujeres como a las familias, a los líderes y a las organizaciones sociales, a la comunidad y a la sociedad regional en su conjunto. Veamos algunas de ellas:

A las demás mujeres: a través de su ejemplo de fuerza, coraje, capacidad de amar, acoger, cuidar, proteger y, sobre todo, su ejemplo de resistencia y de dignidad.

A las familias: a través de la unidad, la solidaridad, la generosidad, el compromiso con el desarrollo de sus hijas e hijos, y su inserción en la sociedad, el cuidado de los demás miembros de la familia y, sobre todo, el esfuerzo por garantizar la unidad familiar.

A los lideres y organizaciones: a quienes han enseñado la apertura y el reconocimiento a su presencia, aporte y derechos, abriendo espacios de reconocimiento y participación que antes no existían.

A la comunidad: han enseñado hasta el cansancio, su capacidad para participar y perseverar, para reconstruir y para exigir los derechos que hacen posible la dignidad.

Y finalmente, a la sociedad regional: desde lo cotidiano, desde lo sencillo, incluso desde el anonimato, nos han enseñado el rostro real de la reconciliación, de la convivencia aun medio de las diferencias y, de esta manera, las rutas posibles hacia la construcción de una paz justa y duradera.

\section{Retos que enfrentan hoy las mujeres víctimas}

A pesar de sus impresionantes logros, las mujeres víctimas también enfrentan retos importantes, problemas que superar, entre los que queremos destacar los siguientes:

1. La transformación de los liderazgos, hacia ejercicios que desborden las viejas prácticas, las inercias sociales a las que eran y son sometidas hoy en día. 
2. Una mayor cohesión en sus procesos organizativos que garanticen mayor presencia e incidencia y, por lo tanto, una mayor efectividad en sus logros.

3. Mayor posicionamiento y empoderamiento en la vida política de la región y del país, desde sus especificidades e intereses, para impulsar transformaciones necesarias desde su mirada de mujer y su sensibilidad.

4. Una vinculación más activa, creativa y visible, a la construcción de la paz, tanto en lo cotidiano (en la familia, la cuadra, el barrio, la calle), como en otros escenarios de la vida pública y de toma de decisiones.

5. Una más vigorosa y creativa articulación a dinámicas productivas.

6. Un papel protagónico en la construcción de políticas públicas.

\section{Conclusiones: la sociedad regional tiene una deuda con las mujeres víctimas}

No obstante todos estos aportes, la sociedad regional tiene una deuda con las mujeres víctimas. No es pertinente referirse a la inmensa deuda histórica pero sí prudente mencionar algunos asuntos que configuran elementos muy importantes con los cuales la sociedad debe resarcir a la población femenina víctima de la violencia.

- En primer lugar, una deuda de reconocimiento, que valore las transformaciones logradas en sus contextos locales y su aporte a los procesos de reconciliación, convivencia y paz.

- En segundo lugar y derivado de lo anterior, una deuda de visibili$\mathrm{dad}$, que socialice y divulgue sus contribuciones y aportes.

- En tercer lugar, una deuda de empoderamiento, que aumente su inclusión, desde su experiencia emprendedora y resiliente, en los espacios de representación de intereses, de propuesta y diseño de 
políticas públicas, de participación en la construcción de proyectos sociales, y de desarrollo laboral en empresas públicas y privadas.

- Y, por último, una deuda de gratitud, por las lecciones que dejan en las vidas de las presentes y las futuras generaciones.

Para terminar, es de vital importancia referir que desde la misión y responsabilidad social universitaria, y a través de los procesos de comunicación para el cambio social (actualmente con los diferentes procesos académicos e investigativos que ha adelantado en los diez años que tiene el grupo Comunicación y Sociedad de la Escuela de Comunicación Social y Periodismo seccional Santa Marta), podemos contribuir a saldar la deuda con las mujeres víctimas de nuestra región, a través de las siguientes premisas:

Con respecto al reconocimiento, a través de actividades académicas e investigativas de lo social, donde las mujeres víctimas tengan una amplia participación.

En relación con la visibilidad, por medio de resultados y socialización de experiencias significativas relacionadas con la investigación de género, en eventos nacionales e internacionales.

Respecto al empoderamiento, ofreciendo capacitación de emprendimiento a la comunidad de mujeres, en el marco del proceso de proyección social.

Y finalmente, respecto a la enorme deuda de gratitud, reconociéndolas y posicionándolas en nuestros diversos espacios académicos, como constructoras de un nuevo tejido social basado en el esfuerzo y la tenacidad para enfrentar la tragedia del conflicto, resistir a la injusticia y luchar por la restitución plena de sus derechos a una vida con dignidad.

\section{Bibliografía}

Asociación Colectivo Mujeres al Derecho (2013). La exigibilidad del derecho a la tierra y el empoderamiento económico de las mujeres como práctica creativa de actuación social para contribuir a la construcción de la paz en Colombia. Delegación de la Sociedad civil de Colombia 
en el 56 periodo de sesión del Comité CEDAW. Recuperado en http:// www.ohchr.org/Documents/HRBodies/CEDAW/RuralWomen/ AsociacionColectivoMujeresDerecho.pdf

Basta Ya. (2013). Memorias de guerra y dignidad, Informe General, Grupo de Memoria Histórica, Centro Nacional de Memoria Histórica, Departamento de la Prosperidad Social, Bogotá, Colombia.

II INFORME SObRe LA SITUACión DE MUJERES Víctimas DEL CONFLicto armado en la Región Caribe: departamentos del Magdalena y Atlántico, Asociación Colectivo Mujeres al Derecho, GTZ, Bogotá.

López, N. (2013) Una mirada a los derechos de las mujeres en Colombia. Informe alternativo presentado al comité de la CEDAW de Naciones Unidas - 2013. Bogotá, Colombia, Enlace Publicitario Editores Ltda.

Jaramillo, D. Ospina, D. Cabarcas y Humphreys, J. (2005) Resiliencia, Espiritualidad, Aflicción y Tácticas de Resolución de Conflictos en Mujeres Maltratadas. Revista de salud pública, Vol. 7 (3), pp. 281-292.

Más. S. La violencia contra la mujer en Cuba. Semanario Elveraz, recuperado de http://elveraz.com/articulo681.htm

Sánchez, L. (2015) Resiliencia en violencia de género. Un nuevo enfoque para los/las profesionales sanitarios/as. Journal of Feminist, Gender and Women Studies 1, pp. 103-113.

Varela R. Moreno, J. Bedoya, M. (2015), Informe 2006-2013 GEM, Colombia. Universidad Icesi Santiago de Cali. 



\section{EL PRÍNCIPE DE MAQUIAVELO: UNA OBRA DE POLÍTICA SISTEMATIZADA}

Carlos Alberto Peña Orozco', Katherine Paola Castro Molina ${ }^{2}$

\section{Resumen}

El Principe de Maquiavelo es una de las obras políticas más referenciadas en estudios de filosofía, teoría y ciencia política, debido su riqueza práctica y conceptual. Esta riqueza lleva a la pregunta ¿qué es ser maquiavélico? Pregunta que podría responderse en términos de ser un pensador estratégico, capaz de defender los intereses propios así sea recurriendo al engaño, la trampa y la manipulación de los demás. Todo esto con el fin de presentar una política (o práctica política) ajena a la moral y a la religión, llevando entonces a una política sistematizada, más que a una sistematización política.

Palabras clave: política, política sistematizada, maquiavelismo.

1 Filósofo, magíster en Educación, Universidad del Norte. Doctorando en Ciencia Política, Universidad del Zulia. Docente Investigador Universidad Sergio Arboleda Sede Santa Marta. carlosal.pena@usa. edu.co

2 Comunicadora social y periodista con énfasis en Comunicación Organizacional de la Universidad Sergio Arboleda, especialista y magíster en Docencia e Investigación Universitaria. Doctoranda en Ciencias Políticas. Docente Investigadora Universidad Sergio Arboleda Sede Santa Marta. katherine.castro@usa.edu.co 


\section{Abstract}

The work of Machiavelli's The Prince is one of the more political works referenced in studies of political philosophy, theory and science, because of the practical and conceptual richness of it. This wealth leads to the question: what is to be Machiavellian? Question could be answered in terms of being a strategic thinker, capable of defending their own interests as well as resorting to deception, cheating and manipulating others. All this in order to present a policy (or political practice) outside morality and religion, leading then to a politic systematized, rather than a systematic policy.

Keywords: polity, systematized politic, machiavellianism.

\section{Introducción}

Referirse a Nicolás Maquiavelo en cualquier trabajo de índole académica implica mencionar a uno de los autores más leídos, interpretado, malinterpretado, amado, odiado, respetado e irrespetado a lo largo de la historia del conocimiento político universal. Es Maquiavelo, sin duda, el gran referente de la política renacentista y moderna, tanto para bien así como para mal.

Desafortunadamente, es más conocido por esa estela del mal que con el paso del tiempo ha parecido y parece acompañarle, y que llevó a utilizar el término maquiavélico de manera peyorativa, basado fundamentalmente en la supuesta filosofía del pensador renacentista florentino que rezaba aquello de que el fin justifica los medios. Razón por la cual se dice de Maquiavelo que:

Es un hombre inspirado por el diablo para conducir a los hombres justos a la perdición, el gran corruptor, el maestro del mal, le doctouer de la scélératesse, el inspirador de la noche de San Bartolomé, el original de Yago. Éste es el «asesino Maquiavelo» de las famosas cuatrocientas y tantas referencias de la literatura isabelina. Su nombre añade un nuevo ingrediente a la más antigua figura de Old Nick. Para los jesuitas es el «socio del diablo en el delito», «un escritor sin honor y descreído» y El Principe es, en palabras de Bertrand Russell, un «manual para pandilleros» (Berlin, 2009, p. 229). 
Al hacer a un lado esta mala imagen de Maquiavelo y centrarse académicamente en sus obras, a fin de indagar qué tipo de orientación asume en sus estudios sobre política, la situación no tiende a ser más sencilla, pues es entendido como tratadista político, filósofo político, sistematizador de la política, científico político o simplemente como un estadista político. $Y$ es precisamente en esta discusión en la que se enmarca el presente escrito, donde se analizará la obra más reconocida del pensador florentino para mostrar que lo realizado por él se enmarca en realidad en el concepto de política sistematizada.

\section{¿Por qué El Príncipe?}

Sería un buen punto de inicio aclarar la razón por la cual fue seleccionada esta obra de Maquiavelo para cumplir con el cometido de este escrito, toda vez que se entiende que la teoría política de este pensador se encuentra condensada primariamente en su obra Discursos sobre la primera década de Tito Livio. Sin embargo, se decidió optar por El Principe debido a que el objetivo es mostrar un nuevo matiz en la obra de Maquiavelo, pues si quisiera mostrarse al tratadista político no cabe duda de que los Discursos serían una buena elección. Sin embargo, la riqueza en matices interpretativos que presenta El Principe constituirá el soporte para lograr ubicar al autor en el concepto de política sistematizada.

Esta riqueza interpretativa de dicha obra proviene de la increíble articulación realizada por Maquiavelo en la misma de teoría y práctica política, llegando a afirmarse incluso que:

El Príncipe de Nicolás Maquiavelo es el título del libro con el que inicia la ciencia política moderna (...) la ciencia política en la obra de Maquiavelo es una disciplina que no sólo reconoce la realidad presente en la que se aplica, sino que demuestra ser ciencia trascendiendo la realidad. No se limita a describir los fenómenos que estudia, busca siempre las mejores soluciones teóricas y prácticas que se derivan de tales fenómenos (Zamitis, 1999, p. 4). 


\section{El Príncipe: entre filosofía, ciencia y teoría política}

El tratar de ubicar esta obra dentro del ámbito de estas tres disciplinas parte de un problema conceptual, y es el de delimitar el campo de acción de aquellas, toda vez que se ha generado gran confusión, como afirma Zamitis (1999), respecto a

la ubicación de los ámbitos entre filosofía, la teoría y la ciencia política, así como sus relaciones y especificidades. La cuestión no se resuelve fácilmente. Para entender el núcleo del problema es necesario conocer las diferentes tradiciones de ciencia política (europea y norteamericanas fundamentalmente) y el modo de posicionarse respecto de algunas corrientes de filosofía política (p. 6).

Podría empezarse por ubicar esta obra dentro de la llamada filosofía política, entendida esta a nivel personal como una aproximación reflexiva y analítica a los conceptos y práctica de la política. Sin embargo, en El Príncipe Maquiavelo depura su análisis de los contenidos puramente teóricos, logrando así, como afirma Sartori (1992), que "el observador se separa de la cosa observada, aun sin despojarse de sus propios fines y valores. De este modo, Maquiavelo rompe con la tradición filosófica, es decir, se aparta de la filosofía" (p. 227).

La gran preocupación de Maquiavelo en esta obra es lograr establecer las acciones a seguir por un príncipe que ostente o quiera el poder, no entregar a este un compendio teórico al respecto. El Principe es un manual para hacer política, como anota Berlin (2009), quién observa en Maquiavelo una fascinación total por las técnicas políticas en sí, tales como

el consejo dado igualmente a conspiradores y enemigos, la apreciación profesional de los métodos de Oliverotto, Sforza o Baglioni, brotan de una curiosidad típicamente humanista, la búsqueda de una ciencia aplicada de la política, la fascinación del conocimiento, cualesquiera pudieran ser las implicaciones (p. 233).

Además en referencia a Bobbio, Felip y Martin (1994), estos pensadores distinguen claramente filosofía política de ciencia política, afirmando que "esta última tendría las tres siguientes características: ser empírica, ser 
descriptiva (no en el sentido de que las teorías empíricas deban «describir» los fenómenos que estudian, sino que las teorías puedan explicar y prever) y ser avalorativa (p. 289). Maquiavelo realiza en esta obra un análisis bastante empírico, cayendo en descripciones permanentes de situaciones históricas y actuales para la época. Así, puede ser desligado parcialmente del rótulo de filósofo político, pero podría relacionarse con la ciencia política.

Esta afirmación no es del todo viable, debido a que Maquiavelo es cuestionado permanentemente por cuán científico resulta su proceder en El Principe. Berlin (2009) anota respecto al respecto que:

para Herbert Butterfield y Raffaello Ramat carece igualmente de sentido científico e histórico. Obsesionado por los autores clásicos sólo contempla un pasado imaginario; deduce sus máximas políticas de una manera antihistórica y a priori de axiomas dogmáticos (de acuerdo con Lauri Huovinen), método que ya era obsoleto en el tiempo en que él escribía; en este sentido, su servil imitación de la antigüedad es juzgada inferior al sentido histórico y al sagaz juicio de su amigo Guicciardini (mucho por el descubrimiento en él de huellas del moderno método científico) (p. 227).

El ejercicio hasta ahora realizado en este escrito deja al pensador florentino con la sombra de ser un teórico político, idea rechazada por completo en el momento en que se concluye la lectura seria de El Principe pues, siguiendo a Berlin (2009), en esta obra Maquiavelo entiende que:

la actividad política es intrínseca a la naturaleza humana, y aunque los individuos, aquí o allá, pueden optar por apartarse, la masa de la humanidad no lo puede hacer así, y la vida comunal determina los deberes morales de sus miembros. De aquí que al oponer las «leyes de la política» a «el bien y el mal», Maquiavelo no contrasta dos esferas «autónomas» de acción, la "política» y la «moral»: contrasta su propia ética "política» con otra concepción de ética que gobierna las vidas de las personas que no le interesan (p. 231).

Esta obra es un ejercicio de conciencia cedido por Maquiavelo para que los hombres entiendan la importancia de desligar los valores individuales de los colectivos en aras de comprender las funciones de la obligación po- 
lítica contraídas para legitimar el poder en el Estado, preocupación última de Maquiavelo.

\section{El Príncipe: entre sistematización política o política sistematizada}

La sistematización política se refiere a la creación de esquemas comparativos que permitan evaluar entre sí distintos sistemas políticos, es decir, se refiere a la creación de topologías de sistemas políticos. Al respecto, pueden verse los esquemas de Samuel Phillips Huntington, David Ernst Apter y Maurice Duverger sobre sistemas políticos.

El Príncipe no constituye precisamente un esquema para ser comparado con otros; en lugar de eso, es una obra de política sistematizada, pues constituye un manual con todas las acciones que, según Maquiavelo, debe ejecutar un príncipe virtuoso, partiendo del hecho de que el concepto de virtuosidad en Maquiavelo está despojado de toda connotación moral. En El Principe no hay espacio para mezclar la moral con los asuntos públicos, razón por la cual un príncipe virtuoso para el pensador florentino es un príncipe audaz, sagaz, astuto, capaz de instrumentalizar sus propias decisiones, capaz de hacer obedecer a los ciudadanos y fuerte.

En palabras del mismo Maquiavelo (2009):

no es, por tanto, necesario a un príncipe poseer todas las cualidades anteriormente mencionadas, pero es muy necesario que parezca tenerlas. E incluso me atreveré a decir que si las tiene y se las observa, siempre son perjudiciales, pero si aparenta tenerlas, son útiles; por ejemplo, parecer clemente, leal, humano, íntegro, devoto, y serlo, pero tener el ánimo predispuesto de tal manera que, si es necesario no serlo, puedas y sepas adoptar la cualidad contraria (p. 131).

Esta política es sistemática en la medida en que Maquiavelo cubre cada frente de acción del príncipe en aras de mantener el poder, como cuando afirma que "los príncipes deben ejecutar a través de otros las medidas que puedan acarrearle odio y ejecutar por sí mismo aquellas que le reporten el favor de los súbditos" (Maquiavelo, 2009, p. 138). 
La diferencia real entre sistematización política y política sistemática es muy fina, sin embargo, con su obra El Principe, Maquiavelo logra evadir cualquier intención puramente teórica (sistematización) para esbozar acciones conjuntas y no aisladas, recomendadas para que un príncipe gobierne de la mejor manera.

Porque Maquiavelo nos da a entender que el ejercicio de gobernar no se fundamenta en utilizar cualquier medio para hacerlo efectivamente, como tradicionalmente se le ha entendido. En vez de eso, para el pensador florentino gobernar es un asunto práctico, pero requiere de un ejercicio personal de convicción por parte del príncipe que debe asumir su práctica gubernamental como un ejercicio sin reversa. En cuanto el príncipe se decida a gobernar, debe ejecutar las acciones pertinentes y necesarias para conseguir sus metas, y sus principios morales tan solo son trabas innecesarias.

\section{Conclusiones}

La propuesta política que hallamos en El Príncipe de Maquiavelo es política sistematizada porque enseña al príncipe a desligar su ámbito público de su ámbito privado, tal como Kant nos lo había indicado en su obra ¿Qué es la ilustración?, pues se verá llevado en ocasiones a ejecutar acciones o tomar decisiones que no serán beneficiosas para sus gobernados, pero que sin lugar a dudas serán claves para gobernar correctamente.

Por esto Maquiavelo critica los abordajes moralistas del poder político. Por eso ataca la idea de la legitimidad del poder a partir de unos principios morales. A partir de lo anterior, Maquiavelo implícitamente afirma que aquel que ostenta el poder tiene todo el derecho a utilizarlo para mandar sin ningún asomo de la moral en ello.

Lo único que en realidad importa al gobernante es cómo llegar al poder y cómo mantenerse en él. En últimas, Maquiavelo muestra en El Príncipe que la política se fundamenta primordialmente en hacer que los ciudadanos cumplan su rol en el Estado y para eso no existen modelos ni teoría suficiente, requiere acciones bien ejecutadas por un príncipe lo suficientemente astuto como para ejecutarlas y mantenerse en el poder. 
No es el bien común la finalidad de la política de Maquiavelo, es lograr que al príncipe no le tiemble la mano en los momentos en que requiera pasar por encima del bien común.

\section{Bibliografía}

Berlin, Isaiah. (2009). La originalidad de Maquiavelo. El Principe. Nicolás Maquiavelo. Colonia: Evergreen.

Felip I Sarda, Josep María y Martin Cubas, Joaquín. (1994). La teoría postempirista de la democracia de Danilo Zolo: una aproximación. Nueva Época, 84, 287-303.

Maquiavelo, Nicolás. (2009). El Principe. Colonia: Evergreen.

SARTORI, Giovanni. (1992). La política, lógica y métodos en las ciencias sociales. México: Fondo de Cultura Económica.

Zamitis Gamboa, Héctor. (1999). Origen y desarrollo de la ciencia política: temas y problemas. Convergencia, 6(20), 85-122. 


\title{
ESFERAS DE LA PROPIEDAD INTELECTUAL: MEDIDAS EN FRONTERAS ADPIC, IMPLEMENTACIÓN LEGAL EN LATINOAMÉRICA
}

\author{
Berónica Narváez Mercado', Rodrigo Parraguez Ruiz²
}

\section{Resumen}

Los acuerdos de la Organización Mundial de Comercio (OMC), y en especial el Acuerdo sobre Aspectos de los Derechos de Propiedad Intelectual Relacionados con el Comercio (ADPIC), incluyeron una serie de regulaciones inéditas, que trajeron como consecuencia la necesidad de los países signatarios de adecuar sus legislaciones, modificando o incluyendo nuevas disciplinas en su normativa interna. Esta investigación analiza el apartado de las "Prescripciones especiales relacionadas con las medidas en frontera" del acuerdo ADPIC, desde la perspectiva de la adopción, implementación y funcionamiento de sus directrices en una serie de países latinoamericanos, luego de más de una década desde su puesta en marcha. Desde el punto de vista metodológico, se busca describir la problemática y analizar el proceso de reformas legales, desde

1 AbogadadelaUniversidadLibre deBogotá. Magísteren Administración y Derecho Empresarial de la Universidad Libre de Derecho San José de Costa Rica. Candidata a doctora en Derecho de la Universidad Libre de Bogotá. Directora de la Línea de Derecho Privado del Grupo GISCER de la Corporación Universitaria del Caribe. Docente de Metodología de la Investigación e Investigación Socio-jurídica.

2 Abogado. Magíster en Estrategia Internacional y Política Comercial de La Universidad de Chile. 
un plano formal y material. El primer aspecto apunta a establecer si existe coherencia entre la disciplina internacional y las reformas legislativas implementadas en Latinoamérica, con el objeto de develar si estas infringen los acuerdos $\mathrm{OMC}$, o si por el contrario han logrado tener un marco de acción más amplio que el texto internacional. Desde el punto de vista material, se busca establecer la efectividad de la reforma en la fiscalización de la piratería y la falsificación, en las zonas de control a cargo de los Servicios Nacionales de Aduanas.

Palabras clave: propiedad intelectual, ADPIC, Fronteras, acuerdos, medidas, comercio, aduanas.

\section{Abstract}

The World Trade Organization agreements, especially the agreement on trade related aspects of intellectual property rights (TRIPS), include a series of new rules, in order to force the signatory countries, to amend their legislation to satisfy the standards of international law. The institution considered in this report was born from these rules and is titled "specials requirements related to border measures", located in the fourth section of the said agreement. This article examines the effects of Latin American Countries legal reform after a decade of application. From the methodological perspective, this research explores the issues and analyzes the legal reform process, from a formal and material perspective. The first aspect seeks to establish if there is coherence between International and Latin-American local Law, in order to reveal which aspects infringe the TRIPS agreement. From the material perspective, we seek to determinate the effectiveness of the reform in the fiscalization of piracy and counterfeit goods, in areas controlled by the international customs services.

Keywords: border measures, intellectual property rights, TRIP agreements, custom fiscalization. 


\section{Introducción}

La OMPI define la propiedad intelectual como "una disciplina normativa que protege la creación del intelecto humano", proveniente de un esfuerzo, trabajo o destreza, digno de reconocimiento jurídico; y reconocidos como uno de los derechos fundamentales en la "Declaración Universal de los derechos Humanos, artículo 27 - inciso 2: Toda persona tiene derecho a la protección de los intereses morales y materiales que le correspondan por razón de las producciones científicas, literarias o artísticas de que sea autora" ${ }^{3}$. La protección en las fronteras del derecho que regula a la propiedad intelectual en la región tiene como antecedente ${ }^{4}$ la participación de nuestros países, en la serie de negociaciones comerciales de la Ronda de Uruguay, que devienen en la creación de la Organización Mundial de Comercio (OMC), en 1994. En ella se establece un marco jurídico multidisciplinar que tiene como punto partida, el Acuerdo General sobre Comercio y Aranceles (GATT), establecido en el pacto de La Habana de 1947, junto a la incorporación de nuevas disciplinas de comercio internacional, donde destacan por su importancia el Acuerdo sobre Comercio de Servicios (GATS), y el acuerdo que regula los Aspectos Relacionados con los Derechos de Propiedad Intelectual (ADPIC). La inclusión de normas sobre Propiedad Intelectual PI en el mencionado texto internacional se debió según Maristela $\mathrm{Basso}^{5}$, al interés de los países miembros del acuerdo, de completar las deficiencias en el sistema de protección entregado por la organización internacional de Propiedad Intelectual OMPI y a la necesidad de vincular definitivamente el tema al sistema de comercio internacional.

Luego que el tratado entró en vigencia, los países signatarios del convenio se vieron obligados a incorporar las nuevas regulaciones de

3 Rengifo García, Ernesto. Propiedad intelectual. El moderno derecho de autor, 2 da. Edición, Bogotá 1997, Editorial Universidad Externado de Colombia.

4 Revisión de Tesis inédita "Análisis de la Ley 19912 sobre medidas en frontera para la observancia de los derechos de propiedad intelectual”, para analizar la problemática desde la perspectiva latinoamericana, Parraguez Rodrigo (2013).

5 Basso Maristela, Propriedade Intelectual na Era Pós-OMC, Libraria do advogado, Sao Paulo 2006. 
comercio internacional en un plazo prudencial, tomando en cuenta su nivel desarrollo ${ }^{6}$.

Es así como mediante reformas legislativas o administrativas, países tan diversos como Colombia, Chile, Brasil, Argentina, Ecuador o Perú , incorporaron en su normativa interna, regulación específica sobre observancia de derechos de autor y propiedad industrial en frontera, dejando de lado un vacío que por años fue suplido mediante resoluciones de carácter jurisdiccional en el marco de procesos penales o civiles, por las cuales los propios Servicios de Aduanas actuaban como denunciantes de infracciones a las leyes de propiedad intelectual.

\section{Metodología}

Tipo de investigación: la presente investigación jurídica está dirigida hacia un estudio cualitativo, con un nivel hermenéutico, ya que busca interpretar y analizar la implementación legal de las medidas en fronteras ADPIC.

La fuente de análisis: la fuente objeto de análisis en la presente investigación serán las esferas de la protección de la propiedad intelectual, fuentes secundarias, iniciando con el estudio de la normatividad existente. Se desarrolló un rastreo bibliográfico mediante la consulta de varias bases de datos jurídicas, en el que usamos como criterio de selección de información los descriptores restrictivos.

Procedimiento: el diseño metodológico se planteó a través de varias etapas

- Primera etapa: análisis bibliográfico orientado a reconstruir un estado del arte.

6 El objeto del Convenio de París son las patentes de invención, los modelos de utilidad, los dibujos o modelos industriales, las marcas de fábrica o de comercio, las marcas de servicio, el nombre comercial, las indicaciones de procedencia o denominación de origen y la represión por la competencia desleal, a cuyos creadores ofrece una protección adecuada, fácil de obtener y respetada. http://www.edicion.unam.mx/ html/3_3_1.html 
- Segunda etapa: el análisis documental efectuado a través de una escala metodológica que parte desde lo internacional, latinoamericano y nacional que permitió la construcción del marco teórico y el estado de la cuestión.

- Tercera etapa: el análisis de la información a través de la redacción del aparato crítico integrado por tres tipos de notas: notas textuales, notas de contenido y notas de referencia, que generaron la interpretación, conclusiones y recomendaciones de la investigación.

\section{Aspectos generales sobre las medidas en frontera}

Las primeras aproximaciones internacionales sobre esta materia surgen a finales del siglo XIX en Europa a partir de los Convenios de París ${ }^{7}$ de 1883 (CP) que regulaban aspectos sobre propiedad industrial, marcas, patentes, diseños industriales y competencia desleal, y los convenios de $\mathrm{Berna}^{8}$ (CB) de 1886 que otorgaba protección a las obras artísticas y literarias. E1 CP en su artículo 9.1 se pronunciaba incipientemente sobre las MF, señalando que “Todo producto que lleve ilícitamente una marca de fábrica o de comercio o un nombre comercial será embargado al importarse en aquellos países de la Unión en los cuales esta marca o este nombre comercial tengan derecho a la protección legal". La expresión "al importarse" indica de manera inequívoca que el embargo podía producirse a instancias de la autoridad aduanera, antes de que la mercadería ingresara al país. En este caso la medida era menos garantista que ADPIC, ya que permitía proceder con la incautación antes de cualquier revisión administrativa o judicial. Este mismo artículo en su segundo y cuarto numeral hacía extensiva las medidas en frontera a

7 La protección de este convenio se extiende especialmente a las traducciones, arreglos musicales y otras transformaciones de una obra original así como a las enciclopedias y antilogías. La protección puede extenderse a los textos oficiales y a su traducción, a los discursos y a los alegatos si la legislación nacional no los excluye. La protección no incluye las meras informaciones de prensa pero puede, en ciertas circunstancias, aplicarse a dibujos o modelos. En http://www.jurisint.org/doc/html/ ins/es/2000/2000jiinses132.html

8 Se llama oficialmente la Unión Internacional para la Protección de las Obras Literarias y Artísticas. Canaval Palacios, Juan Carlos. Manual de Propiedad Intelectual, 1ra Edición, Bogotá, 2008, Ed. Universidad del Rosario. 
las exportaciones y a las mercaderías en tránsito. Por su parte, el CB dispone en su artículo 13.3 que "Las grabaciones importadas, sin autorización de las partes interesadas, en un país en que estas grabaciones no sean lícitas, podrán ser decomisadas en este país". Este artículo al igual que el 9.1 de $\mathrm{CP}$ da a entender que el bien importado podía ser decomisado a nivel de frontera.

Más adelante EE.UU. y la Unión Europea propondrían un código antipiratería bajo los acuerdos del GATT que incorporaba algunas disposiciones sobre observancia de los derechos de propiedad intelectual, pero que fue ampliamente superada en la Ronda de Uruguay, que incorpora el acuerdo ADPIC con un apartado especial sobre medidas en frontera ${ }^{9}$.

\section{Regulación de las medidas en frontera en los tratados bilaterales y multilaterales}

Tratado de Libre Comercio con EEUU: en el ámbito bilateral, el instrumento base para ampliar los niveles de cobertura de las reglas sobre propiedad intelectual, lo constituyen los tratados de libre comercio o TLC, a partir de los cuales se han desarrollado una gran cantidad de disposiciones ADPIC PLUS, en materia de PI y MFPODPI. Para los países desarrollados incluir estas disciplinas entre los puntos de negociación se ha convertido en un requisito esencial para suscribir los tratados comerciales, ya que gran parte de su actividad económica depende directamente del $\mathrm{I}+\mathrm{D}$ (Investigación y desarrollo). En el caso de los países en desarrollo, este tipo de disposiciones son moneda de cambio para garantizar el acceso a los mercados en áreas como la agricultura y los servicios ${ }^{10}$.

Los tratados de libre comercio entre Estados Unidos y los países latinoamericanos contemplan disposiciones sobre observancia de los derechos de propiedad intelectual. En general, las principales obligaciones recaen sobre las acciones de fondo iniciadas con posterioridad a las medidas tomadas en frontera relativas al aseguramiento de estándares mínimos de

9 Wadlow, D. C. (2007). Including Trade in Counterfeit. Intellectual Property Quarterly. P. 352.

${ }^{10}$ Abbott, F. M. (2006). Intellectual Property Provisions of Bilateral and Regional Trade Agreements in Light of U.S. Geneva: UNCTAD. 
publicidad y debido proceso. En cuanto a la observancia de los derechos de propiedad intelectual, estos tratados contemplan disposiciones más rigurosas que ADPIC, pero coherentes con las legislaciones nacionales, que fueron promulgadas con base en estándares de protección más elevados que el texto multilateral. Lo que buscan los TLC es obligar a que las partes cumplan una serie de exigencias mínimas, para desarrollar el proceso de suspensión de despacho de mercancías que infrinjan normas de PI, pero sin detallar la forma en que este procedimiento debe llevarse a cabo.

\section{Medidas en frontera en los Acuerdos ADPIC}

El tratamiento internacional más extendido sobre MFPODPI está basado en las disposiciones del acuerdo ADPIC de la OMC, cuya observancia es obligatoria para los 159 estados miembros, que realizan al menos el 96\% del total de las transacciones comerciales internacionales ${ }^{11}$. La base legal de las medidas en frontera dentro del acuerdo ADPIC, se encuentra establecida en su parte tercera sección cuarta y consta de diez artículos establecidos entre el número 51 y 60.

La obligación de incorporar el acuerdo significa que los países signatarios deben adecuar su legislación a estándares no menos rigurosos que las dispuestas en el texto multilateral, estableciéndose plazos de adecuación normativa, distintos para cada tipo de país, según su nivel de desarrollo ${ }^{12}$.

De manera general el acuerdo ADPIC, en cuanto a las medidas en frontera, sigue el patrón de establecer reglas de aplicación mínimas, de la misma forma que el resto de los acuerdos $\mathrm{OMC}$, dejando a los países miembros la libertad de establecer y decidir qué tipo de regulaciones aplicaran en frontera, según sus necesidades y contingencias internas ${ }^{13}$. Esta técnica

\footnotetext{
${ }^{11} \mathrm{http} / /$ www.wto.org/english/thewto_e/whatis_e/tif_e/org1_e.htm

12 "Art 65.1 Sin perjuicio de lo dispuesto en los párrafos 2, 3 y 4, ningún Miembro estará obligado a aplicar las disposiciones del presente Acuerdo antes del transcurso de un período general de un año contado desde la fecha de entrada en vigor del Acuerdo sobre la OMC. Art 65.2 Todo país en desarrollo Miembro tiene derecho a aplazar por un nuevo período de cuatro año a la fecha de aplicación, que se establece en el párrafo 1, de las disposiciones del presente Acuerdo, con excepción de los artículos 3, 4 y 5".

${ }^{13}$ Medeiros, H. G. (2011).
} 
de establecer estándares mínimos es común en los acuerdos multilaterales donde la diversidad de realidades e idiosincrasias de los países partícipes en las negociaciones impide que existan acuerdos de carácter demasiado restrictivo para las economías o que impongan obligaciones imposibles de cumplir.

\section{Análisis}

La normativa latinoamericana sobre observancia de los derechos de propiedad intelectual en frontera, a pesar de ser garantista a favor de los titulares de los derechos de autor y de propiedad industrial, es bastante respetuosa con el derecho del importador a desarrollar su actividad económica con el menor número de obstáculos, lo que es coherente con los principios de la $\mathrm{OMC}$, que buscan que exista un alto nivel de acceso a los mercados, para posibilitar el mayor desarrollo y bienestar de la economía global.

De esta manera, la norma internacional impone importantes limitaciones para que los titulares de los derechos de propiedad intelectual inicien el procedimiento de suspensión de despacho de mercaderías, con el objeto de disminuir el riesgo de que estas medidas recaigan sobre bienes que no violan derechos de propiedad intelectual, que sean producto de prácticas desleales o anticompetitivas, o que busquen perjudicar o retrasar los derechos de los importadores de bienes legítimos ${ }^{14}$. Es por ello que el artículo 52 de la sección cuarta del acuerdo exige que se presenten pruebas suficientes que demuestren que existe presunción de infracción del derecho de propiedad intelectual y que se detalle con prescripción las mercancías que van a ser objeto de la medida. Por su parte, el artículo 53 establece la exigencia de constituir una fianza o garantía equivalente para proteger al demandado y el artículo 56 estable una indemnización adecuada al importador, consignatario y dueño de las mercancías, por todo daño causado por la retención infundada de las mercaderías.

${ }^{14}$ Téllez, V. M. (2006). The World Custom Organization and border measures for enforcement of IP Rights: setting new stnadars of intellectual property enforcement through the back door? South Bulletin: Reflections and Foresight. p. 4. 
Este texto internacional, además, limita toda dilación indebida en el proceso de observancia de los DPI, con el objeto de no generar obstáculos injustificados en las transacciones comerciales, estableciendo plazos máximos para suspender el despacho de las mercaderías por hasta diez días, prorrogables solo en circunstancias calificadas (art 55).

La idea de esta organización internacional, entendiendo que existen diferencias de desarrollo entre sus miembros, es no obligar a que los países desgasten sus esfuerzos y recursos escasos en la persecución de infracciones de escaso valor, centrando su cometido en que sus miembros contribuyan en la detección y persecución del contrabando internacional de mercancías falsificadas. Es por ello que en el apartado de prescripciones especiales relacionada con medidas en frontera no existen disposiciones que recaigan sobre el despacho de mercaderías que lesionen los DPI, desde el punto de vista de alguno de sus componentes secundarios o cuando se produzcan importaciones paralelas. Tampoco existe la obligación de suspender el despacho de las mercaderías que se encuentren en tránsito o que se vallan a exportar. Igualmente, se establece la posibilidad de excluir las disposiciones sobre observancia de propiedad intelectual, cuando la infracción recaiga sobre pequeñas cantidades que no tengan carácter comercial y formen parte del equipaje personal de los viajeros ${ }^{15}$.

Con el objeto de hacer más efectiva la detención de las suspensiones en frontera, ante la falta de información y medios que tienen los representantes para detectar los embarques y desembarques de mercadería que viola los DPI, es que el convenio dispone en su artículo 58, que los miembros podrán establecer de oficio la suspensión de aquellas mercaderías de las cuales tengan la presunción que infringe un derecho de propiedad intelectual. La convención transforma esta acción en un juicio contencioso en caso de que el importador recurra contra ella.

En cuanto a disposiciones institucionales de este acuerdo, el apartado sobre cooperación internacional del art $69^{16}$ ha sido fundamento, y ha

\footnotetext{
15 Téllez (2006), p. 4.

16 "Los Miembros convienen en cooperar entre sí con objeto de eliminar el comercio internacional de mercancías que infrinjan los derechos de propiedad intelectual. A este fin, establecerán servicios de información en su administración, darán notificación de
} 
permitido que la Organización Mundial de Aduanas haya implementado importantes programas de intercambio de información.

\section{Cooperación internacional}

\section{La Organización Mundial de Aduanas (OMA)}

La Organización Mundial de Aduanas es un ente intergubernamental que tiene como objetivo proveer a sus miembros del soporte técnico e instrumental necesario para que las administraciones aduaneras puedan operar con el más alto estándar de operatividad, implementando medidas en frontera a través de la estandarización y armonización de los procedimientos, a fin de facilitar el comercio y el desplazamiento de personas e impedir el desarrollo de transacciones y actividades ilícitas ${ }^{17}$. Desde el punto de vista de la PI, la OMA asumió un liderazgo político e institucional, en el marco de las negociaciones que condujeron a la promulgación del acuerdo ADPIC, teniendo en cuenta cuáles eran los puntos más sensibles que debían ser regulados y marcando pautas en la agenda legislativa. Esta organización internacional, además, posibilitó que muchos países pudieran cumplir con el acuerdo ADPIC, ya que facilitó herramientas técnicas y normativas a los países que desearan ese soporte. Tan importante es para el comercio internacional este organismo que tiene asignado un escaño en la $\mathrm{OMC}$, a fin de aportar expertiz técnica a la hora de deliberar sobre cualquier asunto de su competencia.

La Agenda Legislativa de Propiedad Intelectual al interior de la OMA está marcada por las actividades del grupo de trabajo denominado $\mathrm{SECURE}^{18}$, que desarrolla modelos de legislación y otras prácticas, para

esos servicios y estarán dispuestos a intercambiar información sobre el comercio de las mercancías infractoras. En particular, promoverán el intercambio de información y la cooperación entre las autoridades de aduanas en lo que respecta al comercio de mercancías de marca de fábrica o de comercio falsificadas y mercancías pirata que lesionan el derecho de autor".

${ }^{17} \mathrm{http}$ //www.wcoomd.org/en/about-us/what-is-the-wco/mission_statement.aspx

${ }_{18}$ Provisional Standards Employed by Customs for Uniform Rights Enforcement. 
coordinar de la manera más eficiente los esfuerzos de las autoridades aduaneras en el combate de la infracción de los derechos de $\mathrm{PI}^{19}$.

Las iniciativas incluidas en esta agenda nacen del impulso del $\mathrm{G}^{20}$, en orden a disponer de la mayor cantidad de medios y recursos para que las autoridades aduaneras puedan detectar cualquier infracción a las normas de PI y para que la autoridad judicial o administrativa pueda sancionar de manera eficaz su inobservancia ${ }^{21}$.

La puesta en práctica de este cuerpo normativo es hasta el momento voluntaria para los miembros de la OMA y no se entiende incorporada a los convenios ADPIC. En términos generales, podemos señalar que estas normas apuntan al desarrollo de procedimientos más cortos, con un control eminentemente administrativo en cuanto a la suspensión del despacho y a la interposición de la acción de fondo. En cuanto al representante de las marcas brinda bastantes garantías, ya que no requiere que estos presenten pruebas que respalden su pretensión y prescinde de la constitución de fianzas. En lo relativo al importador, elimina gran parte de sus garantías procesales, entre ellas el debido proceso y la presunción de inocencia, atentando contra sus posibilidades de defensa, ya que invierte la carga de la prueba y deja en segundo plano la necesidad de ser emplazado.

\section{Agencia RILO22}

El objetivo de esta división de la OMA es el intercambio de información de inteligencia aduanera, entre las autoridades de los distintos países, a fin de detectar y perseguir de manera efectiva todo tipo de infracciones aduaneras y comerciales, entre ellas las vinculadas con los DPI. Para ello, la OMA en

${ }^{19}$ Medeiros, H. G. (2011). Medidas de Fronterira TRIPS-PLUS.implicacoes e kimites á expansao de normas de observáncia dos direitos de propiedade intelectaul. Florianopolis. (2011), p. 101.

${ }^{20} \mathrm{E} 1 \mathrm{G} 8$ (Grupo de los Ocho) es un grupo de países industrializados del mundo cuyo peso político, económico y militar es muy relevante a escala global. Fuente: www. ecured.cu/index.php/g8

${ }^{21}$ Correa, C. F. (2009). The Global Debate on the Enforcement of Intellectual Property Rights and Developing Countries. Geneve.

${ }^{22}$ Con base en información de página web http://www.wcoomd.org/en/topics/ enforcement-and-compliance/instruments-and-tools/rilo.aspx 
colaboración con los países que forman parte de la organización, pusieron en marcha una serie de oficinas regionales por medio de las cuales se realiza un seguimiento de la mercadería que transita por los distintos estados, a fin de poner sobre aviso a las autoridades de frontera, de la existencia de mercaderías que infringen los derechos protegidos por el marco internacional o local.

En cuanto a los DPI, esta agencia maneja datos sobre las principales rutas de contrabando de estos bienes, sobre las marcas y productos con mayores tasas de falsificación, sobre cuáles son las organizaciones que han infringido estos derechos, y sobre los principales mercados de origen y destino de estos bienes.

Esta agencia tiene un soporte tecnológico basado en la plataforma $\mathrm{CEN}^{23}$, o red de protección aduanera, que permite que las autoridades aduaneras encargadas de la plataforma compartan información sensible sobre contrabando en una modalidad 24x7. El mecanismo opera simultáneamente con tres niveles de información, de carácter complementario, según se muestra a continuación:

1) El primer nivel lo constituyen los puntos de contacto nacional $\left(\mathrm{NCP}^{24}\right)$ que reúnen información de sanciones llevadas a cabo a nivel nacional y que son ingresadas vía electrónica al sistema CEN, o a través de carta o correo electrónico al punto de contacto RILO. Por medio de esa información se pueden describir nuevas tendencias en la comisión de actos ilícitos, generar alertas regionales a través de RILO, e intercambiar información con agencias nacionales vinculadas al contrabando.

2) A nivel regional, los puntos de contacto RILO estudian y evalúan las sanciones de carácter internacional, verifican la seriedad de la información aportada a la plataforma $\mathrm{CEN}$, preparan alertas sobre actividades que puedan representar riesgo en las fronteras, emiten análisis en boletines de carácter periódico, y organiza y apoya operaciones conjuntas de carácter regional, facilitando el intercambio de información con los NCP.

\footnotetext{
${ }^{23}$ Custom enforcement network.

${ }^{24}$ National Contact Points.
} 
A nivel internacional, el secretario de la OMA es el encargado de la administración e interoperabilidad del sistema CEN, encargándose de su actualización y de la coordinación con los puntos de contacto RILO. Además, a este nivel se definen los lineamientos y estrategias de operación de la organización, con base en la información disponible en el sistema, emitiendo todo tipo de circulares y estudios y ofreciendo capacitación y herramientas técnicas a los encargados de las oficinas RILO y compartiendo información estratégica con otras organizaciones internacionales, vinculadas al combate del crimen a nivel internacional ${ }^{25}$.

\section{Operación Tigre III}

En diciembre de 2013, la Secretaría de la OMA en conjunto con 16 aduanas regionales de Latinoamérica pusieron en marcha la operación Tigre III, con el objeto de detectar y capturar los embarques de mercadería falsificada, proveniente del este asiático con destino al centro y sur del continente americano. Esta operación coordinó a los órganos administrativos de la OMA, con una parte significativa de las autoridades aduaneras del continente, y tuvo como resultado la captura de un importante volumen de mercadería infractora de los DPI.

El objetivo de estas operaciones fue cuantificar el fenómeno de la piratería y la falsificación en la región, focalizando los esfuerzos en aquellos productos que produjeran riesgos en la seguridad y salud de los consumidores.

Para llevar a cabo esta operación fue necesaria la intensificación de los controles aduaneros destinados a la revisión física de la mercadería con mayor perfil de riesgo y la coordinación de las autoridades aduaneras de cada país en orden a notificar aquellos embarques con mercadería que pudieran ser infractores de los DPI. Cada operación tuvo una duración de cinco días, en las cuales se pudieron detectar una serie de contenedores que contenían productos falsificados, se logró identificar las principales rutas de contrabando y se pudo intercambiar una gran cantidad de información.

${ }^{25} \mathrm{http} / /$ www.wcoomd.org/en/topics/enforcement-and-compliance/instruments-andtools/rilo.aspx 


\section{Regulación de las medidas en frontera en Sudamérica}

\section{Decreto 5244 de la República de Brasil ${ }^{26}$}

$\mathrm{El}$ procedimiento adoptado por la aduana nacional se inicia de oficio, mediante la comunicación al titular de la marca acerca de la suspensión de los productos sujetos a importación. Esta comunicación está acompañada de una notificación, para que el titular de la marca comparezca ante aduanas y retire una muestra significativa de los productos para su análisis. La autoridad aduanera en tanto concede un plazo de diez días hábiles para que el importador presente un certificado de autenticidad del producto. Si no se prueba la autenticidad de dicho producto y el representante de la marca estima que tales mercaderías son falsificadas, el departamento de Hacienda (Receita Federal) envía una nueva notificación al titular de la marca informando acerca del nombre del importador y la cantidad de productos suspendidos, concediendo un plazo de diez días para que este inicie acciones legales.

\section{Argentina, Ley de Marcas y Designaciones}

Si bien la Ley 24425 incorpora los acuerdos de la OMC a la legislación argentina, no se ha avanzado hacia un proceso de suspensión por la vía administrativa. De esta manera, la autoridad competente para suspender el despacho de mercadería será siempre la autoridad judicial. El acto cautelar de suspensión en este país está regulado por la ley de marcas y designaciones, que señala que la solicitud de suspensión podrá ser solicitada por el particular damnificado que tome noticia de la existencia de objetos con marca de falsificación, pudiendo solicitarse la medida de prohibición de innovar $^{27}$. Todas estas medidas deben ser trabadas con la participación de la autoridad aduanera. Una de las principales debilidades de la legislación argentina es no considerar la posibilidad de suspender de oficio el despacho de mercadería, facultad potestativa de los miembros según el acuerdo ADPIC. Esto se debe a que se ha interpretado que las medidas cautelares deben ser emanadas de manera exclusiva por la autoridad judicial.

\footnotetext{
${ }^{26}$ Interpretado según las explicaciones de: Campos, E. M. (2010). Medidas De Fronteira Para Protecao Da Propiedade. Sao Paulo.

${ }^{27}$ Artículo 39 de la Ley 22362 y 230 de CPCCN.
} 
No obstante aquello, el código aduanero establece que la Asociación de Ingresos Públicos (AFIP) será el ente de ejecución de la política tributaria y aduanera de la nación, aplicando las normas legales correspondientes y tendrá una serie de funciones, entre ellas, el control del tráfico internacional de mercaderías dispuesto por las normas legales respectivas, lo que le otorga una serie de facultades para realizar la suspensión de mercaderías, previa petición de la autoridad judicial, por lo tanto, será un órgano coadyuvante y articulador del proceso de suspensión de despacho.

\section{Chile, Ley 19912 sobre medidas en frontera para la observancia de los derechos de propiedad intelectual}

Las medidas en frontera para la observancia de los derechos de propiedad intelectual están tratadas en el título segundo de la Ley 19912 de 4 de noviembre de 2003. Dicha ley consta de 23 artículos y 12 se refieren exclusivamente a la observancia de la propiedad intelectual en frontera. A rasgos generales la ley replica lo dispuesto en la norma internacional, extendiendo el ámbito de aplicación de dicha norma a las exportaciones y mercaderías en tránsito. El legislador chileno entregó el conocimiento de dichos asuntos a la autoridad judicial en caso de la suspensión de despacho requerida, reservando potestades para que la autoridad aduanera suspenda el despacho de mercancía cuando del simple examen de las mismas resultare evidente que se trata de mercadería de marca registrada o falsificada que infringe los derechos de autor. En cuanto a la operatividad de la norma, no han existido casos de suspensión de despacho requerida por el titular de los derechos, debido a la escasa información con la que cuentan los titulares de las marcas acerca de este tipo de importaciones, a la desconfianza en la expertiz del juez civil llamado a conocer de dichos asuntos, y al coste asociado a la acción. En cuanto a la suspensión de oficio, la ley ha sido exitosa, pero existen críticas en cuanto al tiempo de suspensión (solo cinco días) y al estándar de convicción para realizar el procedimiento, basado en evidencia de la existencia de mercaderías infractora de los derechos de propiedad intelectual. 


\section{Decisión 486 de la Comunidad Andina}

La Decisión 486 Comunidad Andina establece un régimen común de propiedad industrial para los países signatarios del pacto $^{28}$, regulando las MFPODPI en el título III de la norma, entre los artículos 250 y 256. Esta decisión entra en vigencia el 14 de septiembre del año 2000 y complementa las disposiciones del acuerdo ADPIC, estableciendo el procedimiento base aplicable en caso de infracción al registro de propiedad industrial ${ }^{29}$ y los plazos máximo de detención del despacho de mercadería ${ }^{30}$. En cuanto a la autoridad administrativa competente para conocer de estas reclamaciones y a las particularidades del proceso de suspensión, entrega libertad a los miembros para definir las condiciones y garantías aplicables según la legislación interna de cada país.

En el caso de Perú, estas medidas están tratadas en el decreto legislativo número 1092, según el cual la solicitud de suspensión de despacho por infracción de propiedad intelectual se presentará a la autoridad aduanera, quien procederá previa verificación de titularidad del requirente y cumplimiento de las formalidades legales. El estándar de aplicación se realizara con base en una presunción legal cuando se verifique la existencia de mercadería falsificada o confusamente similar a la del registro de propiedad industrial. La autoridad aduanera podrá proceder de oficio suspendiendo mercadería en régimen de importación, exportación o tránsito, en caso de mercadería presuntamente falsificada o pirateada, por un plazo máximo de diez días, realizando la notificación al titular del marca en un máximo de tres días para que pueda hacer uso del ejercicio de las acciones legales que estime pertinente.

En el caso de Colombia, la suspensión de despacho de mercadería en régimen de importación, exportación o tránsito se realizará ante la autoridad aduanera a la espera de que la autoridad judicial resuelva la denuncia o demanda que el titular de la marca realice por supuesta condición de pirata de una mercancía o marca falsa. La suspensión también podrá decretarse como una medida cautelar en el proceso judicial. La suspensión de oficio

\footnotetext{
${ }^{28}$ Bolivia, Colombia, Ecuador y Perú.

${ }^{29}$ Régimen Único de la Comunidad Andina.

${ }^{30}$ Diez días desde la notificación de la suspensión de mercadería a la autoridad aduanera.
} 
se realizará cuando existan serios indicios de mercaderías vinculadas a un delito diferente o adicional a los de contrabando o favorecimiento al contrabando, debiendo poner la autoridad los antecedentes a disposición de fiscalía. Una de las particularidades de este proceso es que las mercaderías podrán ser inspeccionadas por el titular de la marca incluso antes de la suspensión del despacho.

En Ecuador, la materia está tratada en los artículos 342 y siguientes de la ley de propiedad intelectual, en la cual la suspensión del despacho de mercadería que viole los derechos de propiedad intelectual es una obligación para la corporación aduanera ecuatoriana y para cualquier autoridad que tenga el control del ingreso o salida de mercadería desde y hacia Ecuador. La medida se desarrollará de oficio o a petición de parte, mediante informe pormenorizado a IEPI (Instituto Ecuatoriano de Propiedad Intelectual), que en un plazo de cinco días confirmará o revocará la medida tomada. Confirmada la suspensión, los antecedentes pasarán al fiscal para que se ejerzan las acciones judiciales. En el caso de la suspensión a petición de parte, la negativa de la autoridad aduanera de realizar la suspensión puede ser recurrida dentro de los tres días siguientes al presidente de IEPI para que la ordene.

\section{Análisis particular del Decreto 4540 de 2006 de la República de Colombia}

E1 Decreto legislativo 4540 de 2006, vigente desde el 23 de enero de 2007, tiene por objeto complementar lo dispuesto en las decisiones 351 y 486 de la Comunidad Andina, que regulan aspectos relacionados con los derechos de autor y propiedad industrial, respectivamente.

\section{Suspensión del despacho iniciado de oficio}

En cuanto a la suspensión de oficio, la autoridad aduanera podrá suspender el despacho de mercaderías, supuestamente piratas o de marca falsa vinculada a una operación de importación, exportación o tránsito, como medida cautelar. El estándar de convicción para realizar dicha operación está basado en una simple presunción, en consecuencia, hay un mayor poder de 
la autoridad aduanera para actuar sin requerimiento expreso del titular de la marca, en comparación con otras legislaciones analizadas. En cuanto al tipo de infracción, se permite que la autoridad aduanera actúe de oficio en caso de bienes supuestamente piratas o de marca falsa, por lo que habría que colegir que dicha entidad puede intervenir en caso de que exista vulneración en cuanto a los derechos de autor de una obra, y en caso de marcas comerciales $^{31}$. Esta amplitud de acción parece proteger de mejor manera a los titulares de derechos de autor o propiedad industrial, sin embargo, la forma en que se realiza despacho de mercadería en aduanas, impide que se puedan detectar infracciones distintas, a aquellas relativas a las marcas o el diseño de un producto. En cuanto a la destinación aduanera, la suspensión puede provocarse en el proceso de importación, exportación e incluso tránsito, lo que supera la obligación del texto multilateral ${ }^{32}$ que solo hace obligatoria dicha suspensión en operaciones de importación.

La norma colombiana tiene la particularidad de establecer expresamente y dar preferencia a la aprehensión de las mercaderías y a la persecución de infracción de delitos distintos al contrabando (que contempla la importación de bienes falsificados o pirateados) sobre las disposiciones legales analizadas en este apartado, a través de la puesta a disposición de la Fiscalía, de las mercaderías objeto del mismo.

Dicha preferencia, si bien significaría, en principio, poner en segundo lugar las obligaciones internacionales contraídas por Colombia en materia de importación de bienes pirateados y falsificados, lo cual causa un efecto muy parecido al buscado, ya que la aprehensión del bien en cuestión por motivos distintos al contrabando, de igual manera, saca de circulación la mercadería infractora, impidiendo de esta forma que el bien falsificado entre en circulación en el mercado formal y/o informal.

${ }^{31}$ Según el artículo segundo del d.1 4540 de 2006, mercancía pirata es "cualquier copia hecha sin el consentimiento del titular del derecho de autor o derechos conexos, o de una persona debidamente autorizada por él en el país de producción y que se realicen directa o indirectamente a partir de una obra o producción protegida cuando la realización de esas copias habría constituido una infracción al derecho de autor o de un derecho conexo".

32 TRIPS OMC. 


\section{Suspensión de despacho provocado o a requerimiento de parte}

En cuanto a la suspensión de despacho a requerimiento de parte o provocada, la ley entrega al titular de un derecho de propiedad intelectual, de mercancías objeto de importación, exportación o tránsito, la facultad de suspender provisionalmente dichas operaciones, mientras la autoridad judicial competente resuelve la denuncia o demanda por la supuesta condición de mercadería pirata o de marca falsa. En concreto la autoridad competente para conocer de dicha suspensión es la Dirección de Impuestos y Aduanas Nacionales de Colombia (DIAN), por medio de la División al Servicio del Comercio Exterior, en sede administrativa y eventualmente la autoridad judicial, como medida cautelar en procesos iniciados antes de que la mercadería llegue a destino, mientras se resuelve el fondo del asunto.

Para que la autoridad aduanera pueda comprobar la supuesta infracción de las normas en materia de marcas, será paso previo que el titular de dichos derechos registre su marca en el directorio llevado al efecto por dicha autoridad. La omisión de este requisito si bien no excluye la posibilidad de que se decrete la suspensión, la dificulta enormemente, debido a los plazos acotados con los que cuenta la autoridad administrativa y judicial.

En cuanto al contenido de la solicitud, la ley señala que el titular del derecho o quien lo represente deberá suministrar información en cuanto a la identidad del reclamante y titular del derecho infringido; de las personas autorizadas o licenciadas en el país para disfrutar del derecho de propiedad intelectual; descripción de los hechos que motivan la solicitud y del derecho infraccionado; identidad del fabricante de la mercadería genuina y del lugar de producción, descripción detallada de la mercadería auténtica, si fuera posible la descripción de la mercadería infractora y su lugar de producción; y si el solicitante lo estima necesario, la petición de autorización para realizar la revisión de la mercadería infractora. Esta solicitud deberá ser respaldada con la documentación que acredita al titular del derecho como tal, a quien lo representa, y en caso de que se hubiese iniciado un proceso ante la autoridad judicial con anterioridad a la solicitud de suspensión de despacho, copia de la denuncia o demanda correspondiente. Finalmente, será necesario aportar las pruebas que justifiquen que existe un indicio de infracción de derecho. La prueba de esta circunstancia es uno 
de los mayores desincentivos para que el titular de la marca inicie la acción, ya que es muy difícil producirla antes de que la mercadería siquiera arribe al puerto de destino.

La petición de examen de las mercaderías serán promovidas como un incidente aparte dentro del procedimiento administrativo, donde se deberá acreditar la calidad de titular del derecho, además de presentar la copia del poder o documento que lo autorice a actuar, en caso de ser una persona distinta del titular. Esta petición o solitud deberá ser resuelta en un plazo máximo de tres días y será notificado al importador, exportador o declarante por cualquier medio. El examen de la mercadería se hará en presencia de un funcionario aduanero y el peticionario, quien podrá estar asistido hasta por dos peritos contratados a su costa. En este procedimiento se respetará en todo momento la protección de la información confidencial.

Luego de presentada y admitida la solicitud ante la autoridad competente, se suspende el despacho de la mercadería a su destinación, ordenando su traslado a un depósito. Esta suspensión tiene una extensión de diez días a la espera de la resolución de la autoridad judicial, que podrá ordenar que se produzca el despacho de la mercadería o decretar alguna medida cautelar o provisoria que impida que las mercaderías entren en circulación o salgan del país.

En cuanto a la tramitación de esta solicitud, la autoridad aduanera tendrá tres días para admitirla o rechazarla, mediante la correspondiente resolución administrativa. En caso de admitirse el trámite de esta solicitud, el tribunal ordenará la suspensión de la operación aduanera; la constitución de garantía bancaria o de compañía de seguro equivalente al 20\% del valor FOB de la mercancía ${ }^{33}$, y de un 100\% del valor FOB de la mercancía para bienes altamente perecederos, a fin de garantizar los posibles perjuicios que se causen al importador o exportador. Se comunicará al depósito sobre dicha situación y se autorizará al peticionario para que dentro de los cinco días siguientes inspeccione la mercadería a su costa.

${ }^{33}$ El valor de la mercadería en el puerto de salida no considera transporte, seguros, ni impuesto. 


\section{Fase judicial de la suspensión de despacho o ante autoridad competente}

En el decreto analizado se entiende que será autoridad competente para conocer el fondo del asunto que originó la operación aduanera, la autoridad judicial con competencia en materia de propiedad intelectual, vale decir, la Superintendencia de Industria y Comercio cuando hay infracción de marcas, los jueces con competencia civil y penal y los fiscales judiciales.

Una vez notificada la solicitud del auto admisorio en sede judicial y dentro de los diez días siguientes, el peticionario deberá presentar en aduanas la garantía del $20 \%$ o del $100 \%$ del valor FOB de la mercadería, según sea el caso, y la demanda o denuncia con la que se promovió el correspondiente proceso ante la autoridad judicial respectiva si no lo hubiere hecho. La omisión de estos requisitos trae aparejado el desistimiento de la acción y el correspondiente despacho de los bienes sujetos a la medida.

En cuanto a la decisión de la autoridad judicial, si se declara la piratería o falsedad marcaria, la autoridad aduanera rechazará el levante o despacho y pondrá la mercancía a disposición de la autoridad judicial. En caso de ser rechazada la solicitud, la operación aduanera continuará su curso normal y se harán efectivas las garantías en favor del afectado. Es el tiempo que media entre el auto admisorio y la decisión del fondo del asunto, no forma parte de lo que la doctrina y la norma internacional ADPIC conoce como suspensión de despacho de la mercadería, que no puede prolongarse más de diez días, sino que se trata de una medida cautelar tomada en el marco del proceso civil o penal, aun cuando estas estén a disposición de la autoridad aduanera en la zona franca o depósito de aduanas.

Este proceso excluye ciertas mercaderías en concordancia con el artículo 60 del convenio ADPIC, que autoriza a excluir de la aplicación de las normas sobre suspensión de despacho las importaciones insignificantes, vale decir pequeñas cantidades de mercadería que no tengan carácter comercial o aquellas que formen parte del equipaje personal de los viajeros. El legislador colombiano incorpora además las entregas urgentes, sin definir qué situaciones se encuentran comprendidas en dicha excepción, quedando a criterio de la autoridad administrativa y/o judicial hacer un examen casuístico de dicha situación. 
Finalmente, es necesario destacar que ni el Decreto legislativo 4540 de 2006, ni la Decisión 486 de la Comunidad Andina de Naciones, se refieren a infracción de normas de propiedad industrial, como las patentes. Cuando el decreto legislativo colombiano se refiere a mercancía pirata, pareciera que existiera una luz de esperanza para proteger las infracciones de propiedad industrial distintas del derecho de marca; lamentablemente, el artículo segundo de esta ley define dicha mercadería como aquella copia hecha sin el consentimiento del derecho de autor o conexo, por lo tanto hacer la norma más extensiva dependerá del juez encargado de resolver la causa o de normativa interpretativa emanada de la potestad reglamentaria de la autoridad administrativa.

\section{Paralelo entre la Decisión 486 de la CAN y Decreto legislativo 4540 de 2006}

La decisión de la Comunidad Andina sobre régimen común de propiedad industrial es bastante acotada y solo se limita a las marcas, por lo que los países signatarios de la normativa OMC-ADPIC requieren de regulación específica sobre medidas en frontera, para cumplir con las obligaciones contraídas en virtud de este pacto multilateral. Así, el Decreto legislativo 4540 de 2006 es más extenso que el pacto regional CAN en cuanto al alcance de la norma, ya que extiende su acción a marcas, derechos de autor y conexos, y como consecuencia de aquello el titular de las medidas en frontera no solo es el titular del derecho marcario, sino también el titular del derecho de marcas, derecho de autor y derechos conexos.

En cuanto a los motivos para iniciar la acción, la Decisión 486 de la CAN requiere de motivos fundados de productos que infringen el derecho marcario, en cambio la normativa colombiana requiere solo de indicios, dando mayor margen interpretativo al personal fiscalizador de aduanas y al titular de los derechos de propiedad intelectual. Para determinar la prioridad de la aplicación de una normativa sobre otra, es necesario señalar que todo aquello distinto al derecho de marcas siempre va a ser regulado por el Decreto legislativo 4540 de 2006, y en caso de transgresión de derecho marcario, también primará la normativa particular de Colombia, debido a su especificidad. 
Finalmente, ambas normativas presentan diferencias en cuanto a la naturaleza de la suspensión oficiosa, ya que la normativa de la CAN la entiende como una potestad administrativa de la autoridad, y el decreto legislativo de Colombia, como una medida de carácter cautelar.

\section{Conclusiones}

Luego de haber estudiado la legislación de una serie de países latinoamericanos sobre observancia de los derechos de propiedad intelectual en frontera, y haber analizado una amplia gama de investigaciones nacionales y extranjeras sobre el particular, es posible concluir que la incorporación de normativa sobre medidas en frontera en las legislaciones nacionales ha influido de manera positiva y significativa en la observancia de los derechos de propiedad intelectual. Esto debido a que la mejor alternativa para frenar el flujo comercial de bienes pirateados o falsificados o que vulneren los derechos de autor es impidiendo su entrada a los mercados locales en el puerto de entrada o salida de la mercadería.

La incorporación de la normativa analizada supone además superar el gran vacío legal que existía en cuanto al hallazgo de mercancía falsificada por parte del personal fiscalizador de aduanas, que iniciaba acciones legales, basado a veces solo en conjeturas que derivaban en la incautación de mercaderías, que en caso de no vulnerar las normas de propiedad intelectual era liberada luego de varias semanas o meses causando un perjuicio incalculable para el importador o exportador de tales bienes.

La normativa de la OMC-ADPIC en cuanto a las prescripciones especiales relacionadas con las medidas en frontera supone establecer criterios reglados y uniformes, aunque flexibles, en los distintos países miembros del acuerdo, lo que mejora la posibilidad de combatir a nivel internacional el contrabando de bienes que vulneran las normas de propiedad intelectual.

La normativa internacional supone, entonces, el establecimiento de criterios reglados y conocidos que mejoran la protección que merecen los titulares de los derechos de propiedad intelectual, pero que a su vez resguardan los intereses de los importadores y exportadores, que no se ven sometidos 
a procesos injustificados y donde se establecen garantías económicas a su favor, en caso de que no hubiesen cometido infracción.

Sobre el cumplimiento de las obligaciones contraídas por nuestros países, a través de la suscripción de los acuerdos de la OMC, al ser este convenio un marco de aplicación mínima y supletoria que deja bastante libertad a sus miembros para establecer y decidir qué tipo de regulaciones aplicarán en frontera, según sus necesidades y contingencias internas, no se detectan áreas en que las leyes analizadas vulneren o transgredan las disposiciones contenidas en los acuerdos ADPIC.

Lo que sí se detectan son insuficiencias de estas regulaciones en cuanto a establecer en algunos casos criterios ambiguos para que la autoridad administrativa actúe de oficio, en otros casos simplemente a no establecer actuación de oficio por parte del personal de aduana. En cuanto a la solicitud de suspensión de mercadería por parte de los titulares de las marcas, se establecen plazos muy acotados para establecer las acciones correspondientes, montos muy elevados de caución a favor de los importadores/exportadores, y dificultad para informarse acerca del envío de cargamentos que vulneren sus derechos, lo que a la larga deriva en que resulta más conveniente que la autoridad actúe de oficio, y esperar ser notificado de dicha infracción para proceder judicialmente.

En atención a los argumentos expuestos, es que consideramos pertinente avanzar hacia un sistema de observancia de derechos de propiedad intelectual en fronteras, donde la solicitud de suspensión del despacho de mercadería infractora se realice por los titulares de los derechos inscritos ante la propia autoridad aduanera, previa notificación del hallazgo de la mercadería, y donde el resto del proceso sea conducido en sede jurisdiccional por el juez con competencia en lo penal, que va a conocer de la acción de fondo.

\section{Bibliografía}

Medeiros, H. G. (2011). Medidas de fronteira trips-plus: Implicações e limites à expansão de normas de observância dos direitos de propriedade intelectual. 
Florianopolis: Universidade Federal de Santa Catarina, Centro de Ciências Jurídicas.

Comunidad Andina. (2007). Medidas en Frontera sobre Propiedad Intelectual. Lima: Proyecto de Cooperación UE-CAN.

VRINS, M. S. (2007). The magnitude and economic and social consequences of counterfeiting and piracy. In M. S. Vrins, 'Enforcement of Intellectual Property Rights trough Border Measures - Law and Practice in the EU. London: Oxford University Press.

Bluztein, N. y. (2009). Las Medidas en Frontera en el Ecuador. Quito.

Castrillón, C. O. (2012). Protection of Intellectual Property through border. Milano: Giuffré Edittore.

The Ministry of Commerce of China. (2008). Roadmap for intellectual Property Protection in China, custom enforcement in China. Beijin.

NúÑEz, J. F. (2010). Marcas y Medidas en Frontera en el acuerdo TRIPS. In Revista de Estudios Aduaneros. Buenos Aires: Revista de Estudios Aduaneros.

Kumar, S. P. (2009). European Border Measures and Trade in Generic Pharmaceuticals: Issues of TRIPS, Doha Declaration and Public Health. In International Trade law E Regulation Journal (pp. 176-184). London: sweet and maxwell.

Vaccaro, C. S. (2012). El acuerdo sobre los derechos de propiedad intelectual relacionados con el comercio, 10 años de vigencia en chile. Concepción.

Seuba, X. (2009). Border Measures Concerning Goods Allegedly Infringing Intellectual Property Rights: The Seizures of Generic Medicines in Transit. Geneva: ICTSD Programme on IPRs and Sustainable Development.

Ruse, K. H. (2011). A Trade Agreement Creating Barriers to International Trade?: ACTA Border Measures and Goods in Transit. American University International Law Review $N^{\circ} 26$, 647-726.

Téllez, V. M. (2006). The World Customs Organization and Border Measures for Enforcement of Ip Rights: Setting New Standards of 
Intellectual Property Enforcement Through the Back Door? South Bulletin: Reflections and Foresights, 6-19.

Correa, C. F. (2009). The Global Debate on the Enforcement of Intellectual Property Rights and Developing Countries. Geneve: ICTSD Programme on Intellectual Property Rights and Sustainable Development.

Rose, G. A. (2011). Border measures to prevent the importation of counterfeit products. APAA 59th Council Meeting - 12-15 November 2011. Manila.

World Customs Organization. (2002). Model Provisions for National Legislation to Implement Fair and Effective Border Measures Consistent with the Agreement on Trade-Related Aspects of Intellectual Property Rights. Brussels.

Reichman, J. (1995). Universal minimum standards of intellectual property protection under the TRIPS component of the WTO agreement. International Lawyer.

Venturini, D. F. (2006). Tutela comunitaria alla frontiera dei diritti di proprietà intellettuale.

Kumar, H. (2004). Border areas for the protection of intellectual Property Rights: An Analisys . Journal of intellectual property Rights , 43-50.

Salazar L, D. O. (2010). Observancia de los derechos de propiedad intelectual en relación con las medidas en frontera de Venezuela. Caracas.

World Trade Organization. (2006). Enforcing Intellectual Property Rights: Border Measures, Communication from the European Communities. Geneve.

WIPO Intellectual Property Handbook: Policy, Law and Use. (2004). Enforcement of Industrial Property Rights, Copyright and Related Rights. Geneva.

Anisefzeswixy, S. (2009). Cordinate Border Management a concept paper. Brussels. 
Polner, M. (2011). Coordinated border management:from theory to practice. Brussels.

World Customs Organization. (2012). Estudio sobre la gestión coordinada de fronteras. Brussels.

Аввотт, F. M. (2006). Intellectual Property Provisions of Bilateral and Regional Trade Agreements in Light of U.S. Geneva: UNCTAD.

Campos, E. M. (2010). Medidas De Fronteira Para Protecao Da Propiedade. Sao Paulo.

Wadlow, D. C. (2007). Including Trade in Counterfeit. Intellectual Property Quarterly.

Organization, W. C. (2011). Custom and IPR report. Geneva: WCO. 



\section{HOLOGRAMÁTICA Y GESTIÓN PEDAGÓGICA EN LA FORMACIÓN JURÍDICA EN COLOMBIA}

Félix Mendoza de la Espriella'

\section{Resumen}

El propósito de este trabajo es la resultante de una primera inquietud en torno a la hologramática y la gestión pedagógica como herramienta para comprender la dinámica propia de la formación jurídica. Lo que se trata de averiguar es en qué medida la hologramática y la gestión pedagógica afectan la formación jurídica y, con ello, el contenido mismo de lo que pensamos y hacemos. Pues bien, la construcción de una perspectiva que emerge de lecturas, observaciones y diálogo con otros abogados, educadores y filósofos nutre este trabajo. Tres grandes ideas le siguen en el tejido realizado a partir de plantear que "la Hologramática es a la Gestión Pedagógica como la Formación Jurídica lo es al contenido mismo de lo que pensamos y hacemos en la Facultad de Derecho". Las emergencias indican que aún lo dicho no es el tejido definitivo, sino que son las ideas que se hilvanan y marcan nudos que se seguirán en muchas dimensiones.

Palabras clave: hologramática, gestión pedagógica, formación jurídica.

1 Abogado. Doctorando en Ciencias de la Educación. Magíster en Educación. Especialista en Gerencia de la Educación. Docente Facultad de Derecho y Ciencias Políticas de la Corporación Universitaria del Caribe (CECAR). felix.mendoza@cecar.edu.co. 


\section{Abstract}

The purpose of the paper is the result of an initial concern about the hologrammatic and Educational Management as a tool for understanding the dynamics of Legal Education. What is to find out it is to what extent and Educational Management hologrammatic affect Legal Education and thus, the content of what we think and do. Well, the construction of a perspective that emerges from readings, observations and discussions with other lawyers, educators and philosophers nurtured this work. Three big ideas followed in the fabric made from the hologramatic raise is the Educational Management Legal Education as it is the very content of what we think and do in the Faculty of Law. Emergencies indicate that this is still not the definitive tissue but are the ideas that weave and make knots to be followed in many dimensions.

Keywords: hologramatic, educational management, legal education.

\section{Introducción}

La situación que provoca esta reflexión fue pensar en que de lo que se trata realmente es de cómo reinventar lo humano desde lo que somos, profesores y estudiantes. ¿Qué significa esto en el marco del interrogante señalado? Pues que pareciese referirse a que lo humano está educativamente descuidado, y no esté el sentido a lo referido; sino que su significado marca otra opción. Más no es una contradicción, es una revelación, tal como lo plantea Edgar Morín (2008b). "Lo que revela la contradicción, si ella es insuperable, es la presencia de un nivel profundo de la realidad que cesa de obedecer a la lógica clásica o aristotélica”. Y ello generó una primera inquietud en la tesis doctoral que adelanto sobre los principios del pensamiento complejo y el discurso jurídico, la cual hace relación a la hologramática y la gestión pedagógica como herramientas para comprender la dinámica propia de la formación jurídica.

El objetivo es averiguar en qué medida la hologramática y la gestión pedagógica afectan la formación jurídica y, con ello, el contenido mismo de lo que pensamos y hacemos en una Facultad de Derecho. Pues bien, el pro- 
pósito en esta ocasión es presentar los resultados obtenidos al desarrollar la respuesta. La manera como se ha venido haciendo esta labor se basa en la idea expuesta por Morin (2010): "Ayúdate y la complejidad te ayudará" (p. 110); también, en que "Estamos obligados a desbanalizar el conocimiento y nuestra visión del mundo" (p. 97).

Este foco generado por el interrogante señalado lleva a que se asuman como presupuestos los siguientes.

- Lo que se ha de ser como sujeto profesional mañana posibilita la formación en una sociedad, que no es la actual, es la que deviene con el conocimiento, el saber ser y saber hacer. Se entiende aquí que la educación prepara para el mañana, pero el mañana no es la sociedad actual, es la sociedad del conocimiento.

- Abordar la planeación del proceso de formación con enfoques diferentes a la tendencia tradicional, normativa.

- La formación constituye un satisfactor y una necesidad en el siglo XXI.

- El conocimiento y el aprendizaje en el siglo XXI apuntan a un nuevo perfil de sujeto.

El andamiaje teórico, epistemológico y metodológico desarrollado para este propósito inicial apuntó desde sus comienzos tanto a generar puentes con esos nuevos mundos de conocimiento y formación como a entablar una interacción con los sujetos que lo constituyen.

Se reconoce que en el marco de ese panorama que se conforma al finalizar el siglo XX y con el que inicia el siglo XXI, la educación del sujeto adquiere mayor importancia cuando se articula cada vez a las necesidades sociales y humanas. En esta afirmación se centra uno de los retos actuales de la formación. He aquí porque urge a

La universidad distinguir, sin oponerlos, entre saberes rentables y saberes indispensables, pues creo que es ahí, en esa encrucijada de saberes, donde se dirime el sentido y el futuro de universidades que se han dado a sí mismas explícitamente un proyecto social, es decir no 
sólo un oficio, el de enseñar, sino una vocación, la de formar ciudadanos (Barbero, Martín J. (2002, p. 65).

En el ámbito problémico antes expuesto e iluminado por la fórmula del poeta griego Eurípides, que data de hace 25 siglos y que está ahora más vigente que nunca, la cual es recordada por Morin en su libro Los siete saberes... y que dice: "Lo esperado no se cumple y para lo inesperado un dios abre la puerta" (1999, p. 2), se origina el planteamiento siguiente: "la Hologramática es a la Gestión Pedagógica como la Formación Jurídica lo es al contenido mismo de lo que pensamos y hacemos en la Facultad de Derecho". Lo planteado se articula en tres planteamientos centrales que se desarrollan a continuación.

\section{La integración, principio hologramático en la organización de la formación en el siglo $\mathrm{XXI}$}

Es comprensible que el mundo cambia permanentemente y es complejo. En relación con esta afirmación es la complejidad como cosmovisión, la que va dar su sentido organizativo. De acuerdo con lo anterior:

Hemos comenzado a comprender el mundo en términos de sistemas dinámicos, donde las interacciones entre los constituyentes de los sistemas y su entorno resultan tan importantes como el análisis de los componentes mismos. El mundo ha comenzado a dejar de ser un conjunto de objetos para presentarse a la mente y al conocimiento como realidad de interacciones de redes complejas, emergencia y devenir (Sotolongo Codina, Pedro Luis. 2006, p. 42).

Desde esta perspectiva, entonces, los opuestos a la integración surgen y se unen. Es decir, una tendencia contraria que en el contexto social y formativo posibilita la desintegración, muestra que en

Nuestras sociedades son, al mismo tiempo, "sociedades del desconocimiento", esto es, del no reconocimiento de la pluralidad de saberes y competencias culturales que, siendo compartidas por las mayorías populares o las minorías indígenas o regionales, no están siendo incorporadas como tales ni a los mapas de la sociedad ni siquiera a los de sus sistemas educativos (Martín, Barbero, J., 2002, pp. 11-12). 
¿Qué significado tiene esto para la formación? Eso significa negación formativa de unos sujetos a otros sujetos. Y la urgencia de superación de la incomprensión. Morin (1999) señala que "el planeta necesita comprensiones mutuas en todos los sentidos” (p. 3). Los sentidos mutuos a los que se alude en este caso constituyen posibilidades comprensivas de superación de oposiciones y abertura de opciones de religación y organización.

Ahora bien, cuando se religan tanto los sujetos como los sentidos en su homo y heterogeneidad surge la nueva organización. Al respecto, Morin destaca que es necesario religar o articular los principios antagonistas con el objeto de hacer emerger otro principio superador como es el de la organización (Morin, 2008b). Esta concepción organizativa, que el autor denomina "hologramática" (1998:22, 1999, 2008b), implica, entonces, dar cuenta de la relación dialéctica entre el todo y las partes, destacando de qué modo el todo está presente siempre en las partes y las partes presentes de forma inherente en el todo (2008b).

Desde la anterior visión, por ejemplo, la organización de la formación en una Facultad de Derecho partirá de cada elemento constitutivo de los subsistemas articulados entre sí: académico-investigativo, administrativo, evaluativo, comunicativo y otros, hacia el todo que es la facultad como sistema formativo institucional, y quien a su vez se articula a uno mayor: la universidad. Esta nueva forma organizativa es la hologramática en la organización de la formación en el siglo XXI.

Ahora bien, Carlos Maldonado (1999), citado por Sotolongo Codina, Pedro L. muestra una línea de trabajo por desarrollar en la perspectiva de la complejidad: "la complejidad como método de pensamiento (la propuesta de un método de pensamiento que supere las dicotomías de los enfoques disciplinarios del saber y que consiste básicamente en el aprendizaje del pensamiento relacional)" (Sotolongo Codina, Pedro L. 2006, p. 42). Es, por consiguiente, esta línea de trabajo la que abre posibilidades a lo pedagógico en esta nueva visión de la formación en la universidad y en la Facultad de Derecho. 


\section{¿Cómo comprender esto?}

Una parte de la comprensión fue posible encontrarla al responder a la siguiente pregunta: ¿de qué manera se articula el pensamiento complejo a la pedagogía de la formación hologramática emergente? La respuesta se complejiza, ya que, como señala Cerdas Vega, Gerardo (2008), "enseñar y aprender no ocurren en el vacío, sino en tiempos y contextos históricos particulares, donde intervienen distintos proyectos y concepciones acerca del papel que la educación ocupa en la vida social” (p. 328). Así, cada vez que se pretende formar de manera pedagógica y hologramática, necesariamente están presentes de manera organizada y desorganizadamente en la dinámica y dialéctica educativa una serie de elementos de la vida social, la ciencia y el conocimiento, entre otros, que se entrecruzan de manera ineludible, aunque se invisibiliza o se visibilizan dialécticamente en un bucle pedagógico.

Pues bien, en la forma discursiva en que se teje este avance, aparece otra idea, sin que ello indique dar por finalizada esta primera; más bien se busca construir una nueva trama.

\section{Lo humano propio de cada época une al sujeto y al conocimiento en la formación del siglo XXI}

De acuerdo con las notas de análisis realizado, lo humano le es dado al sujeto y a este el conocimiento le deviene. Ayuda a explicar esto las palabras de von Glasersfeld con las que concluye, citando a von Foerster, su ensayo Despedida de la objetividad:

Sea lo que fuere lo que entendemos por "conocimiento", ya no puede ser más la imagen o la representación de un mundo independiente del hombre que hace la experiencia. Heinz von Foerster lo ha dicho con ejemplar concisión: "La objetividad es la ilusión de que las observaciones pueden hacerse sin un observador" (p. 19).

Si lo dicho se asume analógicamente, entonces, la formación humana en la Universidad no podría hacerse sin los sujetos, sin un contexto, sin un 
espacio, sin escenario y sin tiempo. Su organización y desarrollo están de por sí articuladas a la multiversidad de concepciones de saberes, ciencias y visiones antropo-epistémica-social-comunicativas. En este sentido, la perspectiva es ir un paso más allá de lo hecho en la formación en derecho en Colombia en donde

Cada disciplina ha abordado el problema del conocimiento desde un marco disciplinario particular; no obstante, pocos son los marcos epistemológicos que han intentado estudiar y pensar el problema del conocimiento desde una perspectiva de articulación interdisciplinaria, con miras a poner en comunicación los aportes que las distintas disciplinas han realizado al estudio del problema del conocimiento (Rodríguez Zoya, Leonardo G., 2011, p. 24).

El desafió que infiero consiste en empezar a dar formas complejas a la complejización pedagógica de lo humano del sujeto que forma parte del todo formativo y cuya presencia ineludible en el tiempo marca la raíz del contenido y la directriz de lo que se hace y no se hace en la formación universitaria de abogados y abogadas en Colombia.

Ahora bien, si aceptamos como supuesto que toda la formación y pedagogía gira en torno al sujeto, a lo humano y ello tiene como condición de posibilidad la de capacitarle para crear mejores condiciones vitales, sociales, científico-técnicas profesionales (que se manifiesta en las competencias en desarrollo y las evolutivas formas de ver y comprender el mundo); si es cierto que estamos en un universo que es cambiante, diverso y complejo hologramáticamente, podemos ir formativa y pedagógicamente creando un pensamiento complejo que posibilite el cambio de perspectiva sobre lo humano como proyecto en continua deconstrucción-construcción. En otras palabras, es el "otro modo" humano de unir al sujeto con el mundo y con el conocimiento en la formación del siglo XXI en las facultades de derecho en Colombia.

A fin de ganar claridad expositiva, puntualicemos, de modo sintético, lo obtenido en cuanto a la tercera idea. 


\section{La formación complejiza al conocimiento y al aprendizaje}

Cuando se estudia la formación del sujeto desde la universidad actual, surgen las articulaciones que aportan distintos sentidos y significados al contenido, a lo que se hace, pensamos y proyectamos; cada arista de este prisma es aportante: lo administrativo, lo científico, lo humano, lo social, lo comunicativo, lo tecnológico, lo organizativo, lo protocolario. Esta visión lo que permite inferir es que la realidad se complejiza. Y esto es así porque la realidad formativa, el sujeto y la organización del saber científico, es compleja.

La epistemología compleja afirma que el conocimiento es un objeto complejo por dos razones fundamentales. En primer lugar, es complejo porque el conocimiento constituye una totalidad organizada compuesta por un conjunto de elementos heterogéneos (biológicos, sociales, culturales, psicológicos, lógicos, históricos) y en interacción. Por consiguiente, los elementos y procesos constitutivos del conocimiento no resultan separables y no pueden ser estudiados aisladamente. Los componentes que intervienen en el proceso de construcción de conocimiento son interdefinibles, es decir, se determinan mutuamente. En segundo lugar, el conocimiento es un objeto complejo puesto que los elementos y procesos que lo constituyen no pueden ser abordados por una disciplina particular. La pregunta cómo conocer el conocimiento no tiene respuesta disciplinar, se requiere una perspectiva transdisciplinaria que atraviese y vaya más allá de los conocimientos particulares de cada disciplina (Rodríguez Zoya, Leonardo G., 2011, p, 25).

Unido a lo anterior se entiende que:

La formación como fenómeno específicamente humano se compone de acciones educativas emprendidas por seres humanos, sobre o con seres humanos y para seres humanos y, al margen de lo que son unos y otros, no se pueden entender los procesos que constituyen sus actividades (Arroyave G. Dora Inés, 2003, p. 18).

Pensado en este sentido, el conocimiento y el aprendizaje articulado al pensamiento en su complejidad plantean el cambio. En tanto que pedagógica y hologramáticamente el cambio se genera de manera paradigmática. 
Así lo ve Morin cuando plantea que "una reforma del pensamiento es una reforma paradigmática. Se trata de un cambio en los principios de pensamiento y de organización de los saberes, lo cual no puede ser aislado de un cambio en los principios de organización de la sociedad, la economía y la política. Esta transformación en cadena es lo que denomina revolución paradigmática (Morin 1991).

Para Arroyave G. Dora Inés (2003), cualquier forma de saber debe entenderse como una cualidad constitutiva de los agentes que actúan, contribuyendo a construir las acciones transformadoras (p.18). Con esta idea, lo que quiere significar la autora es que hay un ir y venir entre el actuar-sujeto-saber que es indisoluble en la formación y organización hologramática. De manera, que

En el mundo pedagógico las múltiples acciones de los sujetos son, pues, el reflejo de las singularidades de quienes las realizan, esas acciones llevan sus sellos, se entrelazan con otras acciones en un tejido, en una red de relaciones, constituyendo un estilo propio entre quienes se dedican a formar-se y constituyen un proyecto colectivo que suma esfuerzos particulares en el que cabe distinguir, porque las singularidades individuales no se borran, por el contrario, enriquecen a las sociales (p. 18).

\section{Nota final}

Pensar para volver a empezar. Es el volver a la realidad y constituye el ahora, el nudo que marca un encuentro dialógico de estas primeras aproximaciones y observaciones realizadas. Hay aún rupturas e incertidumbres que requieren mucha más atención y profundidad. A manera ilustrativa planteamos la siguiente pregunta: ¿qué tanta capacidad para rupturas y encuentros se están tejiendo en la formación universitaria para no alejarse de la compleja y dinámica realidad actual en Colombia y en otros países del planeta?

\section{Bibliografía}

Arroyave G. Dora Inés. (2003) Pensamiento Complejo. La revolución pedagógica precedida por la revolución del pensamiento: un encuentro 
entre el pensamiento moriniano y la pedagogía. Tomado de: Manual de Iniciación Pedagógica al Pensamiento Complejo. Publicaciones Unesco, Ecuador, pp. 330-361. Recuperado de http://cmap.upb.edu.co/ rid=1196125280484_1443768333_965.

Cerdas Vega, Gerardo. (2008) La reforma de la educación superior universitaria en América Latina: una aproximación crítica desde el pensamiento freireano. En publicación: Paulo Freire. Contribuciones para la pedagogía. Moacir Godotti, Margarita Victoria Gómez, Jason Mafra, Anderson Fernández de Alencar (compiladores). Buenos Aires. CLACSO, Consejo Latinoamericano de Ciencias Sociales.

Ernst von Glasersfeld (1994): “Despedida de la objetividad”, pp. 1931. Paul Watzlawick y Piter Krieg (Comps.) El ojo del observador. Contribuciones al constructivismo. Gedisa, Barcelona.

Ernst von Glasersfeld (1988): "La construcción del conocimiento", pp. 115-128. Dora Freíd Schnitman.

Martín, Barbero, J. (2002) Tecnicidades, identidades, alteridades: desubicaciones y opacidades de la comunicación en el nuevo siglo. En revista Diálogos de la comunicación. Federación Latinoamericana de Facultades de Comunicación Social (FELAFACS), №. 64, pp. 9-24 ISSN 1813-9248 Recuperado de http://www.infoamerica.org/ documentos_pdf/martin_barbero1.pdf

Martín, Barbero, J. (2002) Transformaciones del saber y del hacer en la sociedad contemporánea. En revista Sinéctica $N^{\circ} 21$, julio-diciembre.

Morín, E. (2010). Complejidad restringida, complejidad general. Traducción de Maiala Meza, con la colaboración de Julián Meza. Estudios 93, vol. VIII, verano 2010.

Morín, E. (2008b). Epistemología de la complejidad. Biblioteca Virtual Participativa de la Complejidad, 2004. Recuperado de http://www. pensamientocomplejo.com.ar/documento.asp.

Morín, E. (1999). Los siete saberes necesarios a la educación del futuro. Traducción Mercedes Vallejo-Gómez. París. Francia. UNESCO. 
Organización de las Naciones Unidas para la Educación, la Ciencia y la Cultura.

Morín, Edgar. (1991). El método IV. Las ideas (1998, 20 ed.). Madrid: Cátedra. Fuente: Pacarina del Sur.

Gómez, Nelson Vallejo. (1998) De la hechizadora ideología a la verdad de la incertidumbre. Edgar Morin en sus vivencias, en Trabajo Social.

Rodríguez Zoya, Leonardo G. (Coordinador) (2011). Exploraciones de la complejidad. Aproximación introductoria al pensamiento complejo y a la teoría de los sistemas complejos. Buenos Aires, Centro Iberoamericano de Estudios en Comunicación, Información y Desarrollo (CIECID).

Rodríguez Zoya, Leonardo G. (2011). Introducción crítica a los enfoques de la complejidad: tensiones epistemológicas e implicancias políticas para el Sur. En:

Rodríguez Zoya, Leonardo G. (Coordinador) (2011). Exploraciones de la complejidad Aproximación introductoria al pensamiento complejo y a la teoría de los sistemas complejos. Buenos Aires, Centro Iberoamericano de Estudios en Comunicación, Información y Desarrollo (CIECID).

Sotolongo Codina, Pedro Luis. (2006) La revolución contemporánea del saber y la complejidad social: hacia unas ciencias sociales de nuevo tipo / Pedro Luis Sotolongo Codina y Carlos Jesús Delgado Díaz 1a ed. Buenos Aires: Consejo Latinoamericano de Ciencias Sociales - CLACSO. 



\section{EL CAMINO A LA IMPUNIDAD: LA SITUACIÓN DE LOS DERECHOS HUMANOS DE LOS NIÑOS, NIÑAS Y ADOLESCENTES EN EL PROCESO DE JUSTICIA Y PAZI}

Margarita Jaimes Velásquez ${ }^{2}$

\section{Resumen}

El presente trabajo constituye un avance de la investigación "El derecho a la reparación individual de niñas niños y adolescentes. ¿Una utopía?”, el cual reúne los hallazgos iniciales del proceso científico de investigación. La metodología empleada se abordó desde un enfoque cualitativo, con una población de estudio circunscrita a la ciudad de Sincelejo (Sucre) en el periodo comprendido entre 2012-2013. Como técnicas de recolección de información se realizaron grupos focales con adolescentes entre 12 y 17 años, entrevistas semiestructuradas a funcionarios y funcionarias la Unidad de Justicia y Paz de la

1 Investigación desarrollada por el Grupo de Investigaciones GICSER, adscrito al Departamento de Investigaciones de la Facultad de Derecho de la Corporación Universitaria del Caribe - CECAR.

2 Abogada de la Universidad del Atlántico. Docente investigadora de la Corporación Universitaria del Caribe - CECAR. Especialista en Derechos Humanos y Derecho Internacional Humanitario de la ESAP, con estudios en Derechos Humanos en el Instituto Raoul Wallemberg de la Universidad de Lund (Suecia). Estudiante del programa de DH del Instituto Interamericano de Derechos Humanos (Costa Rica) (2007). Magistra en Educación de los Derechos Humanos del Centro Regional para la Educación de Adultos en América Latina y el Caribe -CREFAL (México). margarita.jaimes@cecar.edu.co 
Fiscalía General de la Nación y de la Unidad de Víctimas, territorial Sucre.

Palabras clave: justicia y paz, sistema de responsabilidad penal adolescente, derechos humanos y niñez.

\section{Summary}

This work is a breakthrough research "RIGHT TO REPAIR THE INDIVIDUAL CHILD AND ADOLESCENT GIRLS. A utopia?" Which brings together the initial findings of the scientific research process. The methodology is approached from a qualitative approach with a study population confined to the city of Sucre Sincelejo- in the period 2012-2013. As information gathering techniques focus groups with adolescents between 12 and 17 years, semi-structured interviews with officials and officials of the Justice and Peace Unit of the Attorney General's Office and territorial Victims Unit Sucre were made. This chapter book brings together the initial findings of the scientific research process.Keywords: justice and peace childhood, adolescent criminal liability system, human rights.

\section{Introducción}

El espíritu de la Convención de los Derechos del Niño y de la Constitución Política Colombiana es el mismo: colocar a los niños y niñas como una prioridad y un imperativo jurídico para el Estado sin distinción alguna. Los niños, niñas y adolescentes son sujetos de derechos, por consiguiente, respetar sus derechos, permitir su acceso y goce constituye un imperativo para la familia, la sociedad y el Estado.

No obstante lo anterior, en materia de derecho penal y especialmente en el proceso de Justicia y Paz, las investigaciones que realiza la Fiscalía General de la Nación no dan cuenta de las especificidades de las violaciones a los derechos de la niñez y la adolescencia, como tampoco del impacto diferencial del daño en razón de la edad y el nivel de desarrollo humano del individuo; eso es igual a decir que existe una negación del derecho a 
la justicia, pues la identificación e inventario de los daños está sujeta a la adecuación típica en tanto constituye un prerrequisito para el acceso a la justicia y la reparación de que trata la Ley 975 de 2005.

La edad es un factor determinante en el incremento de la vulnerabilidad cuando de acciones armadas se trata. La niñez y la adolescencia sufren particularmente cuando sus derechos a la recreación, el libre desarrollo de la personalidad y la educación, entre muchos otros, son restringidos o vulnerados por las acciones de los actores armados ilegales que ejercen el control en el territorio. No obstante esta realidad, rara vez en la justicia penal se diseñan programas metodológicos para investigar este tipo de conductas lesivas y transgresoras de los derechos específicos de la niñez y la adolescencia, razones que se convierten en un obstáculo para el acceso a la justicia de los niños, las niñas o los adolescentes, quienes difícilmente podrán participar activamente en el proceso judicial de Justicia y Paz en condición de víctimas, máxime cuando deben enfrentarse a otras dificultades formales y procesales para recurrir por sí mismos al sistema judicial a fin de que se protejan sus derechos y exigir la reparación integral por el daño sufrido.

A pesar de ser un tema trascendental por la afectación directa y diversa a un grupo etario de especial protección constitucional, son pocos los trabajos y estudios encontrados al respecto. Se hallaron investigaciones sobre el reclutamiento forzado de niños, niñas y adolescentes (en adelante NNA), la Coalición Contra la Vinculación de Niños, Niñas y Jóvenes al Conflicto Armado en Colombia (COALICO) y la Comisión Colombiana de Juristas, con el apoyo de War Child, Agencia de Cooperación Técnica Alemana al Desarrollo (GTZ), y el Fondo de las Naciones Unidas para la Infancia (UNICEF) publicaron en el 2009 el libro El delito invisible. Criterios para la investigación del delito de reclutamiento ilícito de niños y niñas en Colombia. Este estudio plantea elementos para la construcción de una estrategia jurídica para el litigio de casos de vinculación de niños y niñas al conflicto armado, a fin de lograr sus derechos a la verdad, la justicia y la reparación integral por esta infracción al DIH, sin abordar otras victimizaciones sufridas por esta población. Lo anterior es preocupante ya que es poco el avance en las investigaciones o estudios referidos a otras formas de violencia sufrida por la niñez y la adolescencia en el marco del conflicto armado. 
En el campo de los derechos humanos este tema es de suma relevancia, en tanto es obligación del Estado cimentar y promover el enfoque de protección integral adoptado a nivel universal, que declara que los niños, niñas y adolescentes tienen derecho a ser partícipes en los procesos, como en toda actuación ante las autoridades competentes, máxime en el acceso a la justicia dentro del proceso de Justicia y Paz por las violaciones a sus derechos humanos realizadas por los grupos paramilitares.

\section{El marco de los derechos humanos de los niños, niñas y adolescentes}

El preámbulo de la Declaración Universal de los Derechos Humanos toma en consideración la libertad, la justicia y la paz en el mundo desde el reconocimiento de la dignidad humana y la igualdad de todas las personas, exhortando a los Estados parte a garantizar a todos sus derechos esenciales. Establece, así mismo, el derecho a que se instituya un orden social e internacional en los derechos y libertades proclamados en la Declaración.

Los derechos de los niños, niñas y adolescentes se sustentan en varios instrumentos internacionales de protección a los derechos humanos, entre los cuales se mencionan para los fines de la discusión los siguientes: la Convención sobre los Derechos del Niño, de 1989, que constituye el primer documento normativo sobre la materia y el Protocolo Facultativo de la Convención sobre los Derechos del Niño relativo a la participación de niños en los conflictos armados del año 2000. En estos instrumentos se establecen obligaciones relativas a la creación de medidas especiales de protección y asistencia a los niños, niñas y adolescentes, deberes que son sustentados detalladamente en la Observación General No. 2 de 2002 del Comité de los Derechos del Niño de las Naciones Unidas, al recordar que "el estado de desarrollo de los NNA los hace particularmente vulnerables a violaciones de derechos humanos".

Aunque en el Sistema Interamericano de Derechos Humanos el concepto niño, niña o adolescente no se encuentra claramente definido, la Convención Americana de Derechos Humanos establece su protección y las respectivas obligaciones de los estados frente a su garantía; por otra parte, la Comisión Interamericana, así como de la Corte Interamericana de 
Derechos Humanos en diversos fallos ha reiterado que el concepto de niño acogido por el Sistema Interamericano es el contenido en el artículo $1^{\circ}$ de la Convención de los Derechos del Niño de 1989.

\section{Convención internacional de los derechos del niño}

Ahora veamos, la Convención Internacional de los Derechos del Niño (CDN) ha sido determinadora al momento de redefinir el enfoque de atención a la niñez y la adolescencia en su relación con los adultos y los estados asumiendo una doctrina de protección integral, en la que prevalece el interés superior del niño o de la niña. $\mathrm{La} \mathrm{CDN}$ les reconoce en el artículo 12 el derecho a expresar sus opiniones libremente en todos los asuntos que le afectan, así como el derecho a ser escuchado por las autoridades judiciales y administrativas; en su artículo 13, regula el derecho a la libertad de expresión, a buscar, recibir y difundir informaciones e ideas de todo tipo; el derecho a la libertad de pensamiento, de conciencia y religión plasmado en su artículo 14, de igual forma, el derecho de acceso a la información contenido en el artículo 16. Conviene subrayar, además, que protege ampliamente los derechos económicos y sociales de los NNA a la vida, al desarrollo, la educación y la formación profesional a través de los artículos 28 y 29, esto es, a la práctica de los derechos humanos y de los mismos derechos del niño. Reafirma la protección ante conflictos armados; los derechos del niño refugiado, del niño impedido, del niño abandonado, del semiabandonado, de aquellos con familia uniparental, y el derecho a la recuperación e integración tras abusos, tortura y conflictos armados (CDN, 1989).

\section{El interés superior del niño y/o la niña}

El numeral $1^{\circ}$ del artículo 3 de la $\mathrm{CDN}$ establece que "en todas las medidas concernientes a los niños que tomen las instituciones públicas o privadas de bienestar social, los tribunales, las autoridades administrativas o los órganos legislativos, una consideración primordial a que se atenderá será el interés superior del niño".

En reiterada jurisprudencia de la Corte Interamericana de Derechos Humanos (en adelante CoDH), así como los contenidos de las Observa- 
ciones Generales del Comité de los Derechos del Niño, se ha establecido que el interés superior del niño es un principio general de interpretación de la Convención, por lo que es un principio rector-guía, que debe fungir como pauta interpretativa en todas las decisiones relativas a los derechos de los niños, niñas y adolescentes, ese carácter de fundamental y prevalente supera el ordenamiento jurídico y entraña una adecuada ponderación entre las obligaciones que le asisten al Estado y los derechos específicos de esta población de modo que hagan tránsito a la creación de políticas públicas incluyentes.

En otras palabras, privilegiar ciertos derechos específicos de los niños $\mathrm{y}$ niñas frente a situaciones conflictivas, a tal punto que reconoce su prevalencia frente a las actuaciones del Estado; ese núcleo duro está compuesto por los derechos a la vida, la nacionalidad y a la identidad, a la libertad de pensamiento y de conciencia, a la salud, a la educación, a un nivel de vida adecuado, a realizar las actividades propias de su edad y las garantías propias del derecho penal y del procesal penal.

\section{El interés superior y el reconocimiento de la situación de sujeto de derecho del niño y la niña}

Transformar la cultura de no hacer el mal al niño y/o la niña, para pensar en garantizar su bienestar, constituye una evolución en el reconocimiento de su condición de sujetos plenos de derechos humanos y beneficiarios de cierta protección en su calidad de grupo más vulnerable. Se supera la doctrina de la situación irregular para trascender a la doctrina de la protección integral, que se fundamenta en los principios de no discriminación y el de audición de la palabra del niño (CDN, 1989).

Reconocer la humanidad del niño, la niña y el adolescente discurre por reconocer al ser en todas las dimensiones y en todos los ámbitos del desarrollo. Reconociéndole su condición de sujeto social, sujeto político y sujeto de derechos. Como bien lo expresa el exjuez de la CIDH, A. A. Cançado Trindade: "no basta afirmar que el niño es sujeto de derecho, importa que él lo sepa, inclusive para el desarrollo de su responsabilidad" (CIDH, O.C - 17, de 28 de agosto de 2002). Entonces, el interés superior del niño 
funge también como prenda de garantía en el acceso a la justicia en tanto compromete al poder legislativo y judicial a garantizar el goce efectivo de derechos de la niñez.

\section{Contexto jurídico sobre derechos de la niñez y la adolescencia en el marco de los conflictos armados}

\section{Derecho Internacional Humanitario}

El derecho internacional humanitario es el derecho internacional aplicable a los conflictos armados, que impone limitaciones a los medios y métodos en la guerra para proteger a los no combatientes. En el artículo 24 del Convenio IV impone una obligación a favor de la niñez y los adolescentes que no participan en las hostilidades y en el artículo $3^{\circ}$ común a los cuatro Convenios de Ginebra y a los dos Protocolos adicionales.

La Asamblea General de la Organización De Los Estados Americanos, en su Resolución 3318 con fecha de 14 de diciembre de 1974, también conocida como la Declaración sobre la Protección de la Mujer y el Niño en Estados de Emergencia o de Conflicto Armado, establece que:

Las mujeres y los niños que formen parte de la población civil y que se encuentren en situaciones de emergencia y en conflictos armados en la lucha por la paz, la libre determinación, la liberación nacional y la independencia, o que vivan en territorios ocupados, no serán privados de alojamiento, alimentos, asistencia médica ni de otros derechos inalienables, de conformidad con las disposiciones de la Declaración Universal de Derechos Humanos, el Pacto Internacional de Derechos Civiles y Políticos, el Pacto Internacional de Derechos Económicos, Sociales y Culturales, la Declaración de los Derechos del Niño y otros instrumentos de derecho internacional.

El derecho especial a la protección en los tiempos de guerra contenido en la Convención de los Derechos del Niño se queda corto cuando afirma en los artículos 38 y 39 que los niños, niñas y adolescentes afectados por los conflictos armados tienen derecho a protección especial para lograr su reintegración y recuperación. Adviértase que este instrumento que no hace 
alusión al derecho a la justicia cuando ha sido violentado alguno de sus derechos, sin embargo, cabe recordar que el Estatuto de la Corte Penal Internacional tipifica como crimen de guerra el reclutamiento o alistamiento de niños, niñas y jóvenes menores de 15 años o su empleo activo en los enfrentamientos armados, así como en conflictos internacionales.

Deberes del Estado colombiano dimanante de los derechos humanos de la niñez y la adolescencia

En virtud del artículo 93 de la Constitución colombiana, las normas sobre derechos humanos se integran a la normativa interna a través de la figura del bloque de constitucionalidad, de manera que las disposiciones establecidas en la Convención de los Derechos del Niño (en adelante CDH) tienen carácter vinculante y son de obligatorio cumplimiento para el Estado.

Frente a los derechos de la niñez y la adolescencia, como derechos humanos, se ha dicho que para que el Estado pueda cumplir plenamente con su deber de hacer efectivos los derechos humanos, tiene que hacerlo desde su sistema jurídico, político e institucional simultáneamente. Esa obligación contempla el deber de prevenir, investigar y sancionar las violaciones, así como también el de respetar, proteger y promover los derechos humanos. Por ello, para el pleno y cabal cumplimiento de sus obligaciones debe procurar el restablecimiento y en la medida de lo posible la reparación de los daños causados, entendiendo que estas son complementarias y nunca sustitutivas (CIDH, C. Velázquez Rodríguez, Sentencia 29 de julio de 1988).

La Resolución 1314 de 2000 del Consejo de Seguridad de las Naciones Unidas insiste en la responsabilidad de los estados en la lucha contra la impunidad. Por otro lado, el Informe del Relator Especial sobre cuestión de Impunidad de los autores de violaciones de derechos humanos recuerda que un elemento indispensable para garantizar un recurso efectivo ante las autoridades es la obligación de realizar una investigación exhaustiva, que debe conducir al procesamiento y condena del autor de las violaciones. 


\section{Los derechos de la niñez y la adolescencia en Colombia}

Colombia es un Estado social y democrático de derecho fundado en el principio de la dignidad humana y el reconocimiento de los derechos humanos sin distinción de ninguna índole. La Constitución Política de 1991 reconoce la primacía de los derechos de la persona y lo desarrolla ampliamente en el articulado comprendido entre el 11 y el 44, dando a estos el carácter de derechos fundamentales de los colombianos y las colombianas.

Es significativo que el artículo 44 establece con rango constitucional la prevalencia de los derechos de los niños, niñas y adolescentes sobre los derechos de las demás personas reforzando además el carácter de fundamental de todos los derechos de la niñez y la adolescencia.

Referida a esto, la Corte Constitucional ha sostenido que los derechos de la niñez y la adolescencia no son solo derechos especiales, sino que estos están por encima de los derechos de las demás personas: "Es evidente que los niños son acreedores de ese trato preferencial, a cargo de todas las autoridades públicas, de la comunidad y del propio núcleo familiar" (Colombia, Corte Constitucional, Sentencia SU-225 de 1998). Explica además en la Sentencia C- 535 del 2000 que

Las razones básicas de esta protección a los niños y a los adolescentes (Art. 45 C.P) son, por una parte, su naturaleza frágil o vulnerable, por causa del desarrollo de sus facultades y atributos personales, en grado inverso a su evolución, en la necesaria relación con el entorno tanto natural como social, y, por otra parte, el imperativo de asegurar un futuro promisorio para la comunidad, mediante la garantía de la integridad, salud, educación y bienestar de los mismos". Adiciona en este sentido: "Estas situaciones ponen de presente la necesidad apremiante de que el Estado colombiano procure instrumentos eficaces para cumplir la enorme responsabilidad que entrañan la asistencia y la protección de su población infantil, entre los cuales ocupan lugar preponderante los acuerdos de cooperación internacional".

Paralelamente, la Ley 1098 de 2006 en su artículo 7 reconoce que la protección integral es el conjunto de políticas, planes, programas y acciones en todos los ámbitos del desarrollo, es decir, la prevalencia de los derechos 
debe reflejarse en las políticas públicas que defina el Estado en todos sus niveles: financiero, político, jurídico, legislativo o administrativo. La misma norma en el artículo 26 instituye el debido proceso en todas las actuaciones administrativas y judiciales en que se encuentren involucrados ampliando su contenido al establecer que tendrán que ser escuchados y sus opiniones tenidas en cuenta.

\section{Proceso de Justicia y Paz}

La Ley 975 de 2005 o Ley de Justicia y Paz es el marco jurídico especial a través del cual se reguló el proceso de desmovilización y reinserción individual o colectiva de los grupos armados al margen de la ley, como autores o partícipes durante y con ocasión de su pertenencia al grupo armado, garantizando los derechos de las víctimas a la justicia, la verdad y la reparación.

Esta ley establece un procedimiento judicial en materia penal en cuanto a aspectos de investigación, imputación y sanción de los delitos cometidos por el desmovilizado durante su pertenencia al grupo armado ilegal, teniendo la posibilidad de otorgar una pena alternativa como sanción definitiva por todos los delitos cometidos que sean confesados y aceptado por el postulado. Este beneficio será otorgado dependiendo del cumplimiento de ciertos requisitos, como son la contribución efectiva a la paz y colaboración en la realización de los derechos a la verdad, la justicia y la reparación de las victimas (Ley 975 de 2005).

\section{Concepto de víctima}

Según el artículo 5 de la Ley 975 de 2005, se considera víctima a

la persona que individual o colectivamente haya sufrido daños directos tales como lesiones transitorias o permanentes que ocasionen algún tipo de discapacidad física, psíquica y/o sensorial (visual y/o auditiva), sufrimiento emocional, pérdida financiera o menoscabo de sus derechos fundamentales. Los daños deberán ser consecuencia de acciones que hayan transgredido la legislación penal, realizadas por grupos armados organizados al margen de la ley. También se tendrá por víctima al cónyuge. 
La condición de víctima se adquiere con independencia de que se identifique, aprehenda, procese o condene al autor de la conducta punible y sin consideración a la relación familiar existente entre el autor y la víctima.

La definición de víctima se aplica para la mayoría de los delitos establecidos en el Código Penal, como los delitos contra personas protegidas por el derecho internacional humanitario. Pero solo aquellas víctimas cuyo victimario cumpla con los requisitos establecidos en la Ley 975 de 2005, pueden acceder a los mecanismos establecidos en la misma.

\section{El derecho a la justicia de las víctimas}

Todas las víctimas de violaciones a los derechos humanos tienen derecho a interponer recursos efectivos y a obtener reparaciones. Es obligación del Estado investigar y juzgar a los autores materiales e intelectuales, e imponer la sanción penal correspondiente. La jurisprudencia constitucional ha dicho que el derecho a la justicia de las víctimas es el derecho a que se haga justicia en el caso concreto, es decir a que no haya impunidad.

Este derecho se sustenta en el Preámbulo de la Constitución Política y en los artículos 29 (debido proceso) y 229 (protección judicial) de la misma norma. En virtud del bloque de constitucionalidad, en los artículos 8 (garantías judiciales) y 25 (protección judicial) de la Convención Americana de Derechos Humanos y en los artículos 14 (garantías judiciales) y 26 (igualdad ante la ley) del Pacto Internacional de Derechos Civiles y Políticos.

En el marco de la Ley 975 de 2005, en su artículo 6 establece el derecho a una investigación efectiva que conduzca a la identificación, captura y sanción de las personas responsables por los delitos cometidos por los miembros de los grupos armados al margen de la ley; así como el derecho a recursos eficaces que reparen el daño.

En la Sentencia C-370 de 2006, la Corte Constitucional reitera que el reconocimiento de los derechos universales a la verdad, la justicia y la reparación lleva implícita la potestad de intervenir en todas las fases del proceso, otorgándole un papel activo a la víctima que permita el goce de 
estándares de protección similares a los del postulado. En el mismo sentido, afirma que "el derecho de las víctimas a participar en el proceso penal se encuentra ligado al respeto de la dignidad humana" (Colombia, Corte Constitucional, Sentencia C-370 de 2006).

\section{El acceso a la justicia de los niños, niñas y adolescentes en el marco del proceso de justicia y paz}

La posibilidad de que niños, niñas y adolescentes accedan a la justicia en el marco del proceso de Justicia y Paz como sujetos de derechos a la verdad, la justicia y la reparación integral en clave de garantías de no repetición presenta algunos inconvenientes desde la realidad procesal, que si bien no la niegan de plano sí entorpecen la aspiración de justicia de este grupo.

La Corte Constitucional ha sostenido que el interés superior del niño, la niña y el adolescente no constituye un ente abstracto sino que, por el contrario, solo se puede establecer prestando la debida consideración a las circunstancias individuales e irrepetibles de cada niño, niña o adolescente (Sentencia T-510 de 2003). En el marco de la ley de Justicia y Paz, esta condición no se materializa debido a múltiples aspectos que a continuación se describen.

Las violaciones a los derechos humanos de la niñez y la adolescencia producto del control territorial y social que ejercieron los paramilitares en las regiones se manifestaron de diversas maneras y de acuerdo al grupo poblacional el impacto fue diferente. Los patrones de victimización estuvieron ligados a especificidades tales como la edad, el sexo, la etnia, el estrato social y la profesión, por mencionar algunas particularidades de los grupos afectados.

Los derechos al libre desarrollo de la personalidad, el derecho a la recreación y al juego, el derecho a la educación básica, a crecer en el seno de una familia, el derecho a la alimentación, el vestido y muchos que constituyen el núcleo básico de los derechos de la niñez y la adolescencia, que por demás son fundamentales y prevalentes, fueron violados sistemáticamente por los actores armados ilegales autodenominados Autodefensas Unidas de Colombia. Al respecto, conviene aclarar que en tanto derechos económi- 
cos, sociales y culturales, y partiendo de la interdependencia de los derechos humanos, este grupo de derechos por ser prioritarios para la niñez y la adolescencia deben ser justiciables penalmente. Sin embargo, en el proceso de Justicia y Paz (en adelante JyP) no existe un tipo penal autónomo que permita imputar este tipo de conductas antijurídicas a los postulados a los beneficios la Ley de Justicia y Paz.

Al no existir tipicidad, no obstante que la conducta haya sido antijurídica, no es posible hacer juicio de culpabilidad al postulado, lo que se convierte en una barrera jurídica infranqueable a las exigencias de justicia de esta población. Al afirmar esto, decimos que un alto porcentaje de violaciones de los derechos humanos de la niñez y la adolescencia no ingresan al sistema judicial y por ende los niveles de impunidad se incrementan, lo que redunda, además, en la imposibilidad de acceder a la reparación integral.

Lo anterior supone un contrasentido: por un lado, se reconoce la primacía de los derechos de la niñez y la adolescencia, pero por otro lado, el sistema legal no contiene los elementos normativos necesarios para perseguir, juzgar y sancionar a los responsables de las violaciones de los derechos humanos de los NNA en situaciones de conflicto armado.

Responder a la aspiración de justicia de esta población requiere del Estado de derecho la consagración de disposiciones jurídicas en materia penal que tipifiquen además del reclutamiento forzado de niños, niñas y adolescentes, otras conductas lesivas que atentan contra los derechos más importantes de la niñez y la adolescencia y su normal desarrollo humano.

La justicia efectiva presupone que los hechos sean investigados de manera minuciosa y exhaustiva, máxime en el sistema penal donde la prueba ocupa un lugar central. El programa metodológico diseñado por los fiscales de la Unidad de Justicia y Paz es la herramienta de trabajo necesaria para que el ente investigador organice la indagación, "realice la recolección de la evidencia que permita demostrar la existencia de una conducta constitutiva de delito" (Avellana, 2007). Al no existir tipos penales que permitan adecuar típicamente las conductas antijurídicas y lesivas de los actores armados a una disposición penal, no hay programa metodológico encaminado a reunir el acervo probatorio para aquellas violaciones a los derechos fundamen- 
tales de la niñez y la adolescencia ligados a su ciclo vital, ejemplo de ello, las limitaciones al ejercicio libre de la personalidad, mediante imposición de normas de conductas a los adolescentes, la prohibición de juegos en las calles y la obligación a realizar trabajos forzados para los paramilitares por reunirse a conversar en las esquinas.

La ausencia de investigación o una inadecuada investigación constituye una violación del derecho a la protección judicial de conformidad con el art 25 de la Convención Americana sobre Derechos Humanos. Al respecto, conviene recordar que investigar y sancionar son obligaciones del Estado colombiano encaminadas a erradicar la impunidad; que a la luz de los estándares internacionales se configura por "la falta de investigación, persecución, captura, enjuiciamiento y condena de los responsables de las violaciones a los derechos humanos protegidos por la Convención Americana" (CIDH, Blake contra Guatemala. Sentencia 24 de enero de 1998).

Por su especial condición, la niñez y la adolescencia han sido víctimas directa o indirecta de un sinnúmero de violaciones a sus derechos fundamentales, por lo que hacen parte del universo de víctimas, pero por más que existe claridad jurisprudencial respecto a la necesidad de ser consultados en aquellos aspectos en los que se pueden ver afectados sus derechos; de acuerdo a la no respuesta de la Unidad de Justicia y Paz de la Fiscalía General de la Nación en cuanto a la consulta del número de víctimas perteneciente a este grupo etario, presumimos que no existen registros que den cuenta de otros hechos victimizantes. Lo anterior se sustenta en el ejercicio de observación que permitió conocer que a las jornadas de atención programadas por la Unidad de Justicia y Paz no son convocados los NNA para que presenten las denuncias por las violaciones directas o indirectas a sus derechos, salvo en los casos de reclutamiento forzado o violencia sexual.

Para los casos en que la conducta está tipificada el procedimiento se adelanta a través de los padres y madres o del tutor o persona encargada de los cuidados del niño, la niña o el adolescente y solo concurren al proceso para las entrevistas y recolección de pruebas, no para escuchar sus pretensiones, necesidades y requerimientos de verdad, justicia y reparación. Aunque las normas internacionales y nacionales, establecen que la edad no 
puede ser obstáculo para la participación real y efectiva del niño, la niña o el adolescente en el proceso judicial, su condición de menor de edad les impide opinar sobre su representación judicial y por ende otorgar poder a fin de que sus intereses sean representados de acuerdo a sus necesidades y pretensiones, aspiraciones que en la mayoría de los casos difieren de las pretensiones de los adultos y del ICBF.

Según las Directrices sobre la Justicia en asuntos concernientes a los Niños Víctimas y Testigos de Delitos, aprobada por el Consejo Económico y Social en la Resolución 2005/20 de 22 de julio de 2005, el derecho a la participación implica la posibilidad de expresar con sus propias palabras de manera libre sus creencias y pareceres sobre aquellos asuntos que le afectan. Igualmente, recuerda que todo niño debe ser tratado como una persona con sus propias necesidades, deseos y sentimientos personales. Reitera además que la edad no debe ser obstáculo para la participación plena de los niños, niñas y adolescentes en el proceso de justicia

El acceso y capacidad de actuar en las etapas de la investigación de las víctimas y por consiguiente de los niños, niñas y adolescentes es un derecho y por tanto una obligación del Estado en virtud de las normas de la Convención Americana, de la Convención Internacional de los Derechos de los Niños, de la Constitución Política Colombiana en sus artículos 29, 229 y 44 y de la Ley 1098 de 2006. Una participación eficaz también implica la asistencia que incluya profesionales de salud mental y asesoría legal de manera que puedan objetar, presentar pruebas, ser informados y tener acceso al proceso. No obstante los estándares, la Defensoría del Pueblo manifestó que no representa a ningún menor de dieciocho años en el proceso.

Como quiera que se desconozca al niño, la niña o el adolescente su condición de sujeto de derecho, se le desconocen implícitamente sus derechos a la verdad, la justicia y la reparación.

En este punto, vale la pena preguntarse sobre el papel protector del Ministerio Público que, como se sabe, tiene como propósito fundamental dentro de los procesos velar porque las autoridades brinden la atención adecuada a las necesidades de los niños, niñas y adolescentes. Evidentemente ese protagonismo no se ha comprobado en el proceso de Justicia y Paz. 
Se identificó que en aquellos casos en que concurren varias víctimas por el mismo hecho o delito, las afectaciones sufridas por los NNA quedan subsumidas y relegadas frente a los delitos de alto impacto como el homicidio, la desaparición forzada o el desplazamiento del núcleo familiar; sin que las autoridades indaguen sobre el impacto diferenciado ocasionado por la condición de vulnerabilidad de esta población al momento de los hechos.

Aunado a lo anterior, la Ley 975 de 2005 no hace una referencia específica en relación con la reparación integral de la niñez y la adolescencia, ni siquiera establece unos parámetros que permitan pensar en la satisfacción de dicho anhelo, partiendo de elementos como la edad y la interpretación que el adolescente haga del derecho a la reparación integral.

Lo anterior desencadena en la inexistencia de un grupo especializado que investigue este tipo de violaciones a los derechos humanos específicos de la niñez y la adolescencia. Las razones pueden tener su origen en lo arriba expuesto o en la visión técnica de la norma y los derechos protegidos en ella y no en clave de ejercicio de derechos humanos.

Es preciso recordar que uno de los objetivos establecidos por las Directrices sobre la justicia en asuntos concernientes a los niños víctimas y testigos de delitos es orientar al Estado para que se implementen los procedimientos adecuados y de capacitación, así como en la selección del personal interdisciplinario que permitan proteger los derechos de la niñez víctima; no obstante, han transcurrido nueve años del proceso de justicia y paz, y tales recomendaciones no han sido incorporadas al sistema de justicia transicional vigente en Colombia (NU, Resolución 2005/20, julio 22 de 2005).

De existir un equipo interdisciplinario de profesionales que investigue las violencias específicas sufridas en razón del ciclo vital con enfoque de derechos humanos, posiblemente se adecuarían típicamente muchas conductas antijurídicas y culpables al tipo penal de constreñimiento ilegal contenido en el artículo 182 del Código Penal Colombiano.

La Ley 1098 de 2006, plantea avances en la garantía de protección de los derechos de la niñez y la adolescencia, fundamentado en que el interés 
superior del niño, la niña y el adolescente debe verse reflejado en una política pública integral, más aún en aspectos penales donde los niños, niñas y adolescentes son víctimas. Sobran razones para afirmar que la impunidad, así como la negación a los derechos de verdad, justicia y reparación aumenta la vulnerabilidad de los niños, las niñas y adolescentes y limitan sus posibilidades de desarrollo humano y social.

No es coherente que el Estado Colombiano que ha ratificado además de la CDN otros los instrumentos internacionales que garantizan los derechos de la niñez, tales como el Protocolo de San Salvador, ante el Sistema Interamericano y El Pacto De Los Derechos Económicos, Sociales y Culturales ante las Naciones Unidas entre muchos otros de igual importancia, mantenga la disparidad entre el cuerpo jurídico internacional y la normatividad interna respecto a esta población especialmente protegida.

Mientras que la Constitución Política, es concordante con la $\mathrm{CDH}$, al consagrar los derechos de los niñez y la adolescencia en su carácter de prevalentes sobre los de los demás, así como consagra la facultad de toda persona, valga decir NNA, de exigir la garantía de sus derechos humanos y el castigo para los responsables de violaciones a los mismos; la legislación penal que se reputa garantista, no tipifica aquellas conductas que lesionan gravemente el desarrollo integral de la niñez y la adolescencia en contextos de conflicto armado; esto, sin mencionar que la inadecuada interpretación hecha por los operadores de justicia hace más gravosa la situación de esta población.

El juicio de constitucionalidad a la luz del interés superior del niño debe reflexionar entonces sobre la interdependencia y carácter sistémico de los derechos fundamentales. No es justo en un Estado social de derechos, que los sujetos de especial protección constitucional no puedan acceder a la justicia, la verdad y la reparación en clave de garantías de no repetición por inexistencia de la norma penal. Lo anterior constituye una desigualdad y por qué no, una discriminación frente al resto de víctimas.

En términos de discriminación se encuentra que el sistema penal abiertamente desconoce y anula la posibilidad de acceder al derecho a la justicia, pues de acuerdo a la etapa evolutiva en que sufre el NNA la 
afectación a sus derechos por los actores armados, así será el daño que se causará en el proceso de formación del individuo adulto.

\section{Conclusiones}

Una política pública acorde a los estándares internacionales de protección en donde el interés superior del niño, la niña y el adolescentes sean trasversales debería incluir y hacer efectivo los derechos de la niñez y la adolescencia que denuncia violaciones a sus derechos.

Que un niño, niña o adolescente no pueda acceder al proceso penal de Justicia y Paz por atipicidad de la conducta vulneradora, es un desconocimiento tácito de su condición de persona sujeta de derechos y por tanto, un incumplimiento del Estado Colombiano de las obligaciones adquiridas al ratificar los instrumentos internacionales sobre derechos humanos, que como se sabe, por Bloque de Constitucionalidad prevalecen sobre el ordenamiento interno.

La Ley 975 de 2005, no hace una consideración especial y diferenciada de la niñez víctima, sino que por el contrario la iguala a las demás victimas lo que en suma constituye una discriminación. Esta situación contraría las recomendaciones internacionales sobre la materia al no ponderar las circunstancias fácticas de cada caso en concreto. Las medidas que se aplican observan más los aspectos procedimentales y sustantivos del derecho penal, que el interés superior de los NNA.

El proceso de Justicia y Paz, tal como está concebido desconoce las especificidades y el impacto diferencial de la violencia en la etapa evolutiva del individuo, creando con ello una barrera de acceso a la justicia y por ende toda posibilidad de restablecimiento de los derechos vulnerados. Por otro lado, al no existir referencia específica sobre el concepto de reparación integral en clave de restablecimiento de los derechos de la niñez y la adolescencia y ante la falta de consulta a los afectados, una eventual reparación integral no podría responder adecuada y concretamente a los intereses y necesidades esta población. 
Los obstáculos en el acceso efectivo a la justicia incrementan la impunidad, lo que propicia la repetición de las violaciones a los derechos humanos e incrementa el nivel de vulnerabilidad de este grupo poblacional.

En resumen el acceso a la justicia de los niños, niñas y adolescentes víctimas en el marco del proceso de Justicia y Paz no responde de manera efectiva a la materialización del derecho a la justicia, en la medida que iguala un grupo de especial protección con las demás víctimas. No existe una política pública coherente e integradora que permita al Estado cumplir a cabalidad con las obligaciones internacionales frente al tema de protección de los derechos de la niñez y la adolescencia.

\section{Bibliografía}

Avellana, P. (2007). Programa Metodológico en el Sistema Penal Acusatorio. Bogotá: Fiscalía General de la Nación.

CoAlición CONTRA LA Vinculación DE NiÑos, NiÑAS Y JÓvenes AL conflicto armado en Colombia. Comisión Colombiana de Juristas (2009). El delito invisible. Criterios para la investigación del delito de reclutamiento ilícito de niños y niñas en Colombia. Recuperado de http://www.coalico.org/images/stories/delitoinvisibleactualizado2014_ web.pdf

Asamblea General de Naciones Unidas. (1974). Resolución 3318, Declaración sobre la Protección de la Mujer y el Niño en Estados de Emergencia o de Conflicto Armado.

Comité de los Derechos del Niño de las Naciones Unidas. (2002) Observación General No. 2.

Congreso de la República. (1991) Constitución Política de Colombia.

Congreso de la República. Ley 975 de 2005. Por la cual se dictan disposiciones para la reincorporación de miembros de grupos armados organizados al margen de la ley, que contribuyan de manera efectiva a la consecución de la paz nacional y se dictan otras disposiciones para acuerdos humanitarios. 
Congreso de la República. Ley 1098 de 2006. Por la cual se expide el Código de la Infancia y la Adolescencia.

Consejo Económico y Social de Naciones Unidas. Resolución 2005/20 de 2005.

Consejo de Seguridad de las Naciones Unidas, Resolución 1314 de 2000.

Colombia, Corte Constitucional, Sentencia T-510 de 2003. (M.P.: Manuel José Cepeda Espinosa; Junio 19 de 2003).

Colombia, Corte Constitucional Colombiana, Sentencia SU-225 de 1998. (M.P.: Eduardo Cifuentes Muñoz; Mayo 20 de 1998).

Colombia, Corte Constitucional Colombiana, Sentencia C-370 de 2006. (M.P.: Manuel José Cepeda Espinosa, Jaime Córdoba Triviño, Rodrigo Escobar Gil, Marco Gerardo Monroy Cabra, Álvaro Tafur Galvis, Clara Inés Vargas Hernández; mayo 18 de 2006).

CIDH, (2002). Opinión ConsultivaOC-17/02 de 28 de agosto de 2002. Serie $\mathrm{A} \mathrm{N}^{\circ}$ 17. Voto a favor de la adopción del Juez A.A. Cançado Trindade.

Corte Interamericana, caso Velásquez Rodríguez. (1988) Sentencia del 29 de julio de 1988. Serie C No 4, párrafo 16.

Corte Interamericana de Derechos Humanos, caso Blake contra Guatemala, Sentencia 24 de enero de 1998, Serie C No. 36.

Convención de los Derechos del Niño. Artículos 12, 13, 14,16, 28 y 29. 20 de noviembre de 1989.

Organización de las Naciones Unidas (1948). Declaración Universal de los Derechos Humanos.

Organización de las Naciones Unidas (1966). Pacto Internacional de Derechos Civiles y Políticos. 




\title{
Serie Investigación
}

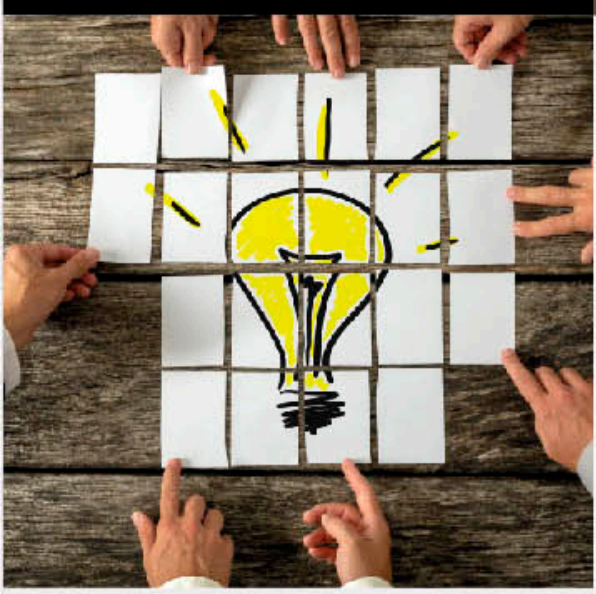

\author{
ÁMBITOS DEL DERECHO: \\ REFLEXIONES SOBRE TENDENCIAS \\ Y PROBLEMAS JURÍDICOS EN COLOMBIA
}

Las Universidades en Colombia han puesto especial énfasis en el fortalecimiento de la investigación, como claro desarrollo de sus políticas de extensión y proyección social, y bajo el entendido de que las funciones de una universidad no solo se deben quedar en la docencia directa y en la extensión; teniendo en cuenta que el propósito de la investigación está orientado a la producción de nuevo conocimiento, a la generación de la ciencia, la tecnología y la innovación.

Este carácter deontológico de la investigación científica propende por contribuir a la solución de problemas nacionales e internacionales y a la

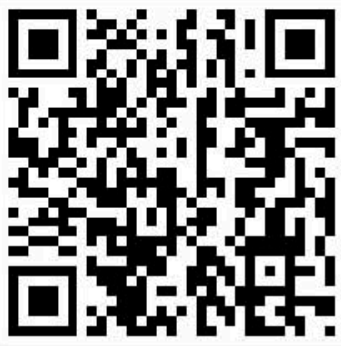

promoción del desarrollo científico, social, económico y sostenible. Esta publicación retoma los logros de la investigación para la formación que se da en el marco de las actividades de los semilleros de investigación que se convierten en escenarios del aprendizaje de la investigación y como espacios académicos creados para estimular los proyectos desarrollados por nuestros estudiantes.

Con los semilleros de investigación se logra el aprendizaje de competencias para la investigación y la difusión de los resultados de los mismos, así mismo se busca incentivar a los jóvenes investigadores, para propiciar la sana crítica, generar criterios de mejoramiento $y$ fortalecer el trabajo interdisciplinar.

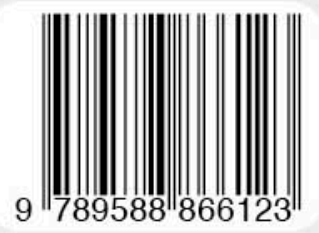

